PAULO CÉSAR PINTO

INVESTIGAÇ̃̃O DE PARÂMETROS DO CCR COM INCORPORAÇÃO DE ESCÓRIA GRANULADA DE ALTO FORNO

PARA UTTILIZAÇÃO COMO BASE DE PAVIMENTOS

Dissertação apresentada à
Escola Politécnica da
Universidade de São Paulo
como parte dos requisitos para
a obtenção do título de Mestre
em Engenharia


PAULO CÉSAR PINTO

Engenheiro Civil, UPF, 2007.

\title{
INVESTIGAÇÃO DE PARÂMETROS DO CCR COM INCORPORAÇÃO DE ESCÓRIA GRANULADA DE ALTO FORNO PARA UTILIZAÇÃO COMO BASE DE PAVIMENTOS
}

\author{
Dissertação apresentada à \\ Escola Politécnica da \\ Universidade de São Paulo \\ como parte dos requisitos para \\ a obtenção do título de Mestre \\ em Engenharia
}

Área de Concentração: Engenharia de Transportes Infraestrutura de Transportes

Orientador: Prof. José Tadeu Balbo 
A busca do conhecimento pelo conhecimento é curiosidade; a busca do conhecimento para se tornar conhecido é vaidade; a busca do conhecimento para servir ao próximo é caridade.

(B. Clairvaux)

Non nobis Domine, non nobis, sed Nomini Tuo da Gloriam.

(Lema dos Cavaleiros Templários) 


\section{AGRADECIMENTOS}

Na conclusão de uma dissertação, além de se ter o sentimento de realização pessoal (devido às dificuldades encontradas, de certa forma superadas, e conhecimentos consolidados), nota-se que este árduo caminho não seria possível senão pela presença diretamente ou indiretamente de pessoas que acrescentaram muito em diversas etapas. Assim sendo, sou grato:

À Deus, ser onipotente, ao qual me abençoa ao longo de minha vida e que nesta fase de conhecimentos e maturidade continuou de forma incomensurável.

À minha familia, Amilcar, Elaine e Izar - pai, mãe e dinda - que sempre estiveram presentes apesar da distância, dando suporte de rocha sã sobre minhas fundações.

À minha namorada, Suelen Rech, pelas inúmeras demonstrações de amor e compreensão na minha temporária ausência.

Ao professor e amigo, Dr. José Tadeu Balbo, pessoa ímpar no conhecimento demonstrado e ao qual tive a grata satisfação de ser orientado.

Aos professores Dra. Tatiane Cureau Cervo e Dr. Selmo Chapira Kuperman pelas contribuições dadas no exame de qualificação que ajudaram, em muito, o enriquecimento do estudo e o compreendimento do assunto.

Aos colegas do grupo de estudos em CCR para pavimentação: M.Eng. André Naleto Mugayar, Dra. Maria da Consolação Fonseca de Albuquerque e M.Eng. Tais Sachet pelos vários dias de pesquisa, ajudas e caminho mútuo procurando um novo horizonte do saber. Às engenheiras colegas do Laboratório de Mecânica dos Pavimentos (LMP - EPUSP), Virgínia Esther Becker e Ester Tseng, pelo companheirismo diário, conhecimentos compartilhados em nossos momentos de estudos e auxílios prestados. À vocês, caros amigos, lembro: livros, artigos, dissertações ou teses estão fadados à poeira e ao esquecimento ao passar do tempo, seja pela evolução da engenharia ou pela defasagem da tecnologia; entretanto, nossos momentos e a amizade construída estarão em nossas 
lembranças, fazendo parte de nossa própria evolução como profissional e, principalmente, como ser humano.

Ao Laboratório de Construção Civil do PCC - EPUSP, em especial ao professor Dr. Antônio Figueiredo, pela disponibilidade de infra-estrutura e equipamentos necessários para a realização deste.

Ao Laboratório de Mecânica das Rochas da EPUSP, Prof. Dr. Carlos Eduardo Sansone e técnico Jorge Sakamoto, pela assistência proporcionada.

À CAPES e ao CNPQ pelo suporte financeiro destinado ao desenvolvimento da pesquisa.

À Holcim Brasil S/A, na pessoa do M.Eng. José Wanderlei Abreu, pela extrema atenção e fornecimento de agregados e cimento sempre em tempo hábil e condizente com nossas necessidades.

À Votorantim Cimentos, ao engenheiro Roberto Rodrigues, pela disponibilidade da escória de alto forno.

À todos meus sinceros agradecimentos. 


\section{RESUMO}

A crescente preocupação ambiental e a atual crise energética fazem com que indústrias, de um modo geral, intensifiquem esforços para maximização de processos de produção e reutilização de subprodutos gerados. Na siderurgia a produção do aço é realizada por meio da extração do minério de ferro adicionando-se fundentes, gerando como subproduto uma ganga em forma de escória de alto forno. Na presente pesquisa foram compostas misturas de concreto compactado com rolo - CCR - visando o emprego como base de pavimentos, utilizando três diferentes materiais de granulometria miúda: areia natural, areia industrial e escória granulada de alto forno (com dimensão máxima de 4,8 $\mathrm{mm}$ ) nas quantidades de 50 $\%$ e $100 \%$; para fins de análise da influência destas diferentes areias foram confeccionados corpos de prova cilíndricos e prismáticos moldados na umidade ótima e no ramo seco da curva de compactação. Foram investigados parâmetros referentes à umidade de compactação, massa específica, resistências à tração indireta e à tração na flexão, módulos de elasticidade por pulso ultrassônico, além de módulos de elasticidade estáticos obtidos a partir de curvas tensão-deformação e por analogia de Möhr (medida de flecha em vigotas em flexão). Visando avaliar a aplicabilidade dos CCR estudados, em especial aquele com escória, foi utilizado o programa computacional MnLayer (para análise de tensões em pavimentos asfálticos) empregando camada de base rígida em CCR para estruturas de pavimentos sujeitos à ação de cargas do tráfego de veículos rodoviários, portuários e aeroportuários, observando a influência dos três tipos de agregados miúdos no nível de tensões da camada cimentada, o que depende em grande parte do módulo de elasticidade da camada de base. Observou-se queda nas resistências dos CCR quando da incorporação de 50 \% ou $100 \%$ de escória granulada; por outro lado, essas misturas apresentaram ganhos de resistência em idades mais avançadas em comparação a misturas que empregaram areias natural ou industrial. O módulo de elasticidade dos CCR, com a presença da escória, parcial ou total como fração areia, em geral decresceu à exceção de seu emprego em conjunto com areia natural. As misturas com escória granulada, do ponto de vista de análise mecanicista, resultaram em exigências de maiores espessuras do material, o que não pode fazer tal mistura economicamente viável em qualquer situação, para os casos de misturas com $100 \%$ de escória granulada de alto forno e com fração mista de areia natural e escória.

Palavras-chave: concreto compactado com rolo, base de pavimentos, escória de alto forno, parâmetros mecânicos. 


\section{ABSTRACT}

The increasing environmental concerns as well as energy sources shortage leads industry to consider both optimization of production processes and sustainable use and disposal of its by-pass products. In siderurgical steel manufactures the most common by-pass product is the blast furnace slag with emphasis to its granulated shape. This study considered the evaluation of rolled compacted concretes (RCC) mixtures containing natural or industrial sands as well as such slags at $50 \%$ and $100 \%$ (with maximum diameter of $4.8 \mathrm{~mm}$ ) as candidates for pavement base layers. The analysis considered laboratory compaction tests in order to verify the influence of such sands on concrete physical parameters as bulk density and optimum moisture content. Evaluation of mechanical parameters as indirect tensile strength, flexural strength, ultrasonic modulus of elasticity and static modulus of elasticity were carried out as part of the study. Through mechanistic analysis using the elastic layered theory-based computational program MnLayer it was possible to verify implications of each RCC mixture design on pavement thickness and tensile stresses in cemented base layers, in consideration of highway, harbor and airport vehicles. Loss of resistance was verified for RCC mixtures at 50\% and 100\% slag sand; on the other hand such mixtures have improved its strengths at advanced ages (180 days) compared to the other sands. The modulus of elasticity also decreased for mixtures containing slag sands with exception to the blend of natural and slag sand. Under the mechanistic stand point slag sand mixtures requires thicker base layers in pavements that could lead, depending on several factors, to less cost-effective results in the case of $100 \%$ slag sands mixtures and blend $(50 \%-50 \%)$ natural and slag sands mixtures.

Key-words: rolled compacted concrete, pavement base, granulated blast furnace slag, mechanical behavior. 


\section{LISTA DE FIGURAS}

FIGURA 1 - ESQUEMA DA PARTE INTERNA DO ALTO FORNO (ZONAS DE AMOLECIMENTO E FUSÃO E DE GOTEJAMENTO).

FIGURA 2 - CONSUMO DE COQUE POR TONELADA DE GUSA 8

FIGURA 3 - REPRESENTAÇÃO DO SISTEMA CAO.SIO ${ }_{2} \cdot \mathrm{AL}_{2} \mathrm{O}_{3}$ DA ESCÓRIA DE ALTO FORNO ...........................12

FIGURA 4 - PROGNÓSTICO PARA O DESENVOLVIMENTO DO CONSUMO GLOBAL DE AGREGADOS E DEMAIS MATERIAIS PARA A CONSTRUÇÃO CIVIL

FIGURA 5 - MAIORES EXTRATORES MUNDIAIS DE AGREGADOS NATURAIS

FIGURA 6 - PRINCIPAIS ESTADOS BRASILEIROS EXTRATORES DE JAZIDAS DE AGREGADOS ............................20

FIGURA 7 - PRINCIPAIS FRENTES PARA REUTILIZAÇÃO DE ESCÓRIA DE ALTO FORNO NO BRASIL ....................21

FIGURA 8 - PRINCIPAIS FRENTES PARA REUTILIZAÇÃO DE ESCÓRIA DE ALTO FORNO NO MUNDO ...................21

FIGURA 9 - VENDA DE ESCÓRIA DE ALTO FORNO APÓS BRITAGEM NA REGIÃO DE DIVINÓPOLIS/MG..............28

FIGURA 10 - DETERIORAÇÃO EM JUNTA TRANSVERSAL DA PLACA DE CONCRETO..........................................34

FIGURA 11 - RESISTÊNCIAS À COMPRESSÃO AOS 28 E 90 DIAS PARA CONCRETOS PLÁSTICOS COM

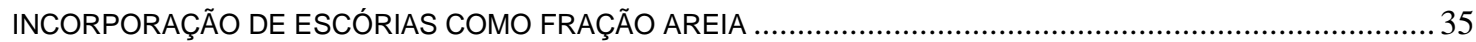

FIGURA 12 - ESTRUTURA INTERNA DAS LIGAÇÕES ENTRE PASTA E AGREGADO NO CCR ...........................41

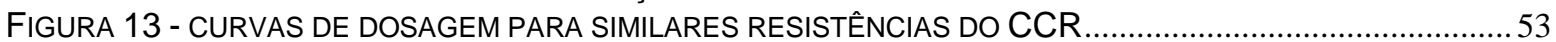

FIGURA 14 - RELAÇÃO ENTRE RESISTÊNCIA À COMPRESSÃO E RESISTÊNCIA À ABRASÃO DO CCR .................54

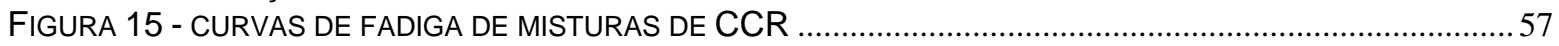

FIGURA 16 - FAIXA GRANULOMÉTRICA DO CCR (DIMENSÃO MÁXIMA CARACTERÍSTICAS DE 25 MM) .............61

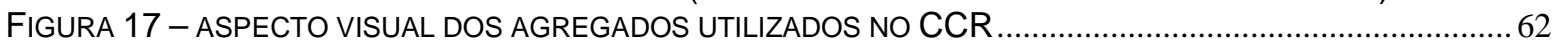

FIGURA 18 - ESTOCAGEM DA ESCÓRIA GRANULADA DE ALTO FORNO A CÉU ABERTO ....................................63

FIGURA 19 - CARACTERÍSTICAS GRANULOMÉTRICAS DAS AREIAS E BRITAS EXTRAÍDAS DE JAZIDAS NATURAIS

FIGURA 20 - CARACTERÍSTICA GRANULOMÉTRICA E HOMOGENEIDADE DAS AMOSTRAS DE ESCÓRIA

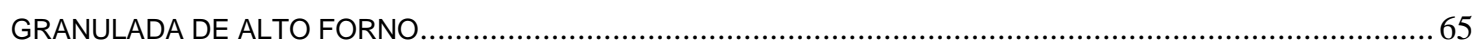

FIGURA 21 - ESCÓRIA GRANULADA DE ALTO FORNO APÓS DESGASTE SOFRIDO NO ENSAIO DE ABRASÃO .....66

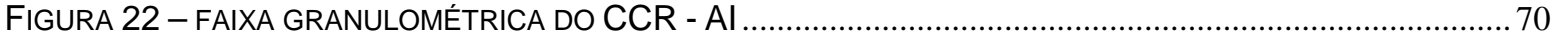

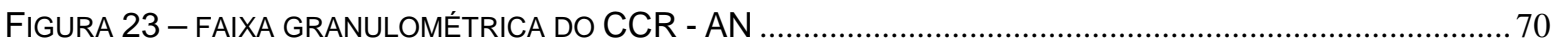

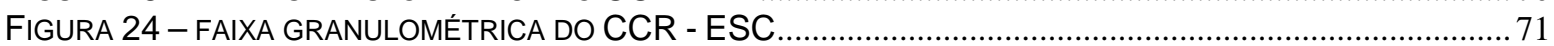

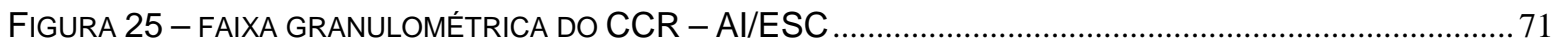

FIGURA 26 - FAIXA GRANULOMÉTRICA DO CCR - AN/ESC ........................................................... 72

FIGURA 27 - COMPACTAÇÃO DA PRIMEIRA CAMADA DE CCR - AI EM CORPO-DE-PROVA PRISMÁTICO...........74

FIGURA 28 - COMPACTAÇÃO DA ÚLTIMA CAMADA DE CCR - AN EM CORPO-DE-PROVA CILÍNDRICO ...............74

FIGURA 29 - BETONEIRA INDUSTRIAL UTILIZADA PARA MISTURA DO CCR ..............................................75

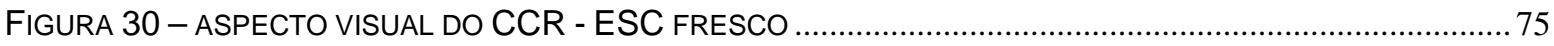

FIGURA 31 - DISTRIBUIÇÃO DA ENERGIA DE COMPACTAÇÃO EM CORPO DE PROVA PRISMÁTICO ...................75

FIGURA 32 - CONTROLE DA ALTURA DE CAMADA DE COMPACTAÇÃO EM CORPO DE PROVA CILÍNDRICO ........75

FIGURA 33 - CORPOS DE PROVA DE CCR APÓS DESEMPENAMENTO: CCR - ESC (ESQ.) E CCR - AI (DIR.)

FIGURA 34 - FATIAMENTO DE CORPOS DE PROVA DE CCR PARA INVESTIGAÇÃO DO GRAU DE COMPACTAÇÃO

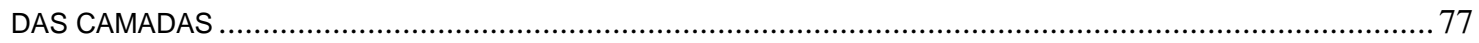

FIGURA 35 - ADEQUAÇÃO DA PRENSA PARA ENSAIO DE TRAÇÃO INDIRETA (INCLUSIVE COM STRAINGAGE)...79

FIGURA 36 - ADEQUAÇÃO DA PRENSA PARA ENSAIO DE TRAÇÃO NA FLEXÃO (INCLUSIVE COM LVDT E

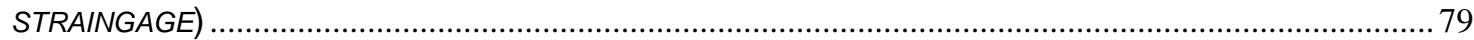

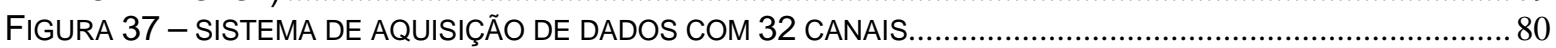

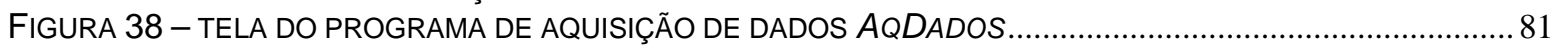

FIGURA 39 - DETERMINAÇÃO DA CURVA TENSÃO X DEFORMAÇÃO E MÓDULO DE ELASTICIDADE (CCR -

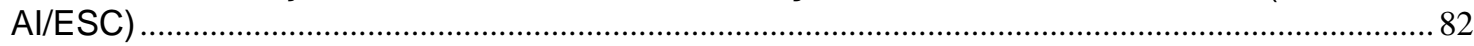

FIGURA 40 - POSICIONAMENTO DO LVDT NO CENTRO DO VÃO DA VIGOTA DE CCR - AN..........................85

FIGURA 41 - STRAINGAGE FIXADO NA FACE INFERIOR DO CCR - AN (EM RELAÇÃO À APLICAÇÃO DE CARGA)

FIGURA 42 - TENSÃO DE TRAÇÃO X FLECHA NO CENTRO DO VÃO (CCR - AI/ESC)

FIGURA 43 - VARIAÇÃO DO MÓDULO DE ELASTICIDADE EM TRAÇÃO NA FLEXÃO (ANALOGIA DE MÖHR) X TENSÃO EM TRAÇÃO (CCR - Al/ESC) 
FIGURA 44 - CALIBRAÇÃO DO EQUIPAMENTO PUNDIT PARA OBTENÇÃO DO MÓDULO DE ELASTICIDADE POR PULSO ULTRASSÔNICO.

FIGURA 45 - OBTENÇÃO DO MÓDULO DE ELASTICIDADE DINÂMICO EM CORPO-DE-PROVA CILÍNDRICO ............90

$(\mathrm{CCR}-\mathrm{Al})$

FIGURA 46 - OBTENÇÃO DO MÓDULO DE ELASTICIDADE DINÂMICO EM CORPO-DE-PROVA PRISMÁTICO..........90

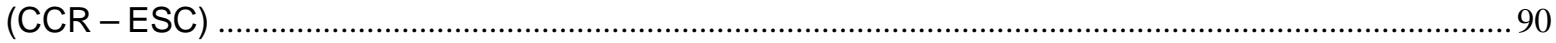

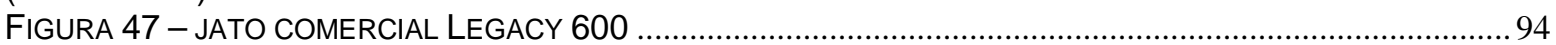

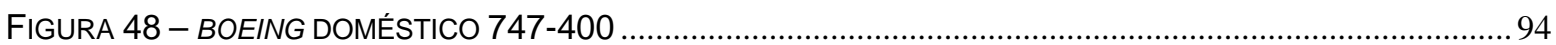

FIGURA 49 - CONFIGURAÇÃO DO TREM DE POUSO DE UM AVIÃO B 474 - 400D......................................... 95

FIGURA 50 - CONFIGURAÇÃO DO TREM DE POUSO DE UM JATO COMERCIAL LEGACY 600 ............................95

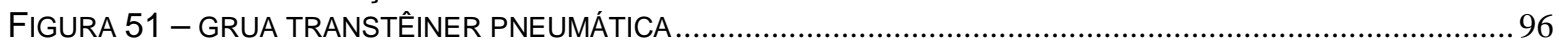

FIGURA 52 - FLUXOGRAMA DE RESUMO DO PROJETO EXPERIMENTAL............................................................. 99

FIGURA 53 - UMIDADES DE COMPACTAÇÃO PARA DIFERENTES CONSUMOS DO CCR - AI ............................. 100

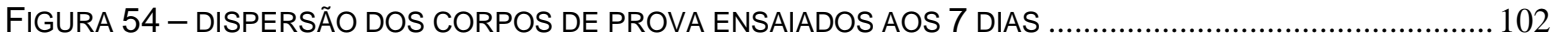

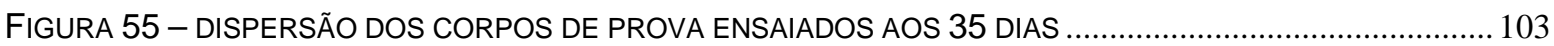

FIGURA 56 - VARIAÇÃO MÉDIA DAS RESISTÊNCIAS À TRAÇÃO COM O CONSUMO DE CIMENTO ………............. 103

FIGURA 57 - CURVAS DE COMPACTAÇÃO PARA CCR COM DIFERENTES MATERIAIS DE FRAÇÃO AREIA......... 107

FIGURA 58 - ASPECTO VISUAL DOS CCR - AI, CCR - AN E CCR - ESC ………….............................. 111

FIGURA 59 - COMPARATIVO ENTRE VALORES DOS ENSAIOS DE TRAÇÃO REALIZADOS AOS 7 DIAS ................112

FIGURA 60 - COMPARATIVO ENTRE VALORES DOS ENSAIOS DE TRAÇÃO REALIZADOS AOS 35 DIAS.............112

FIGURA 61 - CORRELAÇÃO ENTRE OS ENSAIOS À TRAÇÃO INDIRETA POR COMPRESSÃO DIAMETRAL E À FLEXÃO.

FIGURA 62 - RESISTÊNCIAS À TRAÇÃO INDIRETA POR COMPRESSÃO DIAMETRAL AOS 35 E 180 DIAS........... 114

FIGURA 63 - COMPARATIVO ENTRE RESISTÊNCIAS À TRAÇÃO INDIRETA ENTRE CCR COMPACTADOS NA UMIDADE ÓTIMA E NO RAMO SECO.

FIGURA 64 - COMPARATIVO ENTRE RESISTÊNCIAS À TRAÇÃO NA FLEXÃO ENTRE CCR COMPACTADOS NA

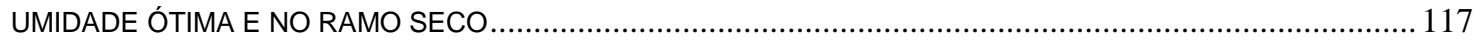

FIGURA 65 - HOMOGENEIDADES DE MISTURAS DE CCR - AI COMPACTADAS NA UMIDADE DE COMPACTAÇÃO (ESQ.) E NO RAMO SECO (DIR.).

FIGURA 66 - RELAÇÃO ENTRE RESISTÊNCIAS Á TRAÇÃO INDIRETA AOS 7 E 35 DIAS ...................................119

FIGURA 67 - RELAÇÃO ENTRE RESISTÊNCIAS À TRAÇÃO INDIRETA AOS 35 E 180 DIAS................................. 120

FIGURA 68 - RELAÇÃO ENTRE RESISTÊNCIAS À TRAÇÃO INDIRETA AOS 7 E 180 DIAS.................................. 120

FIGURA 69 - VARIAÇÃO DA MASSA ESPECÍFICA AO LONGO DAS CAMADAS DO CCR - AI EM CORPOS DE PROVA CILÍNDRICOS.

FIGURA 70 - VARIAÇÃO DA MASSA ESPECÍFICA AO LONGO DAS CAMADAS DO CCR - AN EM CORPOS DE PROVA CILÍNDRICOS

FIGURA 71 - VARIAÇÃO DA MASSA ESPECÍFICA AO LONGO DAS CAMADAS DO CCR - ESC EM CORPOS DE PROVA CILÍNDRICOS..

FIGURA 72 - RELAÇÃO ENTRE MÓDULOS DE ELASTICIDADE ESTÁTICOS MEDIDOS EM CORPOS DE PROVA PRISMÁTICOS

FIGURA 73 - COMPARATIVO ENTRE MÓDULOS DE ELASTICIDADE ESTÁTICOS DOS CCR COMPOSTOS .......... 127

FIGURA 74 - COMPARATIVO ENTRE MÓDULOS DE ELASTICIDADE OBTIDOS EM CORPOS DE PROVA CILÍNDRICOS AOS 35 E 180 DIAS

FIGURA 75 - COMPARATIVO ENTRE MÓDULOS DE ELASTICIDADE ESTÁTICOS DOS CCR MOLDADOS NO RAMO SECO DA CURVA DE COMPACTAÇÃO.

FIGURA 76 - COMPARATIVO DA RAZÃO ENTRE MÓDULOS DE ELASTICIDADE ESTÁTICOS E RESISTÊNCIAS À TRAÇÃO PARA OS CCR MOLDADOS NA UMIDADE ÓTIMA DE COMPACTAÇÃO.

FIGURA 77 - RAZÃO ENTRE MÓDULOS DE ELASTICIDADE ESTÁTICOS E RESISTÊNCIAS À TRAÇÃO PARA OS CCR MOLDADOS NO RAMO SECO DA CURVA DE COMPACTAÇÃO

FIGURA 78 - RELAÇÃO ENTRE MÓDULO DE ELASTICIDADE DINÂMICO E IDADE DOS CORPOS DE PROVA CILÍNDRICOS.

FIGURA 79 - RELAÇÃO ENTRE MÓDULO DE ELASTICIDADE DINÂMICO E IDADE DOS CORPOS DE PROVA PRISMÁTICOS

FIGURA 80 - RELAÇÃO ENTRE MÓDULOS DE ELASTICIDADE DINÂMICOS AFERIDOS EM CORPOS DE PROVA CILÍNDRICOS SUBMETIDOS À CURA ÚMIDA E AO AR (35 DIAS)...

FIGURA 81 - COMPARATIVO ENTRE VALORES DE MÓDULOS DE ELASTICIDADE DINÂMICOS OBTIDOS EM CORPOS DE PROVA CILÍNDRICOS E PRISMÁTICOS MOLDADOS NA UMIDADE ÓTIMA E NO RAMO SECO DE COMPACTAÇÃO AOS 35 DIAS 
FIGURA 82 - RELAÇÃO ENTRE VELOCIDADE DE ONDA ULTRASSÔNICA E MÓDULOS DE ELASTICIDADE DINÂMICOS E ESTÁTICOS PARA CORPOS DE PROVA CILÍNDRICOS DE CCR.

FIGURA 83 - RELAÇÃO ENTRE VELOCIDADE DE ONDA ULTRASSÔNICA E MÓDULOS DE ELASTICIDADE DINÂMICOS E ESTÁTICOS PARA CORPOS DE PROVA PRISMÁTICOS DE CCR

FIGURA 84 - RELAÇÃO ENTRE MÓDULO DE ELASTICIDADE DINÂMICO E MASSA ESPECÍFICA DOS CORPOS DE PROVA CILÍNDRICOS DE CCR

FIGURA 85 - RELAÇÃO ENTRE MÓDULO DE ELASTICIDADE DINÂMICO E MASSA ESPECÍFICA DOS CORPOS DE PROVA PRISMÁTICOS DE CCR. 


\section{LISTA DE TABELAS}

TABELA 1 - ANÁLISE GRANULOMÉTRICA DE DIVERSOS MATERIAIS DA INDÚSTRIA DE SIDERURGIA ...................14

TABELA 2 - PRINCIPAIS FASES CRISTALINAS DAS ESCÓRIAS DE ALTO FORNO ESFRIADA AO AR .......................15

TABELA 3 - PROPRIEDADES FÍSICAS DA ESCÓRIA DE ALTO FORNO ESFRIADA AO AR................................... 16

TABELA 4 - PORCENTAGEM DOS ELEMENTOS COMPONENTES DA ESCÓRIA GRANULADA DE ALTO FORNO ..... 17

TABELA 5 - COMPOSIÇÃO QUÍMICA DAS ESCÓRIAS DE ALTO FORNO BRASILEIRAS ........................................ 18

TABELA 6 - QUANTIDADE DE MATERIAIS UTILIZAÇÃO PARA CONCRETO COM ESCÓRIA PARA PAVIMENTO RÍGIDO

TABELA 7 - RESULTADOS DO ENSAIO EM VIGOTAS DE CONCRETO VIBRADO EMPREGADO EM PISTA

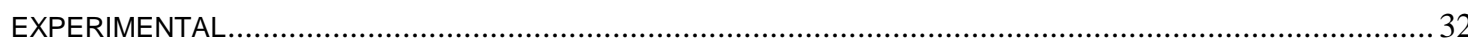

TABELA 8 - PROPORÇÃO DE MATERIAIS PARA OS PAVIMENTOS DE CONCRETO UTILIZANDO ESCÓRIA

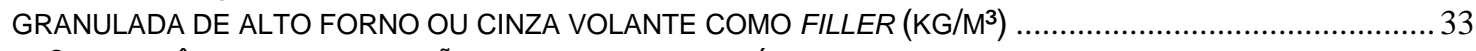

TABELA 9 - INFLUÊNCIA DA UTILIZAÇÃO DE ADITIVOS E ESCÓRIA GRANULADA DE ALTO FORNO EM CONCRETO

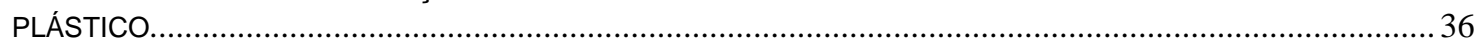

TABELA 10 - SISTEMATIZAÇÃO DE DADOS OBTIDOS NA BIBLIOGRAFIA SOBRE A UTILIZAÇÃO DE ESCÓRIA DE ALTO FORNO EM MISTURAS ESTABILIZADAS OU CIMENTADAS.

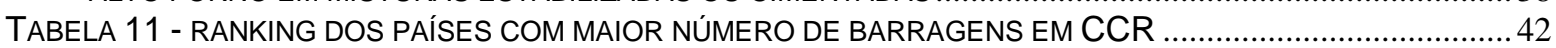

TABELA 12 - ALGUNS CASOS EMBLEMÁTICOS DE UTILIZAÇÃO DO CCR EM PAVIMENTOS NO BRASIL ..............44

TABELA 13 - TRAÇOS UTILIZADOS EM PAVIMENTO RÍGIDO COM BASE EM CCR NA CIDADE DE

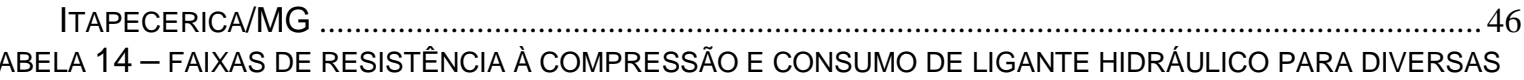
6 UTILIZAÇÕES DE CCR

TABELA 15 - FATORES QUE AFETAM OS PARÂMETROS DO CCR ..............................................................5

TABELA 16 - CARACTERÍSTICAS EXPERIMENTAIS DE TRAÇOS DE CCR DESENVOLVIDOS COM AGREGADOS

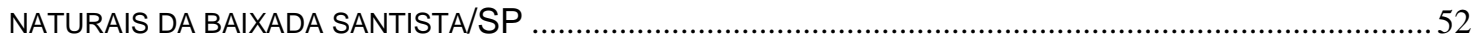

TABELA 17 - INFLUÊNCIA DE DIFERENTES RAZÕES ENTRE TENSÕES SOLICITANTES E DE RUPTURA E

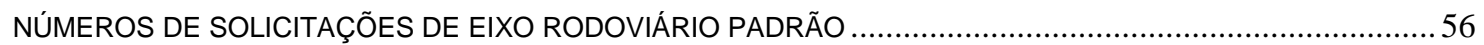

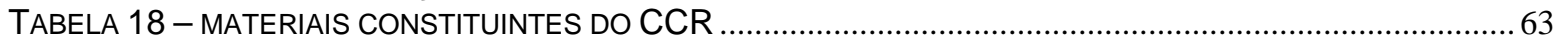

TABELA 19 - CARACTERÍSTICAS DA ESCÓRIA GRANULADA DE ALTO FORNO UTILIZADA NA PRESENTE

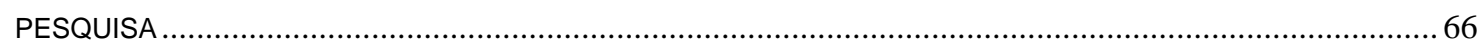

TABELA 20 - COMPOSIÇÃO QUÍMICA DA ESCÓRIA GRANULADA DE ALTO FORNO DA COSIPA .......................66

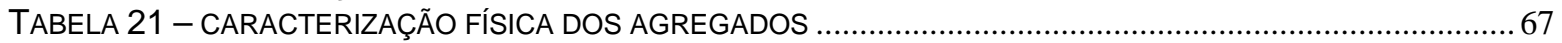

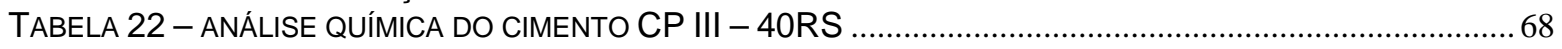

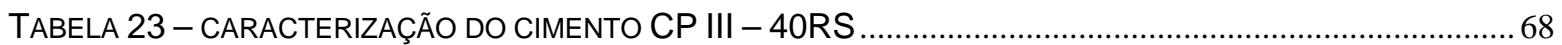

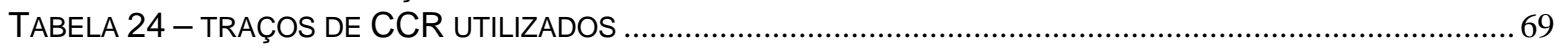

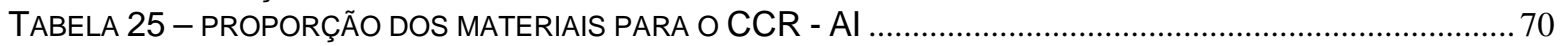

TABELA 26 - CORPOS DE PROVA ENSAIADOS À TRAÇÃO INDIRETA (COMPRESSÃO DIAMETRAL) .....................81

TABELA 27 - EXEMPLO DE AQUISIÇÃO DE DADOS APÓS TRATAMENTO EM PLANILHA ELETRÔNICA PARA O

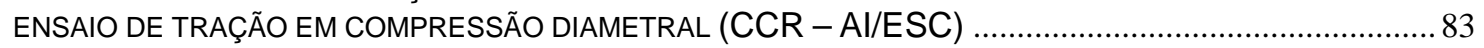

TABELA 28 - CORPOS DE PROVA ENSAIADOS À TRAÇÃO NA FLEXÃO NO ENSAIO DE UM CUTELO ....................85

TABELA 29 - EXEMPLO DE AQUISIÇÃO DE DADOS APÓS TRATAMENTO EM PLANILHA ELETRÔNICA PARA O

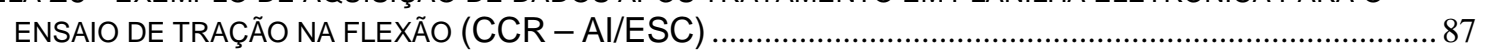

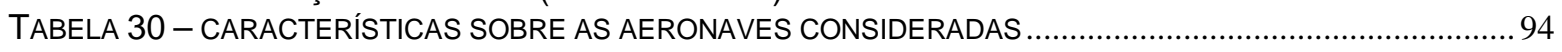

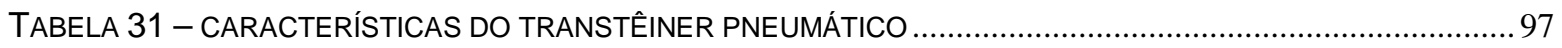

TABELA 32 - CARACTERÍSTICAS DE PALLETS PARA ARMAZENAMENTO (CATEGORIA A2-C) ..........................97

TABELA 33 - FATORIAL DE ANÁLISE PARA PAVIMENTOS COM BASE EM CCR .............................................98

TABELA 34 - RESISTÊNCIAS À TRAÇÃO EM COMPRESSÃO DIAMETRAL PARA DIFERENTES CONSUMOS DE CIMENTO.......

TABELA 35 - RESISTÊNCIAS À TRAÇÃO NA FLEXÃO PARA DIFERENTES CONSUMOS DE CIMENTO .................101

TABELA 36 - COMPARAÇÃO ENTRE RESISTÊNCIAS AFERIDAS POR DIFERENTES PROCESSOS DE MEDIÇÃO.. 104

TABELA 37 - MASSAS ESPECÍFICAS DOS CORPOS DE PROVA DO CCR - AI EM FUNÇÃO DO CONSUMO DE LIGANTE HIDRÁULICO.

TABELA 38 - MÓDULO DE ELASTICIDADE DINÂMICO DO CCR - AI EM FUNÇÃO DO CONSUMO DE LIGANTE

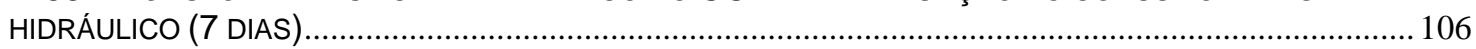

TABELA 39 - MÓDULO DE ELASTICIDADE DINÂMICO DO CCR - AI EM FUNÇÃO DO CONSUMO DE LIGANTE HIDRÁULICO (35 DIAS) . 
TABELA 40 - UMIDADES ÓTIMAS DE COMPACTAÇÃO PARA OS CCR ESTUDADOS ………………………......107

TABELA 41 - MASSAS ESPECÍFICAS DOS CORPOS DE PROVA DOS CCR ESTUDADOS .................................... 108

TABELA 42 - VARIAÇÃO PORCENTUAL DAS MASSAS ESPECÍFICAS DOS CCR ALTERNATIVOS EM RELAÇÃO AO PADRÃO

TABELA 43 - RESULTADOS DE RESISTÊNCIAS À TRAÇÃO EM COMPRESSÃO DIAMETRAL DOS CCR ...............109

TABELA 44 - RESULTADOS DE RESISTÊNCIAS À TRAÇÃO NA FLEXÃO DOS CCR .......................................... 109

TABELA 45 - VARIAÇÃO PORCENTUAL DAS RESISTÊNCIAS À TRAÇÃO DOS CCR ESTUDADOS ....................... 109

TABELA 46 - RESULTADOS DE RESISTÊNCIAS À TRAÇÃO INDIRETA POR COMPRESSÃO DIAMETRAL AOS 180 DIAS.

TABELA 47 - VARIAÇÃO PORCENTUAL DAS RESISTÊNCIAS À TRAÇÃO EM COMPRESSÃO DIAMETRAL AOS 180

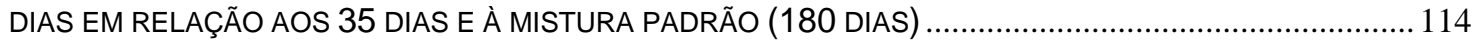

TABELA 48 - RESULTADOS DE RESISTÊNCIAS À TRAÇÃO PARA OS CCR ESTUDADOS NO RAMO SECO DA CURVA DE COMPACTAÇÃO.

TABELA 49 - VARIAÇÃO PORCENTUAL DAS RESISTÊNCIAS À TRAÇÃO PARA OS CCR ESTUDADOS NO RAMO

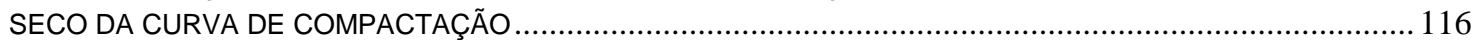

TABELA 50 - VARIAÇÃO PORCENTUAL DAS RESISTÊNCIAS À TRAÇÃO PARA OS ENTRE OS CCR MOLDADOS NO

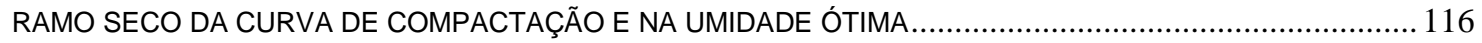

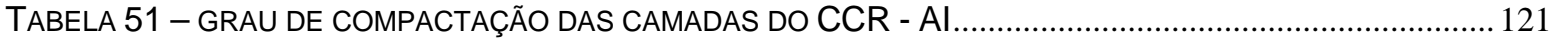

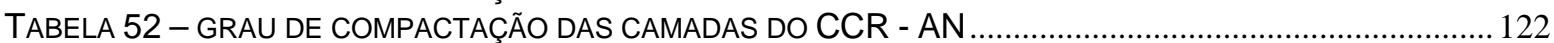

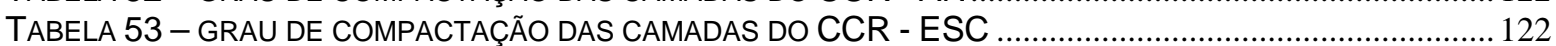

TABELA 54 - VALORES DE MÓDULO DE ELASTICIDADE ESTÁTICO DO CCR - AI (35 DIAS) ............................... 124

TABELA 55 - VALORES DE MÓDULO DE ELASTICIDADE ESTÁTICO DO CCR - AN (35 DIAS) ............................ 124

TABELA 56 - VALORES DE MÓDULO DE ELASTICIDADE ESTÁTICO DO CCR - ESC (35 DIAS) ……................. 125

TABELA 57 - VALORES DE MÓDULOS DE ELASTICIDADE ESTÁTICOS DO CCR - Al/ESC (35 DIAS) ............... 125

TABELA 58 - VALORES DE MÓDULOS DE ELASTICIDADE ESTÁTICOS DO CCR - AN/ESC (35 DIAS) ............ 125

TABELA 59 - VARIAÇÃO PORCENTUAL DOS RESULTADOS DE MÓDULOS DE ELASTICIDADE ESTÁTICO EM

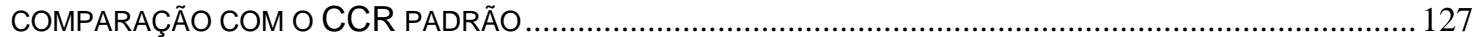

TABELA 60 - VALORES DE MÓDULO DE ELASTICIDADE OBTIDOS POR STRAINGAGE AOS 180 DIAS.................. 128

TABELA 61 - VARIAÇÕES PORCENTUAIS DOS MÓDULOS DE ELASTICIDADE AOS 180 DIAS EM RELAÇÃO AO CCR PADRÃO E AOS DADOS OBTIDOS AOS 35 DIAS

TABELA 62 - VALORES MÉDIOS DE MÓDULOS DE ELASTICIDADE ESTÁTICOS DO CCR - AI MOLDADO NO RAMO

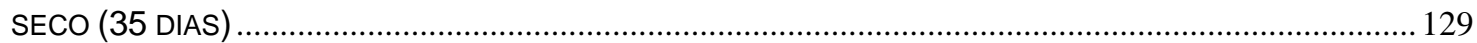

TABELA 63 - VALORES MÉDIOS DE MÓDULOS DE ELASTICIDADE ESTÁTICOS DO CCR - AN (35 DIAS) ......... 129

TABELA 64 - VALORES MÉDIOS DE MÓDULOS DE ELASTICIDADE ESTÁTICOS DO CCR - ESC (35 DIAS)...... 130

TABELA 65 - VARIAÇÕES PORCENTUAIS DOS MÓDULOS DE ELASTICIDADE DOS CCR NO RAMO SECO EM RELAÇÃO AO CCR PADRÃO E AOS DADOS OBTIDOS PARA A MOLDAGEM REALIZADA NA UMIDADE ÓTIMA DE COMPACTAÇÃO

TABELA 66 - VARIAÇÃO PORCENTUAL DAS RELAÇÕES DE MÓDULO DE ELASTICIDADE E RESISTÊNCIAS À TRAÇÃO ENTRE OS CCR MOLDADOS NA UMIDADE ÓTIMA E NO RAMO SECO DE COMPACTAÇÃO............133

TABELA 67 - VALORES DE MÓDULOS DE ELASTICIDADE DINÂMICOS DO CCR - AI........................................ 133

TABELA 68 - VALORES DE MÓDULOS DE ELASTICIDADE DINÂMICOS DO CCR - AN ...................................... 133

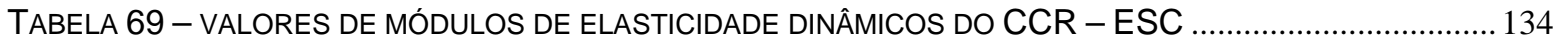

TABELA 70 - VALORES DE MÓDULOS DE ELASTICIDADE DINÂMICOS DO CCR - Al/ESC ............................... 134

TABELA 71 - VALORES DE MÓDULOS DE ELASTICIDADE DINÂMICOS DO CCR - AN/ESC ............................. 134

TABELA 72 - VARIAÇÕES PORCENTUAIS DOS MÓDULOS DE ELASTICIDADE DINÂMICOS AFERIDOS NOS CCR ALTERNATIVOS EM COMPARAÇÃO COM O CCR - AI AOS 7, 35 E 180 DIAS.

TABELA 73 - GANHO DO MÓDULO DE ELASTICIDADE DINÂMICO EM RELAÇÃO ÀS IDADES MEDIDAS ................. 136

TABELA 74 - VALORES DE MÓDULOS DE ELASTICIDADE DINÂMICOS DO CCR - AI NO RAMO SECO ............... 137

TABELA 75 - VALORES DE MÓDULOS DE ELASTICIDADE DINÂMICOS DO CCR - AN NO RAMO SECO ............. 138

TABELA 76 - VALORES DE MÓDULOS DE ELASTICIDADE DINÂMICOS DO CCR - ESC NO RAMO SECO .......... 138

TABELA 77 - VARIAÇÃO PORCENTUAL DO MÓDULO DE ELASTICIDADE DINÂMICO MEDIDO EM CORPOS DE PROVA MOLDADOS NO RAMO SECO EM RELAÇÃO AOS CONFECCIONADOS NA UMIDADE ÓTIMA DE COMPACTAÇÃO

TABELA 78 - TENSÕES EM PAVIMENTO RODOVIÁRIO SUJEITO À CARGA DE VEÍCULOS LEVES ........................ 143

TABELA 79 - ESPESSURAS DE BASE EM CCR PARA PAVIMENTO DESTINADO À ESTACIONAMENTO DE AUTOMÓVEIS

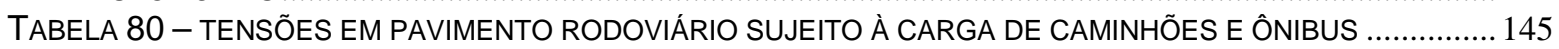

TABELA 81 - ESPESSURAS DE BASE EM CCR PARA PAVIMENTO RODOVIÁRIO ............................................. 146 
TABELA 82 - TENSÕES EM PAVIMENTO AEROPORTUÁRIO DESTINADO À ESTACIONAMENTO DE JATOS EXECUTIVOS LEGACY $(C B U Q=3 \mathrm{CM})$

TABELA 83 - TENSÕES EM PAVIMENTO AEROPORTUÁRIO DESTINADO À ESTACIONAMENTO DE JATOS EXECUTIVOS LEGACY (CBUQ $=6 \mathrm{CM})$

TABELA 84 - TENSÕES EM PAVIMENTO AEROPORTUÁRIO DESTINADO À ESTACIONAMENTO E MANOBRA DE AERONAVES DOMÉSTICAS.

TABELA 85 - ESPESSURAS DE CAMADA DE BASE EM CCR PARA PAVIMENTOS AEROPORTUÁRIOS SUJEITOS À ESTACIONAMENTO DE JATOS EXECUTIVOS.

TABELA 86 - ESPESSURAS DE CAMADA DE REVESTIMENTO PARA PAVIMENTOS AEROPORTUÁRIOS SUJEITOS À ESTACIONAMENTO DE AERONAVES EXECUTIVAS COM CAMADA DE BASE EM CCR (40 CM)

TABELA 87 - TENSÕES EM PAVIMENTO PORTUÁRIO DESTINADO À TERMINAL DE TRANSTÊINERES

TABELA 88 - ESPESSURAS DE CAMADA DE REVESTIMENTO PARA PAVIMENTO PORTUÁRIO SUJEITOS À CARGA DE TRANSTÊINER PNEUMÁTICO COM CAMADA DE BASE EM CCR (40 CM)

TABELA 89 - TENSÕES EM PAVIMENTO PORTUÁRIO DESTINADO À ESTOCAGEM DE PALLETS.

TABELA 90 - ESPESSURAS DE CAMADAS DE PAVIMENTO PORTUÁRIO SUJEITOS À ESTOCAGEM DE PALLETS154 


\section{LISTA DE SÍMBOLOS E SIGLAS}
AASHO
American Association of State Highway Officials
$\mathrm{A} / \mathrm{C}$
relação água - cimento
$\mathrm{ABCP}$
Associação Brasileira de Cimento Portland
$A B M$
Associação Brasileira de Metalurgia e Materiais
ABNT
Associação Brasileira de Normas Técnicas
$\mathrm{ACl}$
American Concrete Institute
ACPA
The American Concrete Pavement Association
$A_{D}$
Abrasão Los Angeles para amostra de graduação D (passante na \# 4,8 $\mathrm{mm}$ e retido na \# 2,4 $\mathrm{mm}$ )
$\mathrm{AF}_{\mathrm{M}} \quad$ monosulfoaluminato de cálcio
$A F_{t} \quad$ etringita
$\mathrm{Al}_{2} \mathrm{O}_{3} \quad$ trióxido de alumínio
$\mathrm{BC}$
British Code
BGTC brita graduada tratada com cimento
$\mathrm{C}$ corpo(s) de prova cilíndrico(s)
CARCR concreto de alta resistência compactado com rolo
CAD concreto de alto desempenho
$\mathrm{CaF}_{2}$ fluoreto de cálcio
$\mathrm{CaO} \quad$ óxido de cálcio
CB Código Britânico da Prática do Uso Estrutural do Concreto (BC - British Code)

CBGB Comitê Brasileiro de Grandes Barragens

$\mathrm{CBUQ}$ concreto betuminoso usinado à quente

CCR concreto compactado com rolo

CEB Concrete European British

$\mathrm{CH} \quad$ hidróxido de cálcio

CONINSA Consultora de Ingeniería S.A.

CONTRAN Conselho Nacional de Trânsito

COSIPA Companhia Siderúrgica Paulista

CP $\quad$ corpo(s) de prova

CPCA Canadian Portland Cement Association 
C-S-H silicato de cálcio hidratado

CST Companhia Siderúrgica de Tubarão/SC

cV coeficiente de variação

DNER Departamento Nacional de Estradas e Rodagem

DNPM Departamento Nacional de Produção Mineral

$\mathrm{E} /(\mathrm{fct} ;$ fct,f) relação entre módulo de elasticidade e resistência à tração indireta ou na flexão

$E_{d} \quad$ módulo de elasticidade dinâmico

EDRS eixo duplo de rodas simples

ESRD eixo simples de rodas duplas

EPUSP Escola Politécnica da Universidade de São Paulo

FAPESP Fundação de Amparo à Pesquisa do Estado de São Paulo

F/C relação cinza volante ou pozolana - cimento

fck $n$ resistência à compressão simples (n: idade de ruptura)

fct $n$ resistência à tração por compressão diametral ( $n$ : idade de ruptura)

$f c t, f_{n} \quad$ resistência à tração na flexão ( $n$ : idade de ruptura)

$\mathrm{FeO} \quad$ óxido de ferro

GC grau de compactação de camadas de CCR

HRB Highway Research Board

IBS Instituto Brasileiro de Siderurgia

IBRACON Instituto Brasileiro de Concreto

ICPA Instituto del Cemento Portland Argentino

IGME Instituto Geológico y Minero de España.

ILAFA Instituto Latinoamericano del Fiero y el Acero

IPR Instituto de Pesquisas Rodoviárias

$\mathrm{K}_{2} \mathrm{O} \quad$ óxido de potássio

LVDT linear variable differential transformer

M/L relação entre a massa estática do rolo compactador e o comprimento da geratriz

$\mathrm{MgO} \quad$ óxido de magnésio

$\mathrm{MnO} \quad$ óxido de manganês

$\mathrm{MnO}_{2} \quad$ dióxido de manganês

$\mathrm{N} \quad$ número de solicitações do eixo padrão rodoviário 
n número de amostras

$\mathrm{Na}_{2} \mathrm{O} \quad$ óxido de sódio

$\mathrm{P} \quad$ probabilidade de ruptura do material à fadiga

p corpo(s) de prova prismático(s)

$\mathrm{P}_{2} \mathrm{O}_{5} \quad$ pentóxido de fósforo

PAC Programa de Aceleração do Crescimento

PCA Portland Cement Association

RCD resíduo de construção e demolição

RT razão entre tensão solicitante e tensão de ruptura

S desvio padrão

SABESP Companhia de Saneamento Básico do Estado de São Paulo

$\mathrm{SiO}_{2}$ dióxido de silício, sílica, quartzo ou areia

SOMISA Sociedad Mixta Siderurgia Argentina

TSCE teoria de sistema de camadas elásticas

USACE United States Army Corps of Engineers

v

velocidade de propagação de uma vibração em meio homogêneo e isótropo

W quantidade de água

$\bar{x} \quad$ média

Z

profundidade média da camada de CCR em corpo de prova cilíndrico 


\section{SUMÁRIO}

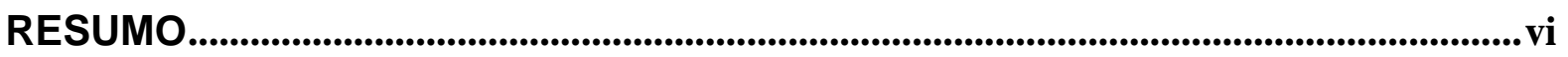

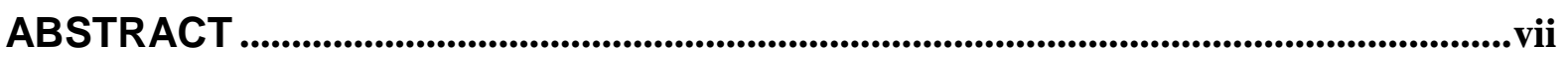

LISTA DE FIGURAS ...........................................................................................................viii

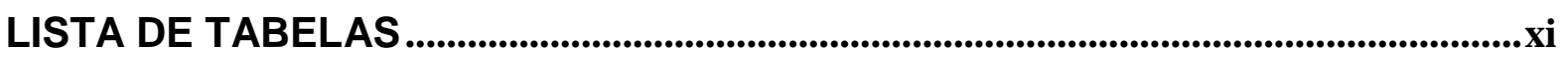

LISTA DE SÍMBOLOS E SIGLAS.............................................................................xiv

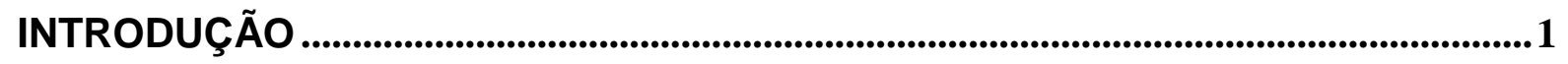

1. ESCÓRIA GRANULADA DE ALTO FORNO .............................................................5

1.1 GERAÇÃO E PRODUÇÃO DA ESCÓRIA DE ALTO FORNO EM

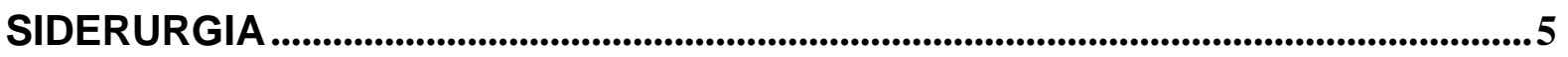

1.2 ESTRUTURA DA ESCÓRIA DE ALTO FORNO ..........................................................10

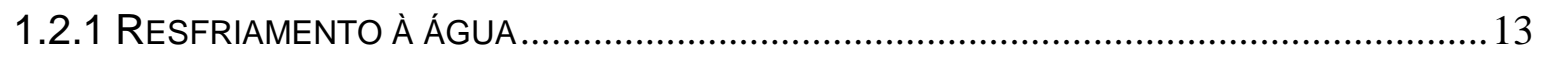

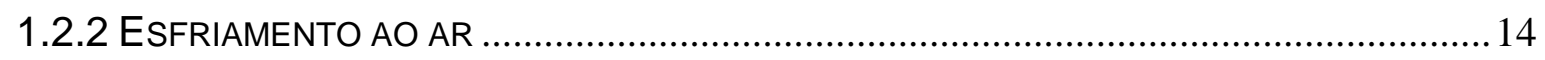

1.3 REUTILIZAÇÃO DA ESCÓRIA DE ALTO FORNO .............................................18

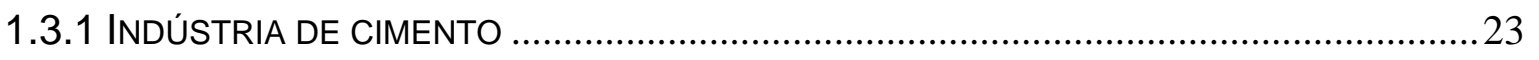

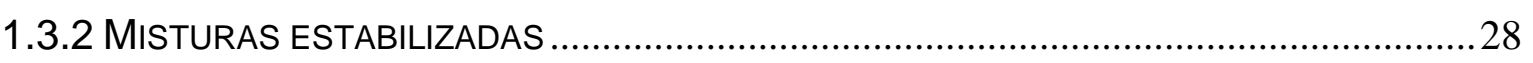

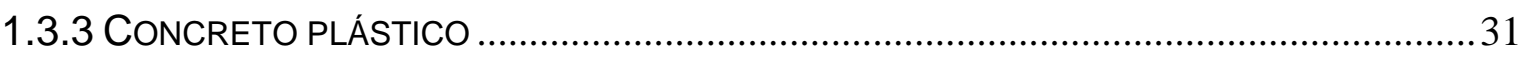

1.3.4 SISTEMATIZAÇÃO DOS DADOS DE BIBLIOGRAFIA SOBRE A REUTILIZAÇÃO DE

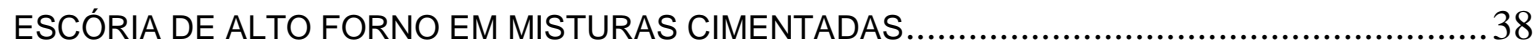

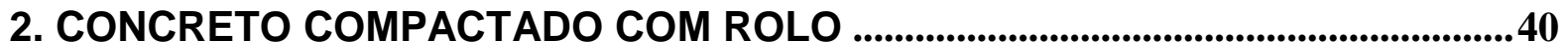

2.1 PARÂMETROS MECÂNICOS .............................................................................49

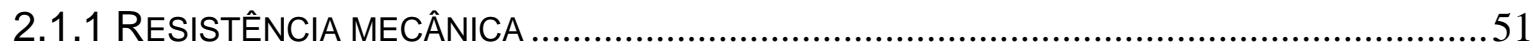

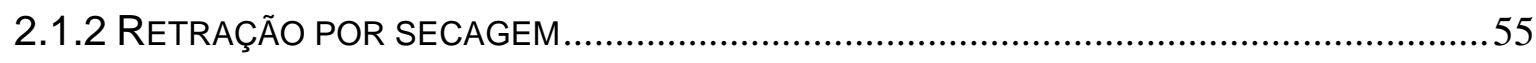

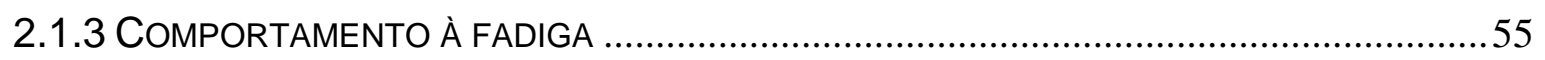

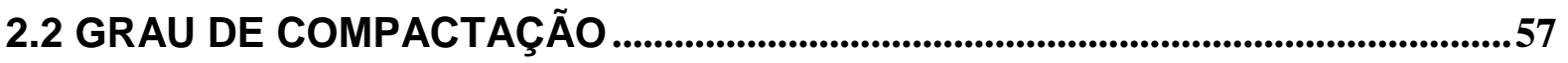

3. METODOLOGIA DA PESQUISA...........................................................................60

3.1 MATERIAIS EMPREGADOS NA DOSAGEM DO CCR .......................................60 
3.3 ENSAIOS ESTÁTICOS .............................................................................................77

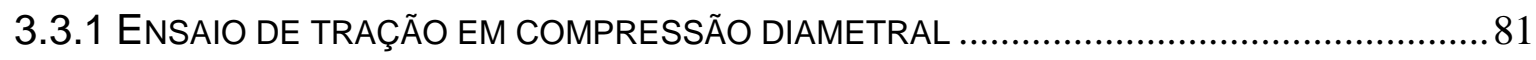

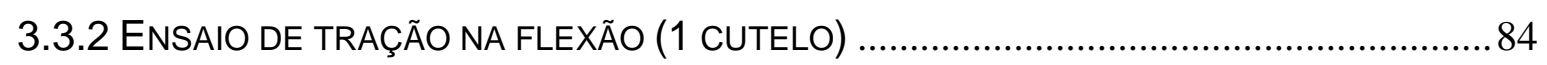

3.4 ENSAIO DE MÓDULO DE ELASTICIDADE POR PULSO ULTRASSÔNICO ..88

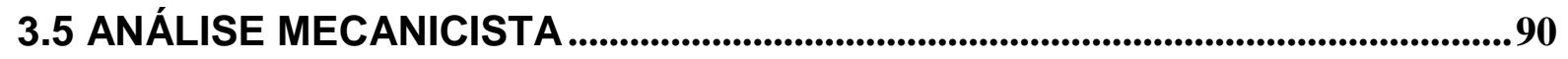

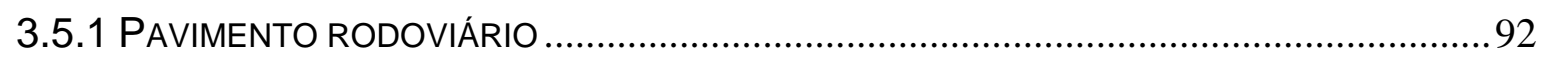

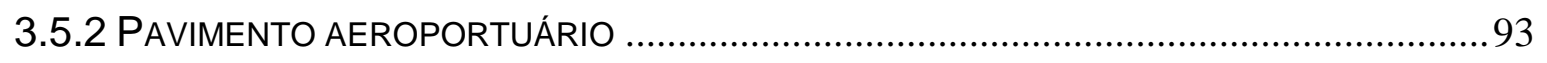

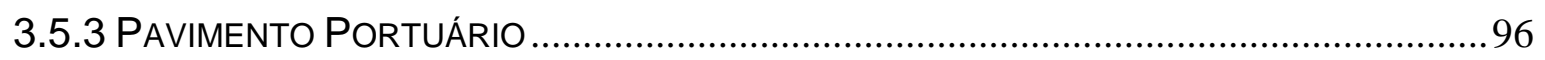

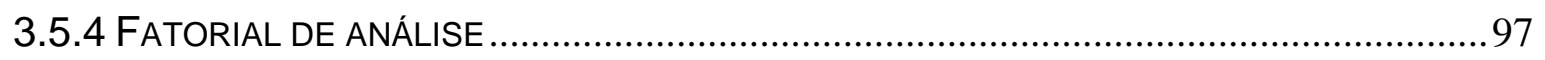

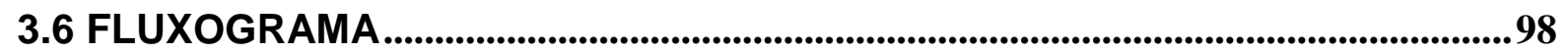

4. APRESENTAÇÃO E DISCUSSÃO DOS RESULTADOS ....................................100

4.1 CONSUMO DE CIMENTO DO CCR PADRÃO .............................................100

4.2 INFLUÊNCIA DE DIFERENTES MATERIAIS DE FRAÇÃO AREIA NOS

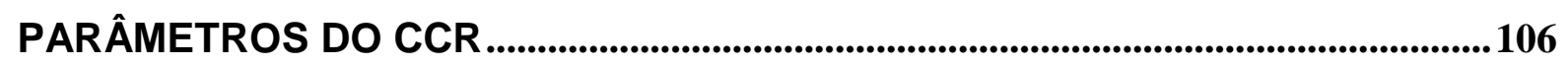

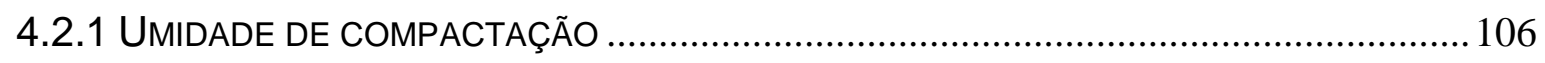

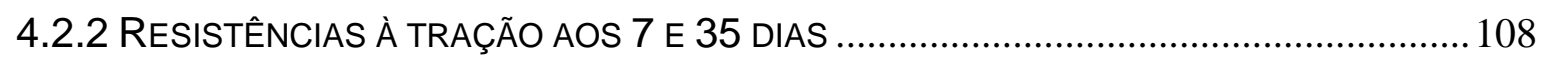

4.2.3 RESISTÊNCIA À TRAÇÃO INDIRETA POR COMPRESSÃO DIAMETRAL AOS 180 DIAS .113

4.2.4 RESISTÊNCIAS À TRAÇÃO NO RAMO SECO DA CURVA DE COMPACTAÇÃO ...............115

4.2.5 RELAÇÕES ENTRE AS RESISTÊNCIAS À TRAÇÃO INDIRETA EM DIFERENTES IDADES119

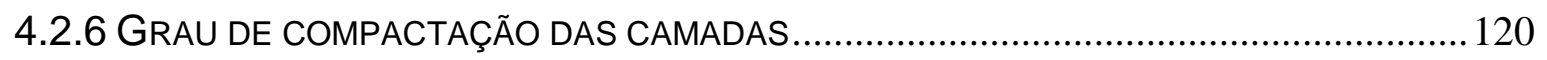

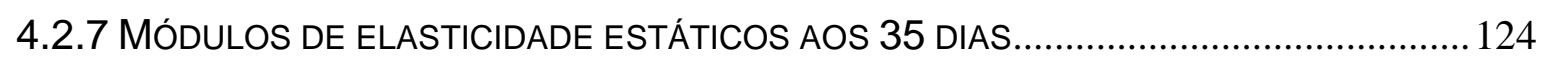

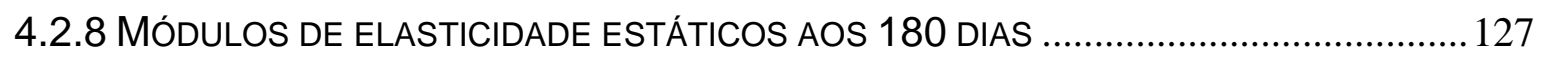

4.2.9 MÓDULOS DE ELASTICIDADE ESTÁTICOS (RAMO SECO) .........................................129

4.2.10 RELAÇÃO ENTRE MÓDULOS DE ELASTICIDADE E RESISTÊNCIAS À TRAÇÃO...........131

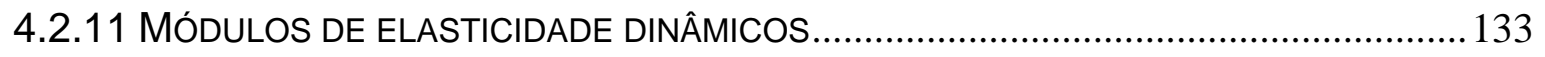

4.2.12 RELAÇÃO ENTRE VELOCIDADE DE ONDA ULTRASSÔNICA E MÓDULOS DE ELASTICIDADE

4.2.13 RELAÇÃO ENTRE MÓDULO DE ELASTICIDADE DINÂMICO E MASSA ESPECÍFICA DOS CCR 
4.3 EMPREGO DOS CCR COMO BASE DE PAVIMENTOS

4.3.1 ESTACIONAMENTO PARA AUTOMÓVEIS. 143

4.3.2 VIAS URBANAS E INDUSTRIAIS.. 145

4.3.3 PÁtIOS DE ESTACIONAMENTO DE AERONAVES EXECUTIVAS E DOMÉSTICAS. 147

4.3.2 TERMINAL DE CONTÊINERES 151

5.3.3 PÁTIO DE ESTOCAGEM DE PALLETS.. .153

CONCLUSÕES. 155

REFERÊNCIAS BIBLIOGRÁFICAS. 160 


\section{INTRODUÇÃO}

A visão tradicional de progresso econômico e social confundia-se com um crescente domínio, transformação e extração de recursos naturais indiscriminadamente. Nesta ótica a natureza era vista como uma fonte ilimitada de produtos e subprodutos, não existindo entraves para o desenvolvimento. Com o passar dos anos, conceitos como economia energética, impacto ambiental, maximização de processos industriais, reaproveitamento de materiais e resíduos tomaram papel crucial para um crescimento sustentável e limpo.

Uma das grandes áreas extratoras de recursos naturais e causadoras de impactos ambientais é a engenharia de transportes pelas suas vultuosas obras de infraestrutura e conseqüências no entorno das vias.

$\mathrm{O}$ aquecimento global deve-se em grande parte à emissão de $\mathrm{CO}_{2}$ na atmosfera. Na fabricação do cimento a queima do clínquer em fornos é responsável por $90 \%$ da emissão de carbono destas indústrias (RESCHKE et al., 2005). Medidas mitigadoras poderiam ser: construção de estruturas que contenham menor consumo de cimento com a utilização de faixas granulométricas contínuas (como é o caso do concreto compactado com rolo - CCR) e a diminuição do teor de clínquer no cimento Portland, adicionando cinzas volantes, pozolanas naturais ou escória moída de alto forno.

Por outro lado a engenharia de transportes e a indústria do concreto possuem um grande potencial para destinação final de resíduos de naturezas e granulometrias diversas. Entretanto, a discussão sobre reutilização ainda permeia, predominantemente, em ambiente técnico-científico; a reciclagem e o emprego destes materiais ainda ocorrem de forma incipiente por empresas e órgãos técnicos nacionais.

A escória granulada é resultante da fabricação do ferro-gusa nos altos fornos, sendo um subproduto inevitável em grande parte dos processos siderúrgicos. Deriva-se da combinação, sob condições específicas, dos minerais presentes no minério de ferro, das cinzas de coque e do fundente. Durante o processo de fusão - aproximadamente à $1.500^{\circ} \mathrm{C}$ - a parte metálica no estado líquido é separada da não metálica a qual forma a escória (menos densa), que 
incorpora todas as impurezas indesejáveis e se solidifica ao ser resfriada (CARMO, CARVALHO e CASTRO, 2005).

Seguindo a metáfora alegórica realizada por Mehta e Monteiro (2004) em relação à mitologia hindu, a reutilização de materiais no concreto pode ser comparada com a absorção do veneno do mundo (kalakata) pelo deus Shiva. O qual, após sorver substâncias tóxicas, teve como única conseqüência a mudança da coloração cutânea para azul. Esse veneno era a antítese da imortalidade, chamado amrita. Para que a imortalidade exista, a morte também deve existir. Assim, Shiva pode absorver o veneno da morte e salvar o mundo, sendo o Senhor da Vida e da Morte, do Nascimento e da Destruição. Neste sentido simbólico o concreto pode assumir o papel de absorvedor de rejeitos dando origem a novos materiais de "colorações diversas" sem mudanças em suas essências, sendo o "Senhor do Nascimento". Entretanto, a utilização de materiais inadequados ou quantidades inapropriadas em conjunto com a falta de investigação técnica, ambiental e econômica pode causar mais que uma simples troca de pigmento e sim, alimentar o lado metafórico obscuro, levando o concreto a mudanças indesejáveis em parâmetros, custos, patologias e queda de desempenho, tornando-se o "Senhor da Destruição".

Assim sendo, as justificativas para o estudo se dão: (1) ao fato da disponibilidade de imensas quantidades de escória granulada de alto forno em indústrias de siderurgia e cimenteiras para reutilização como material alternativo em diferentes frentes; (2) a escolha de uma tecnologia (no caso, o CCR) que pode amortizar estas quantidades e revertê-las em ganhos à sociedade e ao meio ambiente.

Em vista desses aspectos, o estudo tem os seguintes objetivos:

- coletar e caracterizar a escória granulada de alto forno disponível para fins de utilização como agregado miúdo em CCR;

- avaliar a influência de três diferentes materiais de granulometria miúda - areia natural, areia industrial e escória granulada de alto forno nas quantidades de $50 \%$ e $100 \%$ - em parâmetros de misturas de CCR (corpos de prova cilíndricos e prismáticos); sendo eles: umidade de 
compactação, massa específica, resistências à tração indireta em compressão diametral e à tração na flexão;

- analisar medidas de módulos de elasticidade dinâmico (velocidade de onda ultrassônica) e estático (instrumentação eletrônica por meio de straingages e LVDT) aferidas em laboratório pelos ensaios de tração;

- investigar a viabilidade técnica (por meio de análises mecanicistas) dos CCR concebidos visando sua utilização nas proximidades de pólos geradores ou coletores de escória, ou seja, a distâncias de transporte economicamente justificáveis, como base de pavimentos, em obras de infraestrutura rodoviária (estacionamento de automóveis e corredor de ônibus ou caminhão), aeroportuária (estacionamento de Boeing 747 e jato executivo Legacy 600) e portuária (pátio de transtêineres e área de depósito de pallets). Para tanto foi utilizado o programa de análise multicamadas de pavimentos MnLayer.

A estrutura metodológica da presente dissertação é composta por quatro capítulos, a saber:

- Capítulo 1 - escória granulada de alto forno - pesquisa bibliográfica acerca do processo industrial de siderurgia, índices quantitativos de geração e utilização deste resíduo, sua composição química, propriedades e peculiaridades entre métodos de esfriamento; além de sua reutilização na própria planta siderúrgica, indústria cimenteira e materiais cimentados;

- Capítulo 2 - concreto compactado com rolo - revisão de literatura sobre o histórico de utilização em pavimentos no Brasil, vantagens e desvantagens de seu emprego em diferentes camadas de pavimentos e parâmetros do material (resistências mecânicas, retração por secagem, comportamento frente aos carregamentos cíclicos e grau de compactação);

- Capítulo 3 - metodologia e materiais empregados - trata das matérias primas e equipamentos utilizados no estudo, características da confecção das amostras cilíndricas e prismáticas de CCR, descrição 
dos ensaios experimentais realizados e das análises mecanicistas consideradas;

- Capítulo 4 - apresentação e análise dos resultados - através dos dados obtidos pelos ensaios experimentais realizados, discute-se a influência da utilização da escória granulada de alto forno, bem como areia industrial e areia natural em parâmetros mecânicos do CCR; confrontando-os com dados citados na bibliografia consultada.

Ao final são apresentadas as principais conclusões dos estudos bem como as recomendações para continuidade futura de estudos de natureza similar ao presente, inerentes também às necessidades de ampliação do presente estudo que apresentou seus limites de investigação próprios, incluindo aí, portanto, suas limitações. 


\section{ESCÓRIA GRANULADA DE ALTO FORNO}

\subsection{GERAÇÃo E PROduçÃo dA ESCória de ALTO FORNO EM SIDERURGIA}

A partir do século XV (em torno de 1.444), surgiram os primeiros altos fornos, onde, através da quantidade de ar soprado, foi possível o aumento da temperatura e consequente obtenção da mistura em estado líquido entre minério de ferro e fundente, tornando o ferro e as ligas de aço mais resistentes (BAER, 1970 e CHEHEBE, 1987). Basicamente é este processo que gera a escória de alto forno e produz a grande maioria do aço utilizado no mundo até os dias de hoje.

As principais funções dos altos fornos para a produção de ferro gusa são de reduzir os óxidos de ferro e fundir o metal formado. Devido à natureza das cargas metálicas (minérios, sínter e pelota) que têm os óxidos $\mathrm{CaO}, \mathrm{Al}_{2} \mathrm{O}_{3}, \mathrm{SiO}_{2}, \mathrm{MgO}$, $\mathrm{MnO}_{2}, \mathrm{P}_{2} \mathrm{O}_{5}, \mathrm{Na}_{2} \mathrm{O}$ e $\mathrm{K}_{2} \mathrm{O}$ associados aos óxidos de ferro e da presença das cinzas de coque, é gerada a escória de alto forno. Porém esta escória não tem como único papel a eliminação de compostos que são carregados e que não saem com o ferro gusa; é importante para a eficiência global do processo de controle desde a formação da primeira escória dentro do alto forno, até a eliminação completa da escória final de alto forno.

A elaboração de produtos em aço envolve quatro etapas básicas de produção: (1) mineração e tratamento de matérias primas, (2) redução de minério de ferro a ferro gusa, (3) refino do ferro gusa em aço e (4) laminação dos lingotes de aço para obtenção dos produtos finais. Embora estas sejam as atuais etapas do processo de siderurgia, a crescente preocupação ambiental vem tomando papel importante para o crescimento sustentável da sociedade; em vista disso, em um futuro não distante etapas como gerenciamento de resíduos e reuso de subprodutos, incluindo a escória de alto forno, podem ser adicionados a estas etapas básicas de produção.

Em âmbito nacional, a maioria dos metais são extraídos do minério de ferro, os quais sempre estão associados a impurezas, chamadas gangas. Durante a 
extração do metal, esta ganga é eliminada mediante adição de fundentes adequados, gerando assim a escória de alto forno, a qual é insolúvel no metal e com densidade menor (formando uma camada sobrejacente distinta). Os fundentes usualmente utilizados são: $\mathrm{CaO}, \mathrm{MgO}$ e $\mathrm{CaF}_{2}$; porém, em alguns casos, um fundente ácido como o $\mathrm{SiO}_{2}$ pode ser usado (HERASYMENKO e SPEIGHT, 1956; Mc CAFFERY e OESTERLE, 1993 e TIGERSCHIOLD, 1950). A escória de alto forno não somente é necessária para uma simples separação do metal, mas também para o estabelecimento de um rápido equilíbrio que facilita a difusão através da interface entre banho metálico e escória. Portanto, a escória líquida é um elemento fundido homogêneo de um ou mais compostos químicos formados de vários óxidos, o qual se separa da fase metálica por causa de sua insolubilidade e densidade. A natureza e a composição da escória resultante de determinado processo siderúrgico são diferentes, de acordo com sua origem nos processos oxidantes ou redutores e a metodologia de tratamento do resíduo, sendo condicionante para seu posterior reaproveitamento.

Conforme Mc Caffery e Oesterle (1993), os pesos dos diferentes materiais a serem dispostos no alto forno são calculados a partir de análises dos óxidos metálicos carregados, do consumo específico do coque (porcentagem de cinzas) e da quantidade de fundente. A composição desejada da escória de alto forno leva em conta os referidos parâmetros físicos como também dados empíricos de operação. Herasymenko e Speight (1956) e Mealla, Castañeda e Retamozo (1989) afirmam que esta escolha deve considerar alguns fatores, dentre eles se destacam:

- menor requerimento possível de fundente compatível com a qualidade do metal. Maiores quantidades de escória geram maiores consumos de combustível;

- capacidade da escória para ser posteriormente utilizada em manufatura de blocos, cimento, agregado, fertilizante ou algum material com valor agregado;

- baixa densidade e suficiente fluidez para poder se separar do metal e ser retirada facilmente por meios mecânicos simples;

- facilidade de obtenção e preço dos fundentes necessários; 
- natureza do revestimento do forno. A geração de escória ácida em forno revestido com material básico pode causar deterioração rápida.

Tashiro (1980) cita que a formação da escória de alto forno é afetada por várias condições, entre elas: temperatura da chama, distribuição da carga, redutibilidade da carga metálica, quantidade de ganga na carga (volume de escória), tipo de carga e níveis de temperatura.

A escória de alto forno é constituída por óxidos - principalmente $\mathrm{SiO}_{2}, \mathrm{Al}_{2} \mathrm{O}_{3}$, $\mathrm{CaO}, \mathrm{MgO}, \mathrm{MnO}, \mathrm{FeO}$ e $\mathrm{P}_{2} \mathrm{O}_{5}-\mathrm{a}$ interação destes no estado líquido é muito lenta. Porém, em níveis de maiores temperaturas no forno, o óxido de ferro reduzido combina com a ganga de compostos (aluminatos e silicatos) de baixo ponto de fusão, formando assim a escória primária. Essa escória tem temperaturas diferentes de início de amolecimento e final de fusão, o que caracteriza a zona de amolecimento e final de fusão do alto forno. Com a descida do metal e escória através da coluna de coque (zona de gotejamento), os níveis de temperatura são maiores, o $\mathrm{FeO}$ é reduzido rapidamente e o $\mathrm{CaO}$ dos fundentes incorpora a escória (MUAN e OSBORN, 1975). Ilustra-se, na Figura 1, a parte interna do alto forno, destacando as zonas de amolecimento, fusão e de gotejamento.

A escória formada, após a escória primária e acima do nível das ventaneiras, é chamada de escória secundária ou escória de rampa. Finalmente, as cinzas de coque são incorporadas na escória e com a dissolução de mais $\mathrm{CaO}$ e possíveis trocas químicas entre gusa e escória, forma-se a escória de alto forno (final). Logo, existe uma grande diferença de composição química entre as escórias primária, secundária e final (CASTRO et al., 2000). 


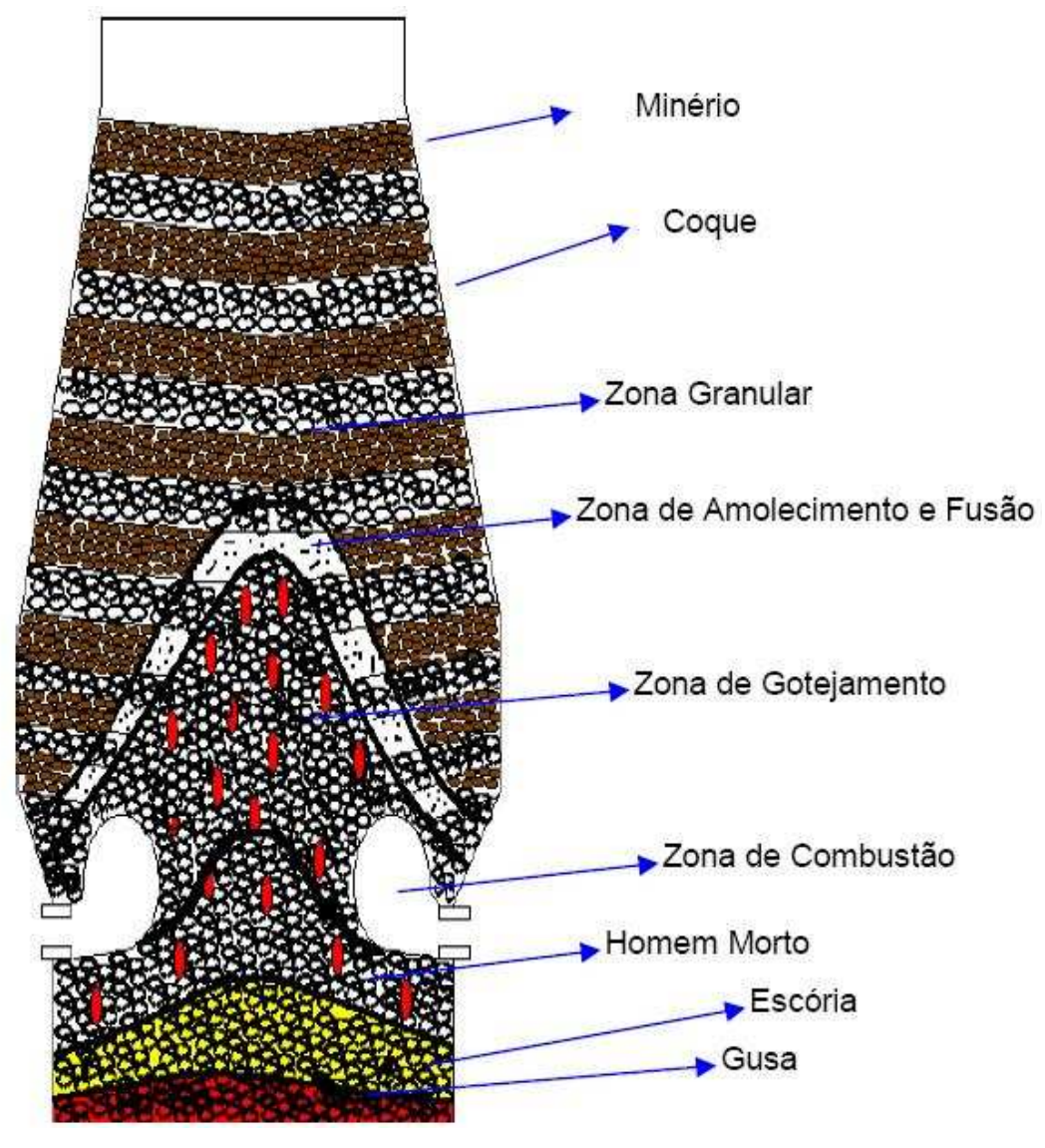

(fonte: CASTRO et al., 2000)

Figura 1 - esquema da parte interna do alto forno (zonas de amolecimento e fusão e de gotejamento)

Feilo e Royster (1988) formularam em forma de ábaco, conforme Figura 2, a diferença de basicidade entre as escórias primárias e finais, mostrando que há acentuação à medida que cresce o consumo de coque, do conteúdo de cinzas de coque e da porcentagem de $\mathrm{SiO}_{2}$ nas cinzas; também se observa a relação entre a basicidade das escórias primárias com o volume de escória para diferentes isobasicidades da escória final. 


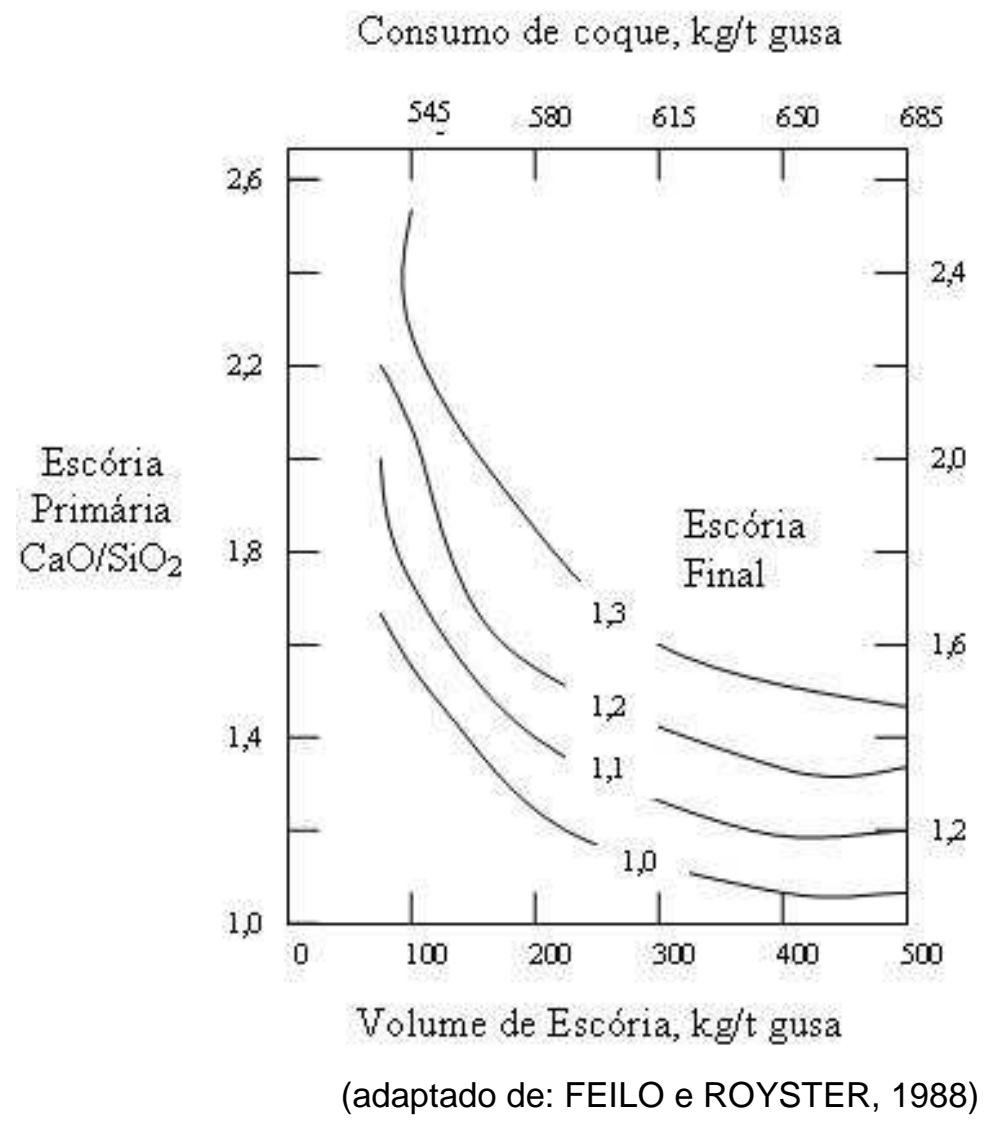

Figura 2 - consumo de coque por tonelada de gusa

A quantidade de escória produzida no alto forno é muito importante, porque ela influencia diretamente na produtividade do processo: a escória de baixa densidade é prejudicial ao fluxo de gases e líquidos no forno, maiores quantidades de escória significam maiores níveis de coque por tonelada de gusa, gerando, assim, maior emissão de gases. A mínima produção de escória deve ser objetivada para se obter ganhos de produção e menores consumos do termorredutor. Além disso, a eficiência da drenagem de líquidos é afetada pela massa de escória produzida (KEIL, 1963; Mc CAFFERY e OESTERLE, 1993 e MEALLA, CASTAÑEDA e RETAMOZO, 1989).

Portanto, para cada situação de operação e matérias primas, o volume de escória mínimo será diferente. Castro et al. (2000) citam que na Companhia Siderúrgica de Tubarão/SC - CST - a porcentagem de $\mathrm{Al}_{2} \mathrm{O}_{3}$ é limitada em 13,5\%, exatamente para o controle do volume de escória. 
As primeiras décadas do século $X X$ foram de avanços para a siderurgia brasileira, impulsionados pelo surto industrial verificado entre 1917 e 1930, chegando a patamares de produção mundial acima de 1.000.000.000 (um bilhão) de toneladas ao ano. Apenas no fim do século, em torno de 1985, esta produção estabilizou-se e começou a diminuir. Atualmente, a produção anual oscila entre 700 e 800 milhões de toneladas ao ano (DZIERVA, 2007).

Conforme o Instituto Brasileiro de Siderurgia (IBS, 2009), o Brasil está entre os dez maiores produtores de aço do mundo, tendo produção atual de 26 milhões de toneladas $\left(26 \times 10^{6} \mathrm{t}\right)$ ao ano; mesmo com este montante, está muito abaixo dos maiores produtores mundiais: Rússia com cerca de $160 \times 10^{6} \mathrm{t}$, Japão com $100 \times$ $10^{6} \mathrm{t}$, EUA com $90 \times 10^{6} \mathrm{t}$, China com $60 \times 10^{6} \mathrm{t}$ e Alemanha com $50 \times 10^{6} \mathrm{t}$. A previsão de investimento no setor (entre 2005 e 2010) é de US\$12,5 bilhões, com projeção de alcançar a capacidade instalada de 49,7 x 106 t em 2010 (IBS, 2009). Esse novo ciclo de investimentos está voltado para o aumento da capacidade de produção do aço a fim de atender ao crescimento da demanda interna (motivados pelo Programa de Aceleração do Crescimento - PAC - e situação econômica nacional) que deve ser superior a $5 \times 10^{6} \mathrm{t}$ por ano. Porém, a atual crise econômica mundial poderá ocasionar queda nestes índices em função da recessão observada no Brasil, a partir do segundo trimestre de 2009.

De acordo com Adams e Dirlam (1986), Little (2009) e a Sociedad Mixta Siderurgica Argentina - SOMISA - (1985), o índice médio de geração da escória de alto forno é cerca de $270 \mathrm{~kg}$ por tonelada de ferro gusa, sendo gerados cerca de $7,3 \times 10^{6} \mathrm{t}$ deste tipo de resíduo no Brasil, em 2009, com taxa média de crescimento anual de 5,5 \% nas últimas três décadas (IBS, 2009).

\subsection{ESTRUTURA DA ESCÓRIA DE ALTO FORNO}

O estudo das reações entre escória líquida e banho metálico em alto forno era baseado no princípio de que os componentes da escória estavam presentes na forma molecular (HERASYMENKO, 1941; HOPKINS, 1954 e TEMKIN, SAMARIN e SCHUARTSMAN, 1945). Posteriormente, a observação da natureza iônica das 
escórias líquidas tem permitido concluir que as reações entre escória e metal são mais iônicas do que moleculares (SHENCK, 1945 e TEMKIN, SAMARIN e SCHUARTSMAN, 1945). Herasymenko (1941) afirma que os primeiros esforços para aplicar as leis físicoquímicas em relações entre banho metálico e escória, utilizando as concentrações totais de materiais reativos não obteve êxito, induzindo ao raciocínio de que algum tipo de combinação devia existir entre os distintos componentes da escória e que somente uma parte da concentração total de um determinado componente podia ser capaz de relacionar-se quimicamente. Assim sendo, utilizou-se o conceito de concentrações livres dos componentes da escória de alto forno para cálculo das constantes de equilíbrio. Estudos neste sentido foram explorados por Flood e Brueggemann (1956) para escórias básicas e Shenck (1945) para escórias ácidas, gerando constantes formuladas a partir de diagramas entre diferentes temperaturas relacionando a concentração livre dos componentes de escória versus a composição da escória determinada por análises químicas.

Apresenta-se, na Figura 3, o diagrama triangular de RANKIN que mostra a faixa de composição química das escórias em relação a outros materiais. 


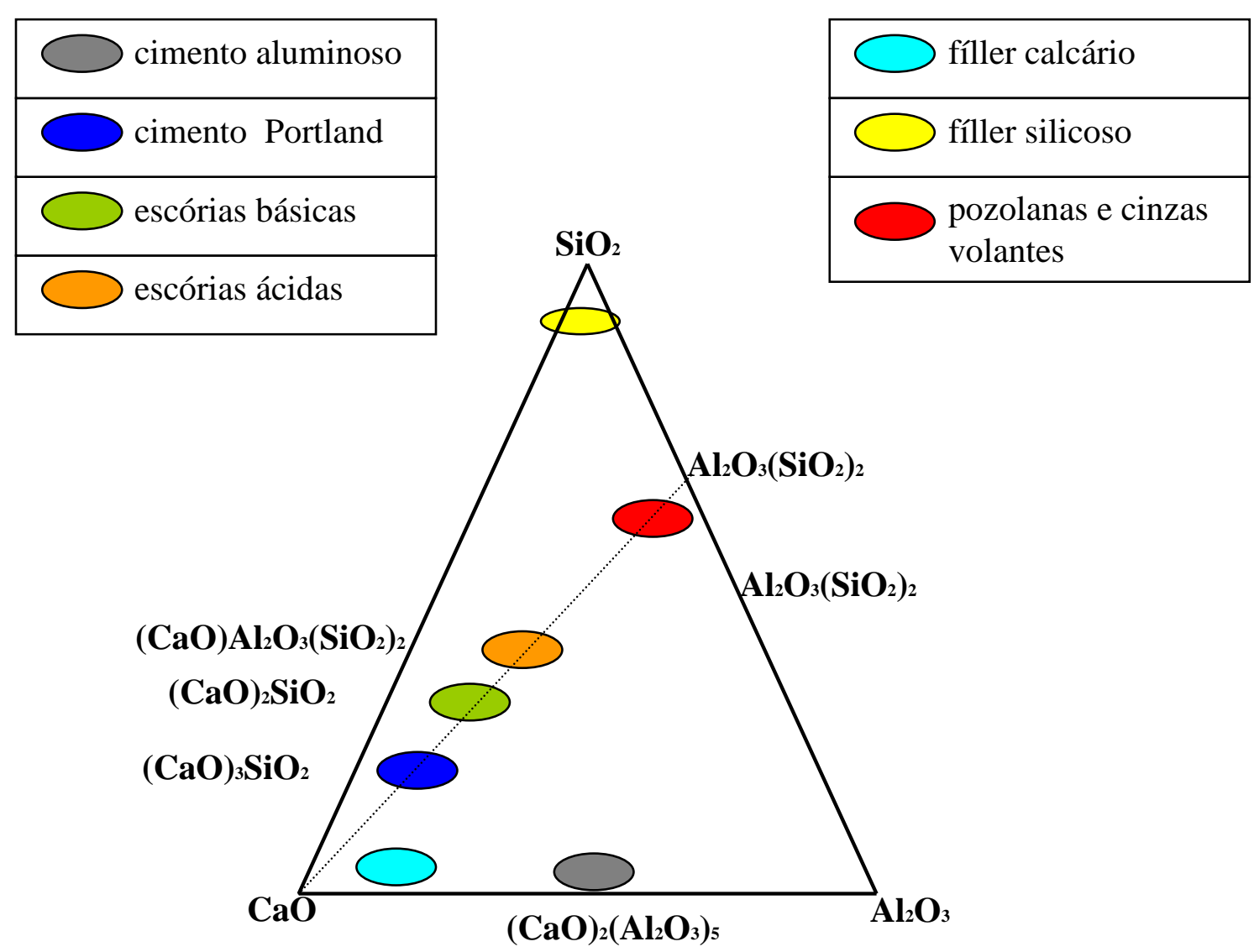

(adaptado de: ALEXANDRE e SEBILEAU, 1988)

Figura 3 - representação do sistema $\mathrm{CaO} \cdot \mathrm{SiO}_{2} \cdot \mathrm{Al}_{2} \mathrm{O}_{3}$ da escória de alto forno

Segundo Feilo e Royster (1981) e Lee (1974), dado que as escórias de alto forno se produzem mediante a completa fusão de seus constituintes seguido de um resfriamento em condições de certa forma controladas, o nível de variação de suas propriedades pode ser amplo. Podendo ser tão cristalina como o granito ou tão amorfa como um vidro, tendo propriedades hidráulicas que se aproximem daquelas do cimento Portland ou ser tão inerte quanto o basalto. A importância da organização atômica da escória é determinante para seu poder aglomerante. Este grau de vitrificação, por sua vez, é caracterizado pela forma e tempo o qual a escória esfria-se.

Quando a escória flui desde o alto forno é um líquido homogêneo, tal qual o vidro fundido. A cristalização se dá quando a escória está esfriando-se, começando quando a queda da temperatura do fundido chega a tal ponto onde o primer mineral pode formar-se no líquido, sendo esse ponto em torno de $1.450^{\circ} \mathrm{C}$ para a 
maioria das escórias (LONGO, 1982 e SOMISA, 1985); finalmente a cristalização cessa quando a massa solidifica-se.

\subsubsection{Resfriamento à água}

O rápido resfriamento da escória de alto forno com água gera rápida solidificação, desintegrando-se, via de regra, em partículas menores que $2 \mathrm{~mm}$, sendo suficiente para a formação de núcleos cristalinos. Portanto, uma escória bem graduada é substancialmente vítrea em sua estrutura, o que é comprovado quando se observa em microscópio petrográfico.

Lee (1974), examinando a escória de alto forno granular em microscópio, notou que os grãos que se vêem consistem em vidro isotrópico e transparente, alguns dos quais mostram zonas de coloração marrom ou negras onde há cristalização incipiente.

O processo de esfriamento rápido em água se introduziu por volta de 1855 com o fim de facilitar a eliminação da escória dos altos fornos, graças a sua natureza granular; em 1862, se descobriu que a escória assim obtida, em conjunto com a cal, desenvolve propriedades hidráulicas, comercializando-se este produto em 1865, na Alemanha e, em 1892, se fabrica o primeiro cimento Portland de alto forno por moagem conjunta de escória de alto forno e clínquer (LONGO, 1982).

A instalação de resfriamento à água consta essencialmente de uma grande fossa estanque comprimida de água ou em bicos pulverizadores, onde se dirige a escória em estado líquido. Produz-se no momento de contato entre escória e água o brusco esfriamento desta e sua imediata vitrificação. Posteriormente, mediante a utilização de pontes gruas com baldes concha, a escória granulada é evacuada da fossa e transportada pelas canaletas de drenagem com a simples finalidade de extrair a maior quantidade de água possível.

A escória amorfa tem uma reação mais enérgica com o cimento que a reação da escória que tem sido esfriada lentamente, já que esta última tem perdido energia interna ou calor latente em produzir sua própria cristalização. 
Keil (1963) submeteu amostras de escória de alto forno resfriadas com pulverização de água em ensaios de difração de raio X; estas apresentaram 90 \% da estrutura amorfa. Resfriadas a velocidade adequada são compostas basicamente por silicatos de cálcio $\left(\mathrm{Ca}_{2} \mathrm{SiO}_{4}\right)$ que podem apresentar mais de um sistema cristalino e monoclínico mais estável, romboidal menos estável e melilita cristalizada em sistemas tetragonal. Sua densidade varia entre 2,1 a 2,8 para as amorfas e 2,8 para as cristalinas.

Mathur, Soni e Murty (2001) analisaram comparativamente a granulometria (porcentagens de material passante nas peneiras) da escória metálica e de alto forno submetidas ao resfriamento em água e ao esfriamento ao ar, e da cinza volante, conforme mostrado na Tabela 1. Percebe-se que a escória de alto forno que sofre esfriamento ao ar apresenta características de granulometria semelhantes às de agregados graúdos; já a escória de alto forno resfriada à água mostra-se semelhante às areias em termos de dimensão máxima do agregado.

Tabela 1 - análise granulométrica de diversos materiais da indústria de siderurgia

\begin{tabular}{cccccc}
\hline $\begin{array}{c}\text { Abertura da Peneira } \\
(\mathbf{m m})\end{array}$ & Cascalho & $\begin{array}{c}\text { Escória de Alto Forno } \\
\text { Resfriada }\end{array}$ & Esfriada & Escória Metálica & Cinza Volante \\
\hline $\mathbf{1 9}$ & 100 & 100 & 100 & 100 & 100 \\
$\mathbf{9 , 5}$ & 95 & 98 & 82 & 84 & 100 \\
$\mathbf{4 , 7 5}$ & 90 & 96 & 55 & 57 & 100 \\
$\mathbf{2 , 3 6}$ & 75 & 82 & 28 & 30 & 100 \\
$\mathbf{1 , 1 8}$ & 70 & 55 & 20 & 22 & 100 \\
$\mathbf{0 , 6 0}$ & 65 & 35 & 8 & 14 & 100 \\
$\mathbf{0 , 1 5}$ & 40 & 8 & - & - & 95 \\
$\mathbf{0 , 0 7 5}$ & 30 & 5 & - & - & 90 \\
\hline & & & (adaptado de: MATHUR, SONI e MURTY, 2001)
\end{tabular}

\subsubsection{Esfriamento ao ar}

As escórias de alto forno esfriadas ao ar apresentam cristais demasiadamente pequenos para serem vistos a olho nu, porém, podem distinguirse rapidamente utilizando um microscópio petrográfico. Estes cristais apresentam uma complicada observação, sendo difícil identificá-los com certeza (LEE, 1974).

De acordo com Longo (1982), sendo processada de uma maneira ou de outra, a composição dos elementos das escórias de alto forno será a mesma 
diferenciando-se fundamentalmente em suas estruturas. Se a escória se esfria lentamente, forma estruturas ordenadas sendo suas principais fases cristalinas, que dependem da composição de seus elementos, conforme se detalha no Tabela 2.

Tabela 2 - principais fases cristalinas das escórias de alto forno esfriada ao ar

\begin{tabular}{|c|c|}
\hline Mineral & Composição Química \\
\hline akermatita & $2 \mathrm{CaO} . \mathrm{MgO} .2 \mathrm{SiO}_{2}$ \\
\hline gehlenita & $2 \mathrm{CaO} \cdot \mathrm{Al}_{2} \mathrm{O}_{3} \cdot \mathrm{SiO}_{2}$ \\
\hline pseudowollastonita & $\mathrm{CaO} . \mathrm{SiO}_{2}$ \\
\hline bredigita & $2 \mathrm{CaO} \cdot \mathrm{SiO}_{2}$ \\
\hline merwinita & $3 \mathrm{CaO} \cdot \mathrm{MgO} \cdot 2 \mathrm{SiO}_{2}$ \\
\hline rankinita & $3 \mathrm{CaO} .2 \mathrm{SiO}_{2}$ \\
\hline
\end{tabular}

Neste caso, mediante um esfriamento lento, a unidade operativa geradora requer uma grande disponibilidade de espaço livre com o intuito de construção de fossas de contenção em esfriamento (slag pits). Usualmente, essas fossas devem ser o suficientemente amplas para permitir o livre acesso de equipes de extração após a solidificação. $O$ emprego desta metodologia de esfriamento obriga a operação com mais de uma fossa pelos efeitos de não condicionar com fatores externos o normal funcionamento do alto forno.

Carmine (1985) cita que este tipo de escória é depositada em extensas camadas de $15 \mathrm{~cm}$ de espessura, favorecendo assim, o esfriamento à temperatura ambiente. A extração definitiva é realizada utilizando escavadores sobre esteira ou carregadores frontais sobre pneumáticos, cujos potenciais oscilam em torno de 300 $\mathrm{HP}$, assegurando produção acima de $250 \mathrm{~m}^{3} /$ hora.

As escórias esfriadas ao ar normalmente são cinzentas, mas seus constituintes em menores quantidades podem variar o tom de coloração. A escória granulada é usualmente de cor mais clara, em tonalidade que varia de amarela a parda, a causa dos coloides (KEIL, 1963). Apresenta-se, na Tabela 3, resultados 
físicos realizados na escória de alto forno esfriada ao ar em comparação à um material granítico da Índia.

Tabela 3 - propriedades físicas da escória de alto forno esfriada ao ar

\begin{tabular}{|c|c|c|c|c|c|}
\hline \multirow{2}{*}{ Propriedade Física } & \multirow{2}{*}{$\begin{array}{l}\text { Método de } \\
\text { Teste }\end{array}$} & \multirow{2}{*}{$\begin{array}{l}\text { Escória de } \\
\text { Alto Forno }\end{array}$} & \multirow{2}{*}{$\begin{array}{l}\text { Material } \\
\text { Granítico }\end{array}$} & \multicolumn{2}{|c|}{$\begin{array}{c}\text { Índices Preconizados pelo } \\
\text { Congresso Indiano de } \\
\text { Rodovias }\end{array}$} \\
\hline & & & & $\begin{array}{l}\text { Sub- } \\
\text { Base/ } \\
\text { Base }\end{array}$ & $\begin{array}{l}\text { Revestimento } \\
\text { Asfáltico }\end{array}$ \\
\hline $\begin{array}{c}\text { Resistência ao impacto } \\
(\%)\end{array}$ & & $18-24$ & 15 & $<40$ & $<30$ \\
\hline $\begin{array}{c}\text { Resistência ao } \\
\text { esmagamento (\%) }\end{array}$ & $\begin{array}{l}\text { BIS - } 2386 \\
\text { PART-IV }\end{array}$ & $24-26$ & 20 & - & - \\
\hline $\begin{array}{c}\text { Abrasão Los Angeles } \\
(\%)\end{array}$ & & $28-32$ & 27 & $<50$ & $<35$ \\
\hline Rugosidade (\%) & BIS 2386 & 12 & 10 & $<15$ & $<35$ \\
\hline Alongamento (\%) & PART-I & 9 & $8-10$ & - & - \\
\hline Absorção (\%) & & $1,5-2,5$ & 0,6 & - & 2 \\
\hline $\begin{array}{c}\text { Massa específica } \\
\left(\mathrm{kg} / \mathrm{m}^{3}\right)\end{array}$ & $\begin{array}{l}\text { BIS } 2386 \\
\text { PART-III }\end{array}$ & 2650 & 2800 & - & - \\
\hline $\begin{array}{c}\text { Massa unitária seca } \\
\left(\mathrm{kg} / \mathrm{m}^{3}\right)\end{array}$ & & 1800 & 1900 & - & - \\
\hline
\end{tabular}

A escória de alto forno esfriada, em comparação com o material granítico, mostra-se mais resistente ao impacto e ao esmagamento, tendo maior rugosidade superficial e absorção; entretanto, possui massa específica menor.

Conforme Waelkens (1971), tradicionalmente na América Latina, utilizam-se ambos os métodos (resfriamento ou esfriamento) em forma indistinta, segundo a utilização posterior a que se destina a escória de alto forno obtida, mas a grande evolução que adquiriu o emprego dos cimentos de escória no começo da década de 1970 e a utilização como adição ao cimento Portland tem derivado em um predomínio das instalações de granulação.

Segundo Johnson (1986), apesar de que, normalmente, o banho metálico contém cerca de $6 \%$ de impurezas, utilizando as leis que se aplicam em soluções diluídas, é possível expressar as diferentes atividades dos componentes 
individuais. Por outro lado, na escória de alto forno, nenhum componente simples está presente em quantidade suficiente para que seja considerado solvente.

As escórias granuladas de alto forno contêm quatro óxidos principais: sílica, alumina, cal e magnesita, os quais constituem aproximadamente $95 \%$ do total (Tabela 4). Os elementos de menor importância incluem o enxofre, magnésio e ferro.

Tabela 4 - porcentagem dos elementos componentes da escória granulada de alto forno

\begin{tabular}{cc}
\hline Componente & Porcentagem \\
\hline Sílica & 33 a $42 \%$ \\
Alumina & 10 a $16 \%$ \\
Cal & 36 a $45 \%$ \\
Magnesita & 3 a $12 \%$ \\
Enxofre & 1 a $3 \%$ \\
Óxido de Ferro & 0,3 a $2 \%$ \\
Óxido de Manganês & 0,2 a $1,5 \%$ \\
\hline \multicolumn{2}{c}{ (fonte: FEILO e ROYSTER, 1981) }
\end{tabular}

De acordo com Feilo e Royster (1981), a porcentagem dos elementos componentes da escória varia de forno para forno, dependendo dos constituintes e suas proporções nos minerais fundentes: coque e outras matérias primas, pureza do material e diferenças na prática operativa.

Battagin (1988) realizou uma detalhada investigação dos componentes químicos dos principais produtores de escória de alto forno no Brasil, sendo estes detalhados na Tabela 5. Dentre estas indústrias, nota-se que não há predominância de natureza básica ou ácida do agregado siderúrgico, independente da região, na qual ele é gerado. 
Tabela 5 - composição química das escórias de alto forno brasileiras

\begin{tabular}{|c|c|c|c|c|c|c|c|c|c|c|}
\hline \multirow{2}{*}{ 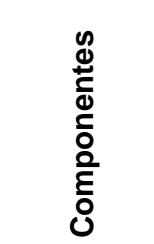 } & \multicolumn{10}{|c|}{ Procedência } \\
\hline & $\begin{array}{l}\text { Usiminas } \\
\text { (MG) }\end{array}$ & $\begin{array}{c}\text { Cosipa } \\
\text { (SP) }\end{array}$ & $\begin{array}{l}\text { CSN } \\
\text { (RJ) }\end{array}$ & $\begin{array}{l}\text { Aliperti } \\
\text { (SP) }\end{array}$ & $\begin{array}{c}\text { Barra } \\
\text { Mansa } \\
\text { (RJ) }\end{array}$ & $\begin{array}{c}\text { Belgo } \\
\text { Mineira } \\
\text { (MG) }\end{array}$ & $\begin{array}{c}\text { Sete } \\
\text { Lagoas } \\
\text { (MG) }\end{array}$ & $\begin{array}{l}\text { Usipa } \\
\text { (MG) }\end{array}$ & $\begin{array}{l}\text { CST } \\
\text { (ES) }\end{array}$ & $\begin{array}{l}\text { Açominas } \\
\text { (MG) }\end{array}$ \\
\hline $\mathrm{SiO}_{2}$ & 35,15 & 33,85 & 32,90 & 37,53 & 40,59 & 38,12 & 40,07 & 43,97 & 35,47 & 35,39 \\
\hline $\mathrm{Al}_{2} \mathrm{O}_{3}$ & 12,79 & 13,00 & 15,44 & 17,02 & 15,39 & 19,44 & 13,65 & 13,21 & 13,20 & 13,88 \\
\hline $\mathrm{CaO}$ & 43,58 & 42,22 & 40,97 & 33,90 & 34,12 & 34,97 & 35,07 & 34,89 & 41,97 & 40,99 \\
\hline $\mathrm{Fe}_{2} \mathrm{O}_{3}$ & 0,37 & 0,68 & 0,91 & 4,26 & 1,95 & 1,30 & 2,53 & 0,40 & 0,83 & 1,97 \\
\hline $\mathrm{FeO}$ & 0,29 & 0,33 & 0,43 & 0,00 & 0,87 & 0,79 & 1,44 & 0,22 & 0,00 & 0,00 \\
\hline $\mathrm{MgO}$ & 5,48 & 7,08 & 5,81 & 3,02 & 3,96 & 1,63 & 1,95 & 3,67 & 5,69 & 6,31 \\
\hline $\mathrm{K}_{2} \mathrm{O}$ & 0,45 & 0,70 & 0,73 & 1,90 & 1,29 & 1,88 & 1,94 & 1,86 & 0,28 & 0,49 \\
\hline $\mathrm{Na}_{2} \mathrm{O}$ & 0,13 & 0,21 & 0,19 & 0,14 & 0,30 & 0,12 & 0,19 & 0,12 & 0,10 & 0,12 \\
\hline $\mathrm{TiO}_{2}$ & 0,54 & 0,48 & 0,49 & 0,00 & 0,74 & 0,62 & 0,21 & 0,16 & 0,53 & 0,00 \\
\hline $\mathrm{Mn}_{2} \mathrm{O}_{3}$ & 0,88 & 0,69 & 0,86 & 0,00 & 3,50 & 1,86 & 0,64 & 0,85 & 0,84 & 0,00 \\
\hline $\mathrm{SO}_{3}$ & 0,05 & 0,12 & 0,00 & 0,00 & 0,05 & 0,02 & 0,00 & 0,02 & 0,07 & 0,00 \\
\hline$S$ & 1,10 & 0,67 & 1,03 & 0,18 & 0,11 & 0,10 & 0,08 & 0,07 & 0,87 & 0,87 \\
\hline $\mathrm{Fe}$ & 0,07 & 0,13 & 0,25 & 0,00 & 0,40 & 0,37 & 0,74 & 0,21 & 0,00 & 0,00 \\
\hline Natureza & básica & básica & básica & ácida & ácida & ácida & ácida & ácida & básica & básica \\
\hline
\end{tabular}

\subsection{REUTILIZAÇÃO DA ESCÓRIA DE ALTO FORNO}

O abastecimento suficiente e contínuo de matérias primas minerais é a condição básica essencial para o desenvolvimento e a capacidade de rendimento de uma economia nacional com caráter industrial. Entre as matérias primas se incluem as rochas não consolidadas e diferentes tipos de rochas consolidadas. De acordo com Tudeshki e Hertel (2008) e o prognóstico de pesquisadores alemães para exploração mineral a céu aberto, o consumo mundial de areia, pedra natural e cimento aumentará, até 2030 , aproximadamente $240 \%$ a $290 \%$. Apresentam-se, na Figura 4, a crescente evolução atual no consumo de agregados mundiais; na Figura 5, a proporção dos maiores extratores mundiais de jazidas naturais para agregados e, na Figura 6, a distribuição dos principais estados consumidores de agregados no Brasil. De acordo com estes índices, o Estado de São Paulo figura entre as regiões do mundo que necessitam de maiores recursos minerais destinados à construção civil, atualmente com patamares de consumo anual de agregados - miúdos e graúdos - em torno de 4,2 × 106 t (em 2009). 


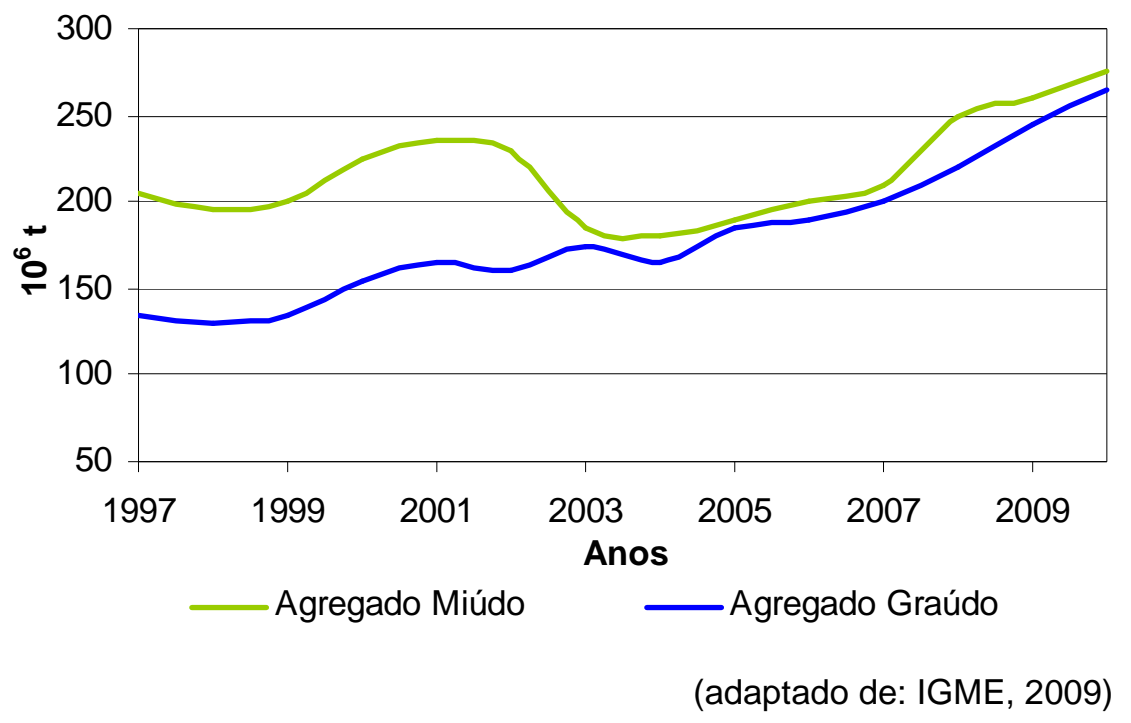

Figura 4 - prognóstico para o desenvolvimento do consumo global de agregados e demais materiais para a construção civil

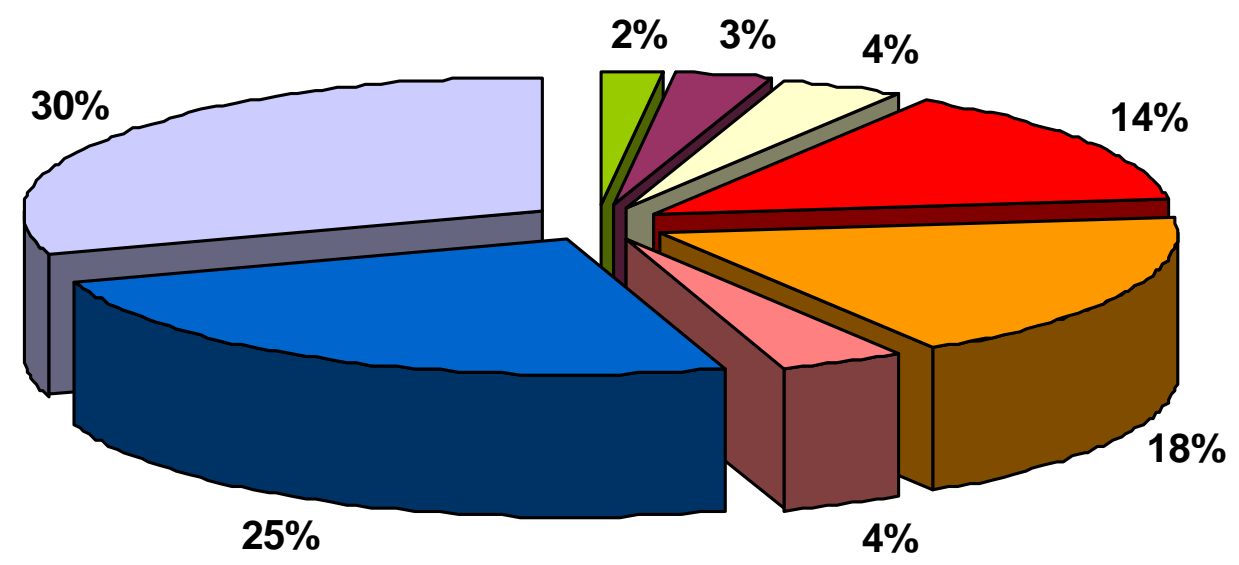

$\square$ Brasil $\square$ Canadá $\square$ Japáo $\square$ EUA $\square$ Europa $\square$ Rússia $\square$ China $\square$ Outros

(fonte: IGME, 2009)

Figura 5 - maiores extratores mundiais de agregados naturais 


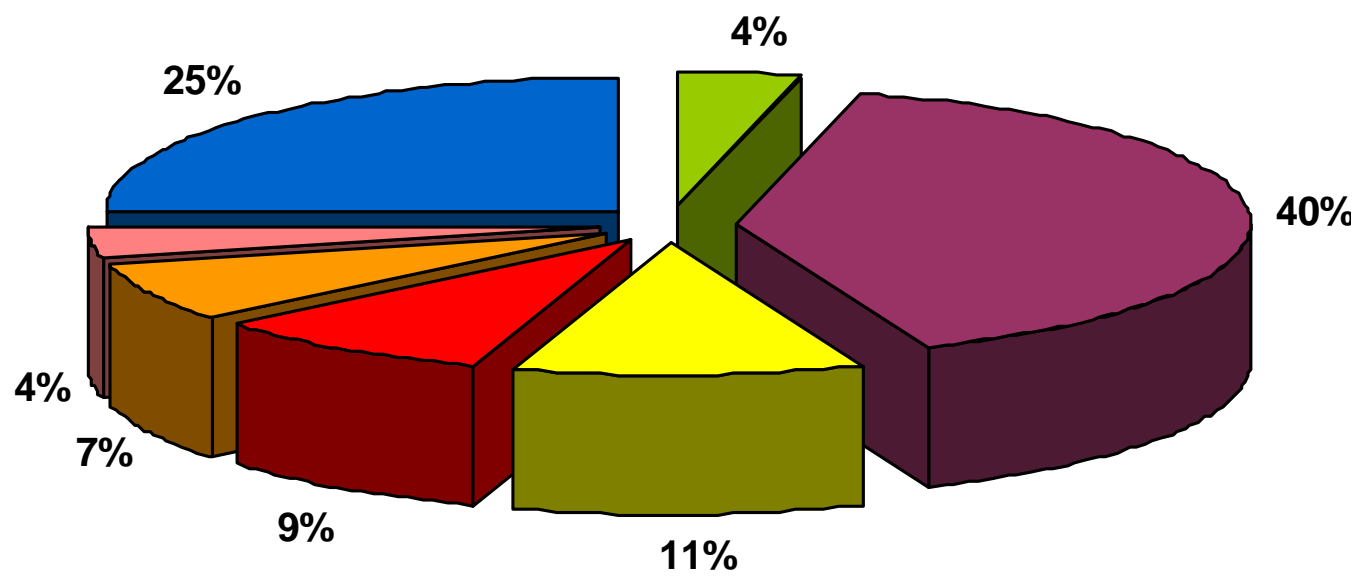

$\square R S \quad \square S P \quad \square M G \quad \square R J \quad \square P R \quad \square S C \quad \square$ Outros
(fonte: DNPM, 2009)

Figura 6 - principais estados brasileiros extratores de jazidas de agregados

Os atuais conhecimentos relativos à limitação na existência de certas fontes de energia e matéria prima, como também a incorporação de novos fatores de condicionamento (controle da contaminação ambiental e da extração de jazidas naturais), têm obrigado a concentração de esforços de investigação e processo de técnicas de recuperação e utilização de maiores quantidades de resíduos industriais. Dentre as indústrias que mudaram seu enfoque de gestão interna, está a siderurgia, onde a escória de alto forno era considerada um rejeito da operação das usinas (sem nenhum interesse econômico), sendo, a partir da década de 1980, vista como um produto secundário e alternativo com valor econômico agregado.

As principais frentes de reutilização da escória de alto forno no Brasil e em países como os Estados Unidos da América, Canadá, Inglaterra, França, Alemanha, Itália, Japão e Coréia do Sul estão mostradas nas Figuras 7 e 8 , respectivamente.

Nacionalmente, o grande predomínio da utilização deste agregado siderúrgico é a sua adição em conjunto com o clínquer Portland na produção do cimento CP III, sendo superior a $90 \%$; em âmbito mundial, este predomínio também existe, entretanto, é inferior a 50 \%. Mostrando assim, que há necessidade de novos estudos neste sentido e que há uma gama de reutilizações a serem exploradas, condicionadas às características fisicoquímicas e natureza das 
escórias de alto forno geradas e as potenciais frentes de trabalho para amortizar estas quantidades.

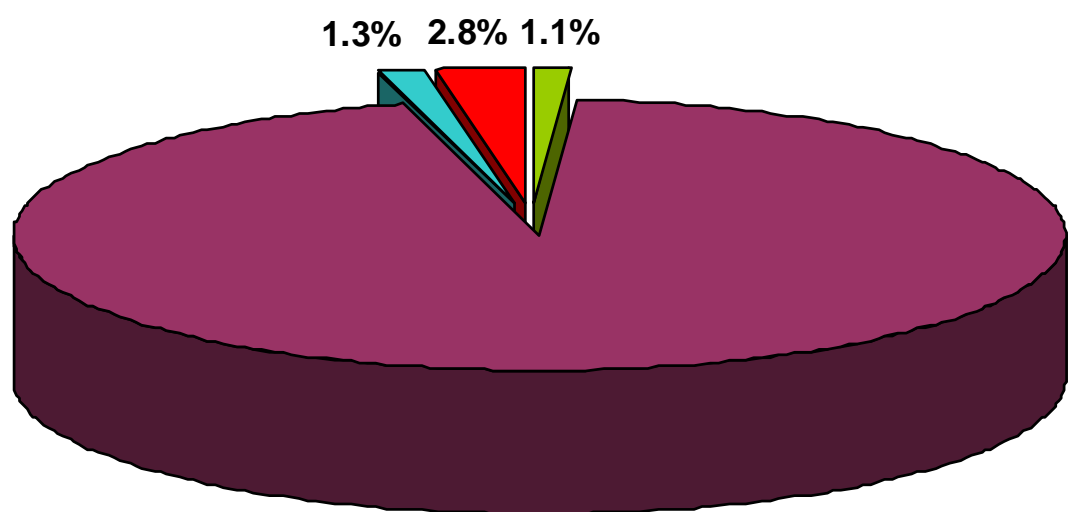

$93.3 \%$

$\square$ Base de Rodovias $\square$ Adição no Cimento $\square$ Agregado no Concreto $\square$ Lã Mineral

(adaptado de: LITTLE, 2009)

Figura 7 - principais frentes para reutilização de escória de alto forno no Brasil

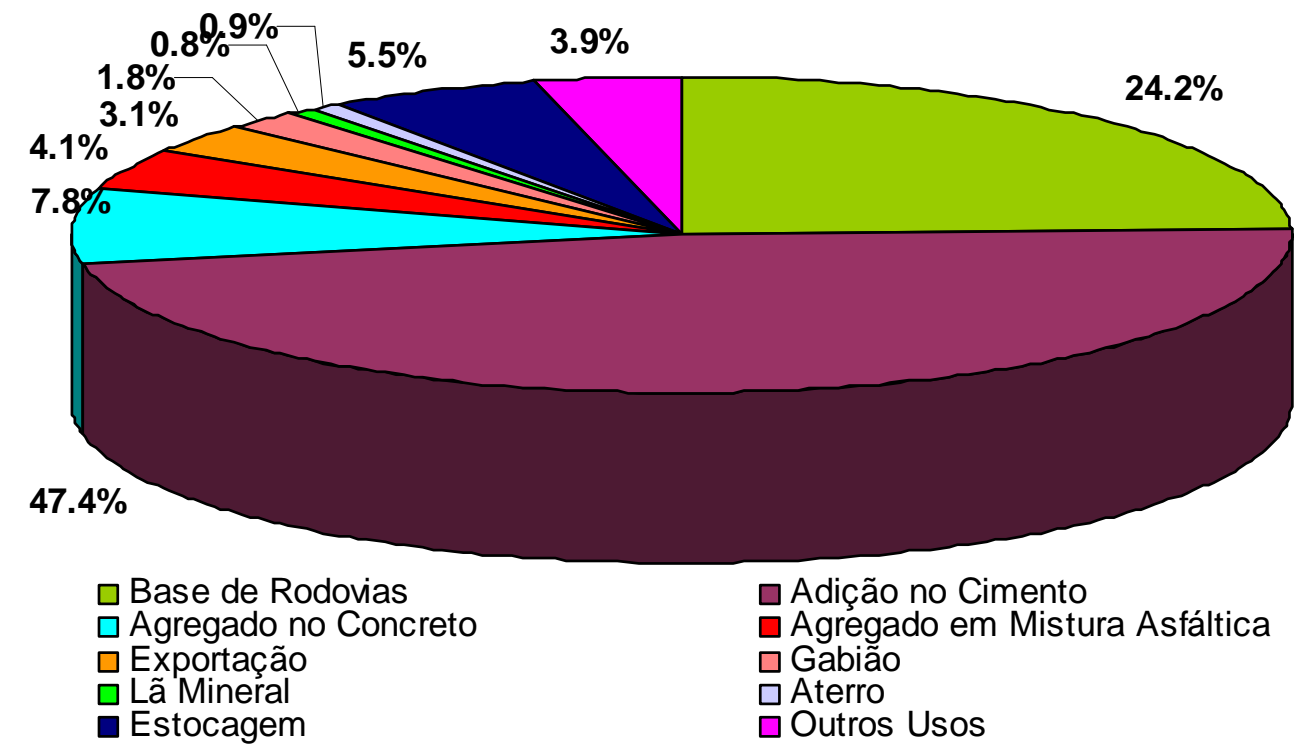

(adaptado de: LITTLE, 2009)

Figura 8 - principais frentes para reutilização de escória de alto forno no mundo 
Mathur, Soni e Murty (2001) afirmam que a Índia tem uma larga rede de empresas de siderurgia localizadas em diferentes partes do país, gerando quantidades maciças de areias industriais como: a escória de alto forno, escória de aciaria, areias de fundição, entre outras. Embora estes rejeitos tenham suas propriedades peculiares, sendo explorados em diversos estudos em infraestrutura de transportes, nunca foram empregados na prática por ausência de normas técnicas. Assim, estes resíduos ocupam imensas áreas em todo o território Indiano; este cenário é comum em diversos países, inclusive, no Brasil. Entretanto, a partir de 1998, o Instituto Central de Pesquisas de Rodovias de Nova Délhi começou o desenvolvimento de especificações técnicas, visando à utilização de areias sólidas para rodovias de baixo volume de tráfego na Índia.

$\mathrm{Na}$ Alemanha, a legislação nacional - em vigor desde 27 de agosto de 1986 - prevê índices de aceitabilidade de diversos resíduos industriais, inclusive, da siderurgia, para reutilização em outros materiais. Hüber (1992) cita que, na reutilização destes subprodutos gerados, cerca de $90 \%$ do montante são utilizados na engenharia civil.

Na França, há especificações que utilizam $100 \%$ de escória em grave laitier (tecnologia francesa de misturas de escória e cascalho ou somente escória tendo em vista a autoestabilização). Nestas misturas, o material se comporta como semirrígido podendo ser usado em base e sub-base de pavimentos. De forma similar, países como Austrália, Holanda, Bélgica e Inglaterra também realizaram investigações de parâmetros técnicos para utilização de escórias em misturas estabilizadas e cimentadas para pavimentos (CHO e YEO, 2004; KOUDA, 1996 e MATHUR, SONI e MURTY, 2001).

Exceto nos casos em que a escória de alto forno é utilizada na fabricação de produtos como cimentos, lã de escória e vidro, as especificações acerca da reutilização deste subproduto, de um modo geral, não incluem requerimentos sobre a composição química, porque um adequado controle de qualidade está assegurado pela especificação das propriedades físicas mais significativas. Todavia, tanto as propriedades químicas quanto as mineralógicas exercem influência nas propriedades físicas da escória. 


\subsubsection{Indústria de cimento}

A data de início da fabricação de cimento utilizando escória granulada de alto forno difere-se entre autores. Segundo Carmine (1985) e Virgalette et al. (1995), seu início foi na Alemanha em 1905; Longo (1982) afirma que, em 1892, se iniciou a fabricação de um cimento Portland de alto forno por moagem conjunta de escória e clínquer. Entretanto, ambos os autores relatam que foi, em 1862, a descoberta das propriedades cimentícias das escórias, quando utilizadas como agregados em conjunto com a cal; Virgalette et al. (1995) comentam que seu início foi, em 1774, quando houve a confecção de argamassas usando uma combinação de escória e cal hidratada.

Conforme Carmine (1985), no início da década de 1980, quase 20 \% do total da produção mundial de ligante hidráulico era de cimento de escória. Nessa época, a produção de cimento de escória na França e Itália representava cerca de $10 \%$ da produção total de cimento; na Alemanha, $16 \%$; no Japão, $5 \%$; na Tchecoslováquia, Polônia e Romênia entre 30 e 50 \%. No Brasil, em 1981, se utilizava mais de um milhão de toneladas de escória granulada de alto forno em cimento Portland, representando $8,9 \%$ da produção total de cimento (LONGO, 1982).

John (1995) indica que, após a década de 1950, a utilização de cimentos de escória foi praticamente abandonada, com exceção dos ativados com álcalis. A baixa resistência inicial e o fato da degradação durante a estocagem não ser facilmente detectável foram as principais causas para essa queda de produção. De maneira geral, os cimentos de escória não apresentavam vantagens competitivas significativas frente ao cimento Portland, exceto o preço.

De acordo com Longo, Carrizo e Pozzi (1989) na industrialização do cimento Portland, são empregados os seguintes gastos energéticos:

- homogeneização e dosagem granular: 230 kcal $/ \mathrm{kg}$;

- clinquerização: $1.090 \mathrm{kcal} / \mathrm{kg}$;

- moagem e classificação: $1.460 \mathrm{kcal} / \mathrm{kg}$. 
Para cálculo da economia energética que significa a utilização de escória granulada em substituição em massa equivalente de cimento considera-se um consumo de $1.320 \mathrm{kcal} / \mathrm{kg}$ para moagem e clinquerização. Estimando uma produção anual no final da década de 1980 de 263.200 toneladas de escória para utilização na fabricação do cimento, resultar-se-ia em economia da ordem de 3,5 x $10^{11} \mathrm{kcal} / \mathrm{ano}$, equivalente a aproximadamente 33.000 t/ano de óleo combustível (LONGO, CARRIZO e POZZI, 1989).

As escórias granuladas de alto forno destinadas à indústria do cimento, requerem unicamente como condicionante posterior à sua extração, uma etapa de escorrimento com o único fim de eliminar a maior parte da água contida. Portanto, uma vez extraídas desde as fossas são transportadas e depositas em grandes áreas durante um tempo especificado que não deve ser demasiado extenso para evitar que as mesmas diminuam seu poder hidráulico de ligantes (SHORT e PAGE, 1981).

Segundo Smolczyk (1980), com respeito à estrutura da escória granulada de alto forno, é importante que contenha uma alta porcentagem de fase vítrea já que sua hidraulicidade aumenta proporcionalmente em cerca de $95 \%$; a resistência é mais elevada em escórias com uma porcentagem da fase vítrea superior, podendo estar relacionado este efeito à disponibilidade de atividade química, aumentando a reatividade.

A finura da escória granulada moída tem uma influência marcante no desenvolvimento da resistência; de acordo com Roy e Idorn (1982), é necessária uma superfície específica superior a $400 \mathrm{~m}^{2} / \mathrm{kg}$, dependendo da resistência inicial desejada.

Cincotto, Melo e Repette (2003) e Lim e Wee (2000) demonstraram que a retração autógena do concreto aumenta quanto maior a finura da escória e o teor de silicato de sódio (ativador), havendo redução no tamanho dos poros da matriz cimentícia, aumentando assim, a pressão nos poros de capilaridade durante a hidratação. A ativação com hidróxido de sódio mostrou os menores índices de retração autógena entre os ativadores, entretanto, ainda acima do cimento Portland (CINCOTTO, MELO e REPETTE, 2003). 
Para uma mesma relação água cimento - A/C - com os cimentos com escória se obtém uma maior trabalhabilidade que outros cimentos, isto permite, para uma mesma trabalhabilidade, utilizar uma relação $A / C$ menor, com as vantagens correspondentes (GEISELER, KOLLO e LANG, 1995; ROY e IDORN, 1982; SMOLCZYK, 1980 e TORRENT, ELOLA e SZTEINBERG, 1990).

Segundo Geiseler, Kollo e Lang (1995), Longuet, Burglen e Zelwer (1973) e Torrente, Elola e Szteinberg (1990) com relação as propriedades do concreto endurecido, as diferenças provêm do mecanismo de hidratação das escórias e da morfologia dos produtos de hidratação, sendo estes similares quimicamente aos do cimento Portland.

De acordo com John (1995), Roy e Idorn (1982) e Smolczkyk (1980), a escória granulada de alto forno apresenta um estado energético mais favorável devido à fase termodinâmica meta-estável com respeito à mistura de fases cristalinas com a mesma composição química centesimal e em presença de água (fases hidratadas). Para obter este estado estável, é necessário que a escória seja ativada, sendo adequado, por exemplo, um meio alcalino.

O meio alcalino nos cimentos com escória é devido ao hidróxido de cálcio, sendo este um produto da hidratação do cimento Portland. Esta ativação também é favorecida por um aumento de temperatura; isto leva a que os cimentos com escória tenham vantagens relativas em curas aceleradas e em concretos massa; por outro lado, não é conveniente seu emprego em climas muito frios. A velocidade de hidratação da escória granulada de alto forno moída é menor que a do cimento Portland, isto leva a um menor desenvolvimento da resistência inicial; contudo, ao longo do tempo há aumento, superando o cimento Portland em idades avançadas (JOHN, 1995; LONGUET, BURGLEN e ZELWER, 1973 e SHORT e PAGE, 1981).

Batista, Graça e Bittencourt (2005) afirmam que, quando não for exigido um tempo muito reduzido entre o lançamento das camadas de concreto compactado com rolo - CCR - e, não houver necessidade de resistência elevadas nas primeiras idades, o uso dos concretos secos com elevado teor de escória de alto forno moída e ativada (até 90 \%) podem ser indicados, de forma que se obtenham resistências aos 180 dias $30 \%$ superiores às misturas sem a presença deste 
resíduo em decorrência do refinamento dos poros através das reações pozolânicas e do efeito filler.

Na prática industrial, o cimento Portland de alto forno apresenta elevada finura para compensar a taxa mais lenta de hidratação das escórias, fato que poderia comprometer as resistências iniciais; devido esta característica favorável à diminuição da exsudação, não se deve, portanto, esperar maior exsudação para o cimento Portland de alto forno em relação ao cimento Portland comum (ESPER e BATTAGIN, 1989).

Liduário et al. (2005) analisaram a adição de escória de alto forno moída, em termos de resistência à compressão, no concreto plástico e no CCR. Neste estudo, a adição de escória moída substituindo $50 \%$ do cimento no concreto vibrado apresentou um ganho de $20 \%$ na resistência à compressão aos 91 dias. No CCR não houve a substituição parcial do cimento, assim sendo, aumentou-se o teor de argamassa da mistura; o CCR com adição de $100 \mathrm{~kg} / \mathrm{m}^{3}$ de escória apresentou acréscimo de 400 \% na resistência à compressão. Segundo Liduário et al. (2005), a utilização de escória granulada moída suplementando a ação do cimento Portland proporciona melhor compacidade ao CCR e, consequentemente, melhoria nas propriedades (reatividade potencial, permeabilidade, resistência à compressão e elevação adiabática da temperatura do concreto).

Geiseler, Kollo e Lang (1995) executaram testes em núcleos de edificações com um período de 25 anos, demonstrando que a resistência à compressão em concretos utilizando cimentos com escória pode chegar a $100 \%$ superiores que a mesma na idade de 28 dias.

John (1995) estudou a ativação da escória granulada de alto forno com silicato de sódio, mostrando que a variação da quantidade de $\mathrm{SiO}_{2}$ pode produzir cimentos com resistência à compressão variante em $300 \%$ (sem alterar o fator $\mathrm{A} / \mathrm{C})$.

Conforme Brodersen (1983), Hogan e Meusel (1981), Longuet, Burglen e Zelwer (1973) e Mehta (1980), a substituição de cimento Portland por escória granulada de alto forno moída diminui, pelo menos proporcionalmente, a quantidade de hidróxido de cálcio produzido no processo de hidratação; este 
produto não contribui ao desenvolvimento da resistência, sendo um ponto vulnerável ao ataque de agentes agressivos.

Esper e Battagin (1989), Lim e Wee (2000) e Smolczyk (1980) citam que a estrutura da pasta endurecida de cimento com escória é mais densa e com poros de tamanho médio menor que a pasta de cimento Portland, isto leva a uma menor permeabilidade e velocidade de difusão de íons. Esta característica, unida com a menor concentração de hidróxido de cálcio, faz que o cimento com escória seja mais resistente em meios agressivos e, internamente, é menor a possibilidade da reação álcali-agregado (FREASON, 1986; HOGAN e MEUSEL, 1981; ROY e IDORN, 1982 e SCHIEL $\beta$ e RAUPACH, 1990).

Marques (1994) observou que o uso de escória substituindo parcialmente o cimento em concretos plásticos não teve influência significativa nos módulos de elasticidade dinâmicos e na velocidade de propagação de onde ultrassônica em corpos de prova cilíndricos com $15 \mathrm{~cm}$ de diâmetro e $30 \mathrm{~cm}$ de altura.

Nos estudos de viabilidade econômica para a barragem da usina hidrelétrica de Bocaina/MG, realizados em 1985, evidenciou-se que as jazidas de materiais impermeáveis encontravam-se relativamente distantes do eixo da barragem. Dentre as alternativas estudadas, o emprego do CCR rico em pasta com a utilização parcial de escória moída de alto forno como aglomerante foi a tecnologia que mostrou melhor relação econômica devido à disponibilidade deste material cimentício e custo em relação ao cimento Portland. A substituição de cimento por escória se deu nas proporções de $75 \%$, 80 \% e $85 \%$ (em peso), mantendo-se constante o consumo de ligante hidráulico em torno de $250 \mathrm{~kg} / \mathrm{m}^{3}$. O resultados de resistência à compressão média aos 90 dias foi 21,0 MPa para todas as misturas, mostrando a possibilidade de redução do consumo de aglomerante Portland. Os resultados mostraram ainda um crescimento significativo da resistência (cerca de $30 \%$ ), quando se aumenta a finura Blaine da escória de 3.700 para $4.800 \mathrm{~cm}^{2} / \mathrm{g}$ (GONÇALVES, FERREIRA e COSTA, 1989).

Guerra et al. (1989) observaram que, à medida que se aumenta a finura da escória de alto forno moída em misturas de CCR, há maior facilidade para compactação, permitindo a redução da água unitária do concreto. 
As especificações técnicas nacionais - NBR 5735 (ABNT, 1991a) e NBR 11578 (ABNT, 1991b) - delimitam uma ampla faixa de incorporação de escória moída de alto forno no cimento CP III - $35 \%$ a $70 \%$ e CP II E - $6 \%$ a $34 \%$, respectivamente. Entretanto, ainda se notam imensas pilhas de estocagem deste material em indústrias cimenteiras e de siderurgia. Apresenta-se, na Figura 9, uma das alternativas encontradas pelas siderúrgicas para eliminação destes resíduos da planta industrial e ganho extra de capital: a venda da escória esfriada ao ar após britagem para utilização como agregado graúdo.

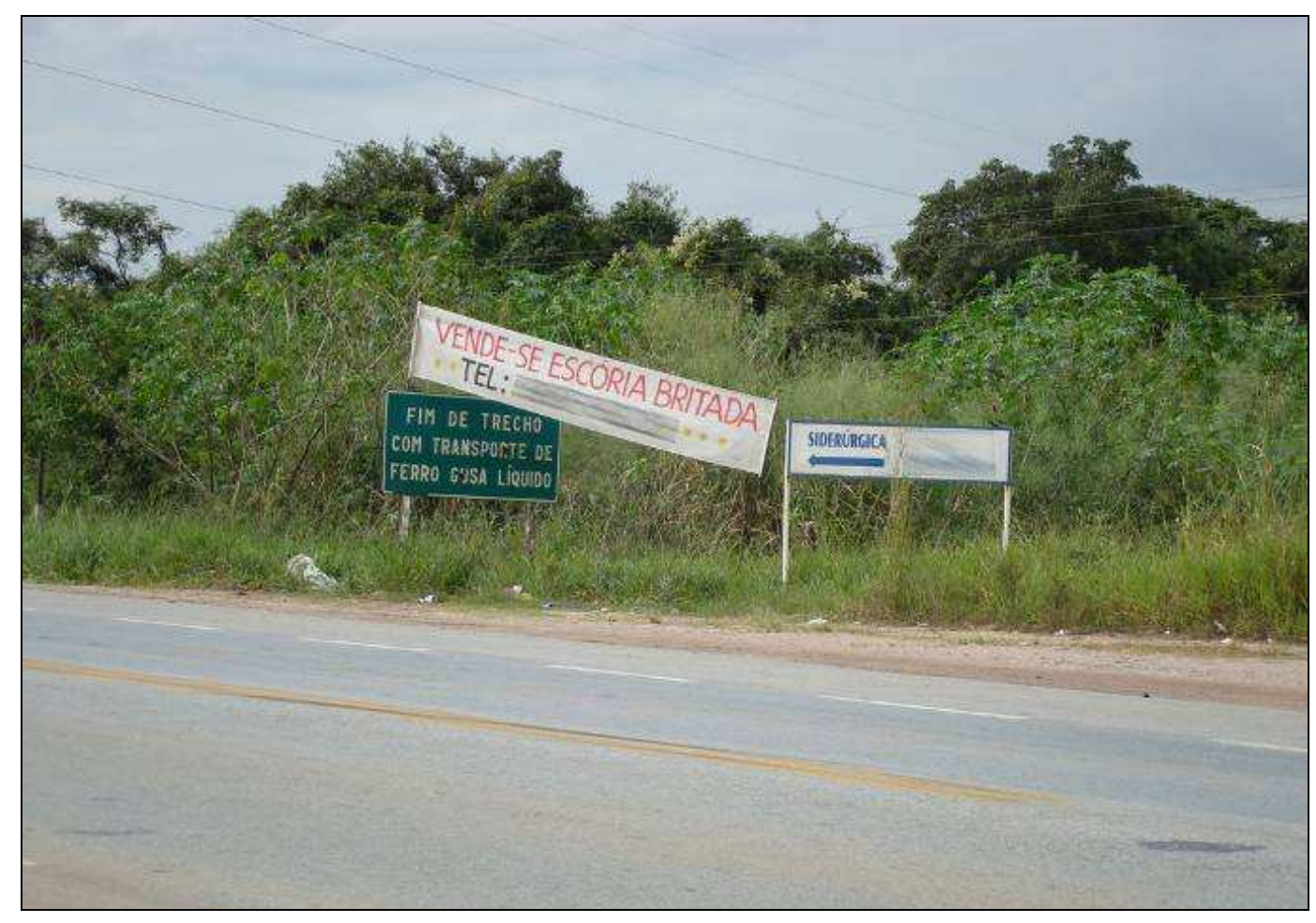

Figura 9 - venda de escória de alto forno após britagem na região de Divinópolis/MG

\subsubsection{Misturas estabilizadas}

O emprego das escórias de alto forno esfriadas ao ar bem como as escórias de aciaria, ambas trituradas, podem ser empregadas em sistemas granulares coesivos estabilizados, do tipo: mecânico, físico granular e fisicoquímico. As escórias de alto forno resfriadas à água, por seu caráter pozolânico e em razão de 
possuir cimentação em meio básico, podem ser empregadas ligeiramente moídas como agentes cimentares, adequadamente ativadas com catalisadores (como a cal).

Os sistemas granulares coesivos podem aumentar sua resistência mecânica diante do desenvolvimento da cimentação, produzida pela adição da escória granulada de alto forno moída ativada com a quantidade suficiente de cal ou outro elemento alcalino capaz de elevar o pH do meio aquoso para 11 ou 12; a partir do qual se produz a solubilização da alumina e do silício dando origem ao fenômeno de cimentação pela formação de aluminato tetracálcio e silicato de cálcio hidratado (PÁRAMO, 1965).

Coninsa (1978) afirma que o emprego da escória granulada de alto forno na estabilização de solos encontra um excelente campo de aplicação nos estabilizados puramente granulares. A friabilidade da escória granulada favorece a formação de finos durante o processo de compactação, devido basicamente ao atrito com o esqueleto granular mais resistente. Este fenômeno não se verifica satisfatoriamente nos estabilizados finos com marcada presença da fração fina; portanto, o grau de finos da escória deve ser alcançado, de forma prévia, mediante moagem.

Mathur, Soni e Murty (2001) investigaram a autoestabilização de misturas de escória granulada de alto forno, cal e agregados graúdos e miúdos em trechos experimentais de rodovias de baixo volume de tráfego, avaliando índices de CBR, resistência à tração na flexão, vida de fadiga e durabilidade. Nota-se, neste estudo, que várias combinações apresentaram $\mathrm{CBR}>20 \%$ e que uma pequena quantidade de cal é suficiente para a ativação da hidraulicidade da escória. Segundo Mathur, Soni e Murty (2001), outro aspecto importante que deve ser devidamente considerado antes de selecioná-la como base ou sub-base de pavimentos é se a estabilidade do material é conservada após anos de exposição às cargas do tráfego e clima. Com esta finalidade, testes de durabilidade foram executados nas melhores misturas compostas; os resultados apontaram que a perda de peso após ciclos de molhagem e secagem foi muito abaixo do admissível. Entre os aspectos aferidos, os melhores resultados foram apresentados pela 
mistura com $36 \%$ de agregado graúdo, $60 \%$ de escória granulada de alto forno moída e $4 \%$ de cal.

Conforme Mathur, Soni e Murty (2001), através de análises laboratoriais e em pista experimental, chega-se a resultados que claramente indicam que as escórias de alto forno (independente do processo de esfriamento) podem ser utilizadas como agregados pétreos em misturas estabilizadas para bases e subbases de pavimentos. A escória granulada de alto forno não possui características de autoestabilização; contudo, com a adição de um pequeno montante de cal ( 2 \% a $4 \%$ ) as características hidráulicas da escória granulada são ativadas.

O projeto da pista do Aeroporto de Venato Tuerto na Argentina contemplou um pavimento flexível com base em solo estabilizado granular, constituído por:

- rocha basáltica: $40 \%$;

- escória de alto forno moída: 50 \%;

- Solo A - 4 (conforme classificação da Highway Research Board - HRB): $10 \%$.

Esta mistura granular foi tratada com $3 \%$ de cimento Portland em peso, ensaiando-se a compressão simples aos 7 dias de cura. A cimentação produzida neste período permitiu obter resistências na ordem dos 7,5 MPa, excessiva para aplicação como base de pavimento flexível, cuja camada de rolamento é um tratamento superficial betuminoso. Procurando reduzir a rigidez da mistura, empregou-se $1 \%$ de cimento e $2 \%$ de cal, a resistência alcançada foi da ordem de 2,9 $\mathrm{MPa}$, sendo esta a mistura a ser utilizada. Neste caso, a decisão técnico econômica se deu pela diminuição do material mais nobre e pelos benefícios de utilização da escória granulada de alto forno moída junto com seu ativador (CONINSA, 1978).

Tosticarelli (1978) cita o exemplo da reconstrução da interseção da Rota Nacional Argentina $n^{\circ} 34$, nas proximidades da cidad e de San Cristóbal, província de Santa Fe. A camada de rolamento consistia em tratamento betuminoso superficial triplo com espessura média de $2,9 \mathrm{~cm}$ e a base de solo - areia emulsão com $8 \mathrm{~cm}$ de espessura média. Estas camadas foram processadas em conjunto visando o seu reaproveitamento; entretanto, a curva granulométrica 
apresentou insuficiência na fração areia. Nas alternativas consideradas estavam: areia de rio ou escória granulada de alto forno moída; utilizou-se a escória por vantagens ambientais e econômicas e pelo fato da evolução da cimentação com o decorrer do tempo.

A mistura com camada de rolamento e base triturada teve adição de $20 \%$ de areia de escória e $2 \%$ de cal hidratada (em peso), empregando-se uma espessura média de $12 \mathrm{~cm}$. Ensaiado este material a compressão simples aos 7 dias, obtiveram-se resistências da ordem de 1,7 MPa com valores de CBR de $81 \%$ (drenado) e $61 \%$ (não drenado). Vistos os valores alcançados, este material de reconstrução estrutural ocupou lugar de sub-base, recebendo camada betuminosa como base e camada de revestimento em concreto asfáltico (TOSTICARELLI, 1978).

Conforme Tosticarelli, Angelone e Andreoni (1987), a utilização da escória de aciaria em misturas estabilizadas deve ser empregada com rigorosa precaução, pois não é possível detectar nem medir a reatividade potencial da escória de aciaria por meio do ensaio de inchamento, após imersão para misturas estabilizadas (4 dias a temperatura ambiente); já que se obtêm valores similares aos de um material estabilizado granular convencional. Isso se explica pelo alto índice de vazios e ausência de rigidez destes tipos de mistura, o que permite absorver a possível expansividade da escória de aciaria; esta expansão não é verificada na utilização da escória de alto forno.

\subsubsection{Concreto plástico}

Balado (1978) estudou a incorporação de escória de alto forno esfriada ao ar previamente britada como agregado graúdo - separando o material em duas frações granulométricas com dimensões máximas de $50 \mathrm{~mm}$ e $30 \mathrm{~mm}$ - em pavimento rígido de concreto, conforme premissa de resistência à compressão aos 28 dias de 3,2 MPa e consistência no tronco de cone de $4 \mathrm{~cm}$. A resistência à compressão deste traço, conforme Tabela 6 , foi de 3,3 $\mathrm{MPa}$ aos 7 dias e 4,1 $\mathrm{MPa}$ aos 28 dias. De acordo com Balado (1978), a resistência pouco maior que a 
especificada em projeto se deu pela superior aderência entre o agregado graúdo e a argamassa, rugosidade superficial e interação com o ligante hidráulico.

Tabela 6 - quantidade de materiais utilização para concreto com escória para pavimento rígido

\begin{tabular}{cc}
\hline Material & Quantidade \\
\hline Cimento Portland & $365 \mathrm{~kg}$ \\
Água & $160 \mathrm{litros}$ \\
Areia & $680 \mathrm{~kg}$ \\
Escória $1-30 \mathrm{~mm}$ & $470 \mathrm{~kg}$ \\
Escória $2-50 \mathrm{~mm}$ & $440 \mathrm{~kg}$ \\
Aditivo plastificante & $2,265 \mathrm{~cm}^{3}$ \\
\hline \multicolumn{2}{c}{ (adaptado de: BALADO, 1978) }
\end{tabular}

O Instituto del Cemento Portland Argentino (ICPA, 1981), de posse dos resultados apresentados por Balado (1978), executou um trecho experimental para averiguação do desempenho do concreto com escória de alto forno britada como agregado graúdo. Apresentam-se, na Tabela 7 , os resultados obtidos em laboratório quando foram ensaiadas três amostras prismáticas (150 × $150 \times 500$ $\mathrm{mm}^{3}$ ) de concreto diretamente elaborado em obra, aplicando duas cargas simétricas no terço central aos 28 dias (ensaio de tração na flexão com dois cutelos).

Tabela 7 - resultados do ensaio em vigotas de concreto vibrado empregado em pista experimental

\begin{tabular}{ccc}
\hline Resistência (MPa) & Concreto com Escória & Concreto Convencional \\
\hline à tração na flexão & 4,7 & 2,8 \\
à compressão & 39,5 & 30,0 \\
\hline & & (adaptado de: ICPA, 1981)
\end{tabular}

Este concreto, com a presença de escória como agregado graúdo, idealizado por Balado (1978), no que diz respeito à fratura, teve ruptura das partículas de agregado pela superior aderência com a argamassa; diferente do que 
- concreto com pedra basáltica, onde a falha se dá normalmente pelo desprendimento com a argamassa.

Ozyildirim (2001) analisou três misturas de concreto para pavimentos de concreto utilizando como filler a escória granulada de alto e cinza volante (Tabela 8). As duas dosagens efetuadas com escória possuíam agregados de dimensão máxima $25 \mathrm{~mm}$ e $50 \mathrm{~mm}$ e a dosagem realizada com cinza volante utilizava somente agregados de $25 \mathrm{~mm}$. Após confecção de trechos experimentais (Virginia - EUA) foram investigados parâmetros referentes à retração das placas, resistência à tração na flexão e diferencial térmico.

\begin{tabular}{|c|c|c|c|}
\hline \multicolumn{4}{|c|}{ alto forno ou cinza volante como filler $\left(\mathrm{kg} / \mathrm{m}^{3}\right)$} \\
\hline Material & Escória - 50 mm & Escória - 25 mm & Cinza Volante - $25 \mathrm{~mm}$ \\
\hline Cimento Portland & 222 & 234 & 251 \\
\hline Escória & 95 & 100 & - \\
\hline Cinza Volante & - & - & 84 \\
\hline Agregado Miúdo & 695 & 722 & 729 \\
\hline Agregado Graúdo & 1148 & 1092 & 1092 \\
\hline Água & 144 & 148 & 148 \\
\hline
\end{tabular}

Os resultados obtidos apontam resistência à tração na flexão, pelo ensaio de dois cutelos aos 28 dias, semelhantes entre a escória - $50 \mathrm{~mm}$ e a cinza volante $25 \mathrm{~mm}$ (aproximadamente 4,8 MPa em corpos de prova prismáticos de $150 \times 150 \times$ $\left.500 \mathrm{~mm}^{3}\right)$; a mistura escória - $25 \mathrm{~mm}$ apresentou a maior resistência (5,4 MPa). A retração ocorrida após um ano de execução mostra valores similares entre as três misturas $(0,04 \%)$ e o diferencial térmico entre topo e fundo das placas foram ligeiramente maiores para as misturas com cinza volante, seguido pela escória 25 e escória 50.

Van Dam et al. (2003) investigaram, após 10 anos de construção, a deterioração prematura em pavimentos de concreto utilizando escória de alto forno como agregado graúdo, conforme mostrado na Figura 10. Para tanto, foram 
extraídas amostras das placas de concreto para posteriores análises físicas, químicas, petrográficas.

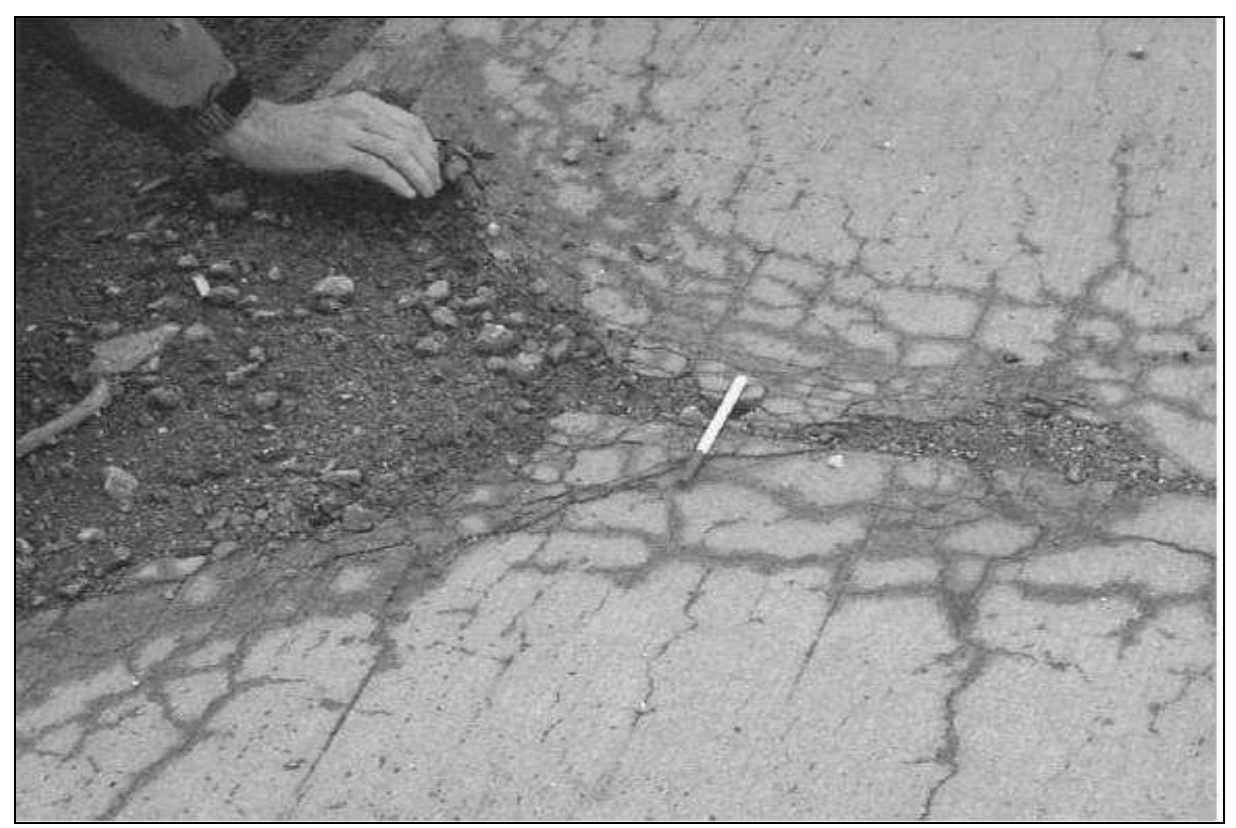

(fonte: VAN DAM et al., 2003)

Figura 10 - deterioração em junta transversal da placa de concreto

A avaliação petrográfica das seções manifestou-se conclusivamente que as partículas de enchimento no agregado miúdo sofreram reações álcali-sílica deletérias em todas as seções de pavimentos deteriorados. Esta reação foi caracterizada pela fratura das partículas agregadas relacionada com a pasta circundante.

Van Dam et al. (2003) explicam que na revisão de todos os dados disponíveis, não houve nenhuma causa única definitiva, isto é, duas hipóteses emergiram como explicação parcial para a deterioração, sendo possível que as duas possam estar atuando em conjunto contribuindo para a deterioração observada. A primeira hipótese concentra-se na reatividade álcali-sílica das partículas de fíller nos agregados miúdos que é agravado pela alcalinidade do concreto. A segunda hipótese concentra-se na dissolução do sulfito de cálcio e a formação de minerais carregados com sulfatos, que resultam em ataque interno devido à formação de etringita - $\mathrm{AF}_{\mathrm{t}}$. Em qualquer caso, a presença de escória 
granulada de alto forno pareceu ocasionar um efeito de mitigação da deterioração. Fatores construtivos também podem ter desempenhado um papel condicionante, em particular à relação com a deterioração e gravidade das patologias.

Yüksel e Genç (2007) utilizaram escória granulada de alto forno (ESC) e escória de fundo de forno Siemens Martin (EFF) como agregado miúdo em concreto plástico com consumo de ligante hidráulico de $340 \mathrm{~kg} / \mathrm{m}^{3}$. As misturas compostas substituem em até $50 \%$ os agregados naturais (em peso), sendo utilizados nesta substituição uma das escórias ou a combinação de 50 \% entre elas (ESC + EFF). Os resultados apontam que quanto maior a quantidade destas escórias, menores são as resistências à compressão e à tração na flexão e maior a trabalhabilidade, requerendo maiores quantidades de água de amassamento. Apresentam-se, na Figura 11, as resistências à compressão obtidas para 28 e 90 dias.

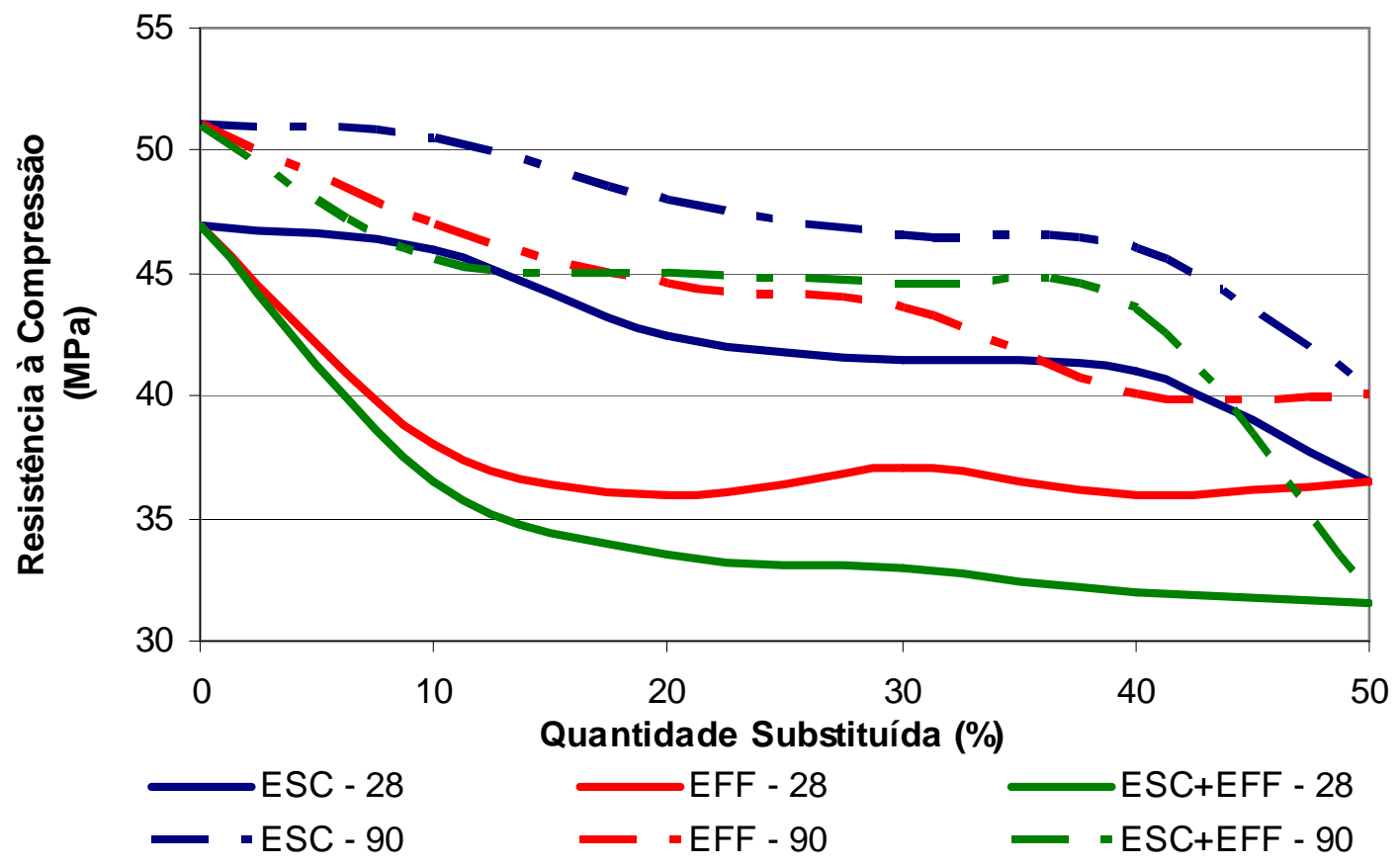

(adaptado de: YÜKSEL e GENÇ, 2007)

Figura 11 - resistências à compressão aos 28 e 90 dias para concretos plásticos com incorporação de escórias como fração areia 
Nota-se que a substituição de escória granulada de alto forno em até $40 \%$ apresenta queda da resistência à compressão de 1,0 \% a 10,6 \%; quando se substitui 50 \% há decréscimo sensível para 22,4\% (em comparação com o concreto sem utilização de escória). Os resultados de resistência à tração na flexão mostram que a substituição de escória granulada de alto forno em $10 \%$ diminui cerca de $10 \%$ a resistência em relação ao concreto convencional. Para 20 \% a $50 \%$ de substituição, os valores decrescem cerca de $30 \%$ para todas as misturas. Yüksel e Genç (2007) apontam como a razão básica para a diminuição das resistências a formação de diferentes estruturas de poros, aumentando a porosidade do material. A utilização de escória como agregado miúdo forma pequenos poros fechados nas superfícies dos agregados; portanto, a zona de transição entre os agregados e a pasta de cimento é relativamente enfraquecida.

Ribeiro, Pinto e Starling (2006) utilizaram escória granulada de alto forno como agregado miúdo em conjunto com aditivos plastificantes visando à diminuição do fator $\mathrm{A} / \mathrm{C}$, aumento da resistência, trabalhabilidade e durabilidade. Apresentam-se, na Tabela 9, os traços utilizados na pesquisa em conjunto com a relação $\mathrm{A} / \mathrm{C}$ (inclusive com a presença do aditivo plastificante) e as resistências à compressão obtidas.

Tabela 9 - influência da utilização de aditivos e escória granulada de alto forno em concreto plástico

\begin{tabular}{cccc|cc}
\hline \multirow{2}{*}{ Material } & Traço & \multicolumn{2}{c|}{ Fator A/C } & \multicolumn{2}{c}{$\mathbf{f}_{\mathrm{ck}, \mathbf{7}}$ (MPa) } \\
& (em peso) & sem aditivo & com aditivo & sem aditivo & com aditivo \\
\hline $\begin{array}{c}\text { cimento: areia: brita } \\
\text { cimento: areia: }\end{array}$ & $1: 2: 3$ & 0,60 & 0,50 & 13,0 & 16,5 \\
$\begin{array}{c}\text { escória: brita: } \\
1: 1,5: 1,5: 3\end{array}$ & 0,58 & 0,45 & 10,8 & 12,5 \\
\hline
\end{tabular}

(adaptado de: RIBEIRO, PINTO e STARLING, 2006)

O ensaio de sanidade com solução de sulfato de sódio realizado na amostra de escória granulada de alto forno apresentou uma perda de 12,7\%, pouco acima do limite preconizado pela especificação técnica ME 089 do Departamento Nacional de Estradas de Rodagem (DNER, 1994a) que é 12 \%. Pode-se também 
verificar que a escória não é um agregado potencialmente reativo, em função do ensaio de reatividade potencial realizado (RIBEIRO, PINTO e STARLING, 2006).

De acordo com Ribeiro, Pinto e Starling (2006), no que se refere à durabilidade da estrutura composta pelo concreto com escória, verifica-se que a diminuição do fator $\mathrm{A} / \mathrm{C}$, potencialmente, diminui o risco de deterioração quando submetidos a agressividades ambientais. Assim sendo, pode-se concluir que a escória granulada de alto forno atende, de forma geral, os requisitos de resistência e durabilidade para estruturas de concreto.

Ensaios experimentais idealizados por Scandiuzzi e Battagin (1991), utilizando escória de alto forno moída como agregado miúdo em concreto plástico, indicam que nas primeiras idades, aos 7 dias, devido ao maior requerimento de água de amassamento, a resistência à compressão dos concretos com escória é menor do que os demais concretos utilizando areia de rio ou de britagem. Porém, em idades mais avançadas, 180 dias, estas diferenças são minimizadas devido à maior aderência entre pasta e agregado.

Uma grande vantagem do emprego da escória de alto forno como fração areia em misturas de concreto plástico, em relação aos agregados naturais, é o aumento da relação entre as resistências à tração por compressão diametral e à compressão simples, nitidamente comprovada por Scandiuzzi e Battagin (1991). Neste estudo, efetivamente, a idade de 7 dias, a razão entre a resistência à tração e a resistência à compressão é $20 \%$ superior ao valor com areia de rio; com o desenvolvimento da idade (180 dias), este valor aumenta para cerca de $50 \%$. Os autores atrelam este fato ao desenvolvimento de uma camada ou película superficial de hidratação na escória que dá origem a produtos ligantes. Assim sendo, ocorrem ligações epitáxicas proporcionando maior aderência entre pasta de cimento e agregado e, por consequência, um aumento da resistência à tração do concreto.

Massucato (2005) analisou propriedades do concreto fresco e endurecido com adição mineral ( 8 \% e 57 \%) de escória granulada de alto forno produzidas a carvão mineral e a coque, comparando-as com um concreto utilizando somente agregados pétreos. As propriedades no estado fresco não apresentaram diferenças significativas entre as escórias; entre os dados obtidos, nota-se aumento da 
exsudação do concreto em cerca de 200 \% com a presença de escória (comparado com a mistura padrão). Em termos de propriedades do concreto endurecido, a utilização de escória de alto forno a carvão mineral reduz as resistências à compressão e à tração por compressão diametral em todas as idades verificadas (1, 3, 7, 28 e 60 dias); a adição mineral da escória de alto forno produzida a coque apresenta maiores resistências mecânicas ao concreto em idades superiores aos 28 dias.

Há consenso nas pesquisas desenvolvidas por Ribeiro, Pinto e Starling (2006), Scandiuzzi e Battagin (1991) e Yüksel e Genç (2007), em quais os principais fatores técnicos que apresentam desvantagem na utilização da escória granulada de alto forno como agregado miúdo em concreto plástico (em comparação à areia de rio): teor insuficiente de finos, forma dos grãos, friabilidade e densidade. Scandiuzzi e Battagin (1991) citam que uma maneira mitigadora de suprir a insuficiência de finos seria a adição de areia extremamente fina ou a moagem de parte da própria escória. O aumento no teor de cimento também pode ser uma forma para melhorar a compacidade do concreto com a presença de escória granulada de alto forno, já que os vazios granulares podem ser preenchidos pelo ligante hidráulico. Entretanto, há custos relacionados a este acréscimo do material mais nobre da mistura, podendo até mesmo inviabilizar economicamente a utilização deste tipo de agregado alternativo frente aos agregados naturais.

\subsubsection{Sistematização dos dados de bibliografia sobre a reutilização de escória de alto forno em misturas cimentadas}

Procurou-se sistematizar, por meio da Tabela 10, os principais resultados obtidos pelos diferentes autores mencionados no presente capítulo no que diz respeito à reutilização da escória de alto forno ativada ou inerte em misturas cimentadas. 
Tabela 10 - sistematização de dados obtidos na bibliografia sobre a utilização de escória de alto forno em misturas estabilizadas ou cimentadas

\begin{tabular}{|c|c|c|c|c|}
\hline \multirow{3}{*}{ Aspecto } & \multicolumn{4}{|c|}{ Reutilização da escória de alto forno } \\
\hline & \multirow{2}{*}{\multicolumn{2}{|c|}{$\begin{array}{l}\text { Indústria cimenteira } \\
\text { oncreto plástico }\end{array}$}} & \multirow{2}{*}{ Misturas estabilizadas } & \multirow[t]{2}{*}{ Agregado em concreto plástico } \\
\hline & & & & \\
\hline Preparação & \multicolumn{2}{|c|}{$\begin{array}{l}\text { Secagem à temperatura ambiente para eliminação de umidade para posterior } \\
\text { secagem e moagem em conjunto ao clínquer Portland (SHORT e PAGE, 1981). }\end{array}$} & $\begin{array}{l}\text { Quando triturada, podem ser } \\
\text { utilizada em sistemas } \\
\text { granulares coesivos; } \\
\text { Quando granulares, utilizadas } \\
\text { como agregados pétreos. }\end{array}$ & $\begin{array}{l}\text { Graúdo, quando esfriada ao ar; } \\
\text { Miúdo, quando resfriada à água; } \\
\text { (ambas sem processo prévio) }\end{array}$ \\
\hline Características & \multicolumn{2}{|c|}{ Alta porcentagem vítrea (SMOLCZYK, 1980). } & $\begin{array}{l}\text { Pequena quantidade de cal } \\
\text { causa ativação das } \\
\text { propriedades hidráulicas da } \\
\text { escória granulada. }\end{array}$ & $\begin{array}{l}\text { Desvantagem no que diz respeito à forma dos grãos do } \\
\text { agregado siderúrgico, teor insuficiente de finos, } \\
\text { friabilidade e densidade (RIBEIRO, PINTO e STARLING, } \\
\text { 2006; SCANDIUZZI e BATTAGIN, } 1991 \text { e YUKSEL e GENÇ, } \\
2007 .\end{array}$ \\
\hline Resistência & $\begin{array}{c}\text { Testemunhos de concreto extraídos } \\
\text { com idade de } 25 \text { anos obtêm } \\
\text { resistências à compressão } 100 \% \\
\text { superiores aquelas obtidas aos } 28 \text { dias } \\
\text { (GEISELER, KOLLO e LANG, } 1995 \text { ); } \\
\text { Substituição em } 50 \% \text { do cimento } \\
\text { apresenta ganho de } 20 \% \text { na resistência } \\
\text { compressão aos } 91 \text { dias (LIDUÁRIO et } \\
\text { al., 2005). }\end{array}$ & $\begin{array}{l}\text { Aumento de } 30 \% \text { na resistência à } \\
\text { compressão quando se aumenta a } \\
\text { finura Blaine da escória de } 3.700 \\
\text { para } 4.800 \mathrm{~cm}^{2} / \mathrm{g} \text { (GONÇALVES, } \\
\text { FERREIRA e COSTA, 1989); } \\
\text { Adição de } 100 \mathrm{~kg} / \mathrm{m}^{3} \text { acarreta em } \\
\text { ganhos de até } 400 \% \text { na resistência } \\
\text { à compressão aos } 91 \text { dias } \\
\text { (LIDUÁRIO et al., 2005). }\end{array}$ & $\begin{array}{c}\text { Utilizando } 3 \% \text { de cimento, } \\
\text { alcança resistências à } \\
\text { compressão de } 7,5 \text { MPa aos } 7 \\
\text { dias (MATHUR, SONI e } \\
\text { MURTY, 2001); } \\
\text { Empregando } 1 \% \text { de cimento e } \\
2 \% \text { de cal, resulta em } \\
\text { resistências á compressão de } \\
2,9 \text { MPa aos } 7 \text { dias (CONINSA, } \\
1978 \text { ); } \\
\text { Na utilização de } 2 \% \text { de cal, } \\
\text { obtém-se } 1,7 \text { MPa no ensaio } \\
\text { de resistência á compressão } \\
\text { aos } 7 \text { dias (TOSTICARELLI, } \\
1978 \text { ). }\end{array}$ & $\begin{array}{l}\text { Resistência à compressão (28 dias) pouco maior, cerca de } \\
10 \% \text { (BALADO, 1978) e resistência à tração na flexão } 30 \% \\
\text { superior, quando utilizado como agregado graúdo (ICPA, } \\
\qquad 1981 \text { ); } \\
\text { Quando utilizado como agregado miúdo, diminuição de } 25 \\
\text { \% na resistência à compressão aos } 7 \text { dias (RIBEIRO, PINTO } \\
\text { e STARLING, 2006), em idades mais avançadas (180 dias) } \\
\text { os valores de resistência tendem a ser semelhantes aos } \\
\text { utilizando agregados miúdos naturais (SCANDIUZZI e } \\
\text { BATTAGIN, 1991); } \\
\text { Valores de resistência à tração na flexão semelhantes para } \\
\text { a utilização de escória (grãos com } 50 \text { mm) e cinza volante } \\
\text { com dimensão máxima de } 25 \text { mm; } \\
\text { Quanto maior a quantidade de escória granulada, } \\
\text { menores as resistências aos } 28 \text { e } 90 \text { dias (YUKSEL e GENÇ, } \\
2007 \text { ) }\end{array}$ \\
\hline $\begin{array}{l}\text { Quantidade de } \\
\text { água }\end{array}$ & $\begin{array}{c}\text { Mesma relação A/C, melhor } \\
\text { trabalhabilidade (GEISELER, KOLLO e } \\
\text { LANG, 1995) }\end{array}$ & $\begin{array}{c}\text { Na medida em que se aumenta a } \\
\text { finura da escória, há diminuição da } \\
\text { umidade de compactação (GUERRA } \\
\text { et al., 1989) }\end{array}$ & - & $\begin{array}{l}\text { Requerem maiores quantidades e proporcionam maior } \\
\text { trabalhabilidade (YUKSEL e GENÇ, 2007) }\end{array}$ \\
\hline $\begin{array}{l}\text { Módulo de } \\
\text { elasticidade } \\
\text { estático }\end{array}$ & $\begin{array}{l}\text { Não há influência na substituição } \\
\text { parcial (50 \%) ao cimento Portland } \\
\text { (MARQUES, 1994) }\end{array}$ & - & - & - \\
\hline $\begin{array}{l}\text { Módulo de } \\
\text { elasticidade } \\
\text { dinâmico }\end{array}$ & $\begin{array}{c}\text { Não há influência na velocidade de } \\
\text { onda ultrassônica em corpos de prova } \\
\text { cilíndricos (MARQUES, 1994) }\end{array}$ & - & - & - \\
\hline
\end{tabular}




\section{CONCRETO COMPACTADO COM ROLO}

O concreto compactado com rolo (CCR) - também referenciado em uma gama de outras terminologias, tais como: concreto rolado, concreto compactado seco, concreto não plástico, concreto sem abatimento, concreto econômico, concreto magro, econocreto e concreto pobre rolado - trata-se, segundo o American Concrete Institute (ACl, 1987), de um concreto seco de ampla utilização na construção de barragens, pisos industriais e estruturas de pavimentos. Além disso, o DNER (1992) cita o CCR como um concreto de consistência dura e trabalhabilidade tal que the permite receber compactação por rolos compressores, vibratórios ou não.

O consumo de cimento no CCR situa-se entre $80 \mathrm{~kg} / \mathrm{m}^{3}$ (caso das sub-bases de pavimentos de concreto simples) e $380 \mathrm{~kg} / \mathrm{m}^{3}$ ou até maior (quando empregado na função de revestimento). Segundo o ACl committee 327 (2004), não há restrições quanto ao tipo de cimento a ser utilizado nesta tecnologia, podendo ser empregado até mesmo o de alta resistência inicial; mas recomenda-se o uso dos cimentos de alto forno, pozolânicos ou com filler.

Conforme Andriolo (2007), o CCR é um concreto com aspecto seco, transportado e aplicado de forma semelhante àquela empregada em enrocamentos ou obras de terra. A quantidade de água na mistura é determinada pelo ensaio de compactação. A energia de compactação a ser aplicada - normal, intermediária ou modificada - é escolhida conforme equipamentos disponíveis, características de materiais e de projeto. Entretanto, de acordo com Pitta e Díaz (1991), há inúmeras desvantagens na utilização de tal metodologia de adensamento, dentre elas: consideráveis dispersões nos ensaios de resistências, grau de compactação variável pelo operador a compactar energicamente, não acomodações e quebras de partículas granulares no interior da estrutura.

Abreu (2002) compara a consistência do CCR com a de um solo úmido, com trabalhabilidade particular de maneira a permitir seu adensamento com rolos compressores lisos, estáticos ou vibratórios. Em aplicação do CCR como camada final de revestimento, são recomendadas associações entre rolos de pneus e rolos lisos para um melhor acabamento da superfície de rolamento (CARVALHO, 1995). 
Santos (1988) afirma que a principal diferença entre o CCR e o concreto plástico (vibrado) é a maior quantidade de material fino, apresentando estrutura granular tal que pode ser compactado mecanicamente. Ao dosar as misturas para mínimos volumes de pasta, a função principal dos finos é ocupar o espaço que, de outra maneira, seria ocupado por cimento e água.

Segundo Balbo (1996), a estabilização química referente a materiais para a execução de bases para pavimentos pode se dar de duas maneiras: alterando-se a susceptibilidade de um material à água e conferindo-lhe ganho de resistência como material de construção. No caso do CCR, onde os grãos são maiores que as partículas do cimento, a ação deste ligante hidráulico se restringe a efetuar ligações pontuais entre os grãos, conforme mostrado na Figura 12, porque este tipo de concreto seco possui quantidade insuficiente de argamassa para 0 completo envolvimento dos agregados como ocorre nos concretos plásticos. Estas ligações pontuais implicam em grande quantidade de vazios não preenchidos, isto é, elevada porosidade.

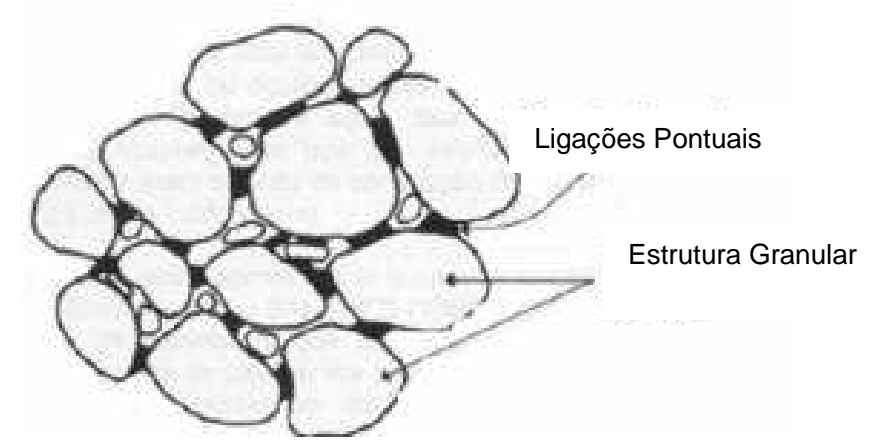

(adaptado de: BALBO, 1996)

Figura 12 - estrutura interna das ligações entre pasta e agregado no CCR

Como fator para a diminuição da porosidade e aumento na quantidade de pontos de contato entre os grãos e a pasta de cimento, a busca por uma distribuição granulométrica bem graduada deve ser parte da composição do CCR. Kim (2007) exemplifica como proporções típicas de dosagens de CCR para camadas de pavimento: $75 \%$ a $85 \%$ de agregados com tamanho máximo de 19,0 $\mathrm{mm}, 9 \%$ a $18 \%$ de ligante hidráulico e $4 \%$ a $7 \%$ de água (em peso). 
O maior consumo de materiais cimentícios no CCR aumenta o teor de pasta da mistura, aumento esse que preencherá de forma mais homogênea e completa os poros do concreto, levando a menores valores de permeabilidade de água e também a menores índices de vazios, fatores indiretos de avaliação da durabilidade do concreto. Contudo, esses maiores consumos são também fatores relevantes ao se avaliar a eficiência das dosagens, custo e elevação adiabática do CCR (BORGES, CASCUDO e GRAÇA, 2006).

A tecnologia do CCR já é largamente conhecida e difundida nas construções de barragens e obras onde se utilizam grandes volumes de concreto, objetivando, assim, a minimização do calor de hidratação. Andriolo (2007) ilustra que não há limites de altura para construção de barragens com esta tecnologia; a média brasileira é de $60 \mathrm{~m}$ a $70 \mathrm{~m}$ de altura, com a mais alta chegando aos $95 \mathrm{~m}$; no exterior, encontram-se barragens em CCR com mais de $200 \mathrm{~m}$ de altura. Estima-se que existam cerca de 320 barragens em CCR no mundo, sendo principalmente localizadas em cinco países (Tabela 11), os quais mantêm cerca de $70 \%$.

Tabela 11 - ranking dos países com maior número de barragens em CCR

\begin{tabular}{ccc}
\hline País & Quantidade de Barragens em CCR & Porcentagem Total \\
\hline China & 59 & $19 \%$ \\
Brasil & 54 & $17 \%$ \\
Japão & 42 & $13 \%$ \\
EUA & 37 & $12 \%$ \\
Espanha & 22 & $7 \%$ \\
\hline & & (fonte: ANDRIOLO, 2007)
\end{tabular}

O ACl (1995) apresenta duas diferenças básicas do CCR em relação ao seu emprego em pavimentos e barragens, sendo elas: (1) dimensão máxima do agregado - no emprego do CCR em pavimentação, recomenda-se uma dimensão máxima característica de $12,5 \mathrm{~mm}$ à $32,0 \mathrm{~mm}$, quando utilizado em barragem esta pode chegar a $150 \mathrm{~mm}$; (2) consumo de cimento - o concreto massa utilizado em barragens deve ter consumos de cimento menores, dado o baixo calor de hidratação desejado. Ainda, quando utilizado como revestimento final (em contato 
com as cargas do tráfego), é desejável uma resistência à abrasão compatível (maior consumo de cimento). Entretanto, em ambas as aplicações, deve-se ter extremo cuidado com o tipo de cimento e agregados empregados, devido às reações álcali-agregado e ações deletérias no concreto.

Segundo Santos (1988), os agregados utilizados no CCR devem seguir as seguintes características gerais:

- resistência suficiente para compactação por rolos compactadores vibratórios;

- não apresentar alto conteúdo de argila, resultando em concretos pouco resistentes;

- como material de granulometria fina deve empregar areias naturais ou produtos finos de britagem com granulometria contínua;

- respeitar o tamanho máximo do agregado graúdo de especificações técnicas para cada aplicação;

- as proporções ótimas de agregado miúdo e graúdo deverão ser resultado de ensaios previstos em normas para cada tipo de obra e faixas granulométricas;

- se o concreto apresentar sinais de segregação deve incrementar o conteúdo de finos da mistura.

A granulometria ideal do CCR para a demanda mínima de argamassa será a correspondente à máxima densidade do material compactado com a mínima área superficial.

Pesquisas realizadas pelo United States Army Corps of Engineers - USACE - na década de 1980 , mostraram que o emprego de $4 \%$ a $10 \%$ de material passante na peneira $0,075 \mathrm{~mm}$ é indispensável para melhoria de valores de massa específica da mistura compactada por rolos vibratórios, resistência à compressão e módulo de elasticidade estático (BRAGA et al., 1989). De acordo com Liduário et al. (2004), apesar dos agregados pulverizados não serem considerados pozolanas, estes materiais podem conferir ao CCR um aumento da durabilidade em função de uma maior densificação da matriz de cimento através do efeito filler (microestrutural). 
Nas aplicações em pavimentação, o CCR tem sido pouco utilizado como revestimento, sendo mais utilizado como base ou sub-base de pavimentos; nestes casos, não havendo necessidade de elevadas resistências mecânicas (RIBEIRO, BITTENCOURT e ALMEIDA, 2000). O uso do CCR como camada de rolamento é prejudicado devido a problemas de textura e uniformidade, que podem trazer desconforto em velocidades superiores a $80 \mathrm{~km} / \mathrm{h}$ (ANDRIOLO, 2007).

O primeiro pavimento em concreto com consistência seca e utilização de rolos compressores para compactação data de 1891 na cidade de Bellefontaine no estado de Ohio (THE AMERICAN CONCRETE PAVEMENT ASSOCIATION ACPA - 2001). Entretanto, somente a partir de 1944, há grande difusão desta tecnologia na pavimentação em vias na Inglaterra e inúmeras aplicações de camadas de pavimento em CCR pelo mundo (CEMBUREAU, 1960).

A Tabela 12 exemplifica, de forma breve, os principais casos emblemáticos da utilização do CCR em pavimentação no Brasil.

Tabela 12 - alguns casos emblemáticos de utilização do CCR em pavimentos no Brasil

\begin{tabular}{|c|c|c|c|}
\hline Ano & Cidade & Característica & Referência \\
\hline 1946 & $\begin{array}{c}\text { São } \\
\text { Paulo/SP }\end{array}$ & $\begin{array}{l}\text { Pavimentação do Vale do Anhangabaú e Rua da } \\
\text { Consolação }\end{array}$ & ANDRIOLO, 1998 \\
\hline 1950 & $\begin{array}{c}\text { São } \\
\text { Paulo/SP }\end{array}$ & Pavimentação do aeroporto de Congonhas & $\begin{array}{l}\text { CARVALHO, GODINHO } \\
\text { e FERREIRA, } 1987\end{array}$ \\
\hline 1972 & $\begin{array}{c}\text { Porto } \\
\text { Alegre/RS }\end{array}$ & $\begin{array}{l}\text { Aplicação como base de pavimentos asfálticos } \\
\text { urbanos }\end{array}$ & SANTOS, 1988 \\
\hline 1984 & Joinville/SC & $\begin{array}{l}\text { Utilização como base de pavimentação com } \\
\text { peças pré-moldadas de concreto em postos de } \\
\text { pesagem }\end{array}$ & GODINHO et al., 1986 \\
\hline 1986 & $\begin{array}{c}\text { Lauro } \\
\text { Muller/SC } \\
\text { Criciúma/SC }\end{array}$ & $\begin{array}{l}\text { Liberação ao tráfego na Serra do Rio do Rastro } \\
\text { (SC-438): CCR como base de pavimento rígido } \\
\text { em concreto } \\
\text { Emprego de CCR como revestimento de vias } \\
\text { urbanas }\end{array}$ & $\begin{array}{l}\text { CARDOSO, PITTA e } \\
\text { TRICHÊS, } 1991\end{array}$ \\
\hline
\end{tabular}


Tabela 12 - alguns casos emblemáticos de utilização do CCR em pavimentos no Brasil (continuação)

\begin{tabular}{|c|c|c|c|}
\hline Ano & Cidade & Característica & Referência \\
\hline 1998 & $\begin{array}{l}\text { São Paulo - } \\
\text { Guarulhos/SP }\end{array}$ & $\begin{array}{l}\text { Duplicação da Via Dutra (SP-60): CCR como } \\
\text { base em pavimentação de concreto }\end{array}$ & BALBO, $2009^{1}$ \\
\hline & São Paulo/SP & $\begin{array}{l}\text { CCR como base de pavimento em concreto } \\
\text { no rodoanel metropolitano Mario Covas }\end{array}$ & BALBO, $2010^{2}$ \\
\hline 2002 & $\begin{array}{c}\text { Baixada } \\
\text { Santista/SP }\end{array}$ & $\begin{array}{l}\text { Construção de } 20,2 \mathrm{~km} \text { de base em CCR na } \\
\text { pista descendente da Rodovia dos Imigrantes } \\
\text { (SP-160) }\end{array}$ & $\begin{array}{l}\text { MELO, ZANETTI e } \\
\text { ANDREUCCI, } 2007\end{array}$ \\
\hline 2004 & $\begin{array}{c}\text { Recife - } \\
\text { Caruaru/PE }\end{array}$ & $\begin{array}{l}\text { Execução de } 100.000 \mathrm{~m}^{3} \text { de CCR em base de } \\
\text { pavimentos na BR } 232\end{array}$ & IBRACON, 2007 \\
\hline
\end{tabular}

O processo construtivo do CCR não necessita de desempenamento, o que não garante por sua vez um acabamento superficial rebuscado quanto à irregularidade longitudinal da superfície pós-construção. Neste contexto, sua utilização como base se torna interessante visto que não há necessidade de desempenamento, pois a camada de rolamento superior (de concreto ou asfáltica) fornecerá a regularidade e planicidade desejada (evitando o emprego de equipamentos como as pavimentadoras de formas deslizantes). Conforme Balbo (2006), o CCR possui numerosas vantagens em caso de sua posição relativa ser como base ou sub-base de pavimentos, empregando para sua execução equipamentos absolutamente convencionais de pavimentação, tecnologia disponível tanto a pequenas como médias e grandes empresas de construção viária.

Carvalho, Godinho e Ferreira (1987) citam que, quando o CCR serve como base de pavimento flexível ou rígido, os valores de resistência característica à compressão simples, aos 28 dias, estão normalmente entre 5,0 MPa e 8,0 MPa.

Dadas estas características favoráveis ao emprego como bases rígidas e de grande durabilidade para pavimentos, o CCR passou nas últimas duas décadas a ser um material de grande interesse. Por tratar-se de um material versátil, é

\footnotetext{
${ }^{1}$ Comunicação pessoal do Prof. Dr. José Tadeu Balbo em 14/12/2009

${ }^{2}$ Comunicação pessoal do Prof. Dr. José Tadeu Balbo em 19/01/2010
} 
possível que seu emprego (em pequena, média e grande escala) venha contemplar a introdução de materiais alternativos, desde que técnica e economicamente justificável. Tendo em vista as grandes demandas de infraestrutura urbanas e rurais no país, há espaço para o crescimento do emprego de subprodutos industriais como agregados - como a escória granulada de alto forno incorporados às misturas convencionais.

Balbo (2005) deixa claro, a possibilidade de arranjos granulométricos na preparação do CCR que resultam em concretos com elevadíssima resistência à tração na flexão (7,0 MPa), com consumos de cimento relativamente baixos (cerca de $320 \mathrm{~kg} / \mathrm{m}^{3}$ ou inferiores). Este aspecto é fundamental, pois a combinação do processo de adensamento (compactação enérgica), boa distribuição granulométrica (descontínua) e baixo consumo de cimento, trabalham conjuntamente para a redução do processo de retração hidráulica no concreto, diminuindo a incidência de fissuras bem como a abertura de trincas. Em análise realizada por Godinho e Ferreira (1995), aplicando CCR como base de pavimento rígido ( $f_{c k: 7 d i a s ~}=5,0 \mathrm{MPa}$ ) e concreto plástico como camada de revestimento $\left(\mathrm{f}_{\mathrm{ct} \text { t: }: 28 \mathrm{dias}}=4,5 \mathrm{MPa}\right)$, conforme características apresentadas na Tabela 13, nota-se que as quantidades de materiais requeridos são peculiares para cada material. $O$ CCR apresenta distribuição granulométrica contínua, diminuindo a quantidade de ligante hidráulico e água requeridos.

Tabela 13 - traços utilizados em pavimento rígido com base em CCR na cidade de Itapecerica/MG

\begin{tabular}{|c|c|c|c|}
\hline \multirow{2}{*}{ Materiais } & \multirow{2}{*}{$\begin{array}{c}\text { Ø máx } \\
(\mathrm{mm})\end{array}$} & \multicolumn{2}{|c|}{ Quantidades de materiais/ $\mathrm{m}^{3}$ de concreto } \\
\hline & & CCR & Concreto Plástico \\
\hline Cimento - kg & - & 109 & 422 \\
\hline Areia-kg & 4,8 & 425 & 570 \\
\hline Brita nO - kg & 9,5 & 468 & - \\
\hline Brita n` - kg & 19,0 & 765 & 463 \\
\hline Brita n2-kg & 25,0 & 468 & 695 \\
\hline Água - I & - & 130 & 173 \\
\hline $\begin{array}{l}\text { Aditivo plastificante e } \\
\text { retardador do tempo de pega }\end{array}$ & - & 0,33 & 1,27 \\
\hline Aditivo incorporador de ar & - & - & 0,14 \\
\hline
\end{tabular}


A primeira utilização de CCR como camada final de rolamento em um rodovia norteamericana - estado de Geórgia em 2004 - obteve resistência a compressão simples de 27,6 $\mathrm{MPa}$ aos 28 dias com o emprego da energia modificada de compactação; a massa específica seca do material era $2,265 \mathrm{~kg} / \mathrm{m}^{3}$, alcançando um grau de compactação in situ de 98 \% (KIM, 2007).

Em experiência realizada na pista experimental do Instituto de Pesquisas Rodoviárias - IPR - empregando o CCR como camada de revestimento, procurouse averiguar em campo o desempenho destas misturas com a presença da ação de cargas do tráfego em escala real (de forma acelerada). Para tanto foram compostas duas misturas de CCR com consumos de $200 \mathrm{~kg} / \mathrm{m}^{3}$ e $280 \mathrm{~kg} / \mathrm{m}^{3}$, a resistência à tração na flexão em corpos de prova de $150 \times 150 \times 500\left(\mathrm{~mm}^{3}\right)$ no ensaio de dois cutelos foi de 3,0 MPa e 4,3 MPa, respectivamente. Com relação ao comportamento do pavimento em CCR, foram verificados parâmetros referentes à irregularidade superficial, deflexão, módulo de elasticidade e inventário da ocorrência de patologias; detalhes destes processos podem ser encontrados em Grossi, Balthazar e Rego (1991) e Rego e Grossi (1991). Nos dados apresentados por Rego e Grossi (1991) sobre a camada de revestimento em CCR antes dos 22 dias de operação do simulador de tráfego, as ondulações máximas foram superiores a $20 \mathrm{~mm}$ na maioria das seções testes (tendo o valor médio acima do especificado). Os valores médios de módulo de elasticidade dos concretos foram de $15 \mathrm{GPa}$ para o CCR com $200 \mathrm{~kg} / \mathrm{m}^{3}$ de cimento ( $\mathrm{cv}=38 \%$ e s $=5,7 \mathrm{GPa}$ ) e 19 GPa para o CCR com $280 \mathrm{~kg} / \mathrm{m}^{3}$ (cv $=50 \%$ e s = 9,2 GPa). Entretanto, de acordo com Grossi, Balthazar e Rego (1991), não se chegou a nenhuma conclusão concreta na época em decorrência das inúmeras falhas construtivas e operacionais apresentadas na execução da camada de CCR; o qual apresentou prematuramente patologias do tipo:

- desgaste superficial com problemas de homogeneidade em algumas regiões;

- escalonamento de juntas de baixa severidade;

- fissuras transversais oriundas da retração hidráulica, uma vez que as juntas foram serradas 24 horas após o horário especificado;

- esborcinamento de juntas em pontos isolados; 
- bombeamento de finos em alguns locais;

- quebra de placas em algumas seções devido a falha de suporte da base.

A deterioração do CCR se dá, basicamente, por efeitos fisicomecânicos, químicos ou eletroquímicos. Jorge et al. (2001) estudaram o mecanismo de lixiviação pela ação de águas puras, avaliando suas implicações nas alterações da microestrutura e parâmetros mecânicos do CCR. Os dados desta pesquisa apontam redução de $18,5 \%$ da resistência à compressão aos 154 dias de percolação de água em corpos de prova cilíndricos $(15 \mathrm{~cm} \times 30 \mathrm{~cm})$. A realização de análise química da água percolada mostrou-se uma ferramenta importante no estudo do mecanismo de lixiviação, pois permitiu inferir sobre a dissolução dos produtos de hidratação da pasta de cimento no CCR. Segundo Jorge et al. (2001), foram observados ciclos de desgaste no concreto, iniciando pela remoção da água dos poros (contendo principalmente sódio e potássio), seguida da dissolução do hidróxido de cálcio $(\mathrm{CH})$, permitindo a dissolução de parte do $\mathrm{C}-\mathrm{S}-\mathrm{H}$ e das fases $\mathrm{AF}_{\mathrm{t}}$ e $\mathrm{AF}_{\mathrm{m}}$; desgastada uma camada, o processo inicia-se novamente com a dissolução de mais $\mathrm{CH}$.

Os principais parâmetros de projeto que condicionam o dimensionamento da espessura de camadas de pavimentos em CCR é a resistência à tração na flexão e a fadiga do concreto, sendo utilizados os mesmos métodos de dimensionamento que em pavimentos de concreto vibrado.

Conforme Muñoz e Vera (1991), os pavimentos de CCR se comportam estruturalmente de forma similar aos pavimentos de concreto plástico; isto significa que devem cumprir com a resistência em determinada idade especificada pelo projetista. Na maioria dos países, esta resistência é determinada pelo ensaio de tração indireta (compressão diametral). Isto se deve, em parte, pelas solicitações que sofre o pavimento e, por outra, a utilização dos moldes de CBR para a confecção dos corpos de prova.

As resistências do CCR para casos de médio e baixo volume de tráfego são facilmente obtidas para consumos de cimento na mistura que variam de $160 \mathrm{~kg} / \mathrm{m}^{3}$ a $250 \mathrm{~kg} / \mathrm{m}^{3}$ (BALBO, 2005). Ilustra-se, na Tabela 14, valores típicos de consumo 
de ligante hidráulico e resistência de projeto para diferentes utilizações de CCR em pavimentação.

\begin{tabular}{ccc}
$\begin{array}{c}\text { Tabela } 14 \text { - faixas de resistência à compressão e consumo de ligante hidráulico para diversas } \\
\text { utilizações de CCR }\end{array}$ \\
\hline Utilização & $\begin{array}{c}\text { Resistência à Compressão } \\
\text { aos } \mathbf{7} \text { dias } \mathbf{( M P a )}\end{array}$ & $\begin{array}{c}\text { Consumo de Cimento } \\
\mathbf{( k g / \mathbf { m } ^ { 3 } )}\end{array}$ \\
\hline $\begin{array}{c}\text { Base de pavimento de concreto } \\
\text { Acostamento revestido }\end{array}$ & $5-8$ & $85-115$ \\
$\begin{array}{c}\text { Base de pavimento rígido } \\
\text { Base de pavimento flexível } \\
\text { Acostamento não revestido }\end{array}$ & $8-12$ & $115-150$ \\
\end{tabular}

(adaptado de: DNER, 1992)

Abreu (2002) confeccionou concreto de alta resistência compactado com rolo (CARCR) utilizando cimento CP-V ARI com consumo de $250 \mathrm{~kg} / \mathrm{m}^{3}$; os valores de resistência à compressão foram superiores a 45,0 MPa aos 28 dias de idade e os valores de resistência à tração na flexão, no ensaio de dois cutelos, de 5,5 MPa. Assim sendo, obtendo valores superiores aos dos concretos plásticos aplicados em obras viárias e que utilizam consumos de cimento superiores a $360 \mathrm{~kg} / \mathrm{m}^{3}$.

\subsection{PARÂMETROS MECÂNICOS}

O CCR composto para pavimentos tem parâmetros mecânicos que variam, fundamentalmente, de acordo com o consumo de ligante hidráulico, quantidade de água, características dos materiais, métodos e energia de compactação empregada, utilização de aditivos, idade, entre outros. A Tabela 15 ilustra os principais fatores que afetam os parâmetros mecânicos do CCR, onde os códigos indicados representam, respectivamente: $\mathrm{C}$ - consumo de cimento; TC - tipo de cimento; $U$ - umidade; $E$ - energia de compactação; $G$ - granulometria; TA - tipo de agregado; A - aditivo; Cura - tipo de cura; I - idade e TS - tratamento superficial. 
Tabela 15 - fatores que afetam os parâmetros do CCR

\begin{tabular}{|c|c|c|c|c|c|c|c|c|c|c|}
\hline \multirow{2}{*}{ Parâmetro } & \multicolumn{10}{|c|}{ Fatores que afetam os parâmetros mecânicos do CCR } \\
\hline & C & TC & $\mathbf{U}$ & $\mathbf{E}$ & G & TA & A & Cura & $\mathbf{I}$ & TS \\
\hline Resistência à compressão & $\mathrm{X}$ & $\mathrm{X}$ & $\mathrm{X}$ & $\mathrm{X}$ & $\mathrm{X}$ & & $\mathrm{X}$ & $\mathrm{X}$ & $\mathrm{X}$ & \\
\hline Resistência à tração na flexão & $\mathrm{x}$ & $\mathrm{x}$ & $\mathrm{x}$ & $\mathrm{x}$ & $\mathrm{x}$ & $\mathrm{X}$ & $\mathrm{X}$ & $\mathrm{X}$ & $\mathrm{x}$ & \\
\hline Módulo de elasticidade & $\mathrm{X}$ & $\mathrm{X}$ & $\mathrm{X}$ & $x$ & & $x$ & & & $x$ & \\
\hline Deformação elástica & $x$ & & & $x$ & & $x$ & & & $x$ & \\
\hline Retração por secagem & $x$ & $x$ & $x$ & $x$ & & $x$ & $x$ & & $x$ & \\
\hline Durabilidade & $x$ & $x$ & $x$ & $x$ & & & $x$ & $x$ & & \\
\hline Permeabilidade & $x$ & & $x$ & & & & $x$ & $x$ & $x$ & $\mathrm{X}$ \\
\hline
\end{tabular}

Notam-se deficiências na Tabela 14, proposta por Pitta e Diaz (1991), nos seguintes aspectos:

- o tipo de agregado influencia diretamente as características do CCR, seja no estado fresco ou endurecido. Arndt, Souza e Bianchini (2007) concluíram que a mesma natureza de agregados, entretanto, com processos de britagem diferentes (britador de mandíbulas e britador de eixo vertical) influenciam as resistências em concretos plásticos, devendo ser este o comportamento inclusive para o CCR. Neste estudo, o tipo de agregado originado pelo britador de mandíbula resulta resistências à compressão aos 28 dias cerca de $10 \%$ inferiores do que o mesmo agregado originado pelo britador de impacto vertical. Ainda, a utilização da brita produzida com eixo vertical apresenta um menor consumo de cimento $\left(15 \mathrm{~kg} / \mathrm{m}^{3}\right)$ para traços de mesma resistência e abatimento. No CCR, o tipo de agregado pode afetar, além da resistência à compressão, a durabilidade e permeabilidade da estrutura devido às solicitações impostas aos agregados pela compactação enérgica do rolo compressor;

- de um modo geral, os parâmetros que influenciam a resistência à compressão influenciam também o módulo de elasticidade (diagrama tensão-deformação) do CCR, embora em diferente grau; contudo, a 
granulometria (principalmente os agregados graúdos) tem particular influência no módulo de elasticidade;

- o módulo de elasticidade e a deformação elástica são influenciados pelos mesmos fatores pela estrita relação entre ambos;

- a permeabilidade é afetada pelo tipo de cimento, pois a estrutura de poros do CCR é condicionada pelos componentes e finura do ligante hidráulico;

- durante a retração do CCR fresco, o processo de movimentação de partículas sólidas deve ser homogêneo; qualquer obstrução causada por armaduras, pela granulometria (agregados de dimensões maiores) ou metodologia de cura pode causar fissuras, comprometendo a durabilidade e permeabilidade do concreto;

- a energia de compactação influi diretamente na densificação do CCR e na sua massa específica, alterando a permeabilidade do concreto.

\subsubsection{Resistência mecânica}

A umidade de compactação é um dos fatores que afetam as resistências mecânicas dos CCR. A diminuição da quantidade de água resulta em concretos com menores resistências à compressão e à tração, indicando que este componente deve ser suficiente para assegurar uma hidratação contínua para a mistura (SANTOS, 1988). Entretanto, segundo Pitta e Díaz (1991), se têm verificado, na prática de pavimentação, que maiores valores de resistência são alcançados com umidades um pouco inferiores às ótimas.

Sabe-se que todas as magnitudes de resistências do CCR reduzem se há segregação de agregados, baixa quantidade de argamassa e deficiência de compactação. Em geral, o controle de compactação em termos de massa específica do CCR em estado fresco é a principal medida durante a construção de estruturas em concreto e, em seguida, o controle é realizado por meio de ensaios de resistência em corpos de prova moldados ou testemunhos extraídos. A resistência é diretamente proporcional à massa específica, se esta é menor (cerca 
de $10 \%)$ do que a especificada em projeto, sua resistência cai aproximadamente $15 \%$ (BORGES, CASCUDO e GRAÇA, 2006).

Conforme Días et al. (1989), o emprego de areia industrial em CCR resulta em valores de resistência à compressão, aos 7, 28 e 90 dias, $10 \%$ superiores que os valores médios para areia natural.

Apresenta-se, na Tabela 16, a variação de magnitude de resistências à compressão e à tração na flexão para misturas de CCR, utilizando agregados da baixada santista com diferentes consumos de cimento.

Tabela 16 - características experimentais de traços de CCR desenvolvidos com agregados naturais da baixada santista/SP

\begin{tabular}{|c|c|c|c|c|c|c|c|c|}
\hline \multirow{2}{*}{$\begin{array}{l}\text { Consumo de } \\
\text { Cimento } \\
\left(\mathrm{kg} / \mathrm{m}^{3}\right)\end{array}$} & \multirow{2}{*}{$\begin{array}{c}\text { Traço em massa } \\
\text { (cimento/agregado) }\end{array}$} & \multirow{2}{*}{$\begin{array}{c}\text { Teor de } \\
\text { ar } \\
(\%)\end{array}$} & \multicolumn{3}{|c|}{$\begin{array}{c}\mathbf{f}_{\mathrm{ck}} \\
(\mathrm{MPa})\end{array}$} & \multicolumn{2}{|c|}{$\begin{array}{c}\mathbf{f}_{\mathrm{ct}} \\
(\mathrm{MPa})\end{array}$} & \multirow{2}{*}{$\begin{array}{c}\mathrm{E} \\
(\mathrm{GPa}) \\
28 \\
\text { dias }\end{array}$} \\
\hline & & & $\begin{array}{c}3 \\
\text { dias }\end{array}$ & $\begin{array}{c}7 \\
\text { dias }\end{array}$ & $\begin{array}{c}28 \\
\text { dias }\end{array}$ & $\begin{array}{c}7 \\
\text { dias }\end{array}$ & $\begin{array}{c}28 \\
\text { dias }\end{array}$ & \\
\hline 85 & $1: 24,84$ & 4,3 & 3,5 & 5,3 & 8,2 & 0,8 & 1,4 & 14,2 \\
\hline 100 & $1: 21,21$ & 4,2 & 4,5 & 7,0 & 10,5 & 1,3 & 1,6 & 15,6 \\
\hline 140 & $1: 15,06$ & 6,6 & 10,1 & 10,1 & 15,5 & 2,0 & 2,7 & 23,6 \\
\hline 220 & $1: 9,37$ & 12,9 & 19,4 & 19,4 & 23,4 & 3,5 & 4,2 & 29,2 \\
\hline
\end{tabular}

A utilização de cinzas volantes ou escória granulada de alto forno moída em CCR como material aglomerante em adição ao cimento Portland é muito empregada em diversos países da Europa (JOFRÉ et al., 1990 e PASKO, 1998). Conforme Mehta (1999), essa adição de finos não somente ocupa espaço e colmata poros da estrutura do concreto como também reduz a tendência de segregação do CCR ao ser compactado e contribui para o aumento da resistência mecânica. Sua influência na geração de calor de hidratação varia inversamente com a relação cinza volante, escória moída de alto forno ou pozolana e o cimento Portland $(F / C)$, de forma tal que para uma determinada resistência à compressão, a mistura com mínimo conteúdo de cimento apresentará mínima liberação de calor.

A contribuição do cimento na resistência do CCR é inicialmente maior; entretanto, em longo prazo, maiores quantidades de cinza volante contribuem para 
maiores ganhos de resistência. Percebe-se, na Figura 13, que maiores quantidades de cinza volante ou pozolana em CCR requerem maiores quantidade de água (W) e podem alcançar resistências à compressão em idades avançadas similares as misturas de concreto com maior consumo de cimento em idades menores.

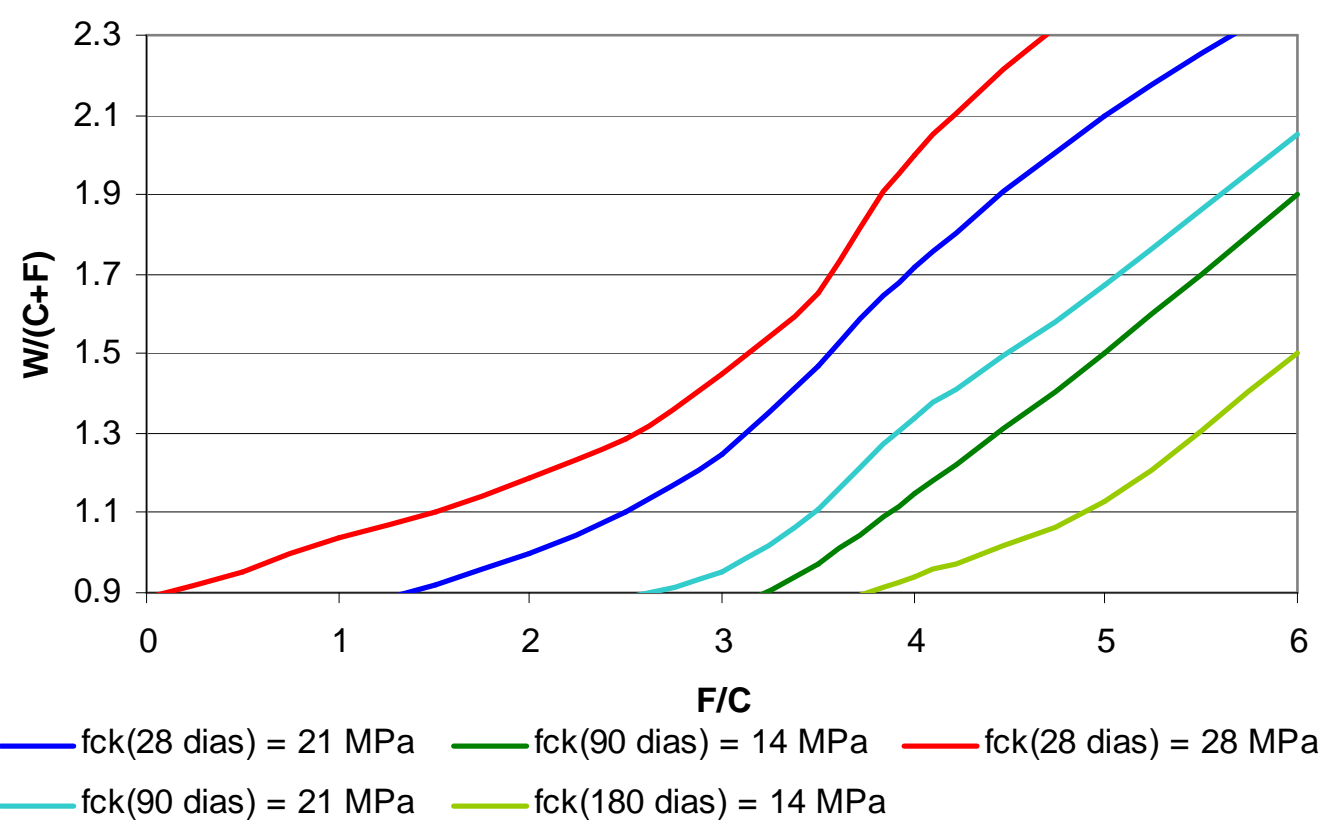

(adaptado de: SANTOS, 1988)

Figura 13 - curvas de dosagem para similares resistências do CCR

A relação entre a resistência à compressão e o desgaste à abrasão no CCR é direta, conforme mostrado na Figura 14. Neste estudo desenvolvido por Nanni (1989) foi aplicado o procedimento da norma britânica BS 8204/87 - semelhante ao procedimento B da NBR 12042 (ABNT, 1992) - o qual provoca desgaste em peças de concreto pela ação rotativa de um disco de aço de $75 \mathrm{~mm}$ de diâmetro. O valor de resistência à abrasão é obtido pela relação entre a perda de espessura por ação abrasiva e da amostra de CCR e sua dimensão inicial. 


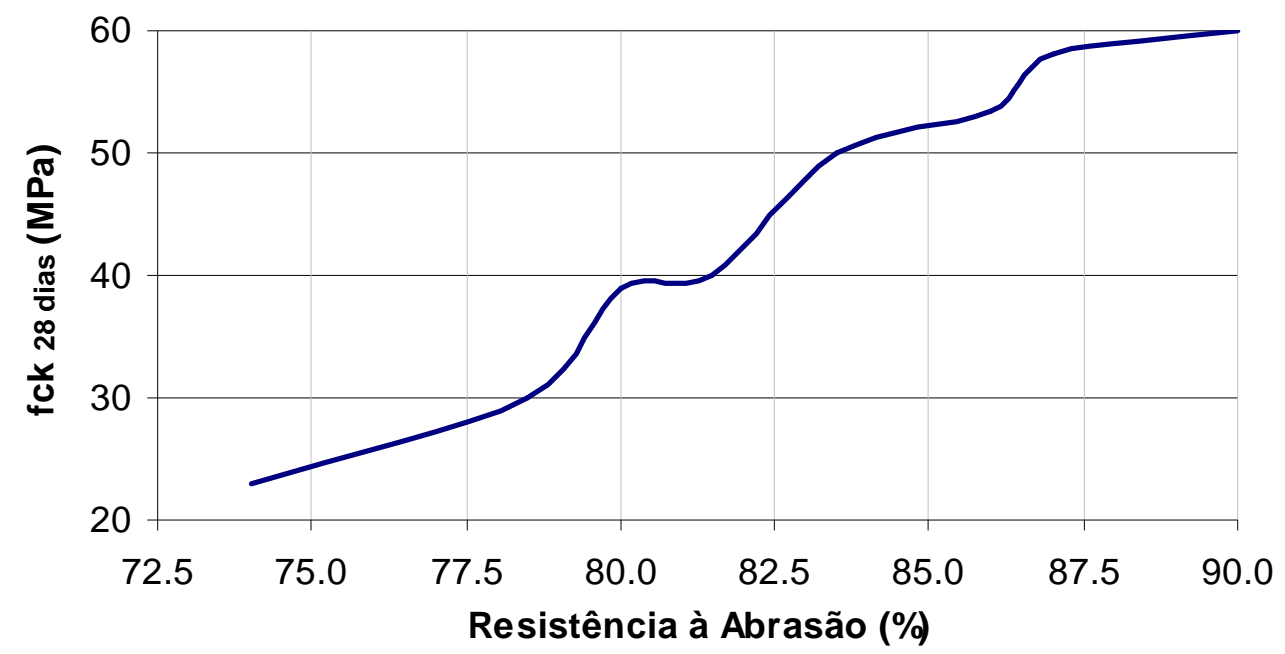

(adaptado de: NANNI, 1989)

Figura 14 - relação entre resistência à compressão e resistência à abrasão do CCR

Muñoz e Vera (1991) prepararam misturas de CCR, empregando diferentes tipos de cimento e procuraram determinar a correlação - através de regressão linear - existentes entre as resistências à tração por compressão diametral aos 7 , 28 e 90 dias. As relações entre resistências geradas foram:

- 7 dias para 28 dias $\left(\mathrm{R}^{2}=0,85\right)$ :

$$
\mathrm{fct}_{7}=0,684 \cdot \mathrm{fct}_{28}-1,24
$$

- 7 dias para 90 dias $\left(\mathrm{R}^{2}=0,81\right)$ :

$$
\mathrm{fct}_{7}=0,78 . \mathrm{fct}_{90}-10,57
$$

- 28 dias para 90 dias $\left(\mathrm{R}^{2}=0,83\right)$ :

$$
\mathrm{fct}_{28}=0,66 \cdot \mathrm{fct}_{90}+7,31
$$




\subsubsection{Retração por secagem}

Pittman e Ragan (1998) relatam que, no início do emprego do CCR na engenharia de pavimentos, não havia preocupações em relação ao desenvolvimento de retração por secagem e variações volumétricas oriundas da temperatura. Entretanto, com o crescimento de seu emprego, observou-se o registro de ocorrências de patologias por falhas de controle. As fissuras por retração no CCR ocorrem, de um modo geral, no intervalo de $10 \mathrm{~m}$ a $25 \mathrm{~m}$.

Em obras de infraestrutura viária realizadas em Boston no final da década de 1980, onde o CCR era a camada final de rolamento com espessura média de 18 $\mathrm{cm}$, as fissuras ocorreram entre $20 \mathrm{~m}$ e $80 \mathrm{~m}$. Do mesmo modo, em Denver, no início da década de 1990, as fissuras de retração se dispuseram entre 25 m e 140 m. O fato da discrepância entre valores típicos e aferidos em campo foi atribuído por Ragan, Pittman e Grogan (1990) ao menor consumo de cimento.

A avenida perimetral de Porto Alegre/RS, pavimentada por volta de $1973 \mathrm{em}$ pavimento asfáltico e base em CCR com consumo de cimento de $120 \mathrm{~kg} / \mathrm{m}^{3}$, apresentou fissuras de retração no CCR espaçadas a cada $6 \mathrm{~m}$ (CARVALHO, GODINHO e FERREIRA, 1987).

A retração por secagem do $C C R$ é relativamente menor quando comparada com o concreto plástico, sendo seu valor na ordem de 8 a $33 \times 10^{-5}$ aos 28 dias, dependendo do teor de cimento utilizado e da granulometria da estrutura dos agregados (PITTMAN e RAGAN, 1998). Conforme estes autores, o efeito individual da retração por secagem em misturas de CCR não chega a ser significante; todavia, a combinação com outros fatores pode ocasionar em queda no desempenho da camada cimentada do pavimento e sua degradação prematura.

\subsubsection{Comportamento à fadiga}

Fadiga é um processo progressivo e permanente de mudança interna do material sujeito à tensão, seja esta oriunda de cargas externas ou da variação de temperatura. Esta mudança pode ser danosa, resultando na progressiva 
propagação das microfissuras internas até certo ponto em que ocorre a fratura do material após um dado número de repetições ( $\mathrm{ACl}, 1991)$; sendo este nível de tensão inferior ao nível de tensões por ruptura estática.

A evidência de que este fenômeno ocorre em camadas de concreto, inclusive de CCR, foi constatado por volta de 1960 em experimento realizado pela American Association of State Highway Officials (AASHO) onde houve fissuração em trilhas de roda após dado número de repetições de carga, mesmo sem haver afundamento em trilha de roda. Os fatores que influenciam a fadiga no concreto são: velocidade do carregamento, razão entre a tensão solicitante e de ruptura RT - períodos de repouso, história do carregamento, condição de umidade e composição da mistura.

Cardoso, Pitta e Trichês (1991) empregaram a análise fenomenológica equações procurando caracterizar um fenômeno para dado material - para a avaliação do comportamento à fadiga do CCR (moldados na energia normal de compactação e consumo de cimento de $\left.120 \mathrm{~kg} / \mathrm{m}^{3}\right)$. Apresenta-se, na Tabela 17, a influência de diferentes $\mathrm{RT}$ no número de solicitações do eixo padrão rodoviário $(\mathrm{N})$ para a ruptura destes CCR e na Figura 15 são traçadas as curvas de fadiga compostas com intervalos de confiança de $5 \%$ a $82,5 \%$ (probabilidade para ocorrer a ruptura por fadiga da mistura - P), comparando-as com a curva de dimensionamento da Canadian Portland Cement Association (CPCA, 1984) e Tayabji e Okamoto (1987).

Tabela 17 - influência de diferentes razões entre tensões solicitantes e de ruptura e números de solicitações de eixo rodoviário padrão

\begin{tabular}{cc|cc}
\hline $\mathbf{R T}$ & $\mathbf{N}$ & $\mathbf{R T}$ & $\mathbf{N}$ \\
\hline 0,953 & 15 & 0,727 & 7.320 \\
0,854 & 40 & 0,644 & 16.120 \\
0,801 & 600 & 0,608 & 315.970 \\
0,784 & 710 & 0,584 & 837.000 \\
0,794 & 1.100 & 0,596 & 1.600 .000
\end{tabular}

(adaptado de: CARDOSO, PITTA e TRICHÊS, 1991) 

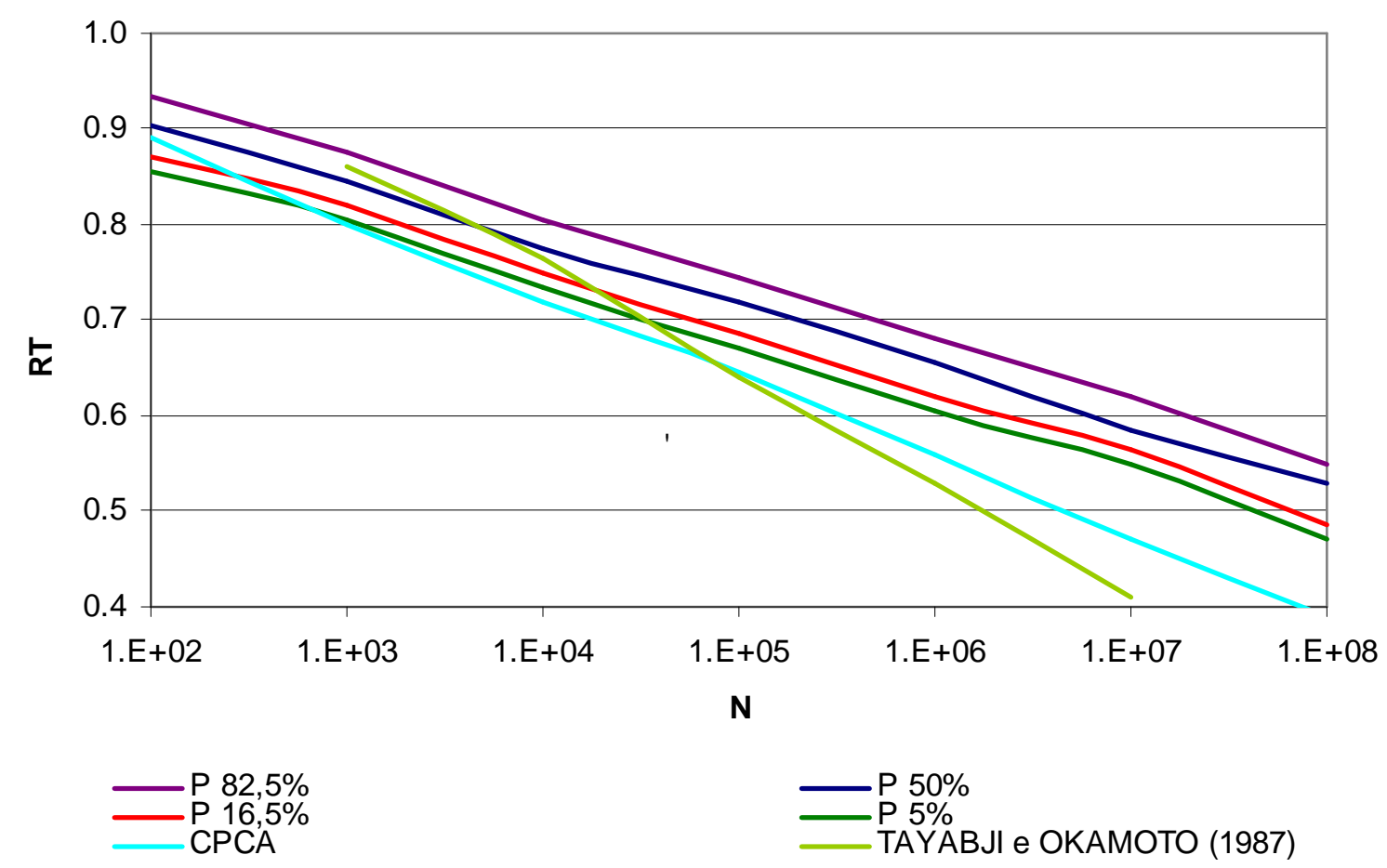

(adaptado de: CARDOSO, PITTA e TRICHÊS, 1991)

Figura 15 - curvas de fadiga de misturas de CCR

A equação obtida para o comportamento à fadiga do CCR composto por Cardoso, Pitta e Trichês (1991) é dada por:

$$
\begin{gathered}
R=0,9666-0,0629 \log N \\
R^{2}=0,91 \\
S=0,0279
\end{gathered}
$$

\subsection{GRAU DE COMPACTAÇÃO}

Um aspecto importante para a operação normal de estruturas em CCR refere-se ao grau de compactação (GC) com que as camadas do concreto são executadas. Inúmeras manifestações patológicas têm sido associadas à menor compactação destas camadas, resultando em maior porosidade no concreto. Isto se deve à dosagem, deficiências no equipamento de compactação e também à 
forma de controle desta compactação (GRAÇA et al., 2004). A fixação do número de passadas do rolo compactador não deve ser somente o fator preponderante para garantir que o CCR tenha sido compactado corretamente. Um funcionamento inadequado deste equipamento, espessuras de camadas elevadas e controle deficiente podem resultar em concretos porosos e suscetíveis à segregação e formação de áreas heterogêneas em termos de tensão de ruptura e massa específica.

O uso do densímetro nuclear para controle da densidade do CCR in situ e, por conseguinte seu GC, tem sido o método que melhor garante que os CCR estão sendo aplicados com os requisitos necessários e adequados ao desempenho da estrutura (LIDUÁRIO et al., 2004). Todavia, outros métodos de controle de densidade têm sido utilizados, como a membrana plástica e o frasco de areia.

Graça et al. (2004) concluíram que um GC = $96 \%$ pode ser entendido como um limite inferior estatístico para controle da compactação em barragens de CCR, uma vez que parâmetros como as resistências à compressão axial simples, tração simples e tração na compressão diametral, permeabilidade de água, ângulo de atrito e coesão mostraram-se inferiores, porém, dentro de limites mínimos aceitáveis. Estes autores ressaltam que, em casos de impossibilidade do uso do densímetro nuclear, os métodos da membrana plástica e do frasco de areia devem ser utilizados com a devida reserva; recomendam a busca por correlações confiáveis entre estes métodos e o densímetro nuclear, considerando a mesma dosagem de CCR e suas propriedades no estado fresco.

Após incidente com materiais radioativos em Goiânia/GO em 1987, a utilização do densímetro nuclear para aferição do GC de camadas de CCR sofreu inúmeras restrições devido aos riscos à saúde do operador e ao meio ambiente. Neste sentido, a procura por métodos alternativos e não destrutivos está sendo crescente ao passar dos anos.

Santos (1996) efetuou o controle tecnológico do GC de camadas de CCR na barragem de Várzea Grande, na Paraíba, através do método não destrutivo da ascultação sísmica de refração. Os resultados obtidos demonstram que este método, além de possuir fácil aplicação e grande produtividade, tem boa correlação 
com o método do frasco de areia. Desta forma, sendo um método alternativo para o controle de qualidade do concreto.

Ribeiro, Casto e Santana (2005) estudaram a utilização do ensaio de propagação de onda ultrassônica para controle de qualidade da ligação entre camadas de CCR e GC em barragens. Em ensaios de tração direta de corpos de prova moldados em duas partes (para simular a ligação entre camadas que ocorre nas barragens), a velocidade de pulso ultrassônico mensurada no concreto da camada inferior tem grande variação numa fase prévia ao instante, a partir do qual, a colocação de uma camada superior dá origem a uma ligação enfraquecida em relação ao concreto massa. Analisando comparativamente a velocidade de onda entre as duas camadas, nota-se relação direta desta com a densidade do material, independente do GC entre as camadas ser diferente.

A variação das velocidades de pulso ultrassônico no CCR pode ser utilizada como critério para a necessidade de tratamento superficial entre camadas, desde que esteja assegurado que a metodologia laboratorial é convenientemente testada e adaptada às condições reais de obra. A sua correlação com outros parâmetros deve ser melhor estudada para verificação de quais quesitos influenciam diretamente e quais limitações de uso (RIBEIRO, CASTO e SANTANA, 2005). 


\section{METODOLOGIA DA PESQUISA}

\subsection{MATERIAIS EMPREGADOS NA DOSAGEM DO CCR}

A metodologia de dosagem do concreto, sendo este vibrado ou compactado, almeja uma composição de materiais que atenda a especificações de desempenho preconizadas, aliando fatores econômicos.

No caso do CCR, entre os materiais que o constituem, a água exerce papel fundamental no desenvolvimento da compacidade e resistência do concreto. A quantidade de água é obtida através do ensaio de compactação - NBR 7182 (ABNT, 1986a) - igualmente empregado na área de engenharia geotécnica.

A dosagem do CCR objetiva a massa específica máxima da mistura; esta, por sua vez, varia com os agregados utilizados, índice de vazios e conteúdo de pasta de cimento. A massa específica máxima do concreto seco é obtida no ponto ótimo de umidificação onde a compacidade e a resistência mecânica seria teoricamente máxima, exceto no caso de misturas estabilizadas com cimento onde a dosagem é realizada no ramo seco da curva de compactação, como é o caso da brita graduada tratada com cimento - BGTC - (BALBO, 1993).

O baixo consumo de ligante hidráulico em misturas de CCR é originado pelo intertravamento granular da mistura e menor volume de vazios, utilizando assim, faixas granulométricas contínuas em sua dosagem. A faixa granulométrica de melhor adequação à utilização do CCR deve ser determinada mediante ensaios de laboratório, selecionando-se aquela que permita cumprir as especificações de desempenho desejadas para o material (DNER, 1992). Os diferentes campos de utilização do CCR condicionarão sua resistência e dimensão máxima dos agregados. As distribuições granulométricas disponíveis para a dosagem do CCR como base ou camada final de pavimento limitam a dimensão do agregado graúdo em $25 \mathrm{~mm}$ por questões de retração, segregação, compactação e acabamento final (DNER, 1992).

$\mathrm{Na}$ presente pesquisa, utilizou-se a faixa granulométrica idealizada por Pittman e Ragan (1998) - Figura 16 - a qual foi idealizada levando em 
consideração o controle da retração no CCR, tendo uma estrutura granular contínua e densa e requerendo menores teores de ligante hidráulico. Esta faixa também foi empregada por Abreu (2002) no estudo de CARCR para revestimento de pavimentos e Ricci (2007) na utilização de resíduo de construção e demolição (RCD) em CCR para base de pavimentos asfálticos híbridorrígidos. Via de regra, estas composições granulométricas levam em consideração a matriz pétrea da mistura considerando sua estabilização granular e o volume de vazios. $\mathrm{Na}$ Espanha, exclusivamente, a faixa granulométrica recomendada considera também a granulometria do próprio ligante hidráulico.

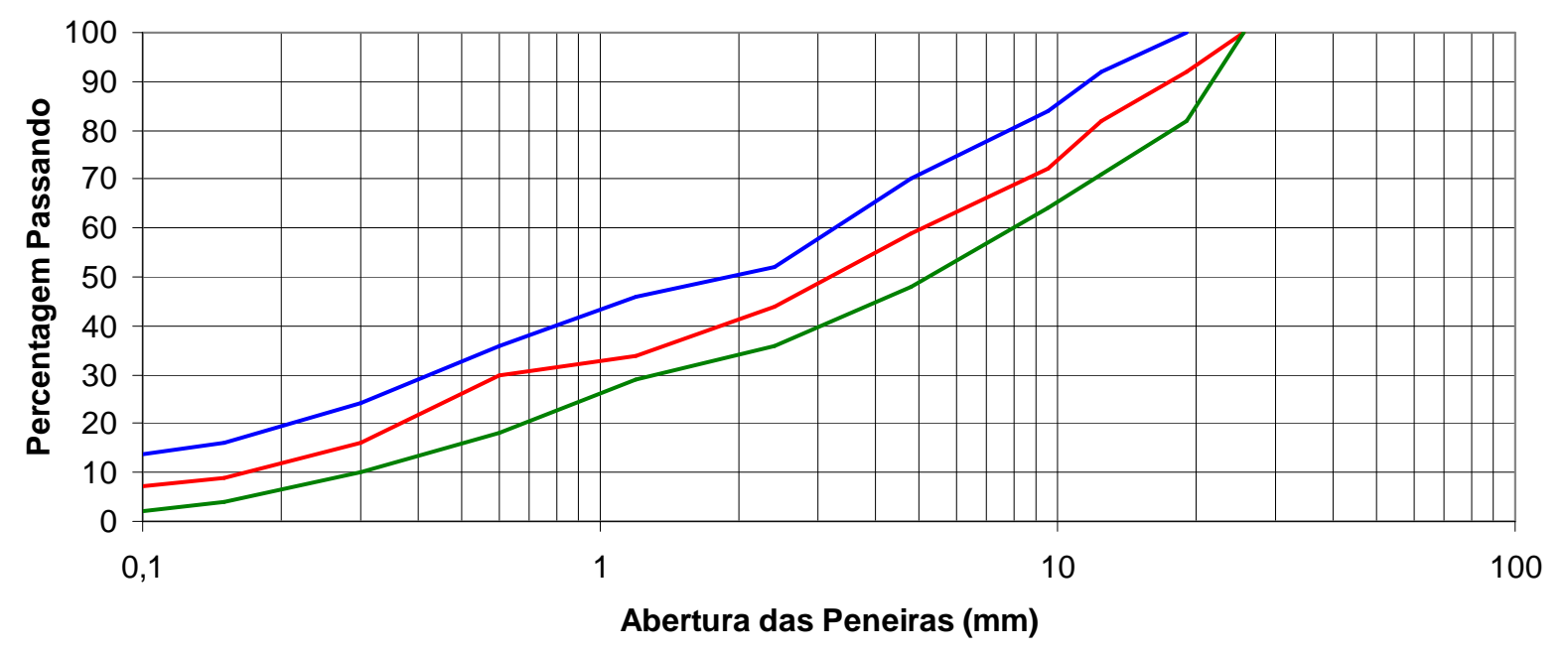

— Granulometria Fina — Granulometria Média — Granulometria Grossa

(adaptado de: PITTMAN e RAGAN, 1998)

Figura 16 - faixa granulométrica do CCR (dimensão máxima características de $25 \mathrm{~mm}$ )

As matérias primas para a confecção do CCR foram escolhidas através da disponibilidade do mercado regional da região metropolitana de São Paulo, sendo estas: cimento CP III - 40 RS, brita 1, pedrisco e areia. Para a fração areia do concreto foram utilizadas: areia industrial, areia natural e escória granulada de alto forno (sem processo prévio de moagem). A utilização de dois tipos de areia (rio e britagem) se deu pela necessidade de comparação de parâmetros com o agregado alternativo siderúrgico e qual a sua influência no comportamento do CCR. Para 
tanto, foi incorporado escória nas quantidades de 50 \% e 100 \% na substituição em peso das areias.

Apresenta-se, na Figura 15, o aspecto visual e granulométrico dos agregados e, na Tabela 18, as origens e procedências dos materiais empregados na dosagem dos CCR.
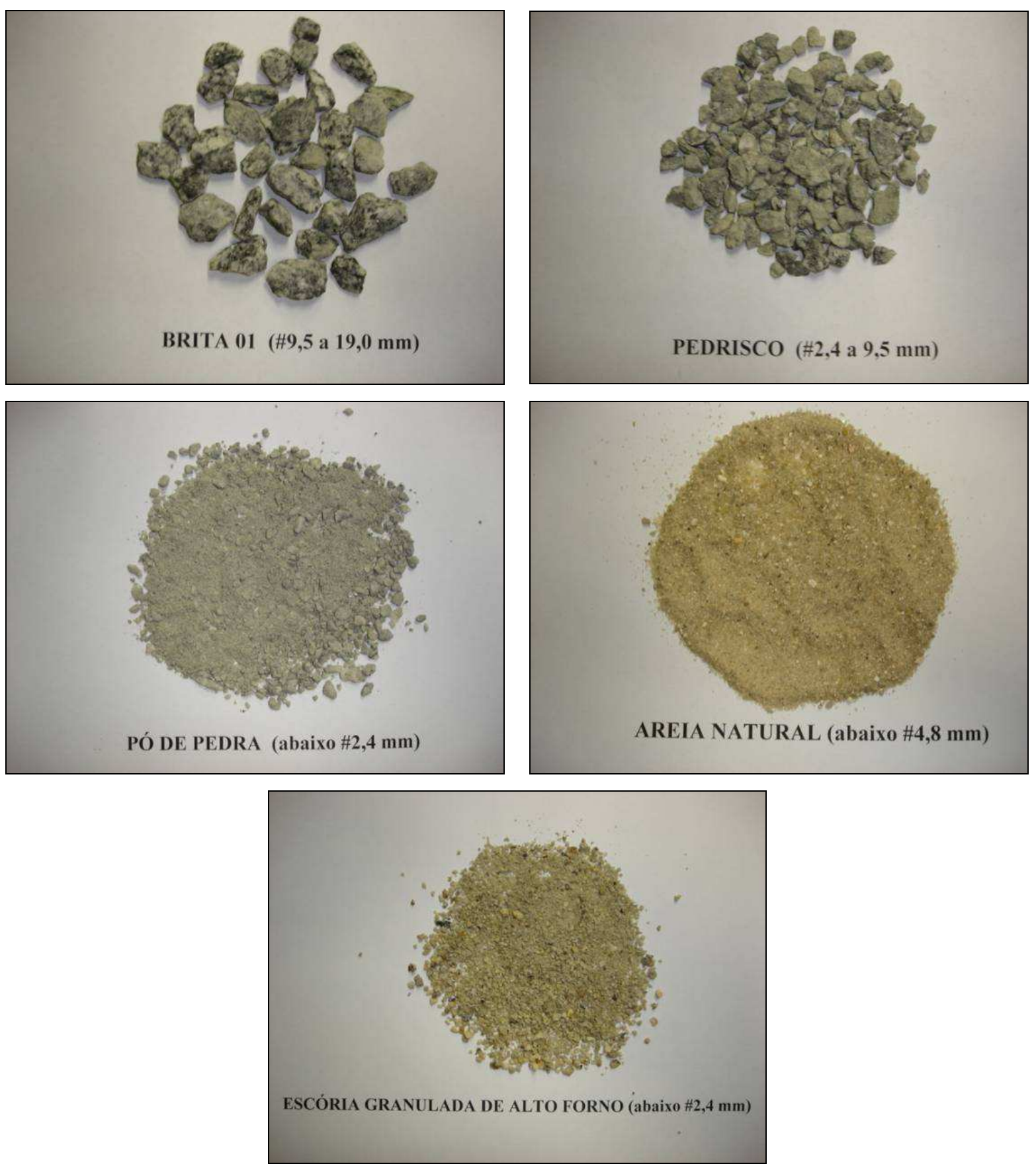

Figura 17 - aspecto visual dos agregados utilizados no CCR 
Tabela 18 - materiais constituintes do CCR

\begin{tabular}{ccc}
\hline Material & Origem & Procedência \\
\hline CP III-40 RS & Holcim & Barroso/MG \\
Areia natural & rio & Serveng/SP \\
Areia industrial & & \\
Pedrisco & rocha granítica & Pedreira Cantareira/SP \\
Brita 1 & & \\
Escória de alto forno & siderurgia & COSIPA/SP \\
\hline
\end{tabular}

A água de amassamento utilizada foi proveniente da companhia de saneamento básico do Estado de São Paulo - SABESP - e, assim sendo, presume-se como satisfatórias suas características e isenção de substâncias prejudiciais ao processo de pega e endurecimento do concreto.

A escória granulada de alto forno empregada foi coletada em pilhas de estocagem do material na indústria de cimentos Santa Helena, em Votorantim/SP, antes de sua secagem e moagem, nas condições de armazenagem a céu aberto, conforme mostrado na Figura 18. O polo gerador da escória é a Companhia Siderúrgica Paulista - COSIPA - em Cubatão/SP. Este material é transportado por ferrovia até a indústria cimenteira (cerca de $50 \mathrm{~km}$ ) para posterior secagem e moagem em conjunto com o clínquer e produção do cimento CP III.
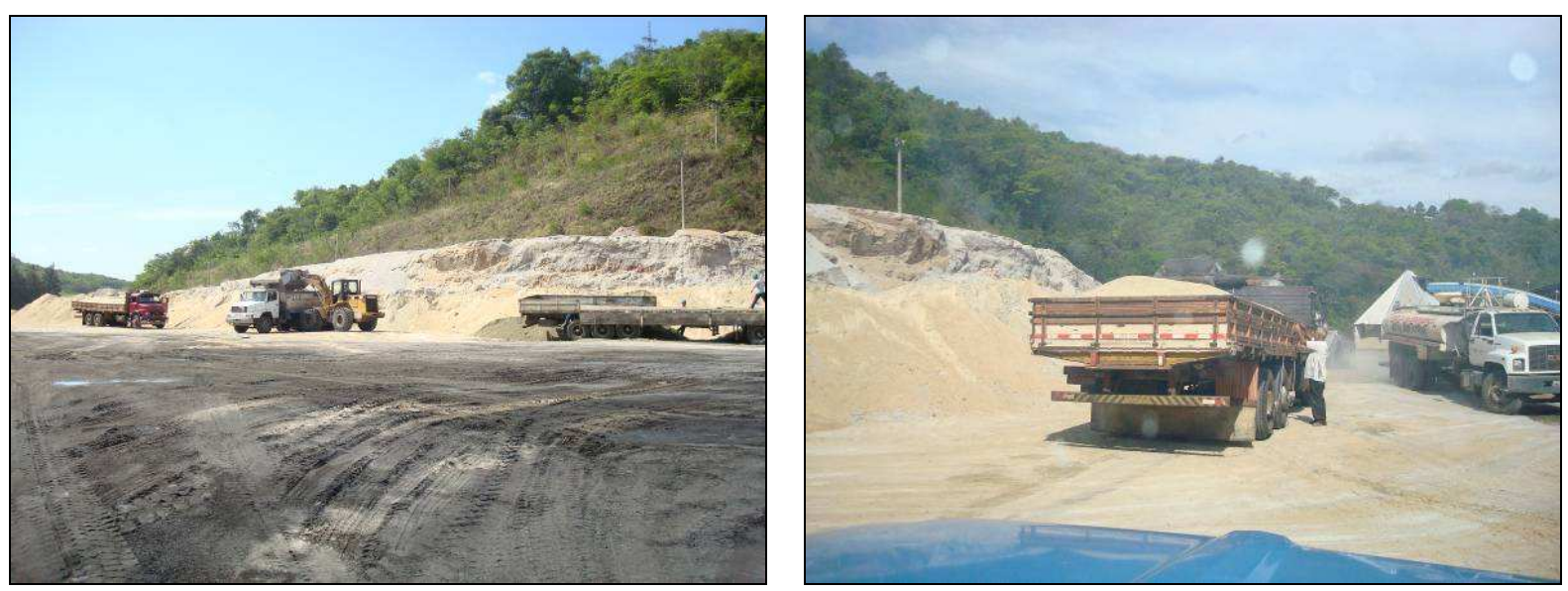

Figura 18 - estocagem da escória granulada de alto forno a céu aberto 
Para todos os materiais granulares convencionais foram realizados ensaios de peneiramento, conforme a NBR 7217 (ABNT, 1987b); os quais são apresentados graficamente na Figura 19. A escória granulada de alto forno também foi peneirada da mesma forma, entretanto, foram submetidas duas amostras ao peneiramento para verificação da homogeneidade do material (Figura 20). Assim sendo, todos os agregados enquadraram-se nos limites preconizados pela NBR 7211 (ABNT, 2005) para utilização em concreto, onde a escória é classificada como areia média.

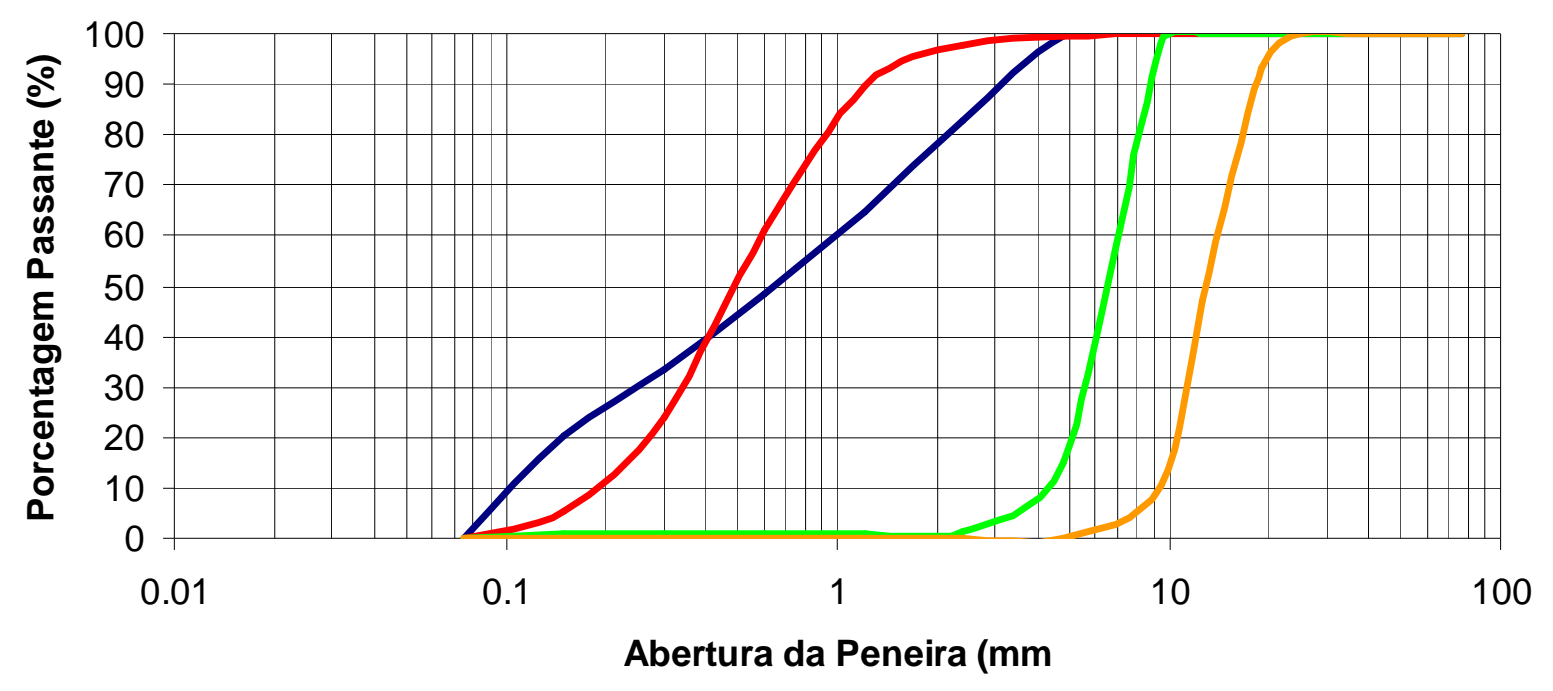

- Areia Industrial — Areia Natural —Pedrisco — Brita 1

Figura 19 - características granulométricas das areias e britas extraídas de jazidas naturais 


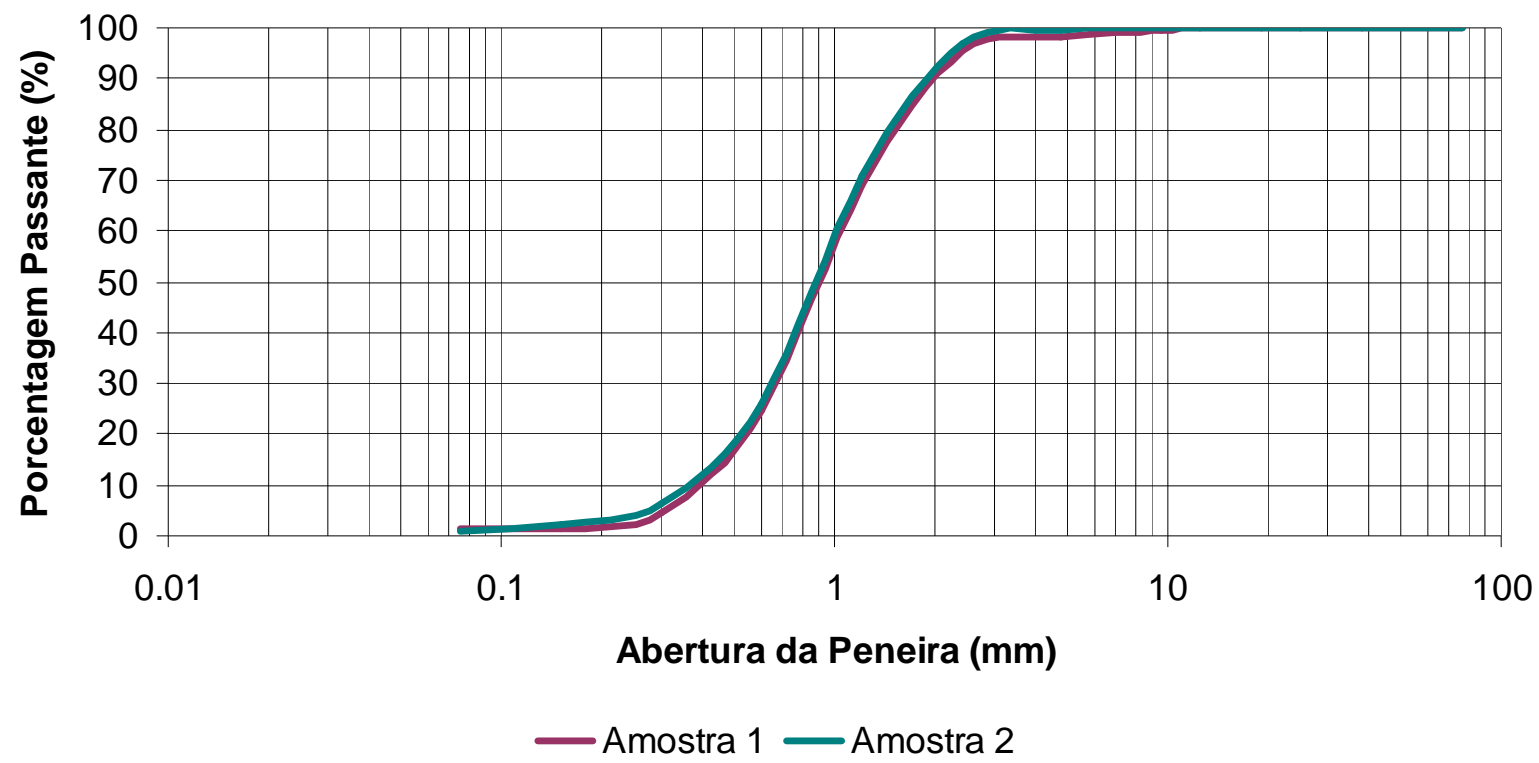

Figura 20 - característica granulométrica e homogeneidade das amostras de escória granulada de alto forno

Dados referentes à escória granulada de alto forno como o grau de vitrificação, o índice de refração, a natureza da escória foram fornecidos pela empresa produtora ${ }^{3}$ (Tabela 19). A composição química da escória (Tabela 20) foi gentilmente cedida pela empresa fornecedora ${ }^{4}$, de onde se extrai que apresentavase pertinente às faixas de valores, para as substâncias encontradas, com as quantidades indicadas por Feilo e Royster (1981), conforme apresentadas anteriormente na Tabela 4. Ainda, foi realizado o ensaio de abrasão Los Angeles, conforme preconizada na norma rodoviária ME-035 (DNER, 1998a), onde o resíduo se enquadra na faixa $D$. O desgaste sofrido pelo material após ação de carga abrasiva está apresentado na Figura 21 (granulometria da escória retida e passante na peneira de malhas quadradas de 1,7 mm - ABNT n912), sendo obtido o valor de abrasão Los Angeles: $A_{D}=83 \%$, ou seja, um material bastante sujeito a modificações granulométricas por esforços de impacto em comparação às rochas naturais (10\% a $50 \%)$.

\footnotetext{
${ }^{3}$ Dados gentilmente cedidos pela laboratorista Rosângela Dallaglio, da COSIPA, em 22/12/2009.

4 Dados gentilmente cedidos pelo engenheiro Roberto Rodrigues, da VOTORANTIM Cimentos, em $11 / 01 / 2010$.
} 
Tabela 19 - características da escória granulada de alto forno utilizada na presente pesquisa

\begin{tabular}{ccc}
\hline Parâmetro & Especificação & Escória \\
\hline Grau de vitrificação & PO GT-5004, rev.4 & $96 \%$ \\
Índice de refração & PO GT-5016, rev.1 & 1,63 \\
Natureza & - & básica \\
\hline
\end{tabular}

Tabela 20 - composição química da escória granulada de alto forno da COSIPA

\begin{tabular}{cc}
\hline Componente & Proporção (\%) \\
\hline $\mathrm{FeO}$ & 0,45 \\
$\mathrm{SiO}_{2}$ & 33,65 \\
$\mathrm{Al}_{2} \mathrm{O}_{3}$ & 12,42 \\
$\mathrm{CaO}$ & 41,60 \\
$\mathrm{MgO}$ & 7,95 \\
$\mathrm{TiO}$ & 0,73 \\
\hline
\end{tabular}
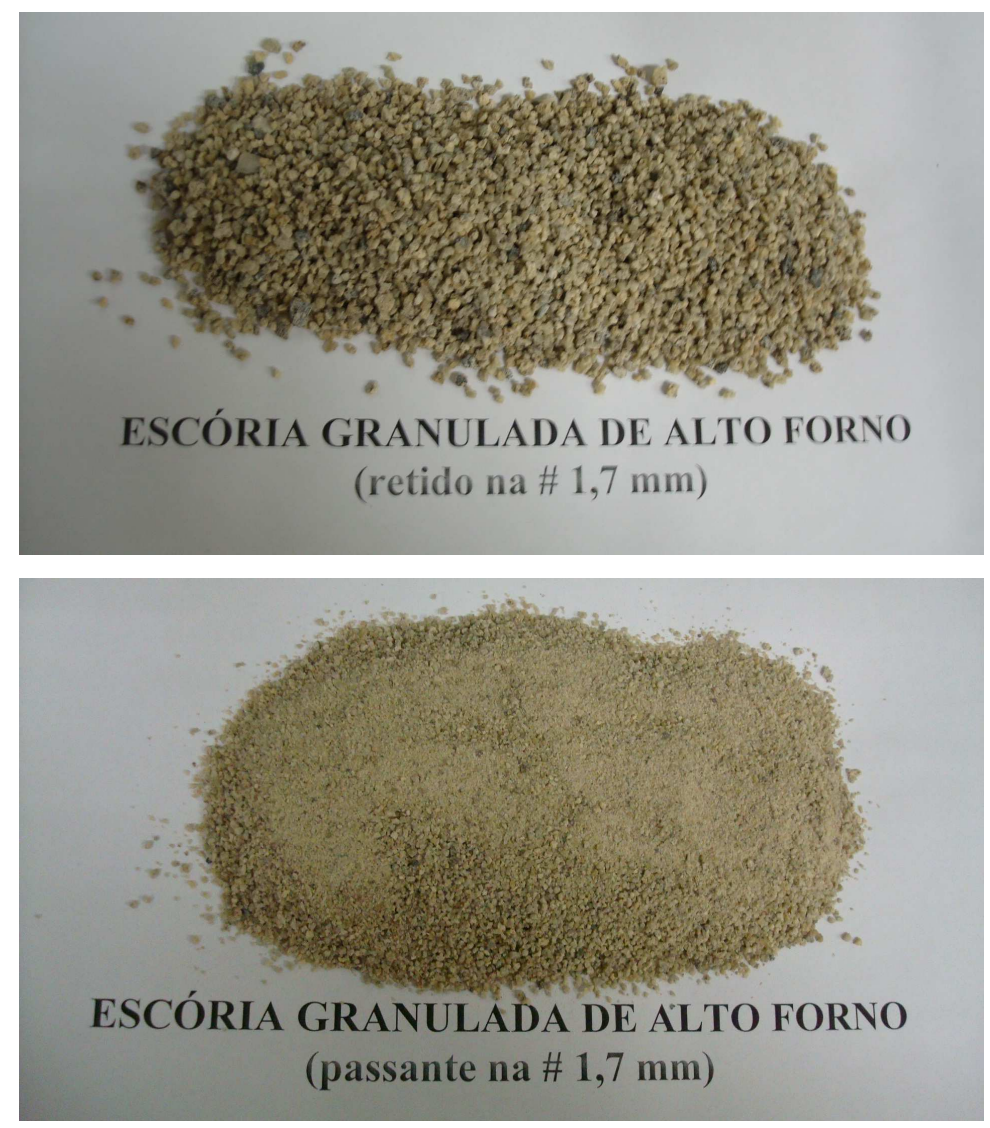

Figura 21 - escória granulada de alto forno após desgaste sofrido no ensaio de abrasão 
Apresentam-se, na Tabela 21, os ensaios de caracterização realizados nos materiais granulares constituintes do CCR. Os ensaios de caracterização química e física do ligante hidráulico foram efetuados e disponibilizados pela HOLCIM, sendo mostrados na Tabela 22 e 23; esses resultados atendem satisfatoriamente aos índices de especificação da NBR 5735 (ABNT, 1991a) para o cimento com adição de escória granulada de alto forno moída (CP III - 40 RS).

Tabela 21 - caracterização física dos agregados

\begin{tabular}{|c|c|c|c|c|c|c|}
\hline Parâmetro & Und. & Brita 1 & Pedrisco & $\begin{array}{c}\text { Areia } \\
\text { Industrial }\end{array}$ & $\begin{array}{c}\text { Areia } \\
\text { Natural }\end{array}$ & Escória \\
\hline $\begin{array}{c}\text { Dimensão máxima } \\
\text { característica } \\
\text { (NBR 7211/05) }\end{array}$ & $\mathrm{mm}$ & 25 & 9,5 & 4,8 & 2,4 & 2,4 \\
\hline $\begin{array}{l}\text { Impureza orgânica } \\
\text { (NBR 7220/87b) }\end{array}$ & - & nd & nd & nd & nd & nd \\
\hline $\begin{array}{c}\text { Massa específica } \\
\text { (NBR 9776/87c) }\end{array}$ & $\mathrm{kg} / \mathrm{m}^{3}$ & 2.682 & 2.708 & 2.620 & 2.472 & 2.341 \\
\hline $\begin{array}{c}\text { Massa unitária } \\
\text { (NBR 9776/87c) }\end{array}$ & $\mathrm{kg} / \mathrm{m}^{3}$ & 1.430 & 1.390 & 1.630 & 1.400 & 1.290 \\
\hline $\begin{array}{l}\text { Módulo de finura } \\
\text { (NBR 7217/86b) }\end{array}$ & - & 6,96 & 5,81 & 2,51 & 3,75 & 4,05 \\
\hline $\begin{array}{c}\text { Teor de argila } \\
\text { (NBR 7218/87a) }\end{array}$ & $\%$ & 0,2 & 0,3 & 0,3 & 0,4 & 0,3 \\
\hline $\begin{array}{l}\text { Teor de material } \\
\text { pulverulento } \\
\text { (NBR 7219/83) }\end{array}$ & $\%$ & 0,6 & 0,8 & 1,6 & 0,6 & 0,4 \\
\hline
\end{tabular}


Tabela 22 - análise química do cimento CP III - 40RS

\begin{tabular}{cc}
\hline Componente & Proporção \\
\hline $\mathrm{SiO}_{2}$ & $28,59 \%$ \\
$\mathrm{CaO}$ & $51,36 \%$ \\
$\mathrm{SO}_{3}$ & $2,06 \%$ \\
$\mathrm{~K}_{2} \mathrm{O}$ & $0,47 \%$ \\
$\mathrm{Al}_{2} \mathrm{O}_{3}$ & $9,07 \%$ \\
$\mathrm{MgO}$ & $4,40 \%$ \\
$\mathrm{MgO}$ & $4,40 \%$ \\
C3A (teórico) & $70,22 \%$ \\
\hline
\end{tabular}

Tabela 23 - caracterização do cimento CP III - 40RS

\begin{tabular}{|c|c|c|}
\hline Parâmetro & Und. & CP III - 40 RS \\
\hline \# 325 & $\%$ & 1,9 \\
\hline$\# 400$ & $\%$ & 4,6 \\
\hline $\begin{array}{l}\text { Superfície específica - Blaine } \\
\text { (NBR 7224/84) }\end{array}$ & $\mathrm{cm}^{2} / \mathrm{g}$ & 4.141 \\
\hline $\begin{array}{c}\text { A/C - pasta de consistência normal } \\
\text { (NBR 11580/91c) }\end{array}$ & $\%$ & 31,2 \\
\hline $\begin{array}{l}\text { Tempo de pega } \\
\text { (NBR } 11581 / 91 d)\end{array}$ & $\min$ & $195-257$ \\
\hline & & 9,8 (1 dia) \\
\hline $\begin{array}{l}\text { Resistência à compressão } \\
\text { (NBR 7215/97) }\end{array}$ & $\mathrm{MPa}$ & $\begin{array}{l}26,0 \text { (3 dias) } \\
38,9 \text { (7 dias) }\end{array}$ \\
\hline & & 51,4 (28 dias) \\
\hline $\begin{array}{c}\text { Perda ao Fogo }-1.000{ }^{\circ} \mathrm{C} \\
\text { (NBR } 5743 / 04 a)\end{array}$ & $\%$ & 2,48 \\
\hline $\begin{array}{l}\text { Resíduo Insolúvel } \\
\text { (NBR 5744/04b) }\end{array}$ & $\%$ & 0,98 \\
\hline
\end{tabular}

Para fins de análise da influência de diferentes materiais de granulometria miúda no CCR, foram compostos cinco traços, conforme detalhado na Tabela 24. Nas misturas 1, 2 e 3 foram empregados diferentes materiais de granulometria miúda na fração total de areia (areias industrial e natural e escória granulada de 
alto forno); nos concretos 4 e 5 esta substituição foi parcial, utilizando-se $50 \%$ de escória granulada de alto forno e $50 \%$ de areia industrial ou areia natural, respectivamente. $O$ pensamento inicial da pesquisa era a comparação, em termos de parâmetros mecânicos de misturas de CCR, entre a areia industrial (concreto padrão) e a escória granulada de alto forno (concreto com agregado alternativo); entretanto, posteriormente, foi adicionada areia natural como fração total areia e em conjunto com a escória (50\%), aumentando a gama de análises comparativas e visando à investigação da influência de tal agregado siderúrgico em comparação com os dois agregados naturais disponíveis no mercado metropolitano de São Paulo.

Tabela 24 - traços de CCR utilizados

\begin{tabular}{cccc}
\hline Mistura & Nomenclatura & Materiais Empregados & Traço (kg) \\
\hline 1 & CCR - Al & cimento, areia industrial, pedrisco e brita 1 & $1: 6,0: 5,4: 3,4$ \\
2 & CCR - AN & cimento, areia natural, pedrisco e brita 1 & $1: 6,0: 5,4: 3,4$ \\
3 & CCR - ESC & cimento, escória, pedrisco e brita 1 & $1: 6,0: 5,4: 3,4$ \\
4 & CCR - Al/ESC & cimento, areia industrial, escória, pedrisco e & $1: 3,0: 3,0: 5,4: 3,4$ \\
& & brita 1 & \\
5 & CCR - AN/ESC & cimento, areia natural, escória, pedrisco e & $1: 3,0: 3,0: 5,4: 3,4$ \\
& & brita 1 & \\
\hline
\end{tabular}

A otimização granulométrica do CCR se deu pela adequação dos materiais granulares utilizados, enquadrando-os dentro dos limites superior e inferior da curva granulométrica proposta por Pittman e Ragan (1998) para emprego em bases de pavimentos. Para tanto, foi tomado como referência a distribuição granulométrica do CCR - Al (Tabela 25) e, para as demais dosagens, foram substituídas a fração areia em peso. Assim sendo, as proporções de materiais foram as mesmas entre as cinco dosagens. Apresentam-se, nas Figuras 22 a 26, as distribuições granulométricas das dosagens realizadas. 
Tabela 25 - proporção dos materiais para o CCR - Al

\begin{tabular}{cc}
\hline Material & Proporção em Peso \\
\hline Areia industrial & $37 \%$ \\
Pedrisco & $39 \%$ \\
Brita 1 & $24 \%$ \\
\hline
\end{tabular}

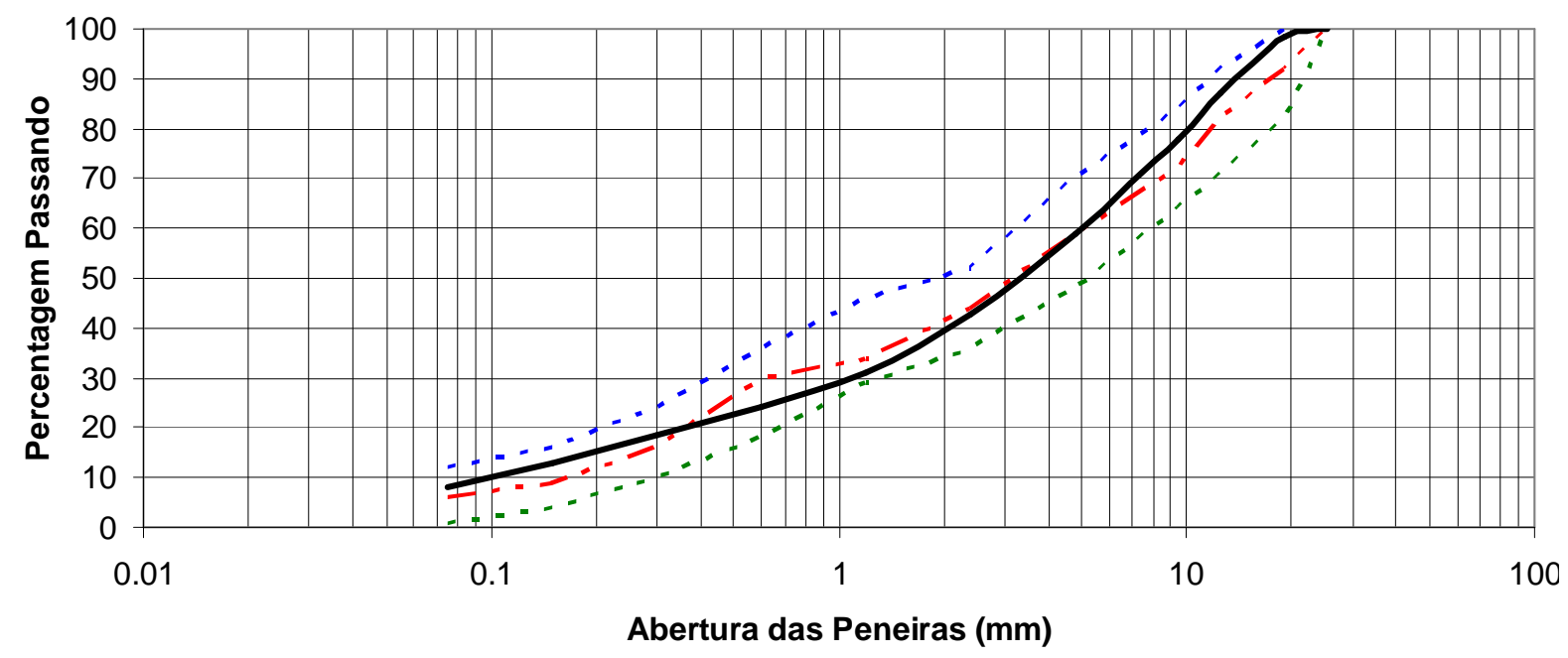

- - - Faixa Superior - - - Faixa Média - - - Faixa Inferior ——Faixa do CCR - Al

Figura 22 - faixa granulométrica do CCR - Al

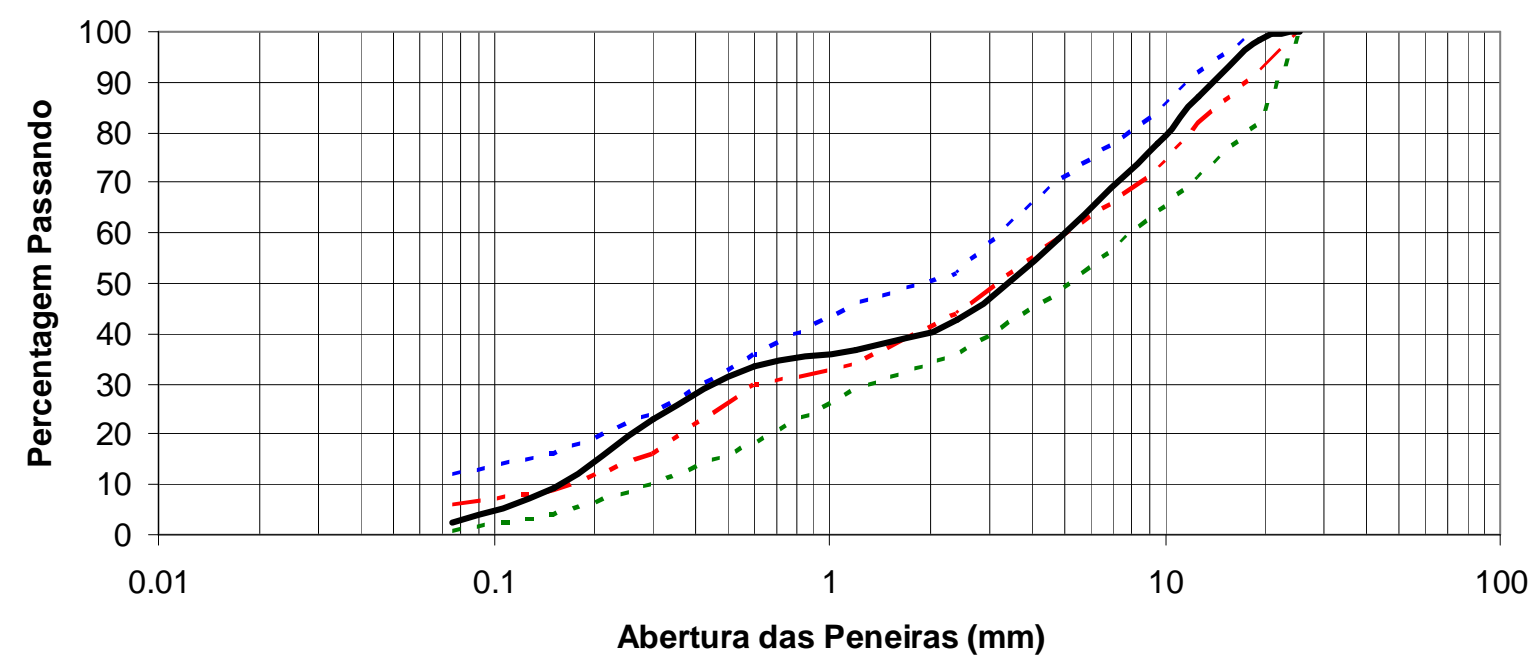

- - - - Faixa Superior - - - Faixa Média - - - Faixa Inferior —-Faixa do CCR - AN

Figura 23 - faixa granulométrica do CCR - AN 


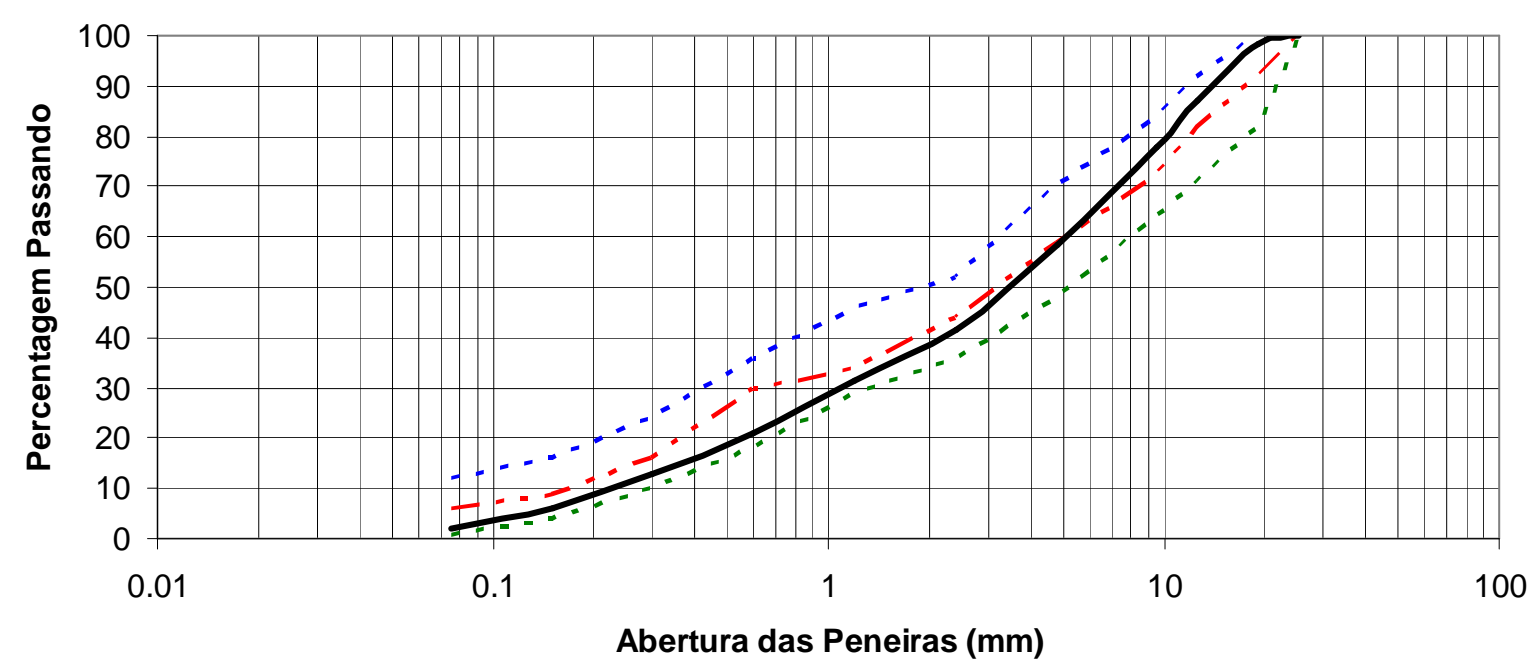

- - - Faixa Superior - - Faixa Média - - - Faixa Inferior — Faixa do CCR - ESC

Figura 24 - faixa granulométrica do CCR - ESC

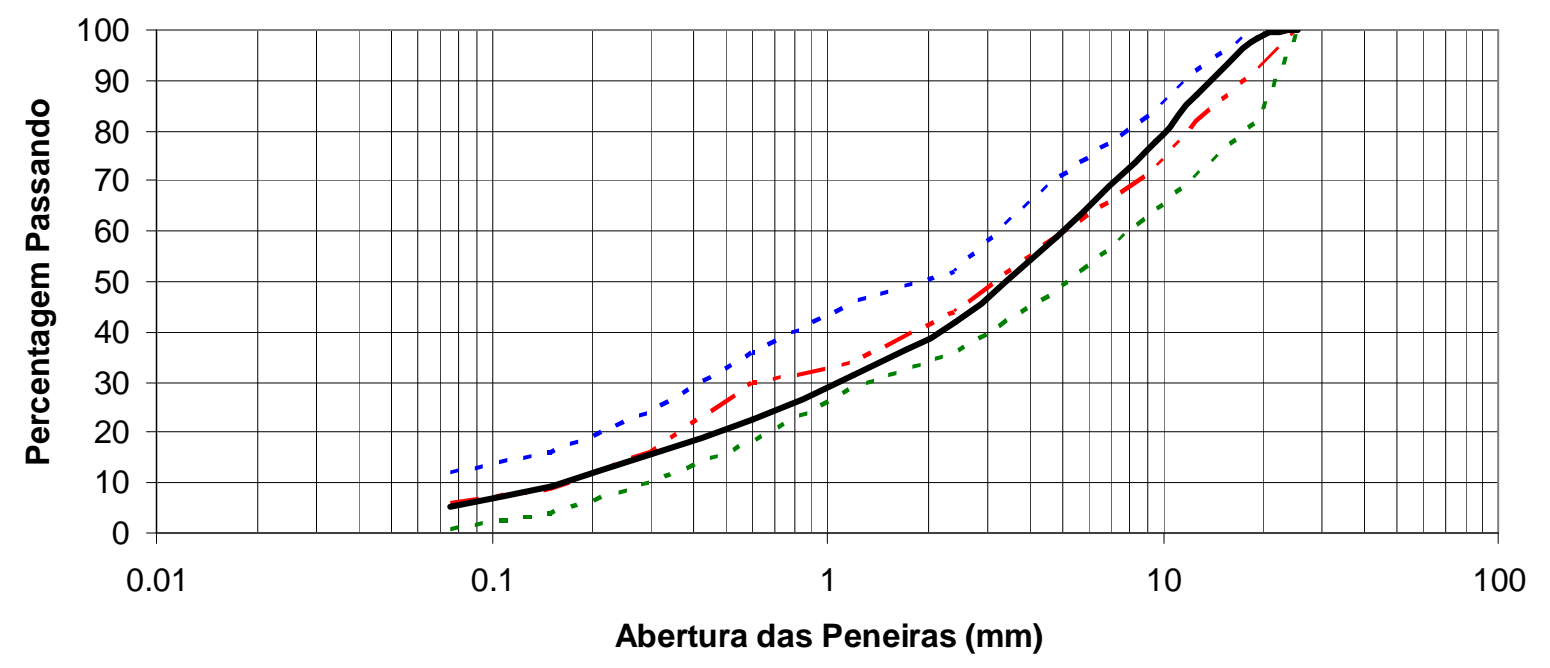

. - - Faixa Superior - - Faixa Média - . - - Faixa Inferior — Faixa do CCR - AlESC

Figura 25 - faixa granulométrica do CCR - Al/ESC 


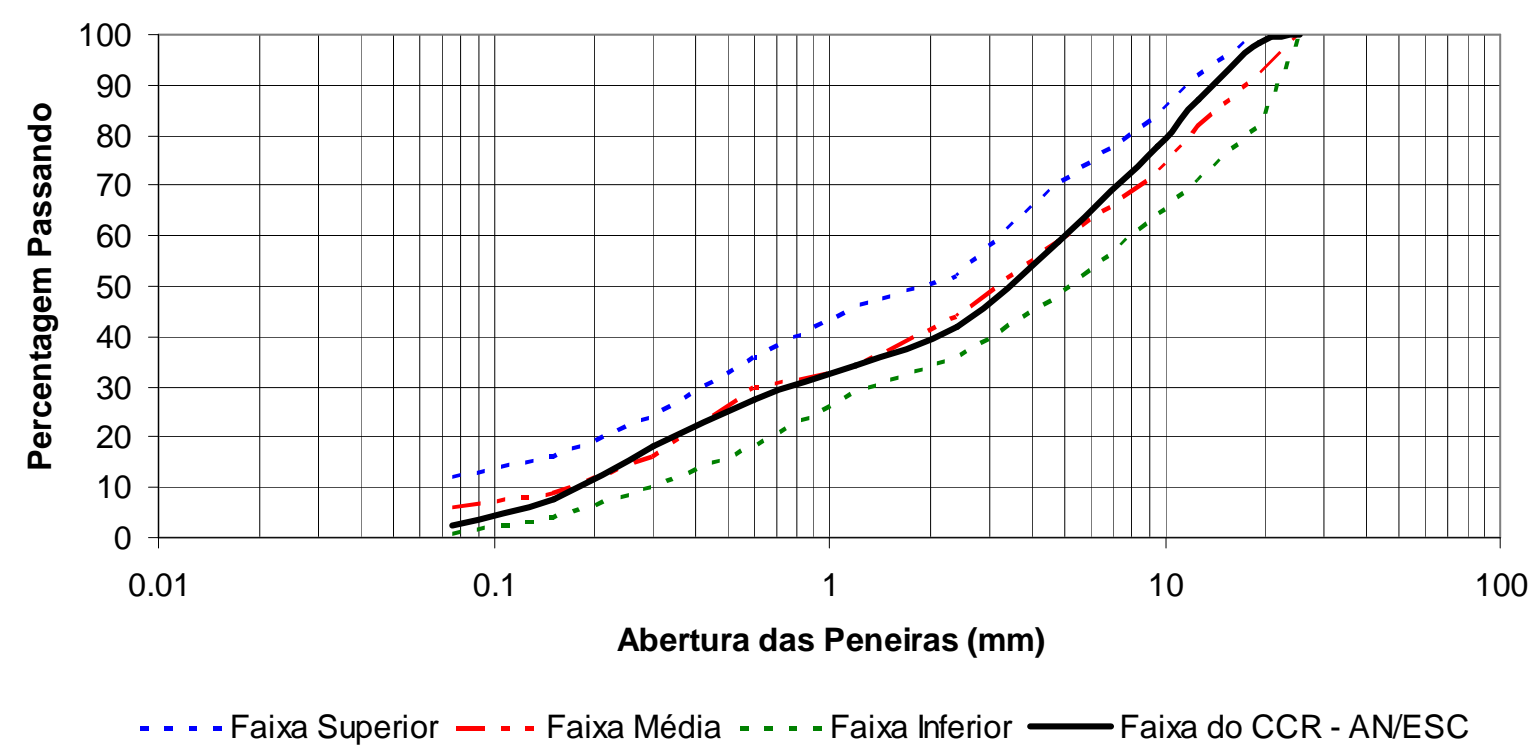

Figura 26 - faixa granulométrica do CCR - AN/ESC

A dosagem dos CCR partiu de ensaios de compactação para a determinação da umidade ótima em corpos de prova cilíndricos com $200 \mathrm{~mm}$ de altura e 100 mm de diâmetro, empregando a energia normal de compactação (593 $\mathrm{kJ} / \mathrm{m}^{3}$ ) distribuída em cinco camadas com soquete de $2.510 \mathrm{~g}$ e altura de queda livre de $300 \mathrm{~mm}$.

Para determinação da curva de massa específica em função da quantidade de água, trabalhou-se com valores nominais de umidade entre 5,5\% e 9,5\%, tomando-se no mínimo cinco pontos - a cada ponto percentual - para traçar a curva de compactação. Ainda, foram moldados corpos de prova das misturas de CCR com utilização total do agregado miúdo por areia industrial, areia natural e escória granulada de alto forno no ramo seco da curva de compactação $(1,5 \%$ abaixo da umidade ótima) de modo similar aos confeccionados na umidade ótima de compactação (número e dimensões); isso foi realizado com objetivo de investigar qual o comportamento destes diferentes materiais em relação à quantidade de água utilizada e sua relação com parâmetros mecânicos do CCR. 


\subsection{PREPARAÇÃO DAS AMOSTRAS}

Aplicando-se o CCR como base de pavimentos rodoviários, aeroportuários ou portuários, os esforços atuantes na estrutura serão, principalmente, de tração na flexão. Em vista disto, na presente pesquisa, fixou-se como resistência de projeto 2,5 $\mathrm{MPa}$, obtido pelo ensaio de tração indireta por compressão diametral (padrão de resistência adequado para base de pavimentos em CCR). Para tanto, foram utilizados consumos de cimento de 90,110 e $130 \mathrm{~kg} / \mathrm{m}^{3}$ no CCR - Al, a fim de buscar qual o consumo mínimo para o critério de resistência especificado. A idade preconizada inicialmente foi 28 dias; contudo, no início dos ensaios da primeira dosagem realizada houve problemas operacionais com a prensa para ruptura dos corpos de prova e esta data foi fixada em 35 dias.

Dois padrões de amostras foram empregados para a moldagem dos corpos de prova de CCR, conforme a NBR 5738 (ABNT, 1994a): prismático $-\mathrm{p}-(100 \mathrm{x}$ $\left.100 \times 400 \mathrm{~mm}^{3}\right)$ e cilíndrico - c - (100 mm x $200 \mathrm{~mm}$ : diâmetro x altura); sendo confeccionados seis exemplares por tipo de corpo de prova (Figuras 27 e 28). Esta especificação recomenda a utilização de corpos de prova prismáticos de $150 \times 150$ x $500 \mathrm{~mm}^{3}$; todavia, de acordo com adendo normativo baseado no estudo desenvolvido por Cervo (2004), há possibilidade de utilização destas dimensões reduzidas sem necessidade de fatores de correção, pois testes estatísticos conduzidos por esta autora confirmaram não existir diferença significativa entre ambos os corpos de prova. Ressaltam-se, assim, inúmeras vantagens para a utilização deste tipo de corpo de prova prismático para CCR: menor consumo de materiais, facilidade de manuseio, produtividade e melhor distribuição da energia de compactação, uma vez que esta é realizada manualmente pelo operador e sujeita à fadiga muscular ao longo de inúmeros golpes. 


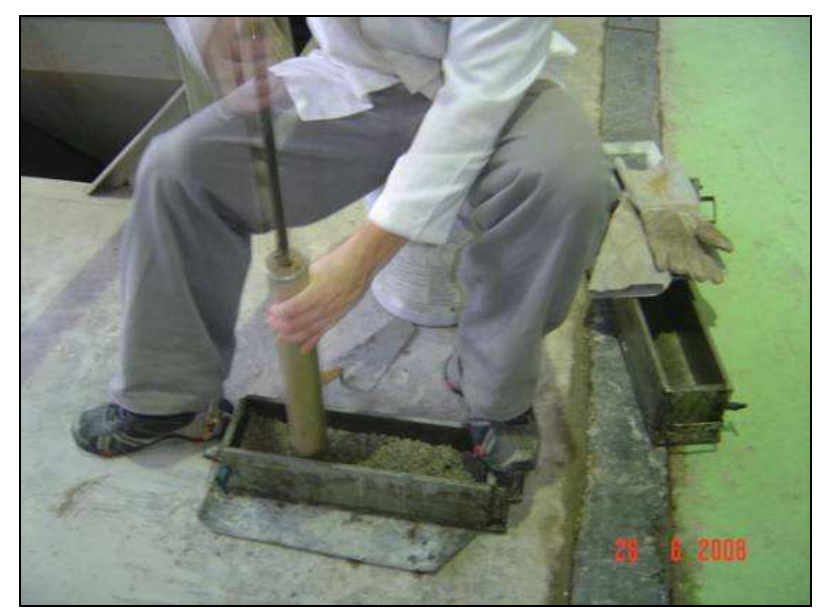

Figura 27 - compactação da primeira camada de CCR - Al em corpo-de-prova prismático

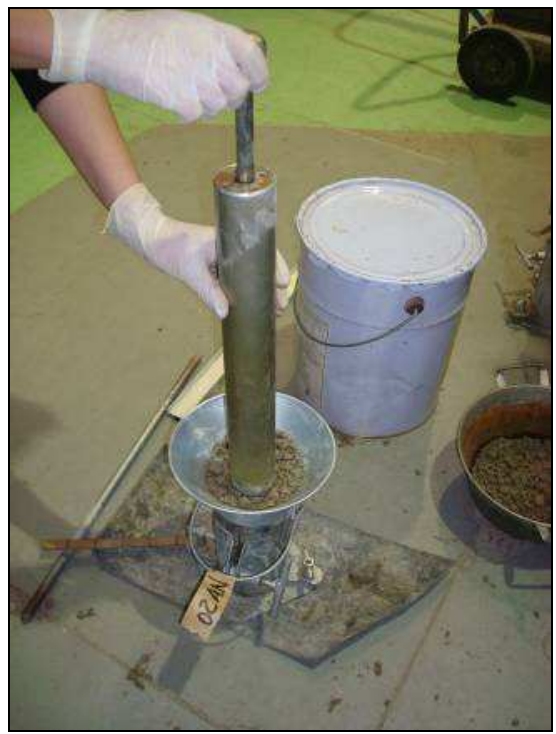

Figura 28 - compactação da última camada de CCR - AN em corpo-de-prova cilíndrico

Durante a preparação dos corpos de prova, foram empregados procedimentos para controle de homogeneidade, compactação e umidade do CCR. A mistura do concreto foi realizada em betoneira fixa industrial - Figura 29 respeitando a quantidade mínima de 30 litros. Procurando padronizar os procedimentos, os primeiros materiais a serem introduzidos na betoneira foram a brita 1 e pedrisco, bem como 1/3 da água de amassamento; após três minutos de mistura e inspeção visual, foram adicionados a areia e/ou escória e o cimento, além de mais $1 / 3$ de água; finalmente, após mais três minutos de mistura e inspeção visual, foi adicionado o restante da água (1/3). O principal critério de avaliação foi a homogeneidade do concreto e inexistência de segregação (Figura 30). 


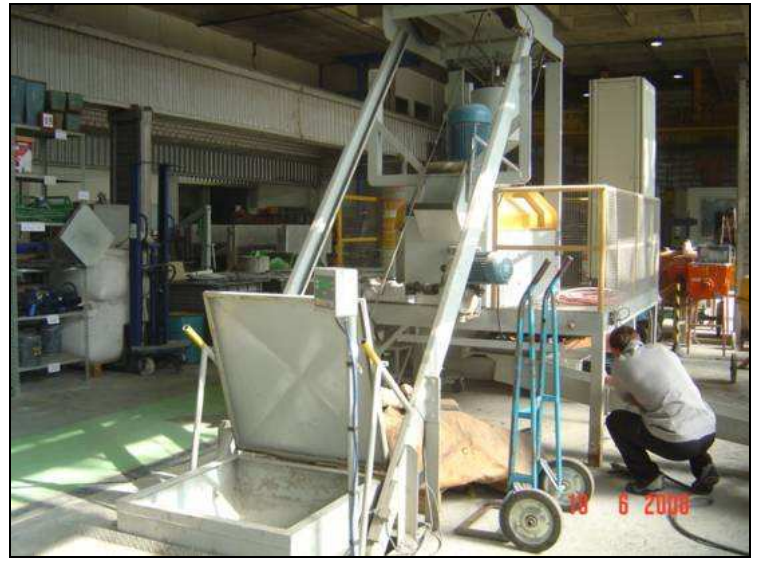

Figura 29 - betoneira industrial utilizada para mistura do CCR

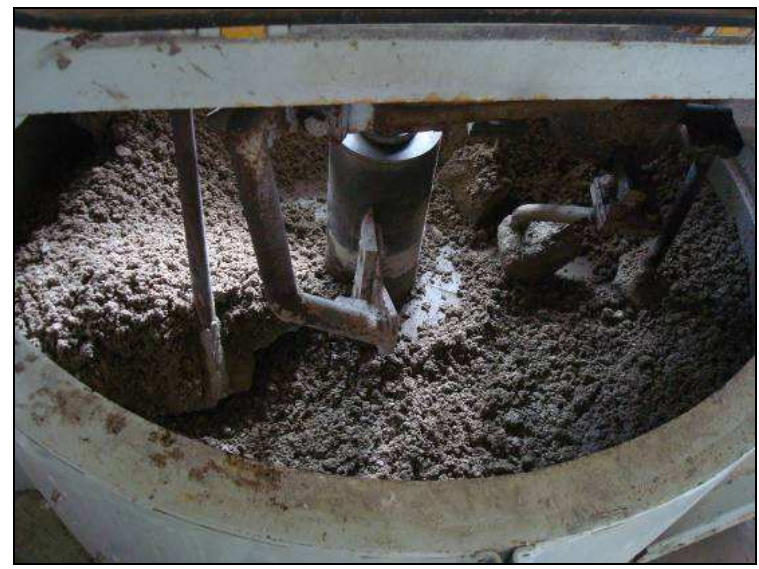

Figura 30 - aspecto visual do CCR - ESC fresco

A energia de compactação se deu de forma homogênea sobre as camadas (Figura 31), a altura das camadas de compactação foi controlada com régua previamente marcada (Figura 32). Para garantir a compacidade da última camada, utilizou-se um dispositivo (gola ou colarinho) para aumentar a altura do molde, de modo a confinar o material e garantir a compactação.

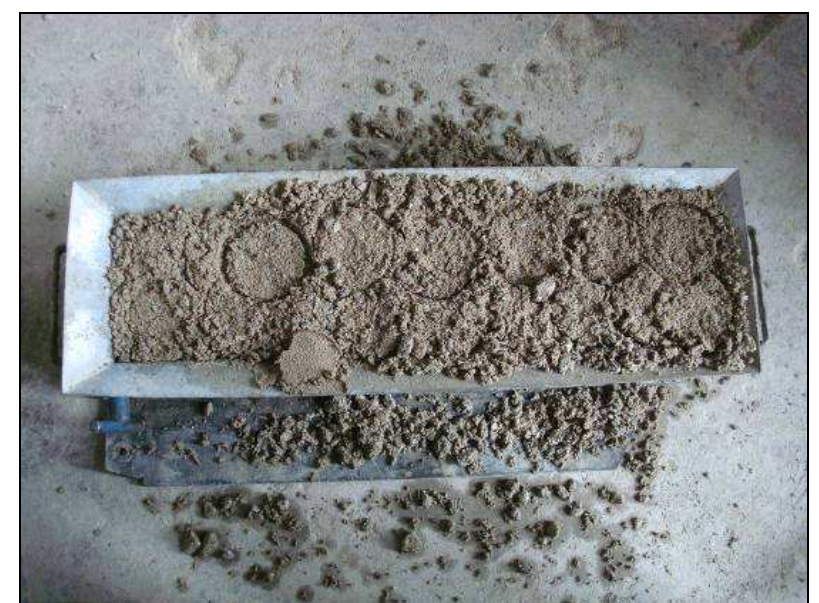

Figura 31 - distribuição da energia de compactação em corpo de prova prismático

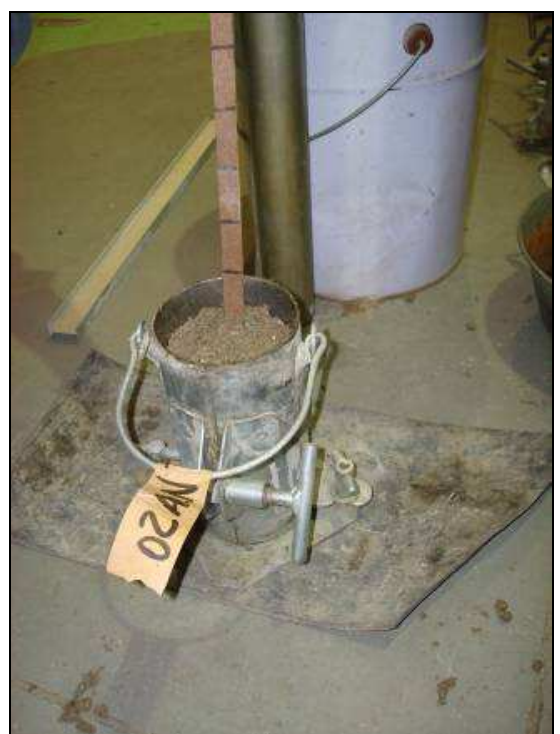

Figura 32 - controle da altura de camada de compactação em corpo de prova cilíndrico 
A fim de verificar a evaporação de água do CCR, durante a confecção dos corpos de prova, foram retiradas amostras de concreto fresco a cada três corpos de prova cilíndricos e a cada dois corpos de prova prismáticos moldados. Estas amostras foram submetidas à estufa durante 24 horas em temperatura de $105^{\circ} \mathrm{C} \mathrm{e}$ posteriormente verificada suas umidades; em geral, a maior discrepância entre a umidade de projeto e a umidade efetiva foi $0,2 \%$.

Devido à superfície rugosa do CCR, a última camada compactada era brevemente desempenada, evitando a presença de desníveis acentuados ou buracos (Figura 33). Assim sendo, ambos os corpos de prova repousavam em local plano protegido com filme plástico durante 48 horas; passado este tempo, eram desmoldados e levados à câmara úmida com temperatura de $23^{\circ} \mathrm{C} \pm 2^{\circ} \mathrm{C}$ e umidade relativa do ar superior a $95 \%$, sendo apenas retirados no momento dos ensaios (massa específica, tensão de ruptura e módulos de elasticidade estático e dinâmico).
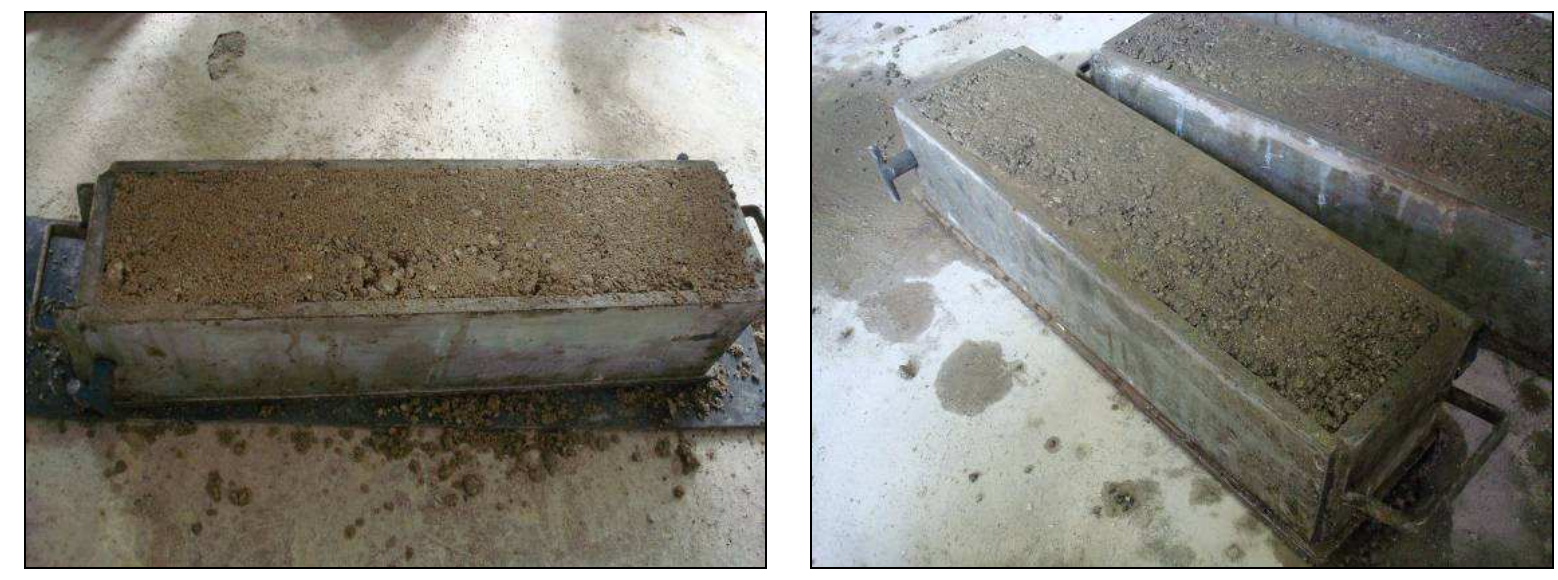

Figura 33 - corpos de prova de CCR após desempenamento: CCR - ESC (esq.) e CCR - Al (dir.)

A massa específica dos corpos de prova (cilíndricos e prismáticos) foi obtida pela relação entre a massa e o volume da amostra. O volume foi mensurado através da média de três leituras de comprimento e altura (corpos de prova prismático) ou altura e diâmetro (corpos de prova cilíndricos), todas estas realizadas com paquímetro. 
Procurando avaliar o grau de compactação de cada camada nos corpos de prova cilíndricos e a influência dos diferentes materiais de fração areia neste, foram serrados 10 corpos de prova cilíndricos das dosagens CCR - AI, CCR - AN e CCR - ESC. As fatias de CCR corresponderam aproximadamente à altura disposta de concreto fresco para compactação $(4 \mathrm{~cm})$ - cinco camadas - conforme Figura 34 . A altura média de cada camada foi obtida pela média de quatro medidas; o diâmetro, por sua vez, foi mensurado pela média de três medidas, ambas realizadas por paquímetro.

O grau de compactação foi obtido através da relação entre as massas específicas da referida camada e a total do corpo de prova.

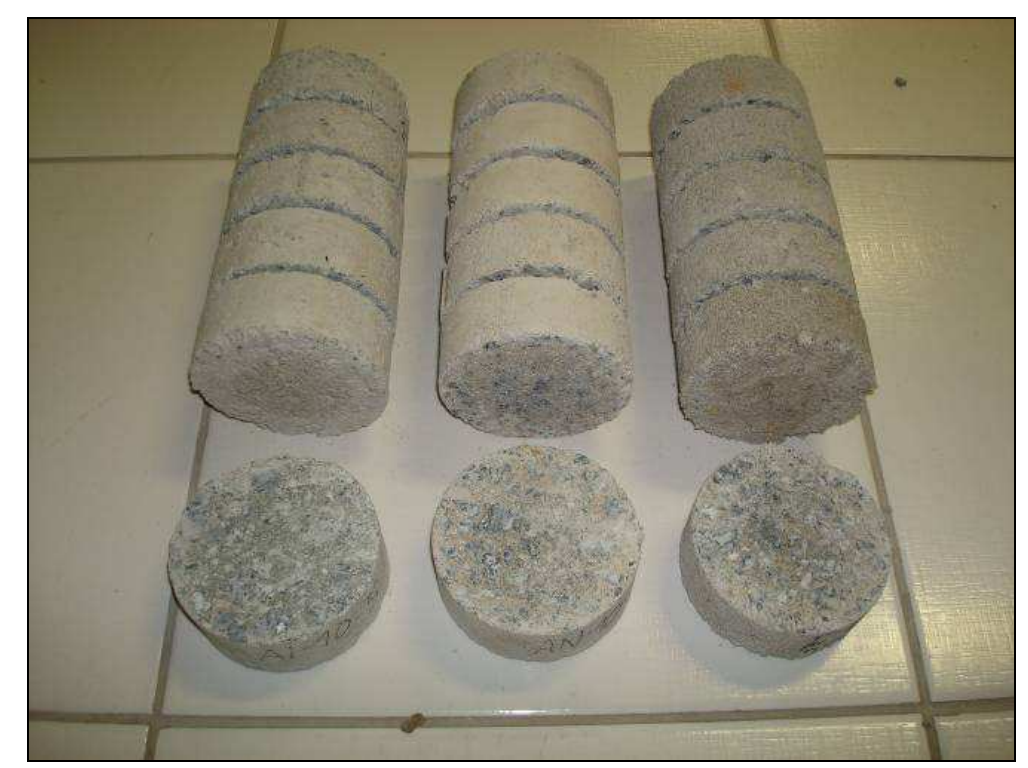

Figura 34 - fatiamento de corpos de prova de CCR para investigação do grau de compactação das camadas

\subsection{ENSAIOS ESTÁTICOS}

As amostras de CCR nos padrões prismáticos e cilíndricos se deram necessárias para aferição de parâmetros estáticos dos concretos entre duas possibilidades de medidas, sendo estas:

- resistência à tração na flexão em vigota; 
- resistência à tração indireta por compressão diametral (ensaio brasileiro);

- módulo de elasticidade em tração na flexão por meio da determinação da flecha (com LVDT) no meio do vão da vigota prismática durante o ensaio de tração na flexão;

- módulo de elasticidade em tração na flexão por meio da determinação da curva tensão $x$ deformação, utilizando straingage de contato para medida da deformação específica de tração;

- módulo de elasticidade em tração indireta, utilizando straingage de contato na zona central tracionada.

O ensaio de compressão simples não foi realizado, devido aos esforços principais na estrutura da camada de pavimento serem à tração na flexão (na fibra inferior); em pavimentação os concretos são normalmente especificados com base em sua resistência à tração quando não armados.

O módulo de elasticidade do concreto, sendo ele plástico ou não, pode ser avaliado de várias maneiras, dentre as quais destacam-se: a interpretação da curva tensão-deformação, por analogia de Möhr, métodos dinâmicos e correlações numéricas com a resistência do concreto.

Assis, Costa e Ferreira (1991b) analisaram correlações propostas por diversos órgãos técnicos - ABNT, Código Britânico da Prática do Uso Estrutural do Concreto $(\mathrm{CB})$, Concrete European British (CEB) e $\mathrm{ACl}$ - entre a resistência à compressão e do módulo de elasticidade do concreto. Ao comparar os resultados em si, nota-se que, no geral, os valores obtidos pela equação proposta pela ABNT foram os maiores e os obtidos pela equação da $\mathrm{ACl}$, os menores. Os autores relatam que estas variações de valores são aceitáveis, estatisticamente, por serem compostas por distintas organizações e o particular tratamento das variáveis envolvidas.

Devido ao fato de que o tipo de agregado graúdo utilizado influencia de maneira diferente a resistência à compressão e o módulo de elasticidade do concreto e tais equações serem propostas para concretos convencionais, os 
resultados obtidos por Assis, Costa e Ferreira (1991b) para concretos lateríticos e calcários não se mostraram confiáveis para a utilização de materiais alternativos.

Segundo Nagato (1983), existem vários conceitos da deformabilidade do concreto baseados na interpretação do diagrama tensão-deformação, definida a partir de ensaios estáticos; o módulo em tangente na origem ou em um dado ponto qualquer e o módulo secante. Para ambos os valores, são necessários, de modo geral, prensas servocontroladas e equipamentos de precisão elevada.

Para concepção dos testes, foi empregada prensa eletrohidráulica - carga máxima de 100 toneladas, divisão do mostrador de 0,01 ff, curso máximo do pistão de $30 \mathrm{~mm}$ e peso bruto aproximado de $250 \mathrm{~kg}$ - comum em laboratórios de controle tecnológico no Brasil e com potencial para ser empregada in situ para ensaios em compressão, tração em compressão diametral e tração na flexão (1 ou 2 cutelos). Para estes casos, são fixados aparatos na estrutura central da prensa a fim de adequá-la às condições geométricas e de carregamento específicas de cada ensaio (Figuras 35 e 36); a velocidade de aplicação de carga é controlada por um relógio analógico, devendo ser calibrada previamente em função do material a ser ensaiado e a velocidade preconizada em norma técnica.

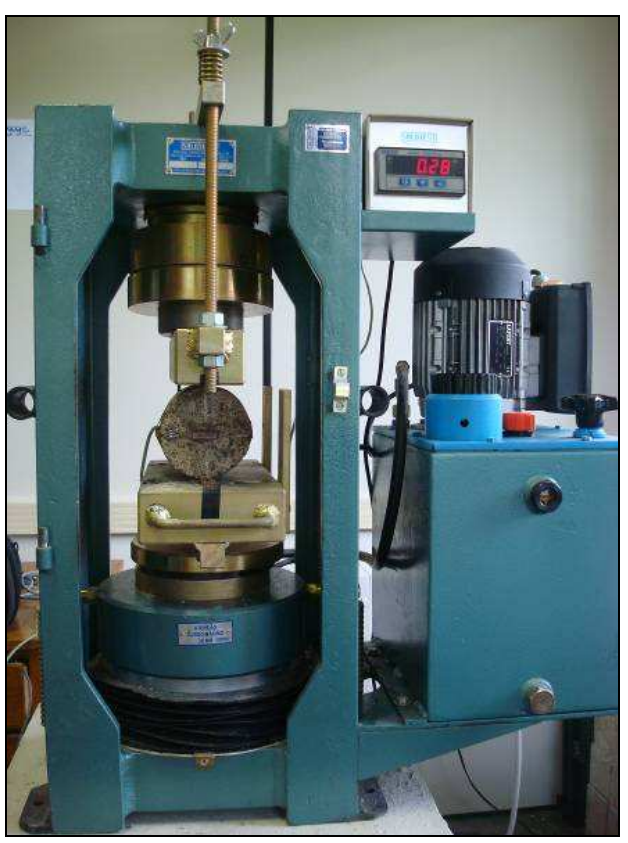

Figura 35 - adequação da prensa para ensaio de tração indireta (inclusive com straingage)

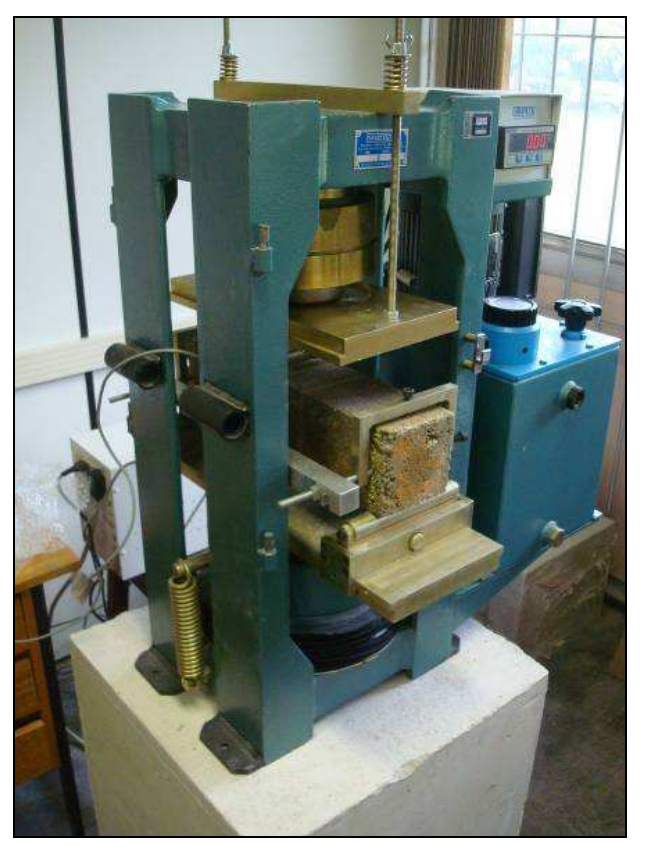

Figura 36 - adequação da prensa para ensaio de tração na flexão (inclusive com LVDT e straingage) 
Devido à necessidade de elevada precisão em relação à carga aplicada, utilizou-se uma célula de carga acoplada na rótula superior para complementação da determinação da força. Ainda, na aferição dos dados de carga, deslocamento do LVDT - linear variable differential transformer - $\left(10^{-6} \mathrm{~mm}\right)$ e deformação do straingage $(\mu \varepsilon)$ foi necessário um equipamento de aquisição de dados (amplificador e condicionador de sinais), conforme mostrado na Figura 37. Este equipamento registra, automaticamente, durante o ensaio, os valores de carga, deformação e deslocamento sofridos pelas amostras de CCR e envia-os para um software que os apresenta graficamente (Figura 38), além de gerar um arquivo texto que pode ser transferido à planilha eletrônica para análises mais detalhadas.

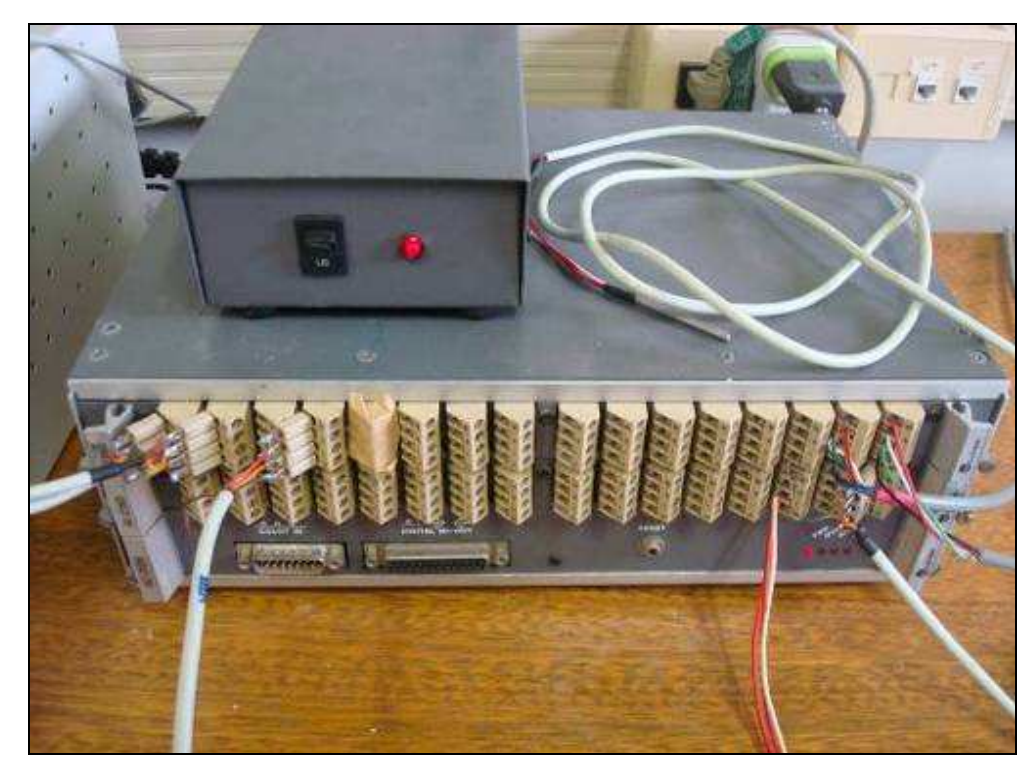

Figura 37 - sistema de aquisição de dados com 32 canais 


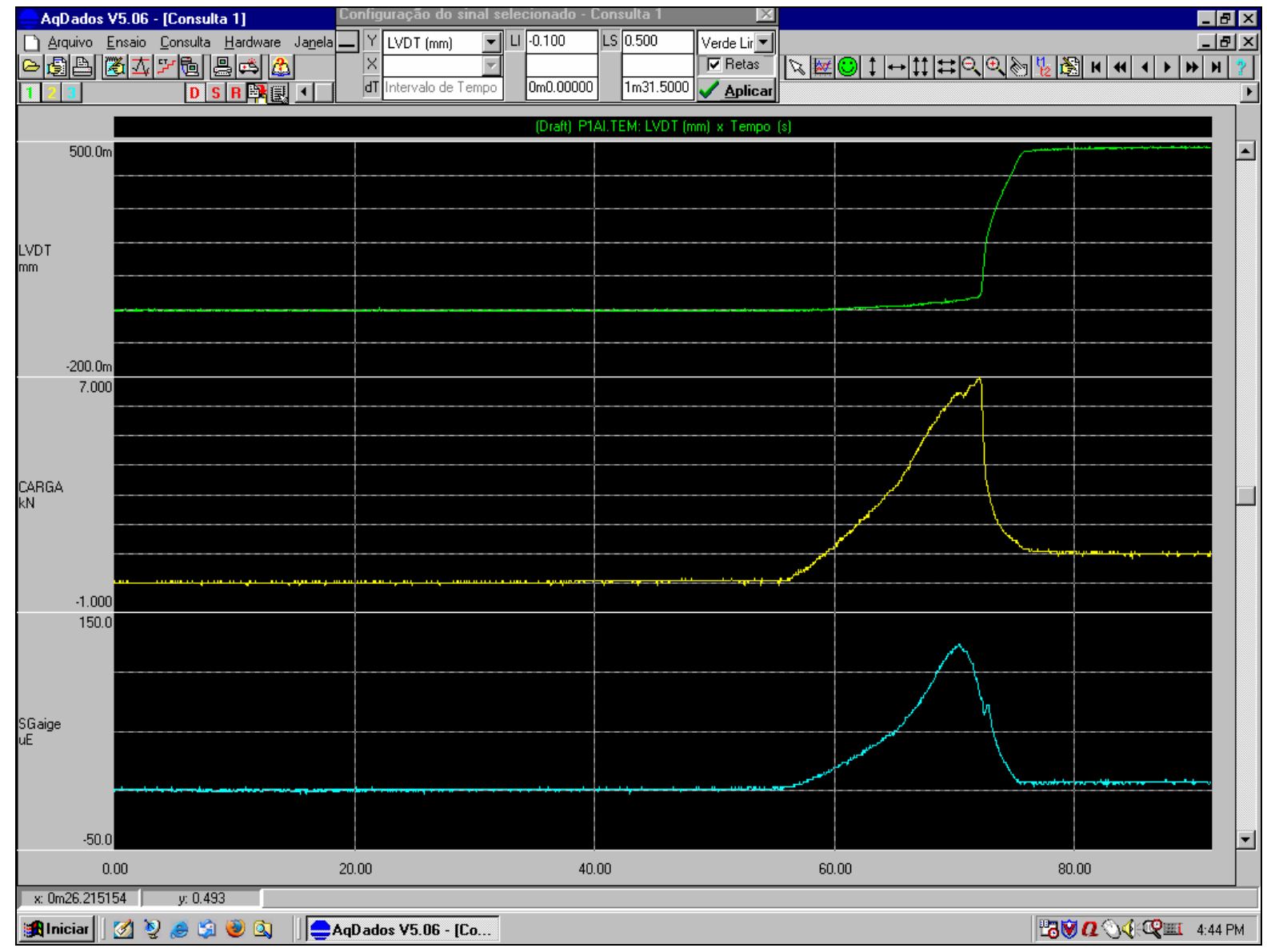

Figura 38 - tela do programa de aquisição de dados AqDados

\subsubsection{Ensaio de tração em compressão diametral}

Este ensaio, preconizado pela NBR 7222 (ABNT, 1994b), foi realizado em corpos de prova cilíndricos para todas as dosagens concebidas, conforme detalhado na Tabela 26.

Tabela 26 - corpos de prova ensaiados à tração indireta (compressão diametral)

\begin{tabular}{ccc}
\hline Idade & Quantidade de amostras & Dosagem \\
\hline 7 dias & 3 & todas \\
35 dias & 6 & todas \\
6 meses & 6 & CCR - Al, CCR - AN e CCR - ESC \\
\hline
\end{tabular}


O ensaio realizado, aos seis meses de idade dos corpos de prova, procurou detectar possíveis ganhos de resistência adicionais pelo emprego total da escória granulada de alto forno, já que ao ser moída e adicionada ao clínquer ou ativadores, apresenta propriedades cimentícias. A compactação enérgica, possível moagem de partículas e o grau de vitrificação podem condicionar a atividade hidráulica da escória com produtos da hidratação do cimento Portland (hidróxido de cálcio) em meio alcalino, ao longo de idades avançadas.

$\mathrm{Na}$ busca da dosagem do CCR que atendesse à resistência especificada, não houve medida de módulo de elasticidade. Depois de dosado, para os demais CCR, foi colado um straingage de contato na superfície média tracionada do corpo de prova e obtida a deformação em tração.

A medida de deformação permitiu, por meio da instrumentação eletrônica do ensaio, a leitura de pares conjugados e simultâneos no tempo de valores de carga e deformação, o que levou a construção de curvas tensão $x$ deformação (Figura 39), determinando-se posteriormente (por regressão linear) os valores de módulo de elasticidade do material para o nível de tensão aplicada de $5 \%$ até $70 \%$ da tensão de ruptura de cada amostra. Apresenta-se, na Tabela 27, um exemplo de dados do arquivo de saída do programa AqDados, Observa-se que a instrumentação eletrônica inicia o registro de tempo, carga e deformação antes mesmo da atuação da carga, pois é acionada manualmente (prensa não servocontrolada).

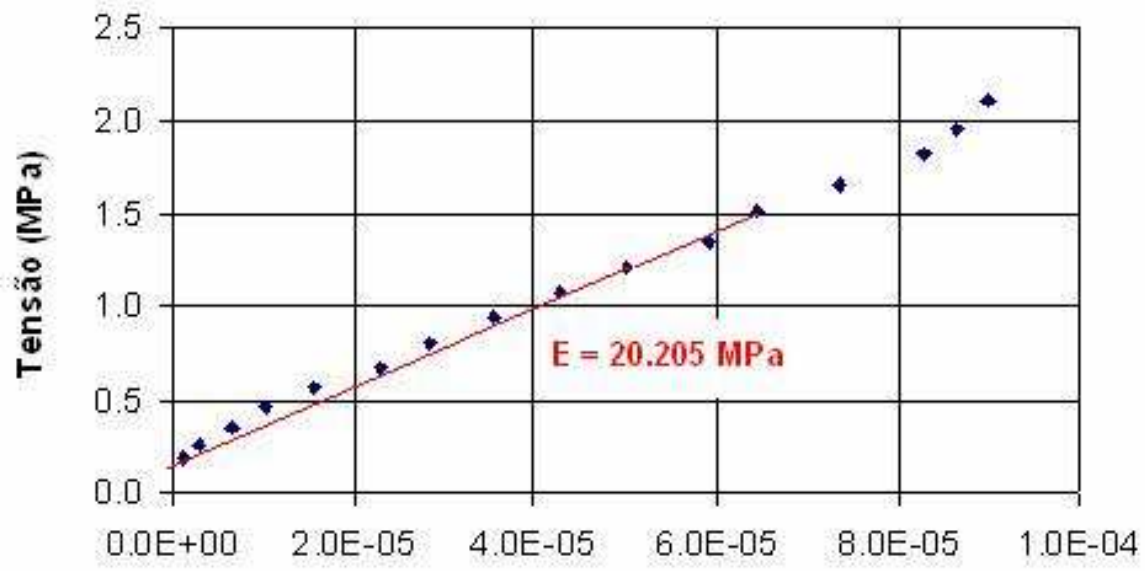

Deformação $(\mathrm{mm} / \mathrm{mm})$

Figura 39 - determinação da curva tensão x deformação e módulo de elasticidade (CCR - Al/ESC) 
Tabela 27 - exemplo de aquisição de dados após tratamento em planilha eletrônica para o ensaio de tração em compressão diametral (CCR - Al/ESC)

\begin{tabular}{cccccc}
\hline $\begin{array}{c}\text { Data } \\
\text { (dd/mm/aa) }\end{array}$ & $\begin{array}{c}\text { Hora } \\
\text { (hh:mm:ss) }\end{array}$ & $\begin{array}{c}\text { Straingage } \\
(\boldsymbol{\mu} \boldsymbol{\varepsilon})\end{array}$ & $\begin{array}{c}\text { Deformação } \\
(\boldsymbol{\varepsilon})\end{array}$ & $\begin{array}{c}\text { Carga } \\
(\mathbf{t})\end{array}$ & $\begin{array}{c}\text { Tensão } \\
(\mathbf{M P a})\end{array}$ \\
\hline $18 / 11 / 08$ & $10: 49: 30$ & $-2,47 \mathrm{E}+00$ & $-2,47 \mathrm{E}-06$ & $-1,14 \mathrm{E}-01$ & 0,00 \\
18/11/08 & $10: 49: 31$ & $-2,47 \mathrm{E}+00$ & $-2,47 \mathrm{E}-06$ & $-2,51 \mathrm{E}-02$ & 0,00 \\
18/11/08 & $10: 49: 32$ & $-2,47 \mathrm{E}+00$ & $-2,47 \mathrm{E}-06$ & $6,39 \mathrm{E}-02$ & 0,00 \\
18/11/08 & $10: 49: 33$ & $-4,29 \mathrm{E}+00$ & $-4,29 \mathrm{E}-06$ & $3,31 \mathrm{E}-01$ & 0,01 \\
18/11/08 & $10: 49: 34$ & $-4,29 \mathrm{E}+00$ & $-4,29 \mathrm{E}-06$ & $7,76 \mathrm{E}-01$ & 0,02 \\
18/11/08 & $10: 49: 35$ & $-6,10 \mathrm{E}+00$ & $-6,10 \mathrm{E}-06$ & $1,58 \mathrm{E}+00$ & 0,05 \\
18/11/08 & $10: 49: 36$ & $-4,29 \mathrm{E}+00$ & $-4,29 \mathrm{E}-06$ & $2,65 \mathrm{E}+00$ & 0,08 \\
18/11/08 & $10: 49: 37$ & $-6,63 \mathrm{E}+00$ & $-6,63 \mathrm{E}-06$ & $3,98 \mathrm{E}+00$ & 0,13 \\
18/11/08 & $10: 49: 38$ & $1,15 \mathrm{E}+00$ & $1,15 \mathrm{E}-06$ & $5,76 \mathrm{E}+00$ & 0,18 \\
18/11/08 & $10: 49: 39$ & $2,96 \mathrm{E}+00$ & $2,96 \mathrm{E}-06$ & $8,07 \mathrm{E}+00$ & 0,26 \\
18/11/08 & $10: 49: 40$ & $6,58 \mathrm{E}+00$ & $6,58 \mathrm{E}-06$ & $1,11 \mathrm{E}+01$ & 0,35 \\
18/11/08 & $10: 49: 41$ & $1,02 \mathrm{E}+01$ & $1,02 \mathrm{E}-05$ & $1,43 \mathrm{E}+01$ & 0,46 \\
18/11/08 & $10: 49: 42$ & $1,56 \mathrm{E}+01$ & $1,56 \mathrm{E}-05$ & $1,77 \mathrm{E}+01$ & 0,56 \\
18/11/08 & $10: 49: 43$ & $2,29 \mathrm{E}+01$ & $2,29 \mathrm{E}-05$ & $2,12 \mathrm{E}+01$ & 0,68 \\
18/11/08 & $10: 49: 44$ & $2,83 \mathrm{E}+01$ & $2,83 \mathrm{E}-05$ & $2,53 \mathrm{E}+01$ & 0,80 \\
18/11/08 & $10: 49: 45$ & $3,56 \mathrm{E}+01$ & $3,56 \mathrm{E}-05$ & $2,95 \mathrm{E}+01$ & 0,94 \\
18/11/08 & $10: 49: 46$ & $4,28 \mathrm{E}+01$ & $4,28 \mathrm{E}-05$ & $3,39 \mathrm{E}+01$ & 1,08 \\
18/11/08 & $10: 49: 47$ & $5,00 \mathrm{E}+01$ & $5,00 \mathrm{E}-05$ & $3,82 \mathrm{E}+01$ & 1,22 \\
18/11/08 & $10: 49: 48$ & $5,91 \mathrm{E}+01$ & $5,91 \mathrm{E}-05$ & $4,28 \mathrm{E}+01$ & 1,36 \\
18/11/08 & $10: 49: 49$ & $6,45 \mathrm{E}+01$ & $6,45 \mathrm{E}-05$ & $4,78 \mathrm{E}+01$ & 1,52 \\
18/11/08 & $10: 49: 50$ & $7,36 \mathrm{E}+01$ & $7,36 \mathrm{E}-05$ & $5,24 \mathrm{E}+01$ & 1,67 \\
18/11/08 & $10: 49: 51$ & $8,26 \mathrm{E}+01$ & $8,26 \mathrm{E}-05$ & $5,73 \mathrm{E}+01$ & 1,82 \\
18/11/08 & $10: 49: 52$ & $8,63 \mathrm{E}+01$ & $8,63 \mathrm{E}-05$ & $6,15 \mathrm{E}+01$ & 1,96 \\
18/11/08 & $10: 49: 53$ & $8,99 \mathrm{E}+01$ & $8,99 \mathrm{E}-05$ & $6,64 \mathrm{E}+01$ & 2,11 \\
18/11/08 & $10: 49: 54$ & $2,67 \mathrm{E}+03$ & $2,67 \mathrm{E}-03$ & $4,43 \mathrm{E}+01$ & 1,41 \\
18/11/08 & $10: 49: 55$ & $2,67 \mathrm{E}+03$ & $2,67 \mathrm{E}-03$ & $2,36 \mathrm{E}+01$ & 0,75 \\
18/11/08 & $10: 49: 56$ & $2,67 \mathrm{E}+03$ & $2,67 \mathrm{E}-03$ & $1,42 \mathrm{E}+01$ & 0,45 \\
18/11/08 & $10: 49: 57$ & $2,67 \mathrm{E}+03$ & $2,67 \mathrm{E}-03$ & $8,34 \mathrm{E}+00$ & 0,27 \\
18/11/08 & $10: 49: 58$ & $2,67 \mathrm{E}+03$ & $2,67 \mathrm{E}-03$ & $6,38 \mathrm{E}+00$ & 0,20 \\
\hline & & & & &
\end{tabular}


Para a determinação da resistência à tração - $f_{c t}-$ no ensaio de compressão diametral foi empregada a equação:

$$
f_{c t}=\frac{2 \cdot P}{\pi \cdot d \cdot h_{c}}
$$

onde:
P: carga aplicada no momento da ruptura;
d: diâmetro do corpo de prova cilíndrico;
$h_{c}$ : altura do corpo de prova cilíndrico.

\subsubsection{Ensaio de tração na flexão (1 cutelo)}

Os ensaios para determinar a resistência à tração na flexão foram realizados conforme a NBR 12142 (ABNT, 1991e), porém com aplicação de carga em apenas um cutelo superior, disposto no meio do vão da vigota de CCR, e apoiado a dois cutelos inferiores (dispostos a cada $20 \mathrm{~mm}$ da borda vertical do corpo de prova). Inicialmente, foi pensado na realização do ensaio de dois cutelos (conforme especificação técnica); entretanto, optou-se pelo ensaio de apenas um cutelo, pois a rótula do aplicador de carga da prensa não apresentava flexibilidade tal que garantisse, de modo confiável, o deslocamento simultâneo de dois cutelos superiores, o que poderia impor aplicação de cargas desiguais entre cutelos. Além disso, o ensaio de um cutelo se mostrou mais adequado pelo fato da superfície de ruptura ser melhor definida (momento fletor máximo), garantindo a leitura de deformação e deslocamento máximo nos corpos de prova nas posições dos instrumentos.

O módulo de elasticidade na tração em flexão do material foi obtido de duas maneiras: (1) por analogia de Möhr, onde era conhecida a força aplicada e o deslocamento (flecha) sofrido no centro do vão da vigota, sendo a aquisição da magnitude da flecha obtida pela instrumentação por LVDT; (2) pela deformação medida no centro da superfície inferior da vigota por meio de straingage de contato. Apresenta-se, nas Figuras 40 e 41, estas duas formas e a disposição dos equipamentos utilizados. 


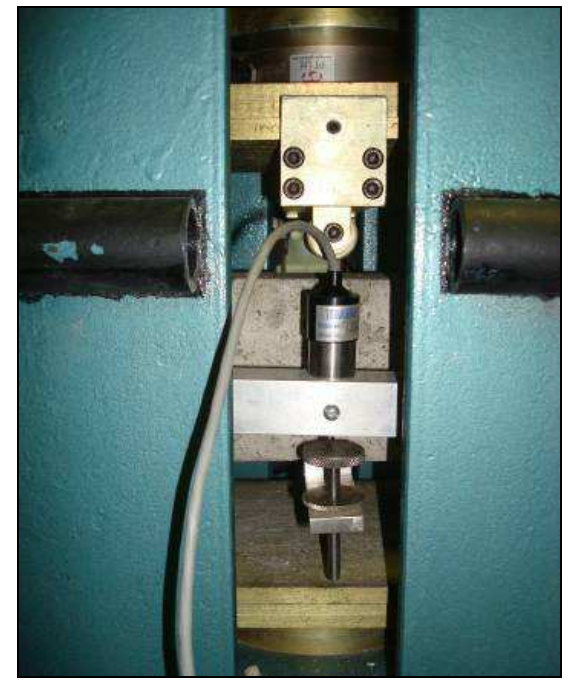

Figura 40 - posicionamento do LVDT no centro do vão da vigota de CCR - AN

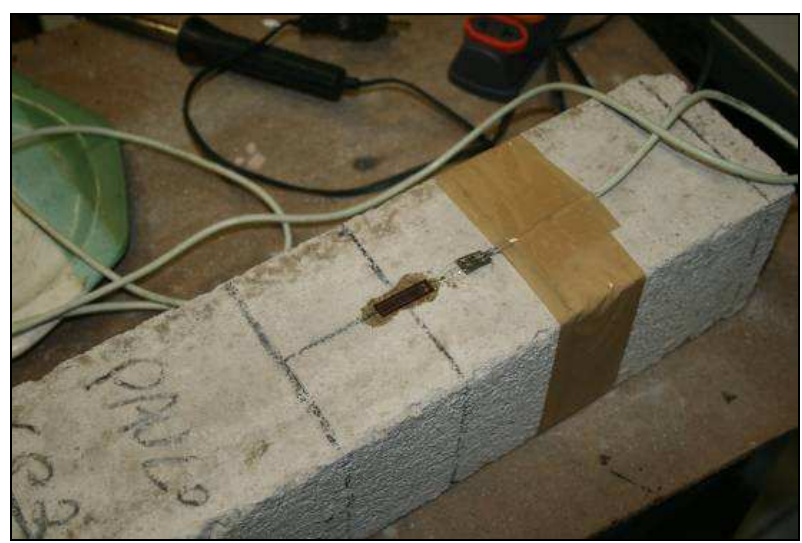

Figura 41 - straingage fixado na face inferior do CCR - AN (em relação à aplicação de carga)

A quantidade de amostras de CCR ensaiadas à tração na flexão, bem como a idade e as dosagens utilizadas estão descritas na Tabela 28.

Tabela 28 - corpos de prova ensaiados à tração na flexão no ensaio de um cutelo

\begin{tabular}{ccc}
\hline Idade & Quantidade de amostras & Dosagem \\
\hline 7 dias & 3 & todas \\
35 dias & 6 & Todas \\
& & (inclusive do ramo seco)
\end{tabular}

A instrumentação eletrônica e aquisição de dados se deram de forma semelhante ao ensaio de tração indireta, sendo, contudo, necessário um canal específico no sistema de aquisição de dados para leitura de deslocamento pelo LVDT. Exemplifica-se, nas Figuras 42 e 43, respectivamente, a determinação da curva tensão $x$ flecha e variação do módulo de elasticidade pelo deslocamento efetivo $x$ tensão; na Tabela 29, é mostrado um exemplo de saída de dados do programa AqDados para este ensaio. Ressalva-se que a obtenção da curva tensão $x$ deformação é similar ao ensaio de tração por compressão diametral. A obtenção 
do módulo de elasticidade, através da analogia de Möhr, empregou valores à 70 \% da flecha máxima, onde tendem a ser constantes.

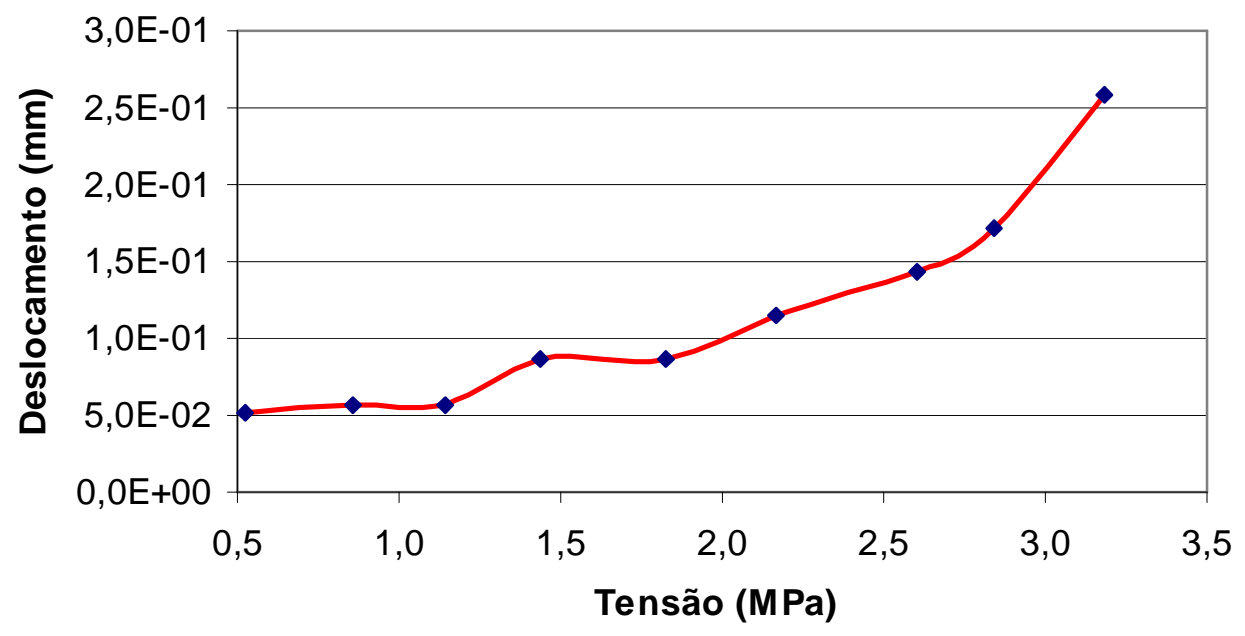

Figura 42 - tensão de tração $x$ flecha no centro do vão (CCR - Al/ESC)

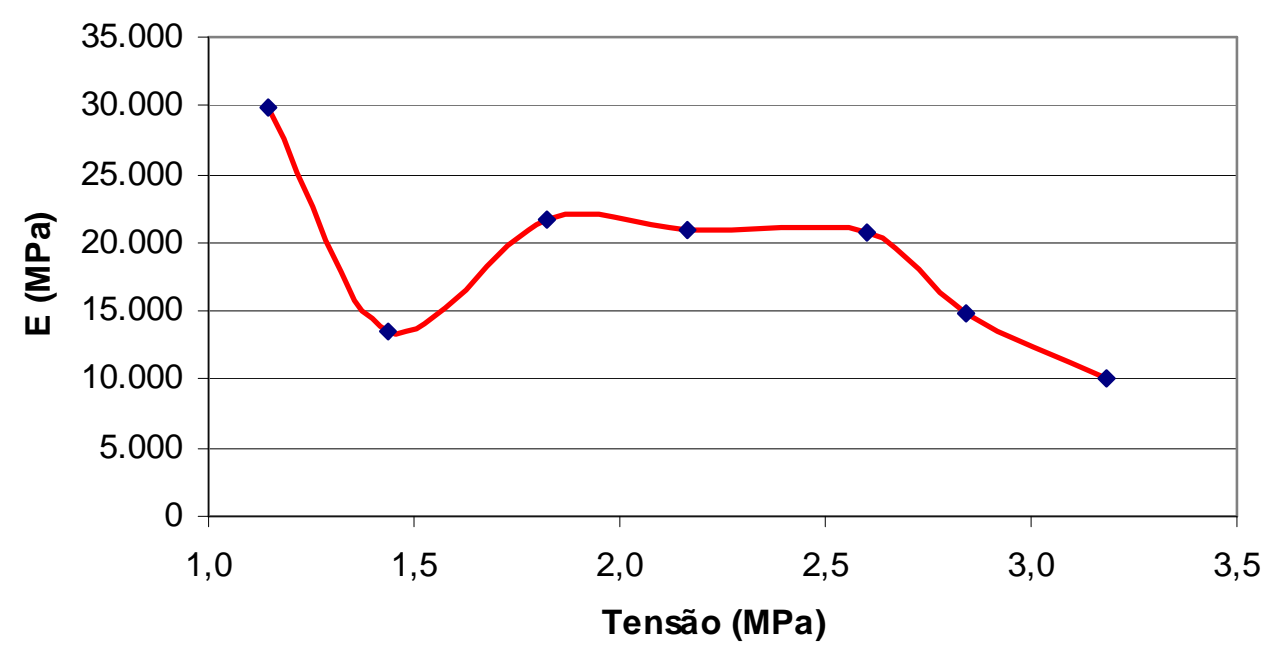

Figura 43 - variação do módulo de elasticidade em tração na flexão (analogia de Möhr) x tensão em tração (CCR - Al/ESC) 
Tabela 29 - exemplo de aquisição de dados após tratamento em planilha eletrônica para o ensaio de tração na flexão (CCR - Al/ESC)

\begin{tabular}{cccccccc}
\hline $\begin{array}{c}\text { Data } \\
(\mathbf{d d} / \mathbf{m m} / \mathbf{a a})\end{array}$ & $\begin{array}{c}\text { Hora } \\
(\mathbf{h h : m m : s s})\end{array}$ & $\begin{array}{c}\text { Straingage } \\
(\boldsymbol{\mu} \boldsymbol{\varepsilon})\end{array}$ & $\begin{array}{c}\text { Deform. } \\
(\boldsymbol{\varepsilon})\end{array}$ & LVDT & $\begin{array}{c}\text { Desloc. } \\
(\mathbf{m m})\end{array}$ & $\begin{array}{c}\text { Carga } \\
(\mathbf{t})\end{array}$ & $\begin{array}{c}\text { Tensão } \\
(\mathbf{M P a})\end{array}$ \\
\hline $27 / 02 / 09$ & $12: 25: 35$ & $2,26 \mathrm{E}+01$ & $2,26 \mathrm{E}-05$ & $-2,86 \mathrm{E}-02$ & 0,0572 & 1,58 & 0,85 \\
$27 / 02 / 09$ & $12: 25: 36$ & $3,23 \mathrm{E}+01$ & $3,23 \mathrm{E}-05$ & $-2,28 \mathrm{E}-02$ & 0,0572 & 2,12 & 1,15 \\
$27 / 02 / 09$ & $12: 25: 37$ & $4,40 \mathrm{E}+01$ & $4,40 \mathrm{E}-05$ & $-2,05 \mathrm{E}-02$ & 0,0858 & 2,66 & 1,44 \\
$27 / 02 / 09$ & $12: 25: 38$ & $5,37 \mathrm{E}+01$ & $5,37 \mathrm{E}-05$ & $-2,00 \mathrm{E}-02$ & 0,0983 & 3,38 & 1,82 \\
$27 / 02 / 09$ & $12: 25: 39$ & $7,13 \mathrm{E}+01$ & $7,13 \mathrm{E}-05$ & $-1,71 \mathrm{E}-02$ & 0,1145 & 4,01 & 2,16 \\
$27 / 02 / 09$ & $12: 25: 40$ & $9,27 \mathrm{E}+01$ & $9,27 \mathrm{E}-05$ & $-1,42 \mathrm{E}-02$ & 0,1431 & 4,81 & 2,60 \\
$27 / 02 / 09$ & $12: 25: 41$ & $1,37 \mathrm{E}+02$ & $1,37 \mathrm{E}-04$ & $-1,14 \mathrm{E}-02$ & 0,1717 & 5,26 & 2,84 \\
$27 / 02 / 09$ & $12: 25: 42$ & $2,25 \mathrm{E}+02$ & $2,25 \mathrm{E}-04$ & $-2,80 \mathrm{E}-03$ & 0,2576 & 5,89 & 3,18 \\
$27 / 02 / 09$ & $12: 25: 43$ & $4,05 \mathrm{E}+03$ & $4,05 \mathrm{E}-03$ & $6,30 \mathrm{E}-02$ & 0,9158 & 2,93 & 1,58 \\
27/02/09 & $12: 25: 44$ & $4,05 \mathrm{E}+03$ & $4,05 \mathrm{E}-03$ & $1,86 \mathrm{E}-01$ & 2,1466 & 2,03 & 1,10 \\
\hline
\end{tabular}

Para a determinação da resistência à tração na flexão $-f_{c t, f}-$ no ensaio de um cutelo, foi empregada a equação:

$$
f_{c t, f}=\frac{3 \cdot P \cdot l}{2 \cdot b \cdot h_{p}{ }^{2}}
$$

onde:

I: comprimento do vão entre os dois apoios;

b: largura da base do corpo-de-prova prismático;

$h_{p}$ : altura do corpo de prova prismático.

A medida do módulo de elasticidade, através da flecha máxima no centro da vigota, por meio da analogia de Möhr, foi obtida através da equação:

$$
E=\frac{P \cdot l^{3}}{4 \cdot f \cdot b \cdot h_{p}{ }^{3}}
$$

onde:

f: deslocamento central da vigota. 


\subsection{ENSAIO DE MÓDULO DE ELASTICIDADE POR PULSO ULTRASSÔNICO}

O ensaio de propagação de onda ultrassônica pode ser considerado um dos mais modernos ensaios não destrutivos, obtendo certo destaque dentre os outros métodos para determinação de vários parâmetros do concreto, tais como: módulo de elasticidade dinâmico, módulo de elasticidade estático, resistência à compressão e resistência à tração; sendo também útil na determinação do grau de compactação de camadas e falhas nas peças de concreto (ASSIS, COSTA e FERREIRA, 1991a).

Komlos et al. (1996) citam que o principio fundamental de especificações técnicas de diversos países como a Alemanha, o Brasil, a Espanha, os EUA e a Inglaterra é o mesmo; este repousa no fato de que as velocidades de propagação de uma vibração em um meio homogêneo e isótropo dependem de constantes elásticas do material, conforme:

onde:

$$
v=\sqrt{\frac{E}{\gamma}}
$$

v: velocidade de propagação de onda;

Y: massa específica.

Segundo Wolle, Costa e Bauer (1973), vários fatores influenciam na velocidade de propagação do som em concretos, dentre eles: idade do concreto, características elastomecânicas, massa específica, tipo de cimento utilizado, fator $\mathrm{A} / \mathrm{C}$, umidade da peça ensaiada, possível existência de aço (concreto armado), direção do ensaio na peça e tipo de adensamento do concreto.

O ensaio de propagação de pulsos ultrassônico não mede diretamente a resistência do concreto; esta é avaliada a partir de correlações. Porém, existe um fator comum que pode proporcionar uma relação entre resistência e velocidade de onda ultrassônica: a massa específica do concreto. A variação da massa específica 
no concreto, a partir de uma dada magnitude, altera a resistência e a velocidade do pulso pelo meio.

O pulso ultrassônico é gerado por um transdutor eletroacústico que ligado a um circuito eletrônico recebe um estímulo para oscilar mecanicamente na sua frequência natural, da ordem de $20 \mathrm{kHz}$ a $250 \mathrm{kHz}$. Este transdutor, portanto, transforma pulsos eletrônicos em ondas vibratórias de energia mecânica, transmitindo-as por contato superficial ao longo da peça ensaiada, utilizando para calibração um bastão metálico (Figura 44). A recepção dos sinais dos pulsos se dá por outro transdutor localizado no outro extremo do corpo de prova. Este realiza a transformação de energia mecânica recebida em eletrônica, que é enviada para um circuito medidor de tempo (HAMASSAKI, 1987).

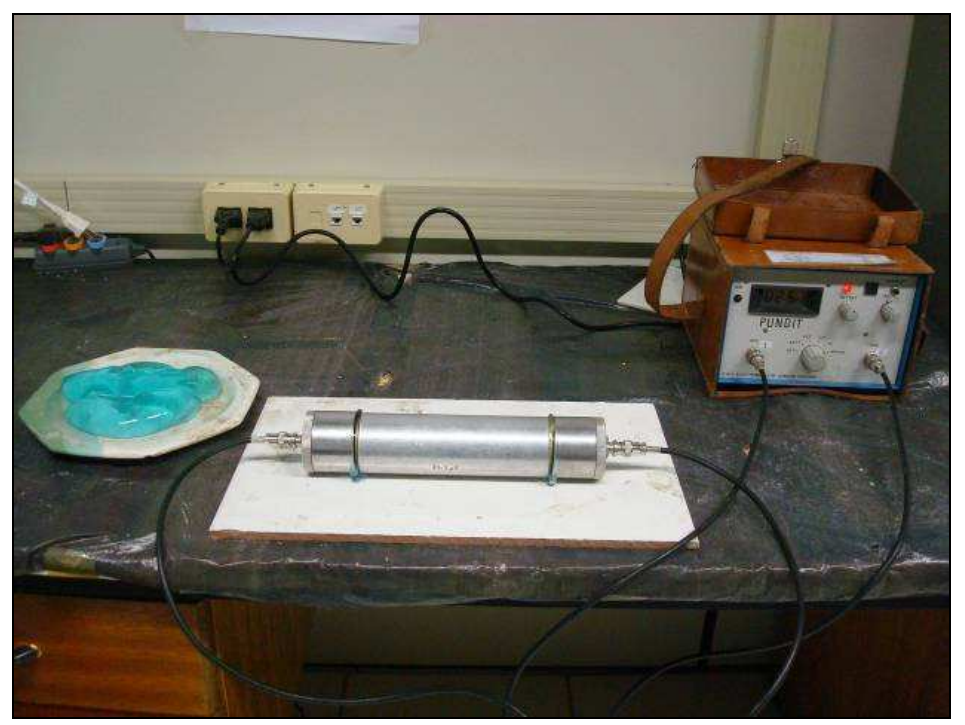

Figura 44 - calibração do equipamento pundit para obtenção do módulo de elasticidade por pulso ultrassônico

Depois de preparados e curados, na idade de ruptura, todos os corpos de prova cilíndricos e prismáticos, previamente aos ensaios estáticos destrutivos, foram avaliados quanto ao módulo de elasticidade dinâmico pelo método da velocidade de pulso ultrassônico (Figuras 45 e 46), segundo o projeto normativo CB-18:400.04-008 (ABNT, 2008). 


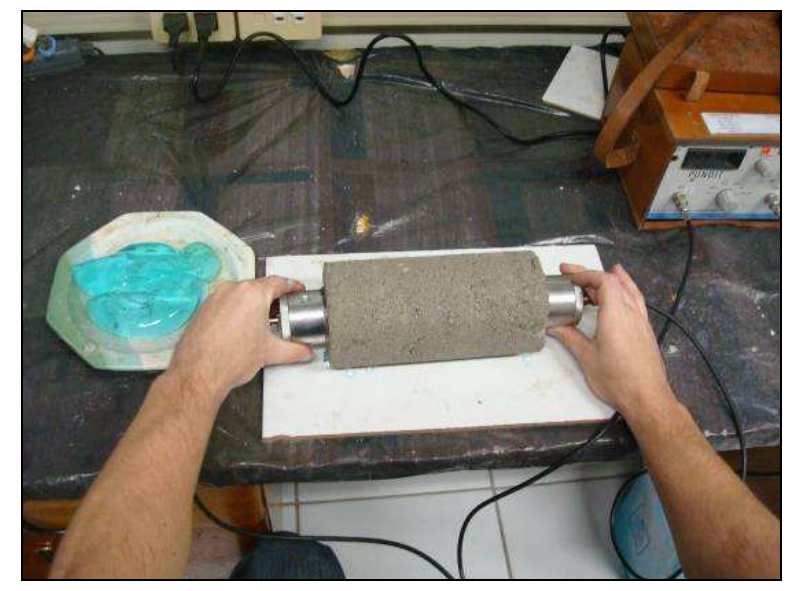

Figura 45 - obtenção do módulo de elasticidade dinâmico em corpo-de-prova cilíndrico $(\mathrm{CCR}-\mathrm{Al})$

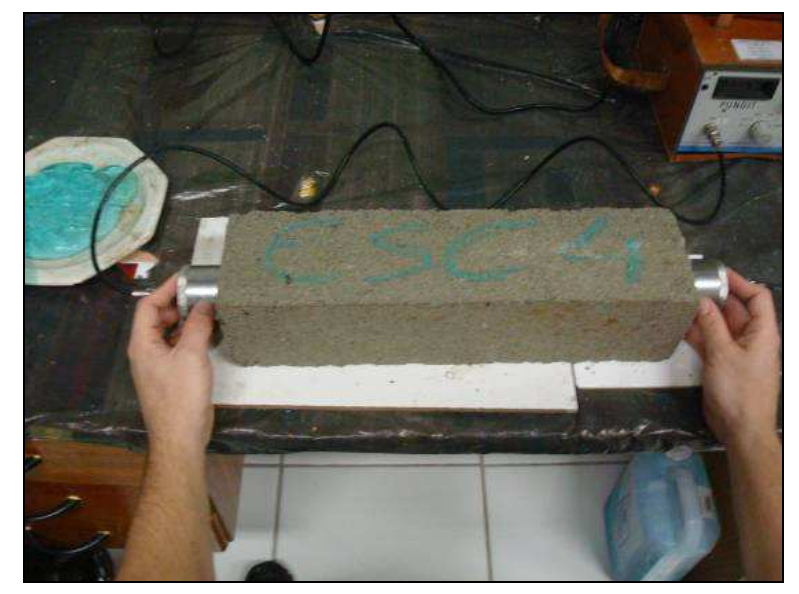

Figura 46 - obtenção do módulo de elasticidade dinâmico em corpo-de-prova prismático (CCR - ESC)

O módulo de elasticidade dinâmico $\left(E_{d}\right)$ foi obtido conforme a equação:

$$
E_{d}=\gamma \cdot v^{2} \cdot \frac{(1+v) \cdot(1-2 v)}{(1-v)}
$$

onde:

v: coeficiente de Poisson

\subsection{ANÁLISE MECANICISTA}

A análise mecanicista de estruturas de pavimentos permite uma melhor compreensão das respostas estruturais das camadas quando solicitadas por cargas oriundas do tráfego ou por agentes externos. Neste caso, emprega-se a teoria de sistemas de camadas elásticas (TSCE), onde se consideram as camadas do pavimento como homogêneas, elásticas e isotrópicas, sendo a Lei de Hooke aplicável aos materiais que as constituem. Assim sendo, é possível determinar os estados de deformação e tensão em vários pontos de cada camada. Conhecidos estes esforços, eles podem, então, ser relacionados com os modelos de 
degradação por fadiga ou por deformação plástica dos materiais de pavimentação (BALBO, 2007).

Ainda, com esta análise, pode-se verificar a compatibilidade entre espessura de projeto versus equipamento de compactação, devendo evitar situações onde a espessura da camada de base do pavimento e os equipamentos de compactação resultem em uma combinação que exija a execução de duas camadas de CCR sobrepostas. Sabe-se que duas camadas não aderidas trabalham com duas linhas neutras e ambas em tração na flexão em suas fibras inferiores; a aderência entre ambas garantiria uma linha neutra no sistema. Contudo, a aderência não se trata, para camadas cimentadas, de uma hipótese satisfatória de projeto, pois se conhece que tal aderência é perdida ao longo dos anos, o que imporia estados críticos de tensões de tração na flexão nessas camadas independentes do CCR. Portanto, as espessuras desejáveis devem ser recomendadas, do ponto de vista de execução em pista, como camada única, o que somente é viável quando há equipamentos que possam fornecer, para espessuras elevadas, o grau de compactação desejado ao material. A compactação do CCR é obtida da superfície para o fundo da camada por rolos metálicos lisos vibratórios, onde a espessura máxima para uma única camada é $400 \mathrm{~mm}$ (equipamento categoria V4: relação entre sua massa estática e o comprimento da geratriz do rolo $-\mathrm{M} / \mathrm{L}-4,5 \mathrm{~kg} / \mathrm{mm}$ apud BALBO, 1993).

Tendo em vista a utilização em média escala de agregados alternativos em camadas de pavimentos, um quesito essencial para a viabilidade econômica do projeto é a distância de transporte do material. Portanto, deve-se aliar a aplicabilidade dos rejeitos industriais nas proximidades das fontes geradoras dos mesmos.

No presente estudo, utilizou-se o programa computacional MnLayer para fins de análise comparativa da influência das cargas do tráfego em camadas de pavimentos rodoviários, portuários e aeroportuários. Para tanto, foram empregadas como base dos pavimentos as misturas de CCR concebidas (CCR - AI, CCR - AN, CCR - ESC, CCR - Al/ESC e CCR - AN/ESC) e seus respectivos valores de resistência à tração e módulo de elasticidade aferido pela curva tensão $x$ deformação em vigota prismática. Para uma perfeita análise, seria necessário o 
desenvolvimento de modelos de fadiga para cada CCR composto, entretanto, como não há objetivos neste aspecto, foi empregada a seguinte relação:

$$
\mathrm{RT}=\frac{\sigma_{1}}{\sigma_{2}}=0,4
$$

onde:

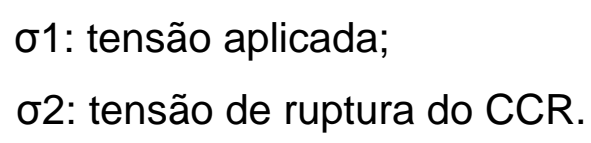

Conforme Cardoso, Pitta e Trichês (1991) e Cervo (2004) esta razão entre tensões - RT - é coerente para um número de repetições do eixo padrão (ciclo de fadiga) na ordem de aproximadamente $10^{6}$ a $10^{7}$ para concreto. $O$ padrão de análise entre estas tensões foi aquele obtido em tração conforme especificado para o estudo.

O programa MnLayer (versão Beta) resolve a TSCE com o auxilio de transformadas diretas e inversas de Hankel, empregando até vinte camadas e dez cargas superficiais. Foi desenvolvido, entre 2006 e 2008, em cooperação entre a Universidade de Minnesota e a Universidade de São Paulo com apoio da Fundação de Amparo à Pesquisa do Estado de São Paulo - FAPESP - (BALBO e KHAZANOVICH, 2007).

\subsubsection{Pavimento rodoviário}

Nas proximidades ou até mesmo no plano interno de indústrias de siderurgia ou de cimento (geradora e consumidora da escória granulada de alto forno), as principais ações do tráfego em camadas de pavimentos rodoviários são oriundas de automóveis, ônibus, caminhões betoneira, caminhões basculantes, caminhões de carroceria, baú e tanque. Assim sendo, em termos de análise do carregamento por eixo destes veículos, foi utilizada a classificação adotada pelo Departamento Nacional de Estradas de Rodagem (DNER, 1998b) que define: 
- veículos leves: carros de passeio, utilitários, furgões e pickups; dois eixos, rodas simples com dois pneumáticos por eixo (4 pneus);

- categoria 2C: ônibus, caminhões leves e médios tendo três eixos: dianteiro de rodas simples e traseiros (tandem duplo ou não) de rodas duplas (10 pneus).

A resolução no 210 do Conselho Nacional de Trânsito (CONTRAN, 2006) estabelece os limites de peso e dimensões para veículos que transitam por vias terrestres. Embasado nisso, a presente análise mecanicista considera para veículos leves uma roda com carga de $5 \mathrm{kN}$ e pressão de inflação do pneu de 0,18 $\mathrm{MPa}$; e para a categoria $2 \mathrm{C}$, eixo traseiro simples com rodas duplas $(20 \mathrm{kN}$ por roda) e pressão de $0,64 \mathrm{MPa}$.

\subsubsection{Pavimento aeroportuário}

Fábricas de cimento e de aço em muitos casos, devido à sua magnitude e natureza de produção, são localizadas em parques industriais ou áreas afastadas de grandes centros populacionais. Um dos quesitos de implantação de novos aeroportos é o afastamento de áreas urbanas devido ao ruído causado, limitação na altura de edificações e riscos inerentes ao tipo de transporte. A implementação ou ampliação de aeroportos em proximidades de estoques de escória granulada de alto forno e devido à geologia local desfavorável à extração de areia, podem ser fatores importantes para a viabilidade técnica e econômica da aplicação deste resíduo como alternativa para a substituição de agregados convencionais utilizados.

Para a análise de esforços solicitantes em pavimentos aeroportuários, foram consideradas duas magnitudes diferentes de aeronaves para aviação executiva e doméstica: um jato executivo Embraer Legacy 600 e um avião do tipo B747 - 400D (Figuras 47 e 48). 


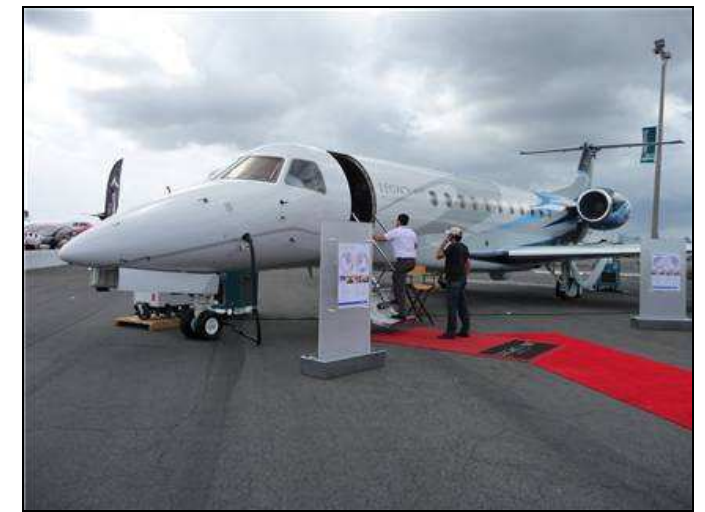

(fonte: EMBRAER)

Figura 47 - jato comercial Legacy 600

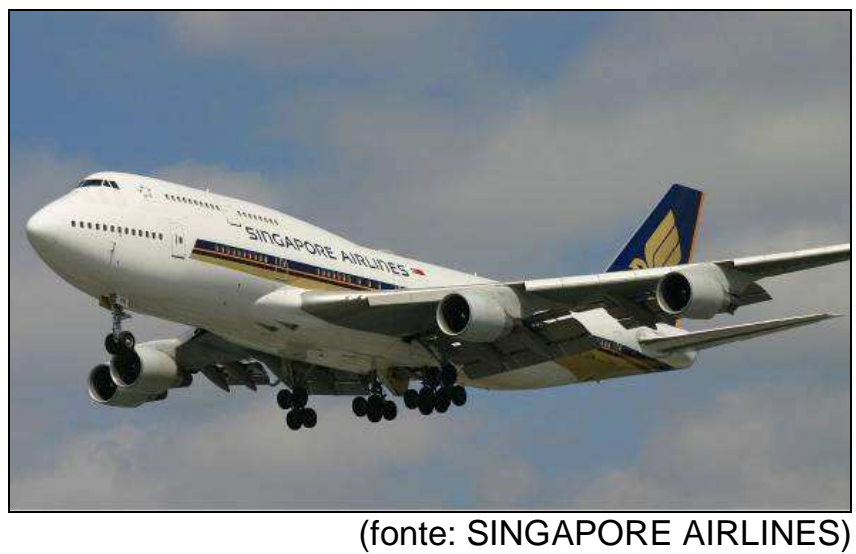

Figura 48 - boeing doméstico 747-400

Em termos de distribuição da carga das aeronaves no pavimento, foi considerado que $95 \%$ desta seja concentrada no trem de pouso principal (main gear) e $5 \%$ no trem de pouso frontal (nose gear). Os principais dados técnicos, referentes às aeronaves consideradas, estão descritos na Tabela 30 e as configurações dos eixos mostradas nas Figuras 49 e 50 (ambas sem escala).

Tabela 30 - características sobre as aeronaves consideradas

\begin{tabular}{ccccc}
\hline Característica & Unidade & Legacy 600 & Boeing 747- 400 D \\
\hline Capacidade & passageiro & 16 & 350 a 450 \\
Envergadura & & 21,17 & 64,4 \\
Comprimento & metro & 26,33 & 70,7 \\
Altura & & 6,76 & 19,4 \\
Peso máximo para decolagem & tonelada & 22,5 & 396,9 \\
Tipo de eixo & - & ESRD & EDRS \\
Carga no eixo & $\mathrm{kN}$ & 63,5 & 661 \\
Pressão no trem de pouso principal & $\mathrm{MPa}$ & & 0,57 & 1,08 \\
Área de contato pneu/pavimento & $\mathrm{cm} 2$ & & $35 \times 17$ & $125 \times 50$ \\
\hline & & & (fontes: EMBRAER e BOEING)
\end{tabular}




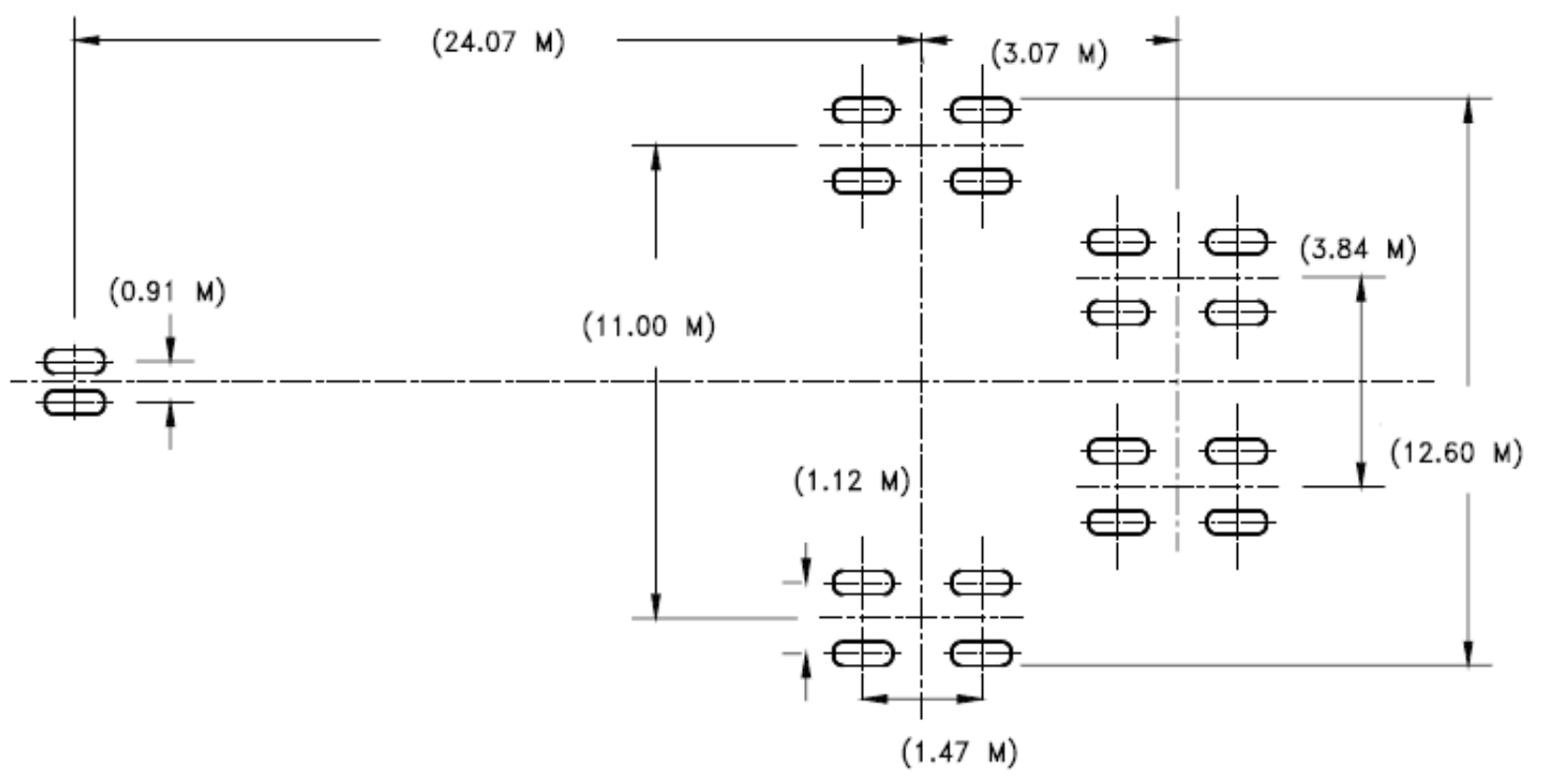

(fonte: BOEING)

Figura 49 - configuração do trem de pouso de um avião B 474 - 400D

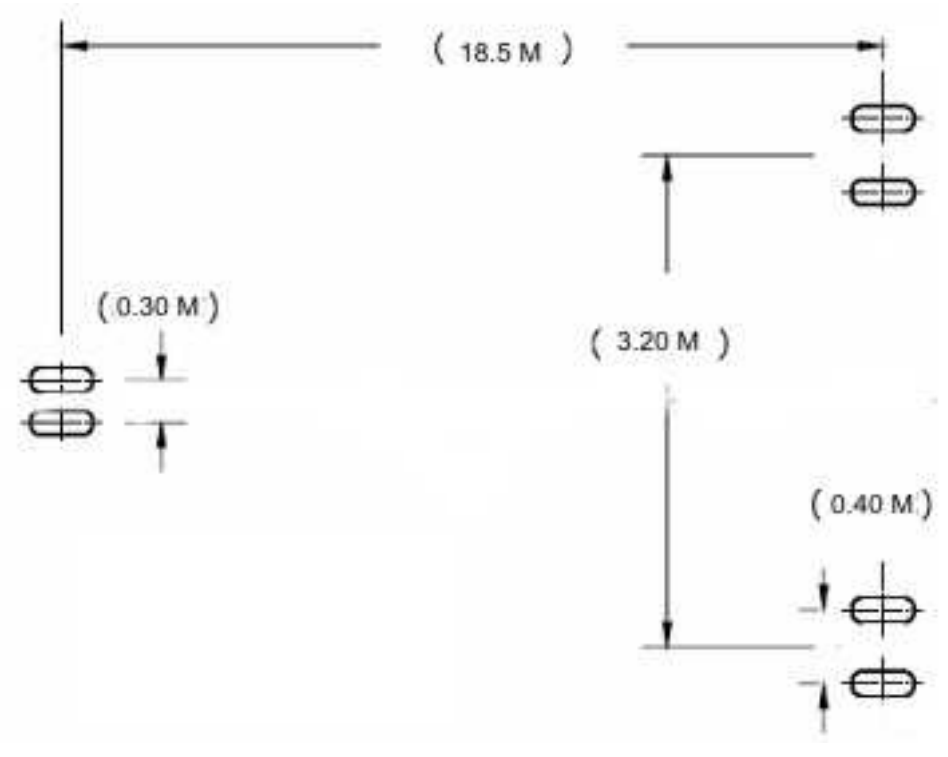

(fonte: EMBRAER)

Figura 50 - configuração do trem de pouso de um jato comercial Legacy 600 


\subsubsection{Pavimento Portuário}

Obras de infraestrutura portuária, como os terminais de contêineres, são um dos elos logísticos de maior importância da cadeia de suprimentos e do comércio internacional, pois estão localizados na fronteira tecnológica entre os países e blocos econômicos e por serem responsáveis pelo escoamento de grande parte da carga manufaturada e semifaturada. Neste sentido, há demanda de construção e manutenção de pavimentos nestas obras, visto a atual conjuntura nacional frente aos países desenvolvidos e às obras do PAC.

Os terminais privativos vêm promovendo uma verdadeira revolução na operação portuária de contêineres no Brasil, através de pesados investimentos em infraestrutura (edificações, cais e vias de acesso) e superestrutura (instalação de modernos equipamentos de movimentação, tais como: portêineres, transtêineres sobre pneus ou trilhos e empilhadeiras de grande porte) (PATRÍCIO e BOTTER, 2004).

As cargas consideradas, neste tipo de pavimento, foram: de um transtêiner pneumático (Figura 51) e de pallets para armazenamento de produtos e matériasprimas (situações típicas de pátios portuários de estocagem), cujas características são apresentadas nas Tabelas 31 e 32.

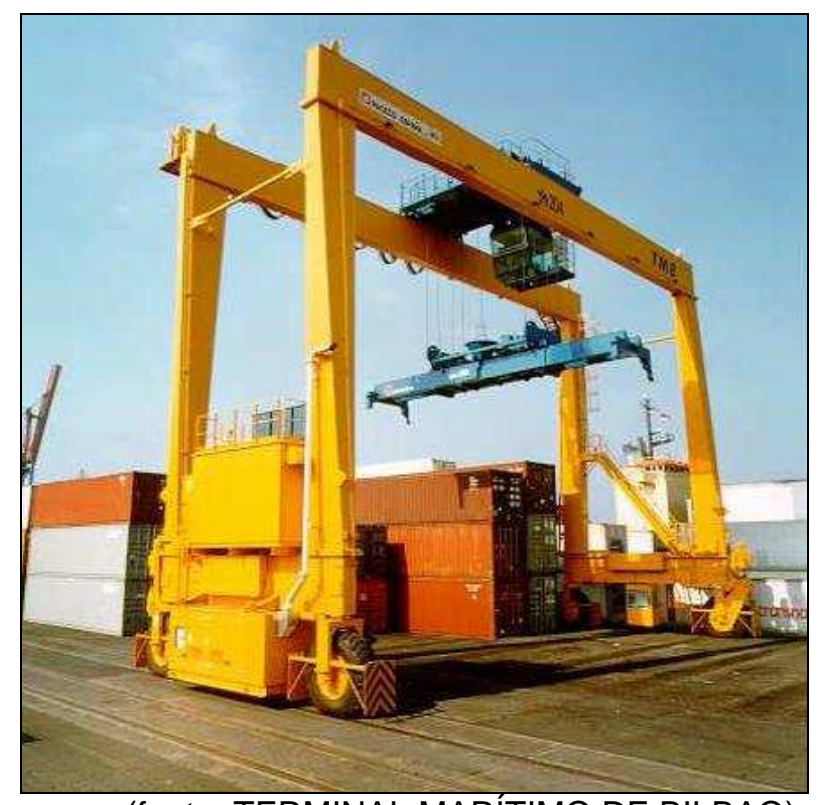

(fonte: TERMINAL MARÍTIMO DE BILBAO)

Figura 51 - grua transtêiner pneumática 
Tabela 31 - características do transtêiner pneumático

\begin{tabular}{ccc}
\hline Característica & Unidade & Transtêiner - RTT4 \\
\hline Fabricação & ano & 2000 \\
Altura de transporte & & 15,24 \\
Altura do pórtico & metro & 18,19 \\
Distância entre eixos & & 22.55 \\
Distância entre rodas & & 10,80 \\
Eixo & - & EDRS \\
Carga no eixo & $\mathrm{kN}$ & 550 \\
Velocidade de içamento & $\mathrm{m} / \mathrm{min}$ & 22 a 52 \\
Velocidade máxima de deslocamento & & 70 \\
Pressão de inflação do pneu & $\mathrm{MPa}$ & 0,94 \\
Área de contato pneu/pavimento & $\mathrm{cm} 2$ & $0,60 \times 0,38$ \\
\hline
\end{tabular}

Tabela 32 - características de pallets para armazenamento (categoria A2-C)

\begin{tabular}{ccc}
\hline Característica & Unidade & Pallet \\
\hline Capacidade & $\mathrm{kN}$ & 55 \\
Empilhamento máximo & & 5 \\
Bases de apoio & & 3 \\
Área de contato base/pavimento & $\mathrm{cm}^{2}$ & $250 \times 30$ \\
\hline
\end{tabular}

\subsubsection{Fatorial de análise}

Procurando aliar fatores construtivos e econômicos, mostram-se, na Tabela 33, as combinações de espessuras das camadas de pavimento para as situações anteriormente estabelecidas. Para todos os casos, foram consideradas as seguintes constantes:

- Módulo de resiliência do Concreto Betuminoso Usinado a Quente (CBUQ): $6.000 \mathrm{MPa}$;

- Poisson do CBUQ: 0,32;

- Módulo de resiliência do subleito: $150 \mathrm{MPa}$;

- Poisson do subleito: 0,49; 
- Módulo de elasticidade da base cimentada: conforme análise laboratorial das misturas de CCR concebidas;

- Poisson dos CCR: 0,20.

Tabela 33 - fatorial de análise para pavimentos com base em CCR

\begin{tabular}{ccc}
\hline \multirow{2}{*}{ Pavimento } & Utilização & $\begin{array}{c}\text { Espessura do Revestimento } \\
(\mathbf{m m})\end{array}$ \\
\hline \multirow{2}{*}{ Rodoviário } & estacionamento para automóveis & 0 \\
& vias urbanas e industriais & 30 \\
\multirow{2}{*}{ Aeroportuário } & estacionamento de aeronaves executivas & 30 e 60 \\
& estacionamento de aeronaves domésticas & $30,60,100,120,150$ e 200 \\
\multirow{2}{*}{ Portuário } & terminal de contêineres & $30,60,100,150$ e 200 \\
& pátio de estocagem & 0,30 e 60 \\
\hline
\end{tabular}

Assim sendo, foram investigadas quais consequências da utilização integral ou parcial de escória granulada de alto forno no nível de tensões na borda inferior da camada de base do pavimento e qual o incremento em sua espessura para uma mesma razão de tensões entre diferentes misturas de CCR.

\subsection{FLUXOGRAMA}

Ilustra-se, na Figura 52, o fluxograma de resumo da metodologia e ensaios empregados no presente estudo. 


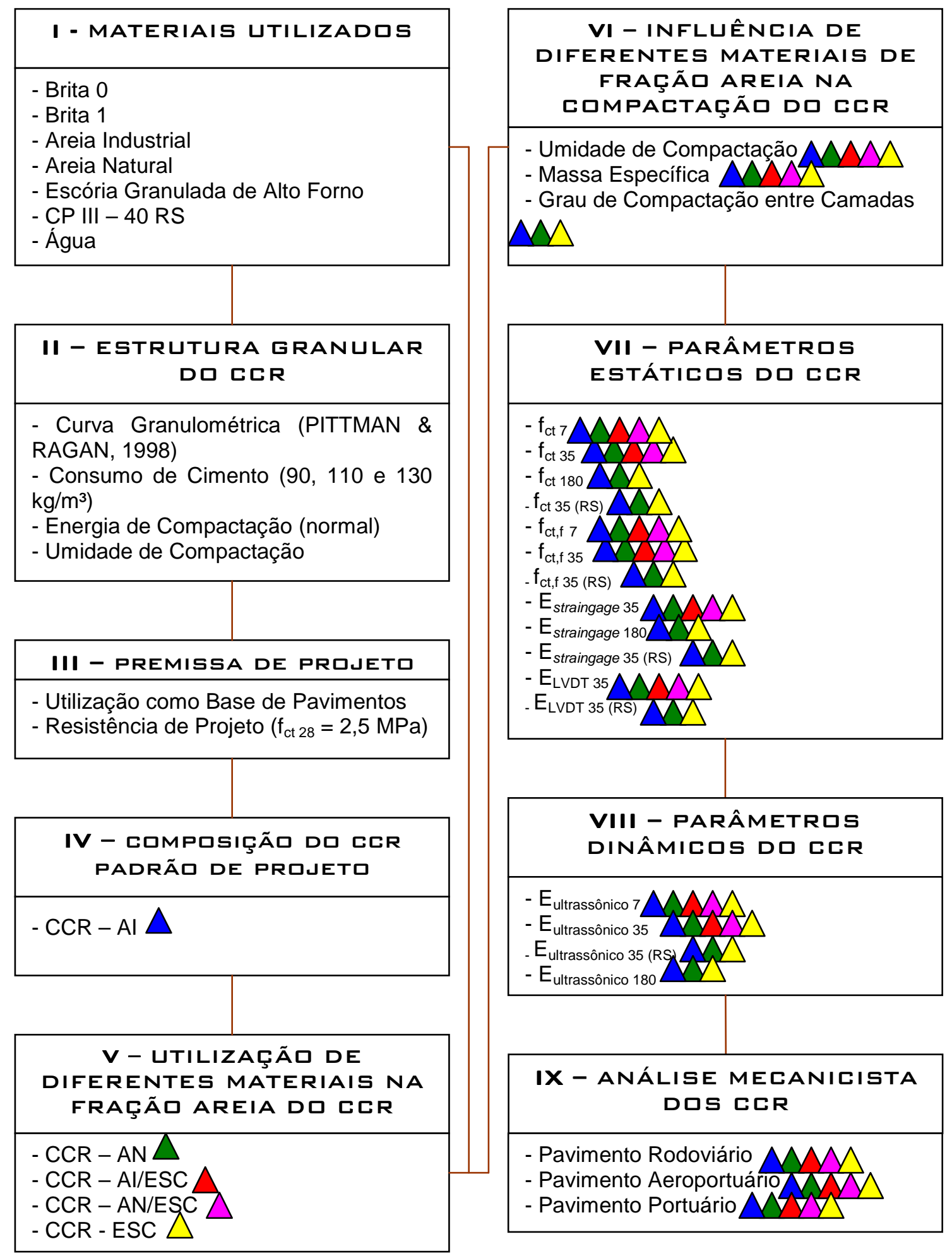

Figura 52 - fluxograma de resumo do projeto experimental 


\section{APRESENTAÇÃO E DISCUSSÃO DOS RESULTADOS}

\subsection{CONSUMO DE CIMENTO DO CCR PADRÃO}

A dosagem do CCR padrão (CCR - Al), em função da premissa de resistência adotada ( $f_{c t} 35=2,5 \mathrm{MPa}$ ), partiu de ensaios de compactação, determinando-se a umidade ótima para os consumos especificados (Figura 53). Observa-se acréscimo da umidade de compactação e massa específica com o aumento do consumo de cimento.

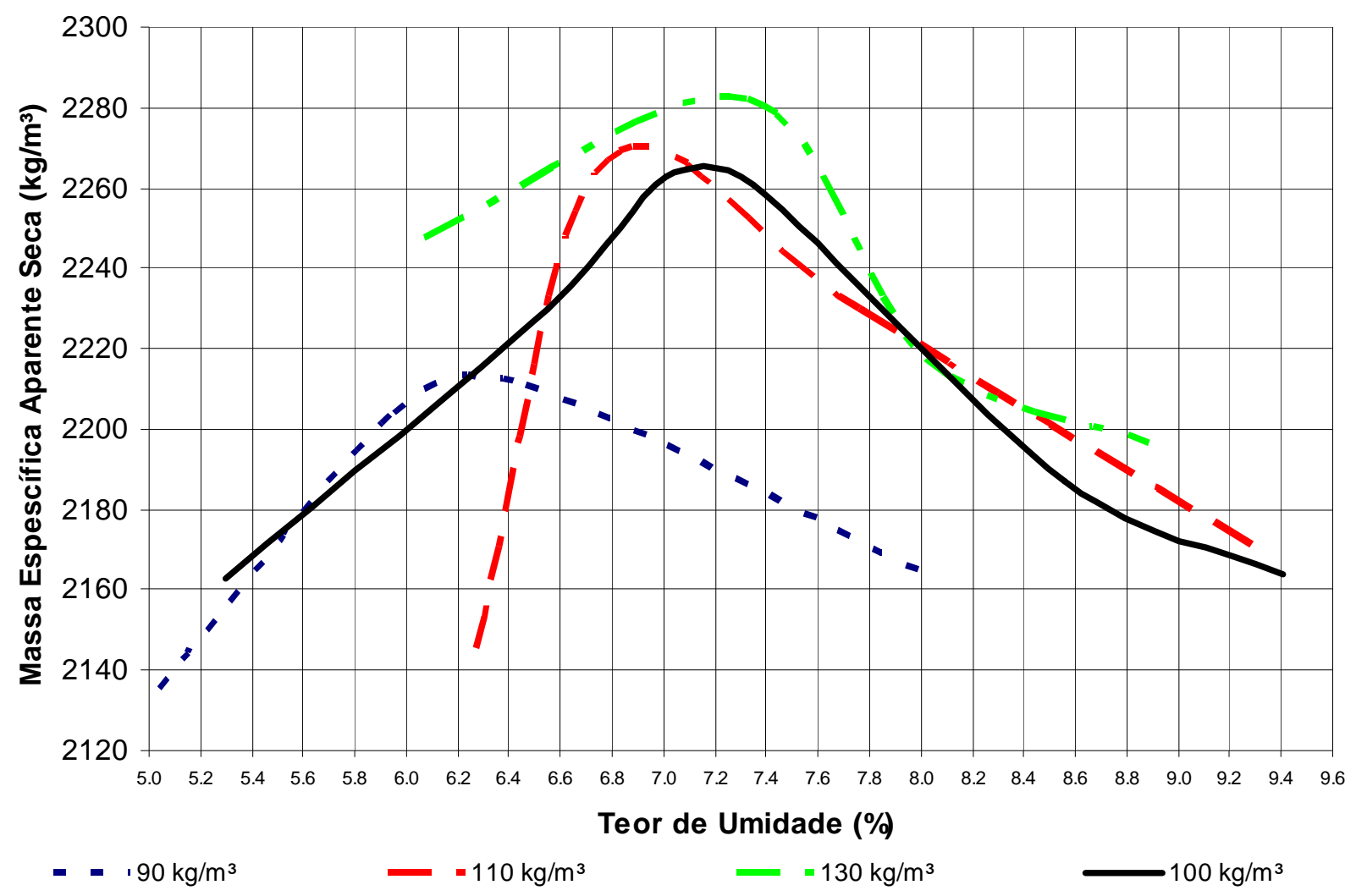

Figura 53 - umidades de compactação para diferentes consumos do CCR - Al

As resistências à tração em compressão diametral e à tração na flexão, para cada consumo de ligante, foram obtidas pela média $(\bar{x})$ dos corpos de prova 
ensaiados; sendo determinados também o desvio padrão (s) e o coeficiente de variação (cv), que denotaram baixa variabilidade de resultados em especial no ensaio de tração em compressão diametral (Tabelas 34 e 35 - onde n é o número de amostras ensaiadas). A tendência de diminuição do cv com o aumento do consumo de cimento não foi confirmada nos corpos de prova cilíndricos ensaiados aos sete dias e nos corpos de prova prismáticos ensaiados aos trinta e cinco dias. Este fato é atribuído ao adensamento (compactação) ter sido realizado por dois diferentes operadores para uma mesma mistura, empregando diferentes distribuições sobre a superfície do material quando da queda do soquete no concreto fresco, causando diferenças de até 7,2 \% entre massas específicas dos corpos de prova prismáticos com consumo de cimento de $110 \mathrm{~kg} / \mathrm{m}^{3}$. A partir desta constatação, optou-se pelo emprego de somente um operador no adensamento de cada mistura e realizou-se dosagem adicional com consumo de $100 \mathrm{~kg} / \mathrm{m}^{3}$, conforme premissa de resistência de projeto.

Tabela 34 - resistências à tração em compressão diametral para diferentes consumos de cimento

\begin{tabular}{cccccccccc}
\hline $\begin{array}{c}\text { Consumo de ligante } \\
\mathbf{C C R}-\mathbf{A l} \\
\left(\mathbf{k g} / \mathbf{m}^{3}\right)\end{array}$ & $\mathbf{n}$ & $\begin{array}{c}\bar{x} \\
\mathbf{( M P a})\end{array}$ & $\begin{array}{c}\mathbf{f} \\
\mathbf{( M P a})\end{array}$ & $\begin{array}{c}\mathbf{c v} \\
\mathbf{( \% )}\end{array}$ & $\mathbf{n}$ & $\begin{array}{c}\bar{x} \\
\mathbf{( M P a})\end{array}$ & $\begin{array}{c}\mathbf{s} \\
\mathbf{( M P a})\end{array}$ & $\begin{array}{c}\mathbf{c v} \\
\mathbf{( \% )}\end{array}$ \\
\hline 90 & 3 & 1,4 & 0,1 & 5,5 & 6 & 2,3 & 0,1 & 4,2 \\
110 & 3 & 1,5 & 0,1 & 8,3 & 6 & 2,7 & 0,1 & 3,0 \\
130 & 3 & 1,9 & 0,2 & 9,4 & 6 & 3,2 & 0,1 & 2,8 \\
\hline
\end{tabular}

Tabela 35 - resistências à tração na flexão para diferentes consumos de cimento

\begin{tabular}{|c|c|c|c|c|c|c|c|c|}
\hline \multirow{2}{*}{$\begin{array}{c}\text { Consumo de ligante } \\
\text { CCR - Al } \\
\left(\mathrm{kg} / \mathrm{m}^{3}\right)\end{array}$} & \multicolumn{4}{|c|}{$\mathrm{fct}, \mathrm{f}_{7}$} & \multicolumn{4}{|c|}{$\mathrm{fct}, \mathbf{f}_{35}$} \\
\hline & $n$ & $\begin{array}{c}\bar{x} \\
(\mathrm{MPa})\end{array}$ & $\begin{array}{c}\mathbf{s} \\
(\mathrm{MPa})\end{array}$ & $\begin{array}{l}\text { cv } \\
(\%)\end{array}$ & $n$ & $\begin{array}{c}\bar{x} \\
(\mathbf{M P a})\end{array}$ & $\begin{array}{c}\mathrm{s} \\
(\mathrm{MPa})\end{array}$ & $\begin{array}{l}\text { cv } \\
(\%)\end{array}$ \\
\hline 90 & 3 & 2,4 & 0,2 & 7,6 & 6 & 2,8 & 0,4 & 13,5 \\
\hline 110 & 3 & 3,8 & 0,2 & 5,8 & 6 & 5,5 & 0,9 & 15,8 \\
\hline 130 & 3 & 3,4 & 0,1 & 2,8 & 6 & 5,9 & 0,6 & 9,3 \\
\hline
\end{tabular}


Foi observado que as amostras com sete dias apresentam resistência à tração indireta por compressão diametral cerca de $60 \%$ da resistência aos 23 dias (61\%, $56 \%$ e $59 \%$ para os consumos de cimento crescentes de 90,110 e 130 $\mathrm{kg} / \mathrm{m}^{3}$, respectivamente). No caso da resistência à tração na flexão, para o consumo de $90 \mathrm{~kg} / \mathrm{m}^{3}$, houve grande ganho de resistência aos sete dias (86 \% da resistência aos 35 dias); para os consumos de 110 e $130 \mathrm{~kg} / \mathrm{m}^{3}$, as resistências aos sete dias foram $69 \%$ e de $58 \%$ daquelas aos 35 dias. Balbo (1993), empregando BGTC com cerca de $90 \mathrm{~kg} / \mathrm{m}^{3}$ de cimento do tipo CP-II 32 obteve, aos 11 dias, $79 \%$ da resistência à tração por compressão diametral em relação à obtida aos 28 dias.

Nota-se que os corpos de prova prismáticos apresentam, de um modo geral, maiores dispersões nos resultados do que os corpos de prova cilíndricos. Atribui-se isto às dimensões do molde para confecção das amostras, disposição do concreto fresco na fôrma e características geométricas do soquete utilizado para compactação face à área da superfície das amostras a serem compactadas.

Apresentam-se, nas Figuras 54 e 55, as dispersões dos corpos de prova ensaiados durante a determinação do consumo de cimento em função das resistências à tração indireta e à tração na flexão obtidas.

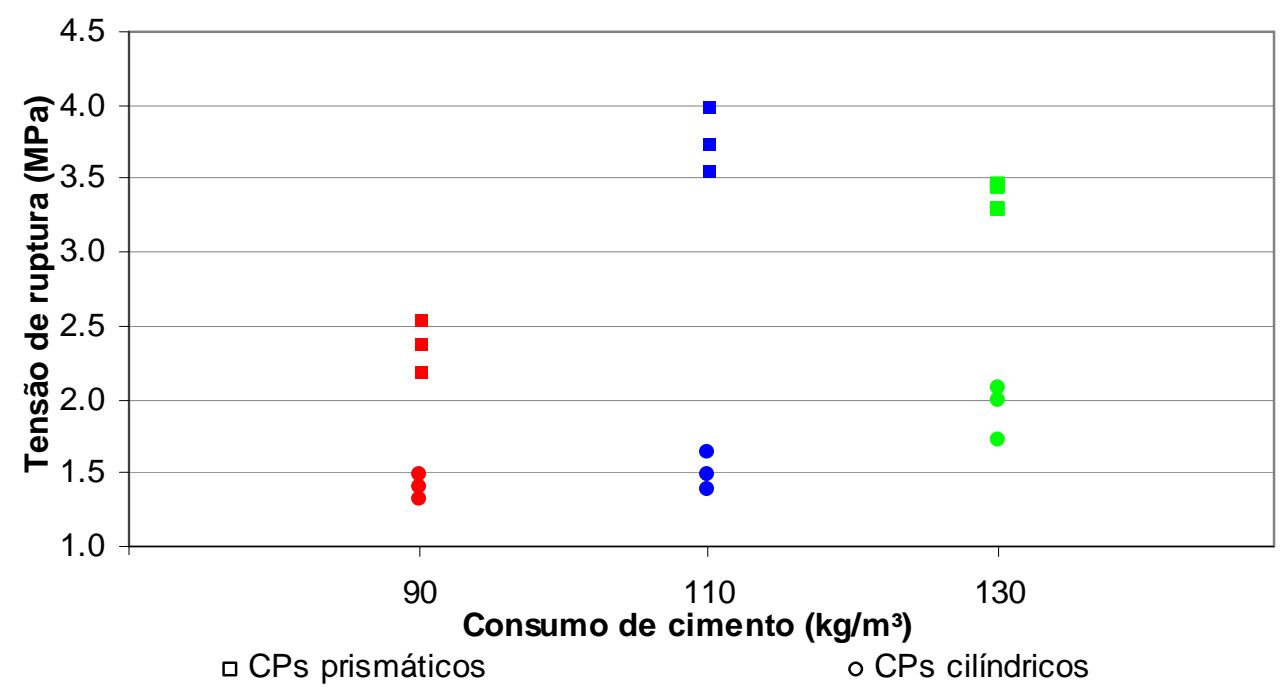

Figura 54 - dispersão dos corpos de prova ensaiados aos 7 dias 


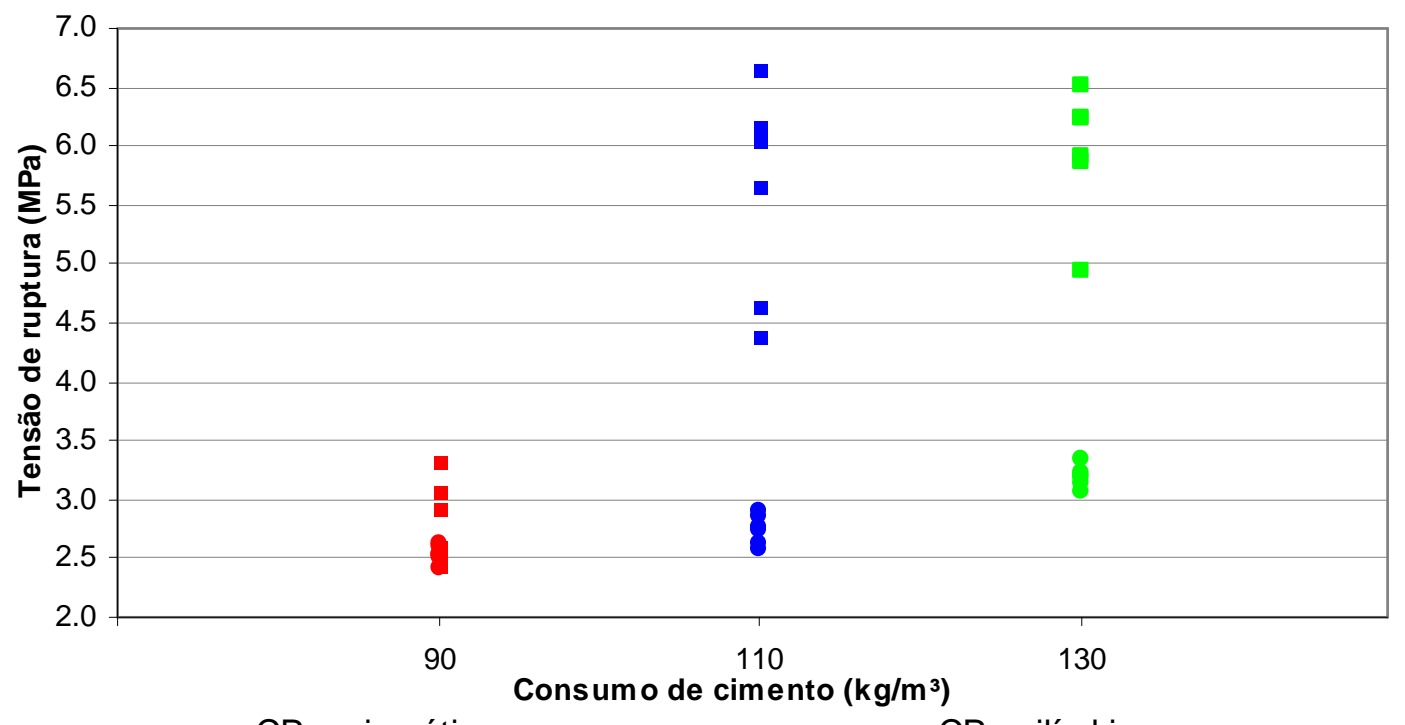

$\checkmark$ CPs prismáticos o CPs cilíndricos

Figura 55 - dispersão dos corpos de prova ensaiados aos 35 dias

Por meio dos pares de tensão de ruptura versus consumo de cimento podese definir a quantidade de ligante hidráulico necessário para que fosse atingida a resistência especificada, conforme mostrado na Figura 56.

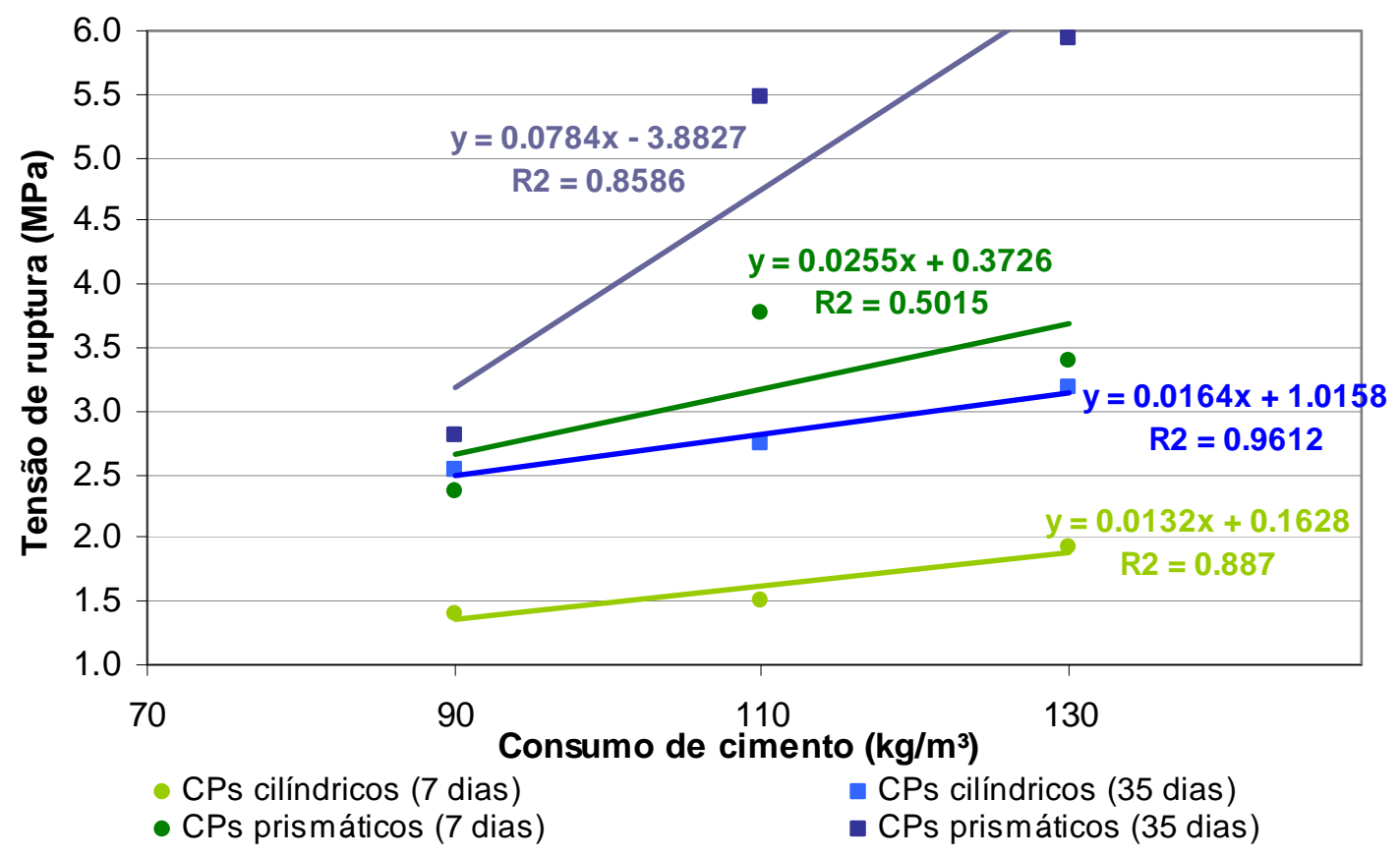

Figura 56 - variação média das resistências à tração com o consumo de cimento 
O consumo de cimento adotado foi $100 \mathrm{~kg} / \mathrm{m}^{3}$; ressalta-se que o consumo de $90 \mathrm{~kg} / \mathrm{m}^{3}$, muito próximo ao consumo típico de uma BGTC, conduz a resistências idênticas aquelas encontradas para a BGTC por Balbo (1993). Assim sendo, a pesquisa prosseguiu com tal consumo de cimento, sendo moldados os corpos de prova para todos os demais testes. Todos os testes para as misturas ajustadas foram realizados, a partir deste momento, com instrumentação eletrônica, equipamentos com célula de carga, LVDT e straingages de contato (medidores de deformação). Na Tabela 36 são apresentados exemplos de diferenças entre magnitudes nos valores de resistência obtidos pelo indicador eletrônico digital (valores microprocessados através da pressão hidráulica no pistão de aplicação de carga) e o sistema de aquisição de dados (amplificador e condicionador de sinais eletrônicos).

Tabela 36 - comparação entre resistências aferidas por diferentes processos de medição

\begin{tabular}{|c|c|c|c|c|c|c|c|}
\hline \multirow[b]{2}{*}{$\begin{array}{c}\text { CCR - Al } \\
\left(\mathrm{kg} / \mathrm{m}^{3}\right)\end{array}$} & \multirow[b]{2}{*}{$\mathbf{n}$} & \multicolumn{3}{|c|}{ Pressão hidráulica } & \multicolumn{3}{|c|}{ Instrumentação Eletrônica } \\
\hline & & $\begin{array}{c}\bar{x} \\
(\mathrm{MPa})\end{array}$ & $\begin{array}{c}\mathrm{s} \\
(\mathrm{MPa})\end{array}$ & $\begin{array}{l}\text { CV } \\
(\%)\end{array}$ & $\begin{array}{c}\bar{x} \\
(\mathrm{MPa})\end{array}$ & $\begin{array}{c}\mathrm{S} \\
(\mathrm{MPa})\end{array}$ & $\begin{array}{l}\text { CV } \\
(\%)\end{array}$ \\
\hline fct 7 & 3 & 1,5 & 0,1 & 4,6 & - & - & - \\
\hline $\mathrm{fct}_{35}$ & 6 & 2,6 & 0,2 & 1,7 & 2,5 & 0,1 & 3,4 \\
\hline fct, $f_{7}$ & 3 & 2,3 & 0,1 & 6,6 & - & - & - \\
\hline $\mathrm{fct}, \mathrm{f}_{35}$ & 6 & 4,7 & 0,5 & 9,9 & 4,2 & 0,3 & 7,5 \\
\hline
\end{tabular}

Nota-se que pelo sistema de aquisição de dados de ruptura da prensa hidráulica, no ensaio de tração na flexão, obtêm-se valores superiores de resistência por comparação aos resultados obtidos com emprego de célula de carga. Isto é atribuído à menor sensibilidade do sistema hidráulico e as baixas cargas impostas até a ruptura do corpo de prova (cerca de 7,9 kN). No ensaio de tração indireta este problema é minimizado pela maior carga empregada (cerca de $78 \mathrm{kN}$ ), resultando, assim, em valores muito próximos entre ambos sistemas (hidráulico e eletrônico). Portanto, para fins de análise comparativa entre tensões, foram empregados os dados obtidos eletronicamente, uma vez que estes têm maior precisão. 
Através das equações obtidas por regressão linear em relação aos consumos previamente definidos, representadas na Figura 56, podem-se estimar valores de resistência para diferentes consumos de cimento e vice versa. Levando em consideração a resistência de referência empregada nessa pesquisa, obtém-se um consumo de ligante hidráulico próximo a $100 \mathrm{~kg} / \mathrm{m}^{3}$, valor este, obtido também experimentalmente.

A massa específica dos corpos de prova cilíndricos se mostrou superior à dos corpos de prova prismáticos (Tabela 37); isto se deve à melhor distribuição da energia de compactação sobre o concreto no molde cilíndrico. Ainda, quanto maior o consumo de cimento do concreto, maior sua massa específica; pois maiores quantidades de ligante hidráulico preenchem mais eficientemente os vazios do esqueleto granular do concreto compactado.

Tabela 37 - massas específicas dos corpos de prova do CCR - Al em função do consumo de ligante hidráulico

\begin{tabular}{|c|c|c|c|c|c|c|c|}
\hline \multicolumn{2}{|c|}{ Consumo de ligante } & \multicolumn{3}{|c|}{ cilindros } & \multicolumn{3}{|c|}{ prismas } \\
\hline $\begin{array}{c}\text { CCR - Al } \\
\left(\mathrm{kg} / \mathrm{m}^{3}\right)\end{array}$ & $\mathbf{n}$ & $\begin{array}{c}\bar{x} \\
\left(\mathrm{~kg} / \mathrm{m}^{3}\right)\end{array}$ & $\begin{array}{c}\mathrm{s} \\
\left(\mathrm{kg} / \mathrm{m}^{3}\right)\end{array}$ & $\begin{array}{l}\text { cv } \\
(\%)\end{array}$ & $\begin{array}{c}\bar{x} \\
\left(\mathrm{~kg} / \mathrm{m}^{3}\right)\end{array}$ & $\begin{array}{c}\mathrm{s} \\
\left(\mathrm{kg} / \mathrm{m}^{3}\right)\end{array}$ & $\begin{array}{l}\text { cv } \\
(\%)\end{array}$ \\
\hline 90 & 9 & 2.400 & 64 & 2,8 & 2.250 & 104 & 4,6 \\
\hline 100 & 9 & 2.410 & 45 & 1,9 & 2.320 & 82 & 3,4 \\
\hline 110 & 9 & 2.440 & 92 & 3,7 & 2.340 & 131 & 5,9 \\
\hline 130 & 9 & 2.450 & 83 & 3,4 & 2.390 & 96 & 4,0 \\
\hline
\end{tabular}

O módulo de elasticidade dinâmico é afetado pelo consumo de cimento da mesma forma que a massa específica o afeta, ou seja, quanto maior a quantidade de ligante hidráulico e menor volume de vazios da estrutura, maior a velocidade de propagação de onda ultrassônica e maior o módulo de elasticidade dinâmico; tendência esta, observada conforme apresentado nas Tabelas 38 e 39. 
Tabela 38 - módulo de elasticidade dinâmico do CCR - Al em função do consumo de ligante hidráulico (7 dias)

\begin{tabular}{|c|c|c|c|c|c|c|c|}
\hline \multirow{2}{*}{$\begin{array}{c}\text { Consumo de cimento } \\
\text { CCR - Al } \\
\left(\mathrm{kg} / \mathrm{m}^{3}\right)\end{array}$} & \multirow[b]{2}{*}{$\mathbf{n}$} & \multicolumn{3}{|c|}{$E_{d}-$ cilindro } & \multicolumn{3}{|c|}{$E_{d}$ - prisma } \\
\hline & & $\begin{array}{c}\bar{x} \\
(\mathrm{GPa})\end{array}$ & $\begin{array}{c}\mathbf{s} \\
(\mathrm{GPa})\end{array}$ & $\begin{array}{l}\text { cv } \\
(\%)\end{array}$ & $\begin{array}{c}\bar{x} \\
(\mathrm{GPa})\end{array}$ & $\begin{array}{c}\mathbf{s} \\
(\mathrm{GPa})\end{array}$ & $\begin{array}{l}\text { CV } \\
(\%)\end{array}$ \\
\hline 90 & 3 & 32,2 & 1,1 & 3,5 & 31,5 & 1,6 & 5,2 \\
\hline 100 & 3 & 33,2 & 1,1 & 3,5 & 36,3 & 0,4 & 1,0 \\
\hline 110 & 3 & 37,9 & 0,5 & 1,2 & 38,4 & 1,2 & 3,1 \\
\hline 130 & 3 & 36,4 & 1,5 & 4,2 & 36,3 & 0,6 & 1,7 \\
\hline
\end{tabular}

Tabela 39 - módulo de elasticidade dinâmico do CCR - Al em função do consumo de ligante hidráulico (35 dias)

\begin{tabular}{cccccccc}
\hline $\begin{array}{c}\text { Consumo de cimento } \\
\mathbf{C C R}-\mathbf{A l}\end{array}$ & $\mathbf{n}$ & $\bar{x}$ & $\mathbf{S}$ & $\mathbf{c v}$ & $\bar{x}$ & $\mathbf{s}$ & $\mathbf{c v}$ \\
$\left(\mathbf{k g} / \mathbf{m}^{3}\right)$ & & $(\mathbf{M P a})$ & $(\mathbf{M P a})$ & $(\%)$ & $(\mathbf{M P a})$ & $(\mathbf{M P a})$ & $(\%)$ \\
\hline 90 & 6 & 38,6 & 0,8 & 1,8 & 34,1 & 2,0 & 6,0 \\
100 & 6 & 40,6 & 0,5 & 1,3 & 37,4 & 2,5 & 6,8 \\
110 & 6 & 44,4 & 0,7 & 1,5 & 43,4 & 1,4 & 3,3 \\
130 & 6 & 43,4 & 1,1 & 2,6 & 45,2 & 1,3 & 2,9 \\
\hline
\end{tabular}

\subsection{INFLUÊNCIA DE DIFERENTES MATERIAIS DE FRAÇÃO AREIA NOS PARÂMETROS DO CCR}

\subsubsection{Umidade de compactação}

Tendo como base o CCR - Al, houve acréscimo na umidade ótima de compactação para misturas contendo areia natural e escória granulada de alto forno, conforme se apresenta na Figura 57 e na Tabela 40.

Nota-se claramente que a adição de escória granulada de alto forno ocasiona queda expressiva na massa específica do CCR (tanto em corpos de prova cilíndricos quanto prismáticos); isto se deve à baixa densidade e 
granulometria dos grãos desse agregado alternativo. Nas Tabela 41 e 42 observam-se a queda significativa na massa específica do CCR quando sua fração areia é substituída completamente pelo agregado siderúrgico e as variações porcentuais das massas específicas devido à utilização de areia natural e escória granulada de alto forno em comparação com a mistura de referência (com areia industrial), respectivamente.

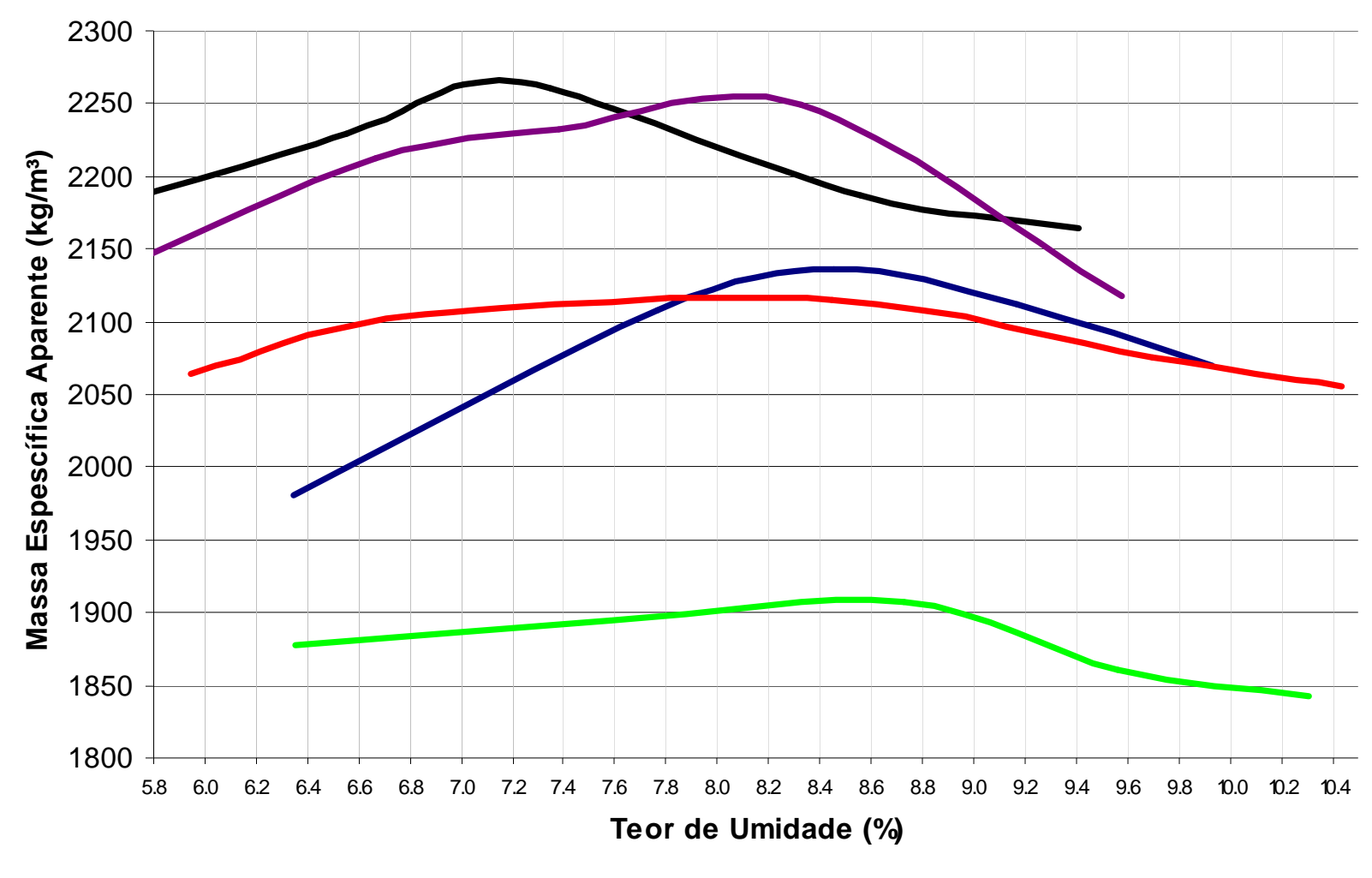

$\longrightarrow \mathrm{CCR}-\mathrm{ANESC} \longrightarrow \mathrm{CCR}-\mathrm{AVESC} \quad \mathrm{CCR}-\mathrm{ESC} \mathrm{CCR}-\mathrm{AI} \quad \mathrm{CCR}-\mathrm{AN}$

Figura 57 - curvas de compactação para CCR com diferentes materiais de fração areia

Tabela 40 - umidades ótimas de compactação para os CCR estudados

\begin{tabular}{ccc}
\hline CCR & $\begin{array}{c}\text { Umidade de compactação } \\
(\%)\end{array}$ & $\begin{array}{c}\text { Aumento na umidade } \\
\text { ótima da mistura (\%) }\end{array}$ \\
\hline CCR - Al & 7,00 & - \\
CCR - AN & 8,05 & $+15,0$ \\
CCR - ESC & 8,60 & $+22,8$ \\
CCR - Al/ESC & 8,30 & $+18,6$ \\
CCR - AN/ESC & 8,40 & $+20,0$ \\
\hline
\end{tabular}


Tabela 41 - massas específicas dos corpos de prova dos CCR estudados

\begin{tabular}{|c|c|c|c|c|c|c|c|}
\hline \multirow[b]{2}{*}{ CCR } & \multirow[b]{2}{*}{$\mathbf{n}$} & \multicolumn{3}{|c|}{ cilindros } & \multicolumn{3}{|c|}{ prismas } \\
\hline & & $\begin{array}{c}\bar{x} \\
\left(\mathrm{~kg} / \mathrm{m}^{3}\right)\end{array}$ & $\begin{array}{c}s \\
\left(\mathrm{~kg} / \mathrm{m}^{3}\right)\end{array}$ & $\begin{array}{l}\text { cv } \\
(\%)\end{array}$ & $\begin{array}{c}\bar{x} \\
\left(\mathrm{~kg} / \mathrm{m}^{3}\right)\end{array}$ & $\begin{array}{c}\mathrm{s} \\
\left(\mathrm{kg} / \mathrm{m}^{3}\right)\end{array}$ & $\begin{array}{l}\text { cv } \\
(\%)\end{array}$ \\
\hline $\mathrm{CCR}-\mathrm{Al}$ & 9 & 2.410 & 45 & 1,9 & 2.320 & 82 & 3,4 \\
\hline $\mathrm{CCR}-\mathrm{AN}$ & 9 & 2.379 & 16 & 0,7 & 2.292 & 27 & 1,2 \\
\hline CCR - ESC & 9 & 2.113 & 5 & 0,3 & 2.070 & 17 & 0,8 \\
\hline $\mathrm{CCR}-\mathrm{Al} / \mathrm{ESC}$ & 9 & 2.284 & 3 & 0,2 & 2.197 & 22 & 1,0 \\
\hline CCR - AN/ESC & 9 & 2.272 & 10 & 0,8 & 2.194 & 28 & 1,3 \\
\hline
\end{tabular}

Tabela 42 - variação porcentual das massas específicas dos CCR alternativos em relação ao padrão

\begin{tabular}{|c|c|c|}
\hline \multirow{2}{*}{ CCR } & \multicolumn{2}{|c|}{ Variação porcentual (\%) } \\
\hline & cilindros & prismas \\
\hline $\mathrm{CCR}-\mathrm{Al}$ & - & - \\
\hline $\mathrm{CCR}-\mathrm{AN}$ & $-1,3$ & $-1,2$ \\
\hline CCR - ESC & $-12,3$ & $-10,8$ \\
\hline $\mathrm{CCR}-\mathrm{Al} / \mathrm{ESC}$ & $-5,2$ & $-5,3$ \\
\hline CCR - AN/ESC & $-5,7$ & $-5,4$ \\
\hline
\end{tabular}

\subsubsection{Resistências à tração aos 7 e 35 dias}

Apresentam-se, nas Tabelas 43 e 44, os resultados obtidos de resistência à tração por compressão diametral e à tração na flexão no ensaio de 1 cutelo nas idades de 7 e 35 dias de cura em câmara úmida. Na Tabela 45, são mostradas as variações porcentuais entre as resistências dos CCR alternativos e padrão. 
Tabela 43 - resultados de resistências à tração em compressão diametral dos CCR

\begin{tabular}{ccccccccc}
\hline CCR & & \multicolumn{3}{c}{ fct $_{\mathbf{7}}$} & & \multicolumn{3}{c}{ fct $_{\mathbf{3 5}}$} \\
& $\mathbf{n}$ & $\begin{array}{c}\bar{x} \\
(\mathbf{M P a})\end{array}$ & $\begin{array}{c}\mathbf{s} \\
(\mathbf{M P a})\end{array}$ & $\begin{array}{c}\mathbf{c v} \\
(\%)\end{array}$ & $\mathbf{n}$ & $\begin{array}{c}\bar{x} \\
(\mathbf{M P a})\end{array}$ & $\begin{array}{c}\mathbf{s} \\
(\mathbf{M P a})\end{array}$ & $\begin{array}{c}\mathbf{c v} \\
(\%)\end{array}$ \\
\hline $\mathrm{CCR}-\mathrm{Al}$ & 3 & 1,5 & 0,1 & 4,6 & 6 & 2,5 & 0,1 & 3,4 \\
$\mathrm{CCR}-\mathrm{AN}$ & 3 & 1,2 & 0,1 & 3,7 & 6 & 2,0 & 0,1 & 2,6 \\
$\mathrm{CCR}-\mathrm{ESC}$ & 3 & 0,7 & 0,1 & 3,5 & 6 & 1,5 & 0,1 & 4,4 \\
$\mathrm{CCR}-\mathrm{Al} / \mathrm{ESC}$ & 3 & 1,0 & 0,1 & 7,0 & 6 & 2,1 & 0,1 & 4,6 \\
$\mathrm{CCR}-\mathrm{AN} / \mathrm{ESC}$ & 3 & 1,1 & 0,1 & 1,9 & 6 & 1,7 & 0,1 & 6,3 \\
\hline
\end{tabular}

Tabela 44 - resultados de resistências à tração na flexão dos CCR

\begin{tabular}{|c|c|c|c|c|c|c|c|c|}
\hline \multirow[b]{2}{*}{ CCR } & \multicolumn{4}{|c|}{ fct, $f_{7}$} & \multicolumn{4}{|c|}{$\mathrm{fct}_{,} \mathrm{f}_{35}$} \\
\hline & $\mathbf{n}$ & $\begin{array}{c}\bar{x} \\
(\mathrm{MPa})\end{array}$ & $\begin{array}{c}\mathbf{s} \\
(\mathrm{MPa})\end{array}$ & $\begin{array}{l}\text { cv } \\
(\%)\end{array}$ & $\mathbf{n}$ & $\begin{array}{c}\bar{x} \\
(\mathrm{MPa})\end{array}$ & $\begin{array}{c}\mathrm{s} \\
(\mathrm{MPa})\end{array}$ & $\begin{array}{c}\text { cv } \\
(\%)\end{array}$ \\
\hline $\mathrm{CCR}-\mathrm{Al}$ & 3 & 3,2 & 0,1 & 0,4 & 6 & 4,2 & 0,3 & 7,5 \\
\hline $\mathrm{CCR}-\mathrm{AN}$ & 3 & 3,1 & 0,1 & 2,1 & 6 & 3,9 & 0,3 & 6,1 \\
\hline CCR - ESC & 3 & 2,1 & 0,3 & 12,4 & 6 & 2,3 & 0,2 & 10,1 \\
\hline $\mathrm{CCR}-\mathrm{Al} / \mathrm{ESC}$ & 3 & 3,0 & 0,1 & 3,7 & 6 & 3,5 & 0,3 & 8,5 \\
\hline CCR - AN/ESC & 3 & 2,4 & 0,2 & 8,0 & 6 & 2,7 & 0,1 & 2,8 \\
\hline
\end{tabular}

Tabela 45 - variação porcentual das resistências à tração dos CCR estudados

\begin{tabular}{ccccc}
\hline \multirow{2}{*}{ CCR } & \multicolumn{4}{c}{ Variação porcentual (\%) } \\
& fct $_{\mathbf{7}}$ & fct $_{\mathbf{3 5}}$ & fct,, $_{\mathbf{7}}$ & fct,, $_{\mathbf{3 5}}$ \\
\hline $\mathrm{CCR}-\mathrm{Al}$ & - & - & - & - \\
$\mathrm{CCR}-\mathrm{AN}$ & $-20,0$ & $-20,0$ & $-3,1$ & $-7,1$ \\
$\mathrm{CCR}-\mathrm{ESC}$ & $-53,3$ & $-40,0$ & $-34,4$ & $-45,2$ \\
$\mathrm{CCR}-\mathrm{Al} / \mathrm{ESC}$ & $-33,3$ & $-16,0$ & $-6,2$ & $-16,7$ \\
$\mathrm{CCR}-\mathrm{AN} / \mathrm{ESC}$ & $-26,6$ & $-32,0$ & $-25,0$ & $-35,7$ \\
\hline
\end{tabular}

Observa-se que, acompanhando a queda da massa específica do CCR com o incremento da quantidade de escória granulada de alto forno, as resistências à tração indireta e na flexão também sofrem queda quando utilizado este agregado 
alternativo; sendo mais sensível na utilização total como fração areia do concreto (respectivamente $40 \%$ e $45 \%$, para ensaios realizados aos 35 dias de cura úmida em câmara).

A estrutura granular dos concretos com utilização total de escória possui maior quantidade de poros devido à granulometria do resíduo e a menor quantidade de finos destas misturas, havendo menores quantidades de ligações pontuais entre argamassa e agregados. Na utilização parcial com outro tipo de areia (natural ou industrial) a queda na resistência não é tão acentuada devido à complementação desta falta de finos com parte dos agregados oriundos de rochas; em especial com a utilização em conjunto com a areia industrial, tendo queda de $16 \%$ para ambos os ensaios de tração realizados aos 35 dias (comparado com o $\mathrm{CCR}-\mathrm{Al})$.

As mudanças nas estruturas granulares dos CCR são claramente visíveis, conforme mostrado na Figura 58. Observa-se que as misturas de CCR - Al e CCR - AN têm estruturas distintas em comparação com o CCR - ESC pela maior presença de grãos com menor diâmetro. Entretanto o CCR - AN não logrou resistências idênticas aos CCR - Al; havendo diminuição de $20 \%$ na resistência à tração indireta e $3 \%$ a 7 \% no ensaio de tração na flexão (em resultados obtidos aos 7 e 35 dias de cura em câmara úmida). Os maiores valores para o CCR - Al devem-se à distribuição granulométrica contínua da areia industrial, menor presença de poros e melhor envelopamento dos componentes. 


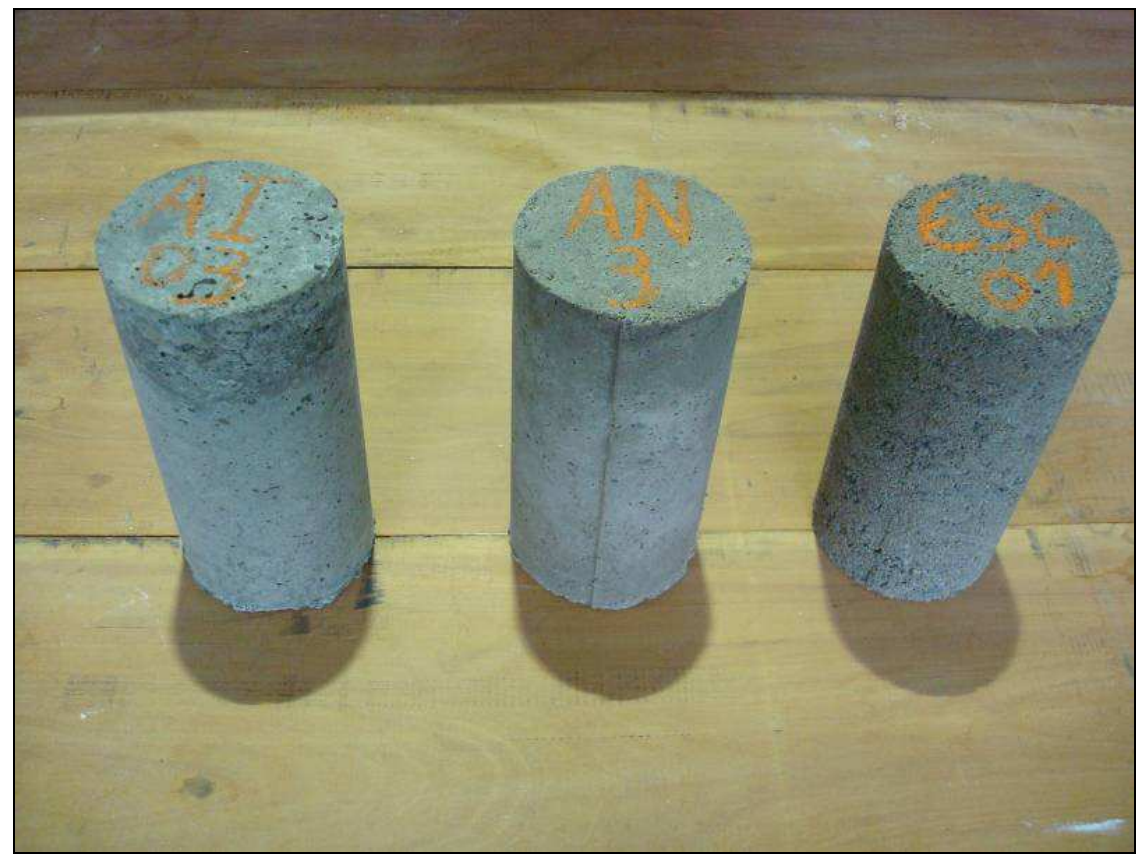

Figura 58 - aspecto visual dos CCR - Al, CCR - AN e CCR - ESC

Analisando comparativamente a redução ocorrida pela adição de escória granulada de alto forno em CCR na resistência à tração na flexão aos 35 dias com os resultados obtidos por Yüksel e Genç (2007) aos 28 dias, onde houve a utilização de escória granulada de alto forno como agregado miúdo em concreto plástico (consumo de cimento de $340 \mathrm{~kg} / \mathrm{m}^{3}$ e fator $A / C$ de 0,56 ), observa-se redução semelhante entre os valores quando se utiliza $50 \%$ de escória em substituição da areia natural, sendo esta, cerca de $35 \%$.

Percebe-se que os valores de resistência à tração na flexão, no ensaio de um cutelo, resultam magnitudes superiores à $100 \%$ do que o ensaio de tração indireta por compressão diametral aos 7 dias e $50 \%$ aos 35 dias; conforme se mostra nas Figuras 59 e 60, respectivamente. Este fato é esperado e conhecido no meio profissional e de pesquisa. 


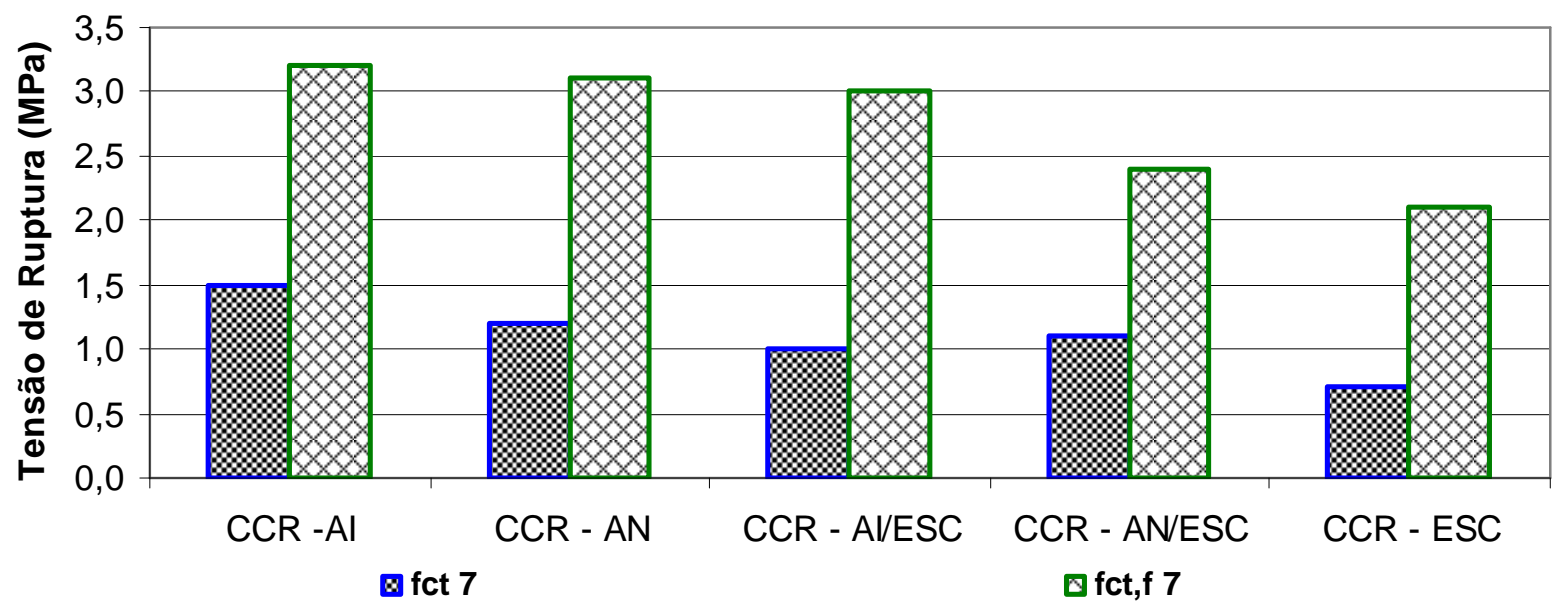

Figura 59 - comparativo entre valores dos ensaios de tração realizados aos 7 dias

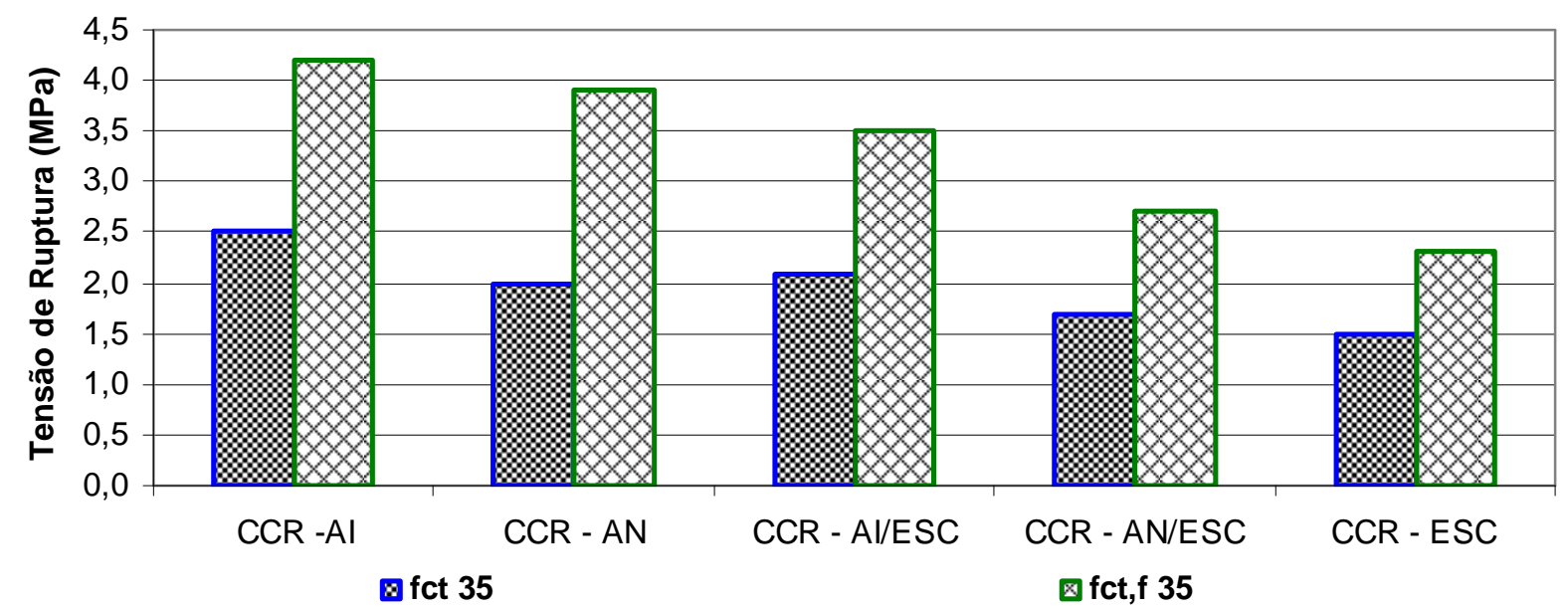

Figura 60 - comparativo entre valores dos ensaios de tração realizados aos 35 dias

Na Figura 61 é apresentada uma tentativa de correlação entre os dois diferentes modos de medida de resistência à tração, quando se observa uma tendência entre ambas. Contudo, esta tendência de correlação não é indicativa que haja uma relação empírica universalmente válida que possa ser empregada para outros tipos de concreto, materiais ou condições de ensaio. 


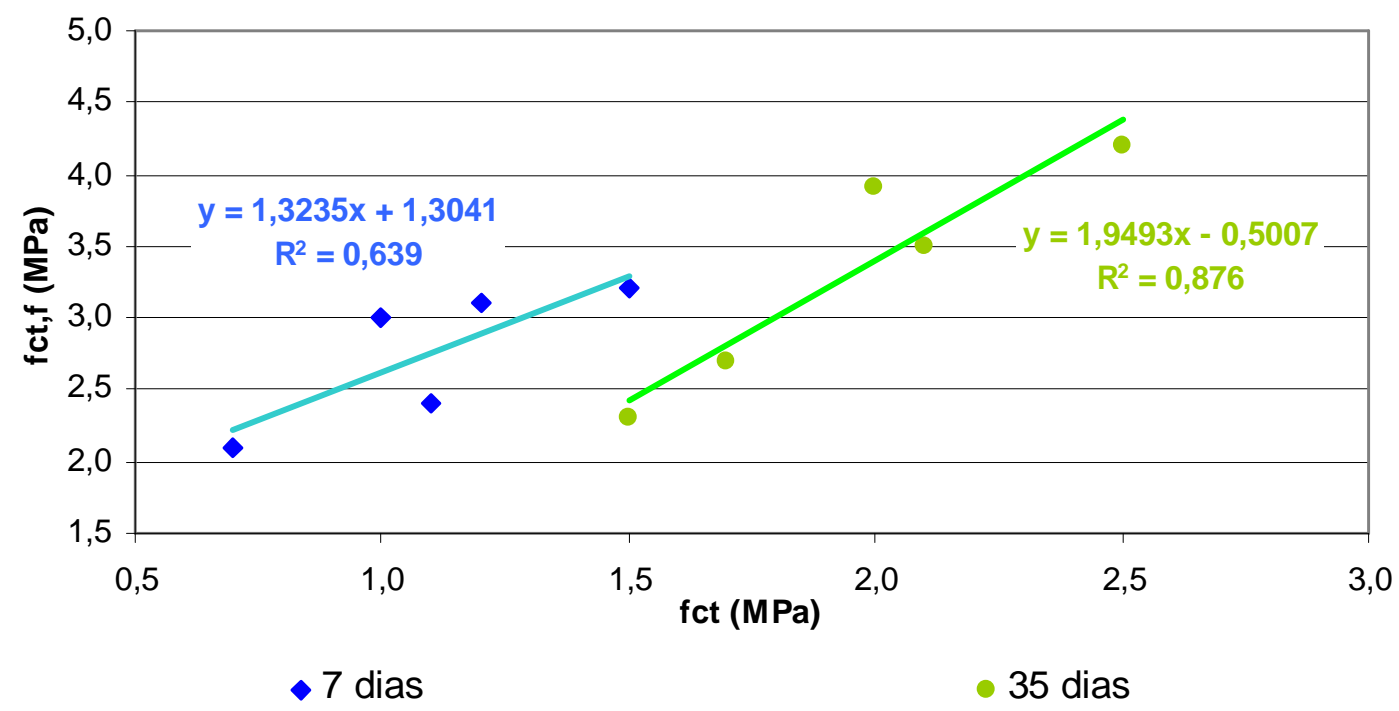

Figura 61 - correlação entre os ensaios à tração indireta por compressão diametral e à flexão

\subsubsection{Resistência à tração indireta por compressão diametral aos 180 dias}

Sabe-se que o cimento CP III, em decorrência da adição de escória moída de alto forno, sofre hidratação mais lenta e há maior ganho de resistência em idades mais avançadas (comparando-o com outros tipos de cimento). Sendo assim, a utilização de escória granulada de alto forno como agregado miúdo em conjunto com a compactação enérgica do CCR pode ocasionar em trituração ou quebra das partículas de escória e condicioná-las à atividade hidráulica ativada por elementos do próprio cimento Portland, resultando, assim, em maiores ganhos de resistência ao decorrer do tempo. Apresentam-se, na Tabela 46, os resultados do ensaio de tração por compressão diametral realizados nos CCR com utilização total da fração areia, fosse ela industrial, natural ou escória.

A utilização de agregados naturais acarreta em aumento semelhante de magnitude (cerca de $5 \%$ a $8 \%$ ) entre resistências de corpos de prova cilíndricos aos 35 e 180 dias de cura úmida; já a utilização de escória granulada de alto forno ocasiona um acréscimo de $20 \%$, confirmando assim, a hidratação de substâncias componentes do agregado siderúrgico ao decorrer do tempo, ativados com aquelas do próprio cimento presente na mistura (Tabela 47 e Figura 62). 
Tabela 46 - resultados de resistências à tração indireta por compressão diametral aos 180 dias

\begin{tabular}{|c|c|c|c|c|}
\hline \multirow{3}{*}{ CCR } & \multirow{3}{*}{$n$} & \multicolumn{3}{|c|}{ fct ${ }_{180}$} \\
\hline & & $\bar{x}$ & $\mathbf{s}$ & cv \\
\hline & & (MPa) & (MPa) & (\%) \\
\hline $\mathrm{CCR}-\mathrm{Al}$ & 6 & 2,7 & 0,1 & 1,5 \\
\hline $\mathrm{CCR}-\mathrm{AN}$ & 6 & 2,1 & 0,2 & 7,9 \\
\hline CCR - ESC & 6 & 1,8 & 0,1 & 5,4 \\
\hline
\end{tabular}

Tabela 47 - variação porcentual das resistências à tração em compressão diametral aos 180 dias em relação aos 35 dias e à mistura padrão (180 dias)

\begin{tabular}{ccc}
\hline CCR & $\begin{array}{c}\text { Variação porcentual (\%) } \\
\text { aos } \mathbf{1 8 0} \text { dias } \\
\text { fct }_{180} \\
\text { (CCR - Al) }\end{array}$ \\
\hline fct & & - \\
CCR $-\mathrm{Al}$ & $+8,0$ & $-22,2$ \\
CCR $-\mathrm{AN}$ & $+5,0$ & $-33,3$ \\
CCR - ESC & $+20,0$ & -3 \\
\hline
\end{tabular}

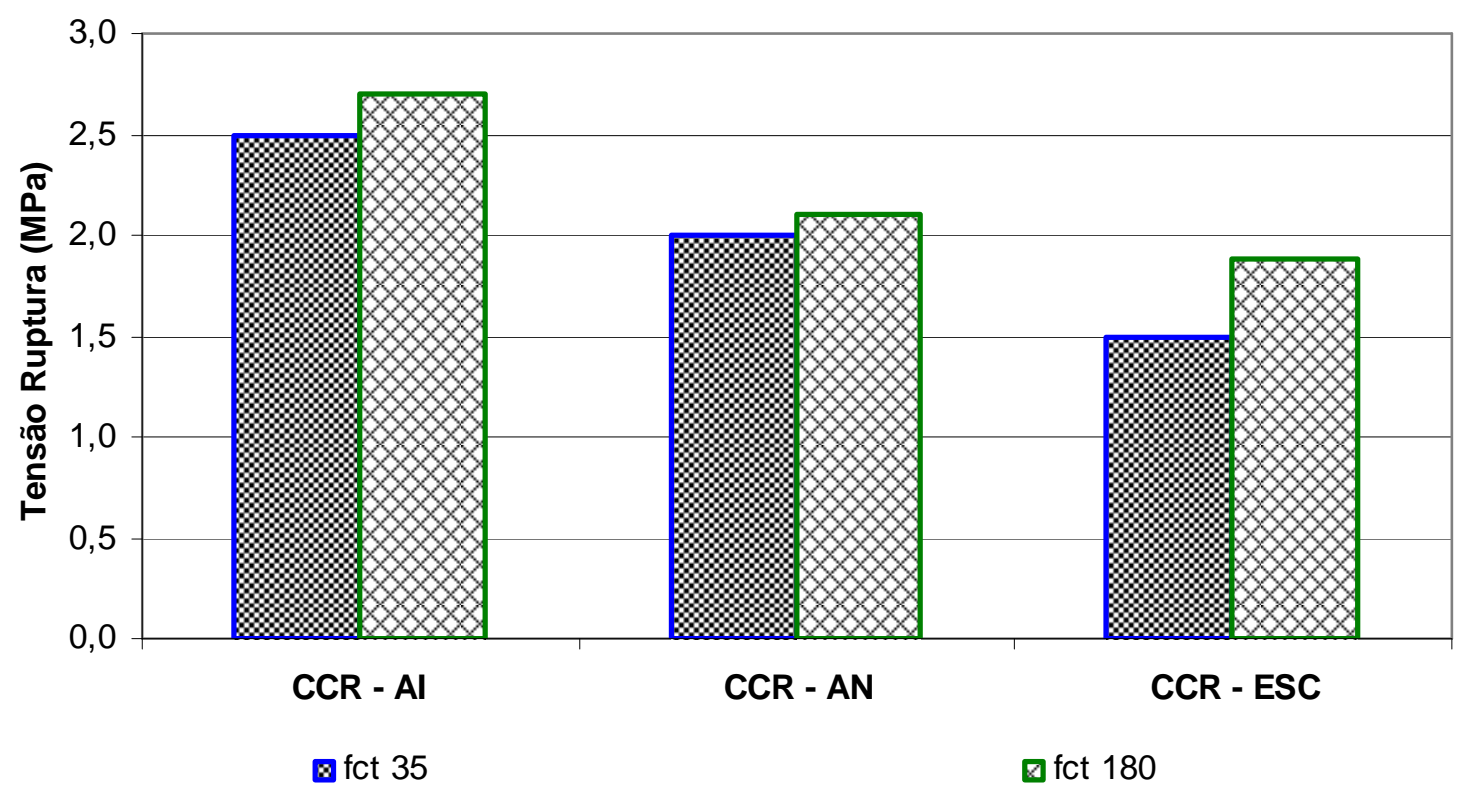

Figura 62 - resistências à tração indireta por compressão diametral aos 35 e 180 dias 
Scandiuzzi e Battagin (1991) obtiveram que, quando se utiliza escória granulada de alto forno como agregado em concreto plástico vibrado (consumo de cimento - CP II - de $280 \mathrm{~kg} / \mathrm{m}^{3}$ e fator A/C 0,42), em termos de resistência á compressão, os valores obtidos aos 7 dias apresentam redução significativa (35 \%); porém, quando eram medidos aos 180 dias, os valores tendiam a serem semelhantes. No caso do CCR, neste estudo, foi verificada queda aos 7 dias de 53 \% e 35 \% nos ensaios de tração por compressão diametral e de tração na flexão; aos 180 dias, no ensaio de tração por compressão diametral, o valor continua a ser menor (33 \%). O baixo consumo de cimento do CCR $\left(100 \mathrm{~kg} / \mathrm{m}^{3}\right)$ e o tipo de cimento (CP III-40 RS, com até 70 \% de escória moída de alto forno) exercem papel fundamental para a hidratação da escória utilizada como agregado e seu ganho de resistência em idades avançadas, pois há menor teor de argamassa e menos componentes do clínquer Portland que possam ativar as propriedades cimentícias do agregado siderúrgico.

\subsubsection{Resistências à tração no ramo seco da curva de compactação}

Apresentam-se, na Tabela 48, os resultados médios de resistências à tração (por compressão diametral e na flexão) das misturas de CCR empregando umidade de compactação 1,5 \% abaixo da umidade ótima e na Tabela 49 são mostradas as variações porcentuais da utilização de materiais alternativos de fração areia (em comparação com a areia industrial) nos CCR moldados no ramo seco de compactação.

Percebe-se que as quedas de resistências à tração pela utilização de escória granulada de alto forno e areia natural em relação ao CCR - Al acontecem nas mesmas proporções que os concretos moldados na umidade ótima de compactação (10 \% a 20 \% e 40 \% a 50 \% para os CCR - AN e CCR - ESC, respectivamente). 
Tabela 48 - resultados de resistências à tração para os CCR estudados no ramo seco da curva de compactação

\begin{tabular}{|c|c|c|c|c|c|c|c|}
\hline \multirow[b]{2}{*}{ CCR } & \multirow[b]{2}{*}{$\mathbf{n}$} & \multicolumn{3}{|c|}{ fct $35-$ ramo seco } & \multicolumn{3}{|c|}{ fct, $\mathbf{f}_{35-\text { ramo seco }}$} \\
\hline & & $\begin{array}{c}\bar{x} \\
(\mathrm{MPa})\end{array}$ & $\begin{array}{c}\mathbf{S} \\
(\mathrm{MPa})\end{array}$ & $\begin{array}{l}\text { CV } \\
(\%)\end{array}$ & $\begin{array}{c}\bar{x} \\
(\mathrm{MPa})\end{array}$ & $\begin{array}{c}\mathrm{S} \\
(\mathrm{MPa})\end{array}$ & $\begin{array}{l}\text { cv } \\
(\%)\end{array}$ \\
\hline $\mathrm{CCR}-\mathrm{Al}$ & 6 & 2,2 & 0,2 & 9,8 & 3,7 & 0,4 & 10,6 \\
\hline CCR - AN & 6 & 1,8 & 0,1 & 5,9 & 3,1 & 0,1 & 3,7 \\
\hline CCR - ESC & 6 & 1,3 & 0,2 & 12,0 & 1,9 & 0,1 & 4,3 \\
\hline
\end{tabular}

Tabela 49 - variação porcentual das resistências à tração para os CCR estudados no ramo seco da curva de compactação

\begin{tabular}{|c|c|c|}
\hline \multirow{2}{*}{ CCR } & \multicolumn{2}{|c|}{ Variação porcentual (\%) } \\
\hline & fct $_{35}$ & $\mathrm{fct}_{,} \mathrm{f}_{35}$ \\
\hline $\mathrm{CCR}-\mathrm{Al}$ & & - \\
\hline $\mathrm{CCR}-\mathrm{AN}$ & $-18,2$ & $-16,2$ \\
\hline CCR - ESC & $-40,9$ & $-48,6$ \\
\hline
\end{tabular}

A confecção dos CCR no ramo seco da curva de compactação acarreta em queda nas resistências à tração (por compressão diametral) de forma semelhante para todos os concretos (próximas de $10 \%$ ); já no caso da resistência à tração na flexão, houve impacto de até $20 \%$ aproximadamente; estes fatos são constatados independentemente do tipo de material utilizado como fração areia (Tabela 50 e Figuras 63 e 64).

Tabela 50 - variação porcentual das resistências à tração para os entre os CCR moldados no ramo seco da curva de compactação e na umidade ótima

\begin{tabular}{ccc}
\hline \multirow{2}{*}{ CCR } & \multicolumn{2}{c}{ Variação porcentual (\%) } \\
& fct $_{\mathbf{3 5}}$ & fct, $^{\mathbf{3 5}}$ \\
\hline CCR - Al & $-12,0$ & $-11,9$ \\
CCR - AN & $-10,0$ & $-20,5$ \\
CCR-ESC & $-13,3$ & $-17,4$ \\
\hline
\end{tabular}




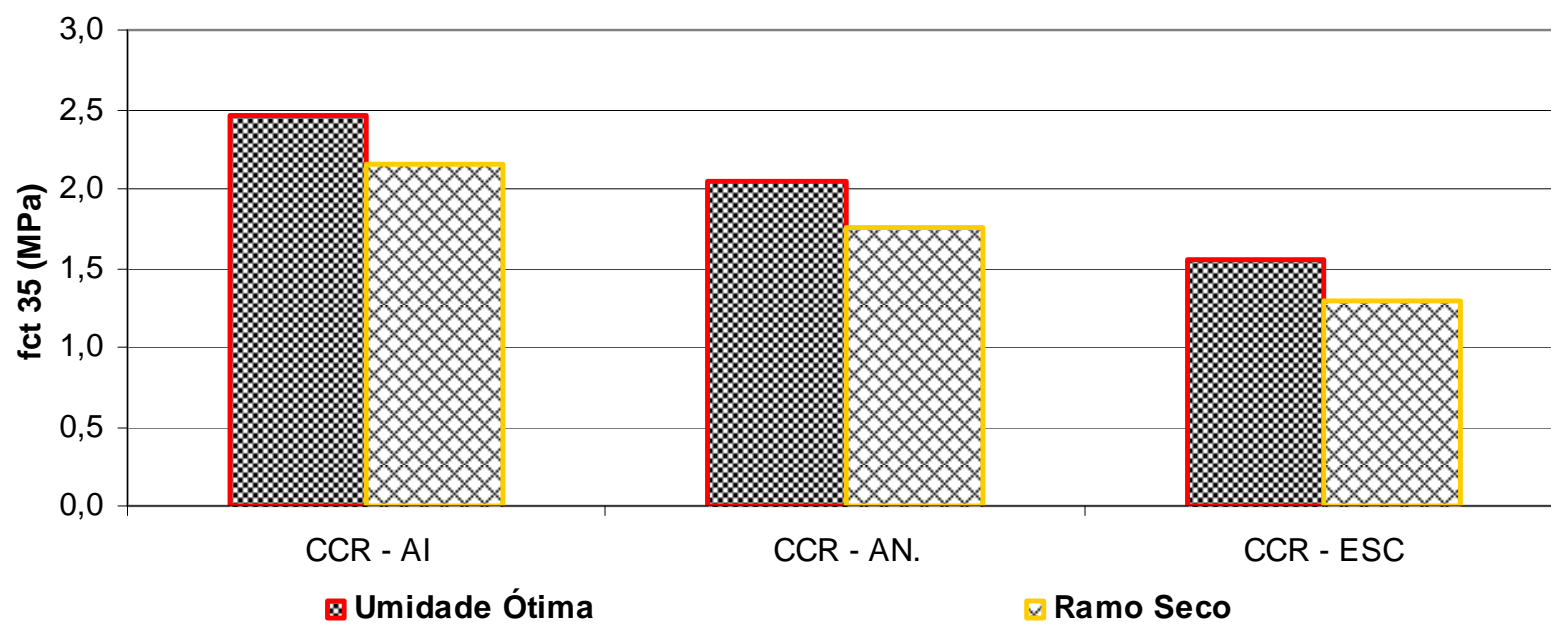

Figura 63 - comparativo entre resistências à tração indireta entre CCR compactados na umidade ótima e no ramo seco

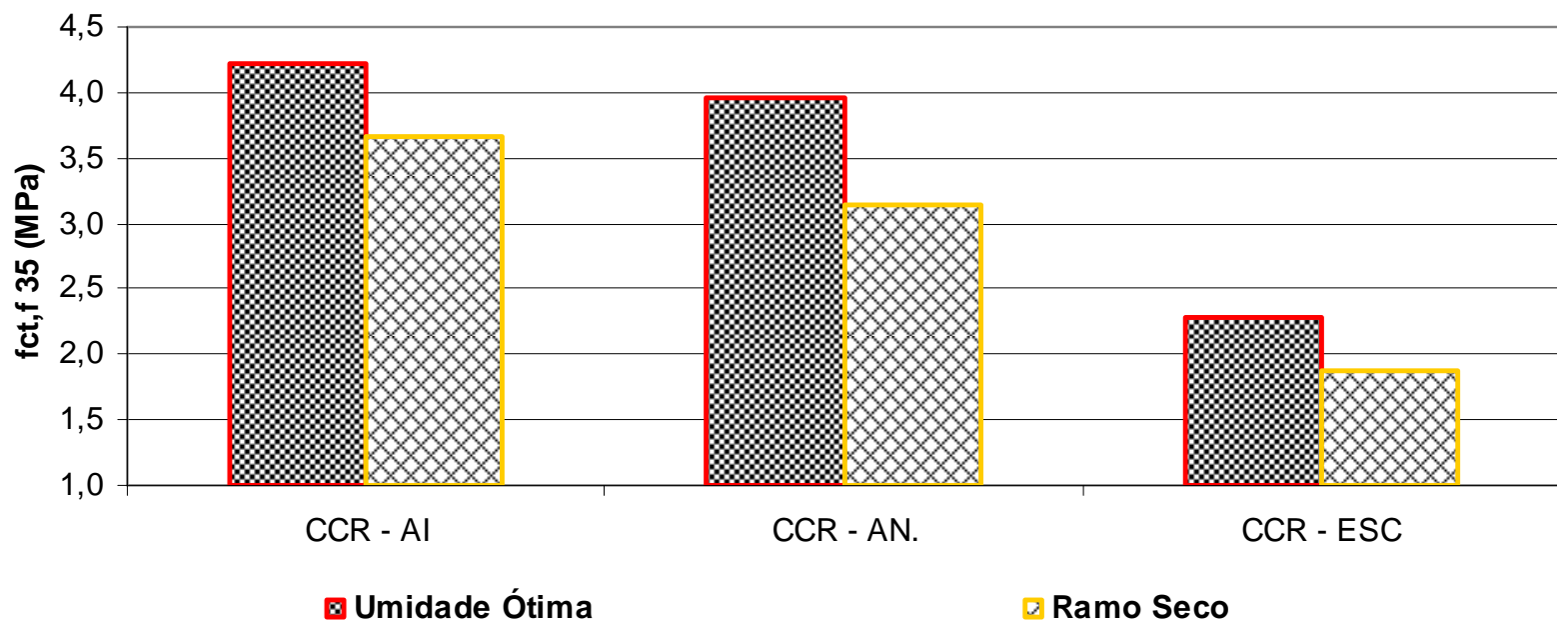

Figura 64 - comparativo entre resistências à tração na flexão entre CCR compactados na umidade ótima e no ramo seco

De acordo com Santos (1988), para misturas de CCR, quanto menor a umidade de compactação, menores são as resistências mecânicas do concreto. Todavia, conforme Pitta e Diaz (1991), maiores resistências são alcançadas com umidade de compactação pouco abaixo da ótima. Balbo (1993) conclui, através de análises laboratoriais, que a BGTC deve ser compactada na energia modificada e teor de umidade inferior ao ótimo. Experimentalmente neste estudo, utilizando umidade de compactação 1,5\% abaixo da ótima e energia normal para misturas de 
CCR, confirma-se a afirmação de Santos (1988) para todas as misturas ensaiadas, independente do material utilizado na fração areia. Este resultado, de certo modo, contesta as afirmações anteriores de Pitta e Diaz (1991); no caso dos resultados apresentados por Balbo (1993), deve considerar-se que os materiais, embora apresentem certas semelhanças, possuem microestruturas distintas.

Balbo (1993) cita que, à medida que se aumenta a relação $\mathrm{A} / \mathrm{C}$ em misturas de BGTC, parte do excesso de água, no curso do processo de hidratação é eliminado da pasta de cimento e vai alojar-se na superfície dos agregados, criando uma espécie de película d'água envolvente, o que impede o estabelecimento de ligações de boa qualidade entre os grãos dos agregados e os componentes cristalizados do cimento. Sob este aspecto, compactando-se o CCR abaixo da umidade ótima, a falta de água na mistura é prejudicial para a hidratação do cimento e há menores níveis de ligações químicas o que resulta em resistências à tração menores.

O CCR no estado fresco, moldado abaixo da umidade de compactação, apresenta maior tendência de segregação e, comparando superfícies destes concretos com as dos CCR confeccionados na umidade ótima, nota-se claramente a maior heterogeneidade da amostra (Figura 65).
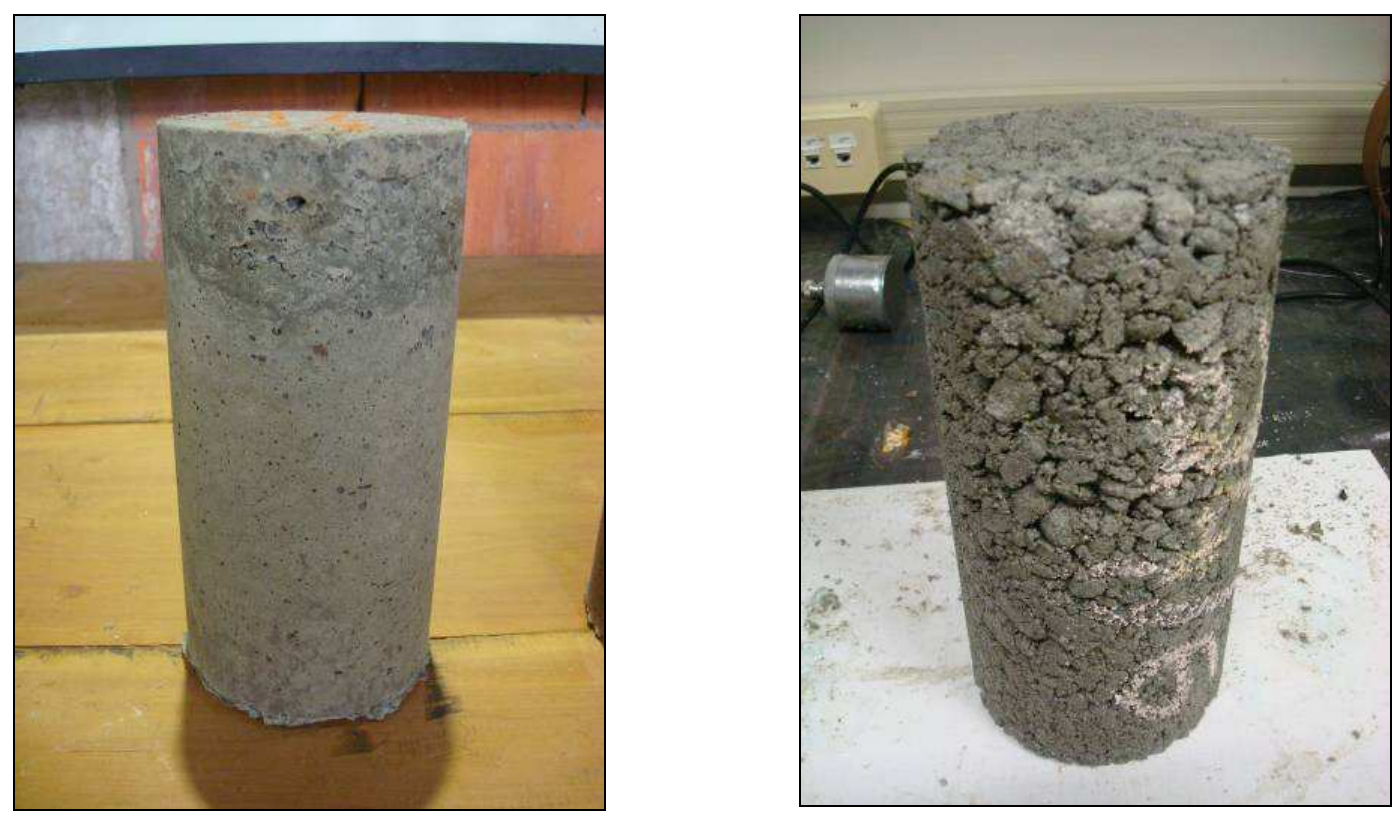

Figura 65 - homogeneidades de misturas de CCR - Al compactadas na umidade de compactação (esq.) e no ramo seco (dir.) 


\subsubsection{Relações entre as resistências à tração indireta em diferentes idades}

Analisando-se comparativamente as equações [1], [2] e [3] compostas por Muñoz e Vera (1991) - Capítulo 2 - com os dados obtidos experimentalmente na pesquisa (Figuras 66, 67 e 68), tomando as devidas precauções em relação às idades de ensaio, percebe-se uma tendência semelhante de coeficiente angular entre as retas de regressão nas relações entre $f_{c t} 7$ e $f_{c t} 28$ ou $f_{c t ~ 35}$. Contudo mostrase claramente (em todas as relações) que não é, de nenhuma forma, prudente a utilização de dados empíricos generalistas para outros tipos de CCR. Mesmo comparando-se equações de idades pouco diferentes entre si, há discrepância considerável entre magnitudes de valores. Por exemplo, tomando como referência resultados médios de $\mathrm{f}_{\mathrm{ct} 7}=1,0 \mathrm{MPa}$, estima-se, por meio da equação [1], $\mathrm{f}_{\mathrm{ct} 28}=$ 2,70 MPa; utilizando-se a equação resultante a partir dos resultados obtidos com os CCR estudados nesse trabalho tem-se que $\mathrm{f}_{\mathrm{ct}} 35=1,74 \mathrm{MPa}$, valor, portanto, 37 $\%$ inferior.

Na medida em que esta relação entre idades aumenta há maior discrepância entre valores, chegando-se a $620 \%$ de diferença (comparando-se $\mathrm{f}_{\mathrm{ct}} 7 \mathrm{com} \mathrm{f}_{\mathrm{ct}} 90$ ou $\left.f_{c t} 180\right)$. Ressalta-se que, em termos comparativos, esta diferenciação entre idades (90 dias para 180 dias) é pouco significativa, pois nestas condições a hidratação do cimento está em estágio avançado e não haveriam ganhos significativos de resistência (de um modo geral).

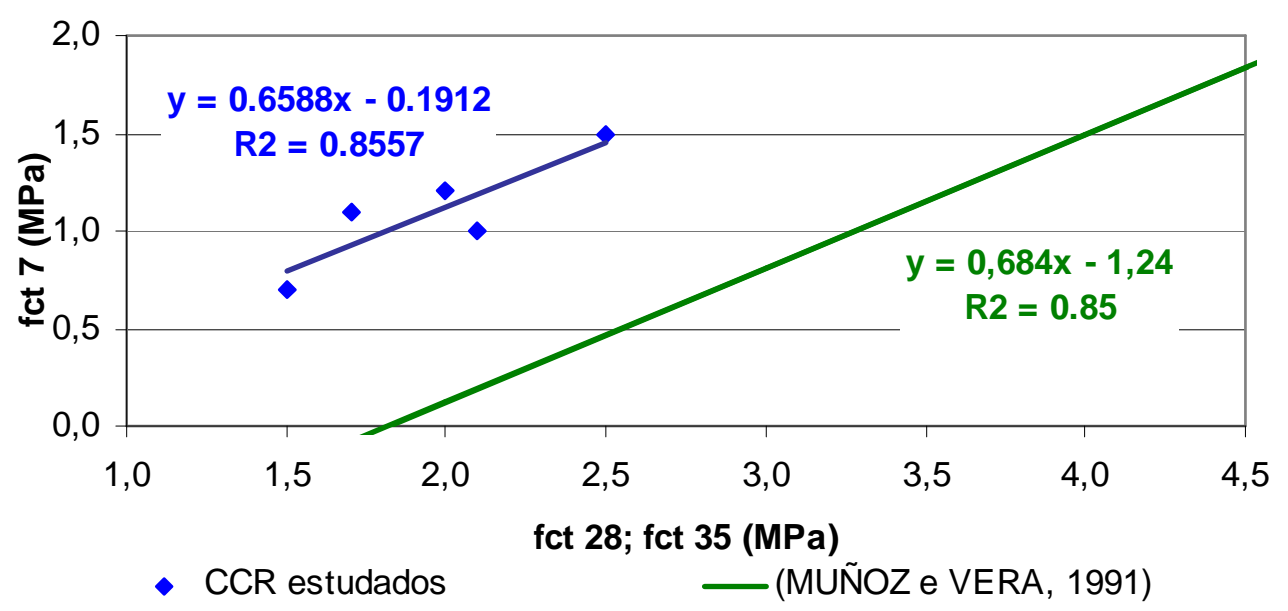

Figura 66 - relação entre resistências á tração indireta aos 7 e 35 dias 


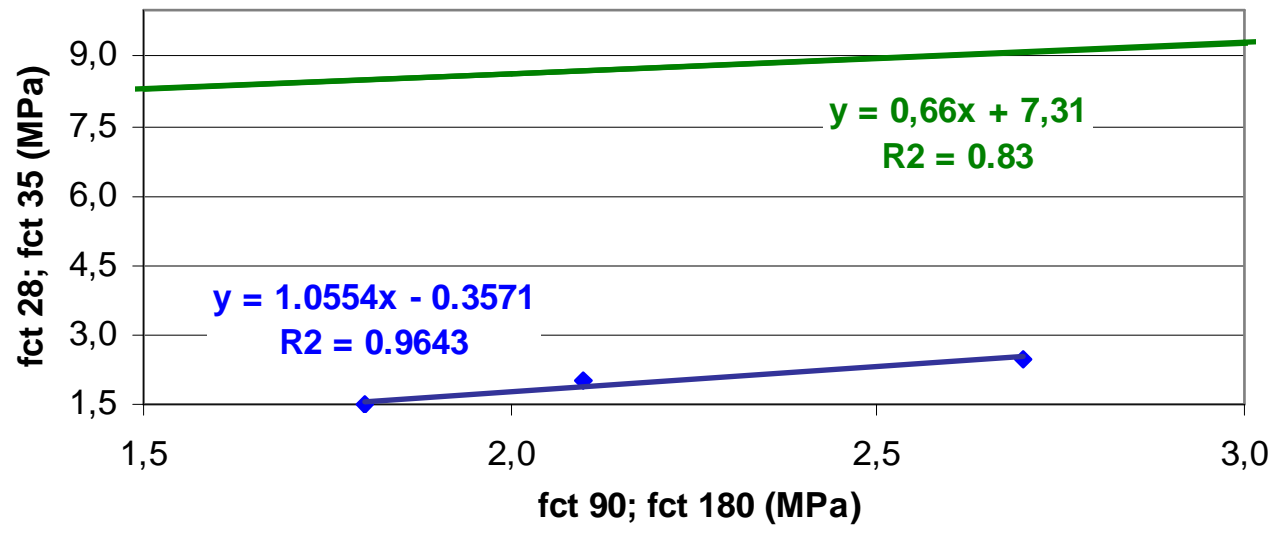

- CCR estudados (MUÑOZ e VERA, 1991)

Figura 67 - relação entre resistências à tração indireta aos 35 e 180 dias

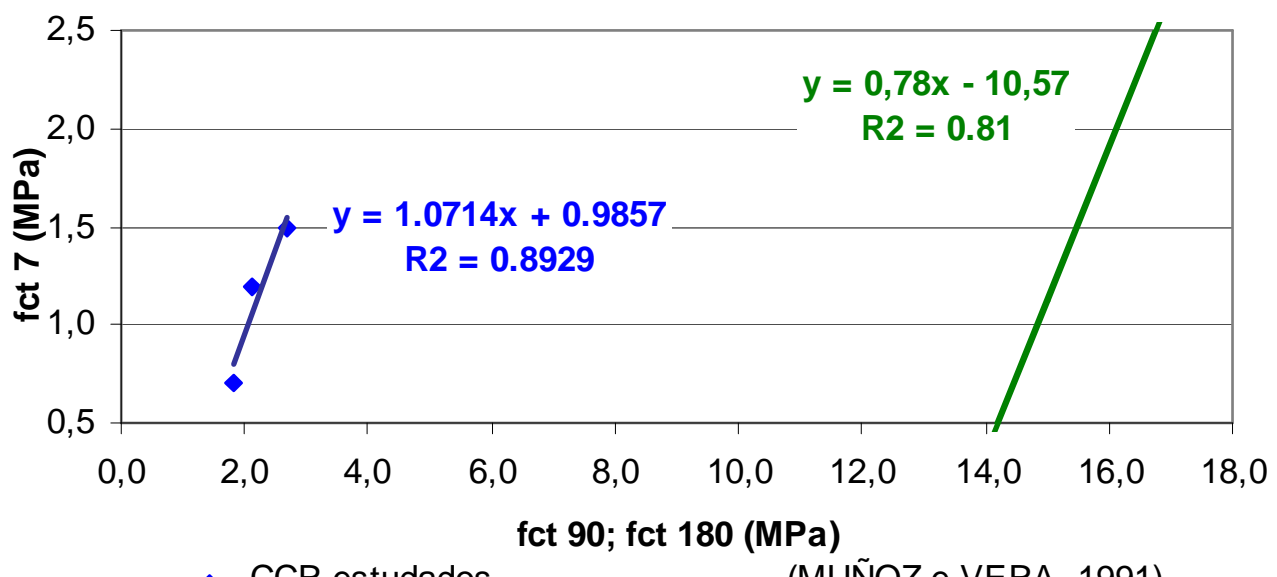

- CCR estudados — (MUÑOZ e VERA, 1991)

Figura 68 - relação entre resistências à tração indireta aos 7 e 180 dias

\subsubsection{Grau de compactação das camadas}

A utilização de diferentes naturezas de areias influência, entre outros parâmetros, o teor de água para a compactação das misturas de CCR, requerendo uma maior ou menor quantidade da mesma. Neste sentido, durante a confecção dos corpos de prova, percebeu-se exudação de água no fundo dos moldes cilíndricos e prismáticos, sendo tal fenômeno percebido de forma mais clara no CCR - Al, a mistura com menor umidade de compactação. 
Nota-se, através da Tabela 51 (onde A significa a camada de topo do corpo de prova cilíndrico e E a camada de fundo), que a utilização de areia industrial resulta em menor grau de compactação nas camadas inferiores dos corpos de prova cilíndricos; fato atribuído a exudação de água devido à compactação enérgica das camadas sobrejacentes. Esta maior quantidade de água presente nas camadas inferiores acarreta em maior afastamento dos grãos da estrutura, diminuindo sua massa específica.

Tabela 51 - grau de compactação das camadas do CCR - Al

\begin{tabular}{|c|c|c|c|c|c|c|c|c|}
\hline \multirow{3}{*}{$\begin{array}{l}\frac{\pi}{0} \\
\stackrel{\mathbb{\pi}}{\mathbb{E}} \\
0 \\
\mathbb{\pi}\end{array}$} & \multirow{3}{*}{ n } & \multicolumn{6}{|c|}{ Massa específica } & \multirow{3}{*}{$\begin{array}{c}\text { Grau de } \\
\text { Compactação } \\
(\%)\end{array}$} \\
\hline & & \multicolumn{3}{|c|}{ Por camada } & \multicolumn{3}{|c|}{ Total } & \\
\hline & & $\begin{array}{c}\bar{x} \\
\left(\mathbf{k g} / \mathrm{m}^{3}\right)\end{array}$ & $\begin{array}{c}S \\
\left(\mathrm{~kg} / \mathrm{m}^{3}\right)\end{array}$ & $\begin{array}{l}\text { cV } \\
(\%)\end{array}$ & $\begin{array}{c}\bar{x} \\
\left(\mathbf{k g} / \mathrm{m}^{3}\right)\end{array}$ & $\begin{array}{c}S \\
\left(\mathrm{~kg} / \mathrm{m}^{3}\right)\end{array}$ & $\begin{array}{l}\text { cv } \\
(\%)\end{array}$ & \\
\hline$A$ & 10 & 2.592 & 149 & 5,7 & & & & 105,4 \\
\hline$B$ & 10 & 2.702 & 107 & 3,9 & & & & 112,4 \\
\hline C & 10 & 2.594 & 124 & 4,8 & 2.406 & 30 & 1,1 & 107,8 \\
\hline $\mathrm{D}$ & 10 & 2.134 & 93 & 4,3 & & & & 88,7 \\
\hline$E$ & 10 & 2.009 & 101 & 5,0 & & & & 83,5 \\
\hline
\end{tabular}

A areia natural e a escória granulada de alto forno, além de requerer maiores quantidades de água para a compactação, não apresentam exudação tão abundante quanto o $\mathrm{CCR}-\mathrm{Al}$, tendo comportamentos semelhantes quanto ao grau de compactação (tendência de constância no grau de compactação em todas as camadas do CCR independente da profundidade, conforme mostrado nas Tabelas 52 e 53). 
Tabela 52 - grau de compactação das camadas do CCR - AN

\begin{tabular}{|c|c|c|c|c|c|c|c|c|}
\hline \multirow{3}{*}{$\begin{array}{l}\frac{\pi}{8} \\
\stackrel{\pi}{\pi} \\
\frac{\mathbb{\pi}}{J}\end{array}$} & \multirow{3}{*}{$\mathbf{n}$} & \multicolumn{6}{|c|}{ Massa específica } & \multirow{3}{*}{$\begin{array}{c}\text { Grau de } \\
\text { Compactação } \\
(\%)\end{array}$} \\
\hline & & \multicolumn{3}{|c|}{ Por camada } & \multicolumn{3}{|c|}{ Total } & \\
\hline & & $\begin{array}{c}\bar{x} \\
\left(\mathrm{~kg} / \mathrm{m}^{3}\right)\end{array}$ & $\begin{array}{c}\mathrm{S} \\
\left(\mathrm{kg} / \mathrm{m}^{3}\right)\end{array}$ & $\begin{array}{l}\text { cV } \\
(\%)\end{array}$ & $\begin{array}{c}\bar{x} \\
\left(\mathrm{~kg} / \mathrm{m}^{3}\right)\end{array}$ & $\begin{array}{c}\mathrm{s} \\
\left(\mathrm{kg} / \mathrm{m}^{3}\right)\end{array}$ & $\begin{array}{l}\text { cV } \\
(\%)\end{array}$ & \\
\hline A & 10 & 2.334 & 30 & 1,3 & & & & 98,6 \\
\hline B & 10 & 2.386 & 29 & 1,2 & & & & 99,1 \\
\hline C & 10 & 2.395 & 38 & 1,6 & 2.380 & 10 & 0,4 & 97,6 \\
\hline D & 10 & 2.387 & 43 & 1,8 & & & & 101,5 \\
\hline$E$ & 10 & 2.395 & 15 & 0,6 & & & & 101,6 \\
\hline
\end{tabular}

Tabela 53 - grau de compactação das camadas do CCR - ESC

\begin{tabular}{|c|c|c|c|c|c|c|c|c|}
\hline \multirow{3}{*}{ 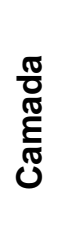 } & \multirow{3}{*}{$\mathbf{n}$} & \multicolumn{6}{|c|}{ Massa específica } & \multirow{3}{*}{$\begin{array}{c}\text { Grau de } \\
\text { Compactação } \\
(\%)\end{array}$} \\
\hline & & \multicolumn{3}{|c|}{ Por camada } & \multicolumn{3}{|c|}{ Total } & \\
\hline & & $\begin{array}{c}\bar{x} \\
\left(\mathrm{~kg} / \mathrm{m}^{3}\right)\end{array}$ & $\begin{array}{c}\mathrm{s} \\
\left(\mathrm{kg} / \mathrm{m}^{3}\right)\end{array}$ & $\begin{array}{l}\text { cv } \\
(\%)\end{array}$ & $\begin{array}{c}\bar{x} \\
\left(\mathrm{~kg} / \mathrm{m}^{3}\right)\end{array}$ & $\begin{array}{c}\mathrm{s} \\
\left(\mathrm{kg} / \mathrm{m}^{3}\right)\end{array}$ & $\begin{array}{l}\text { cv } \\
(\%)\end{array}$ & \\
\hline A & 10 & 2.130 & 60 & 2,8 & & & & 101,8 \\
\hline B & 10 & 2.116 & 74 & 3,5 & & & & 99,8 \\
\hline C & 10 & 2.128 & 47 & 2,2 & 2.124 & 26 & 0,4 & 101,1 \\
\hline D & 10 & 2.121 & 43 & 2,0 & & & & 100,8 \\
\hline$E$ & 10 & 2.124 & 44 & 2,1 & & & & 100,8 \\
\hline
\end{tabular}

Percebe-se, em todos os CCR, que a utilização de colarinho para compactação da camada de topo do corpo de prova cilíndrico (A) não prejudica seu adensamento enérgico, tendo grau de compactação próximo aos $100 \%$.

llustra-se, nas Figuras 69, 70 e 71, a variação da massa específica em função da profundidade média da camada compactada (z) para os CCR utilizando areia industrial, areia natural e escória granulada de alto forno, respectivamente; mostrando a diferença de tal parâmetro em relação ao material de granulometria miúda utilizada. 


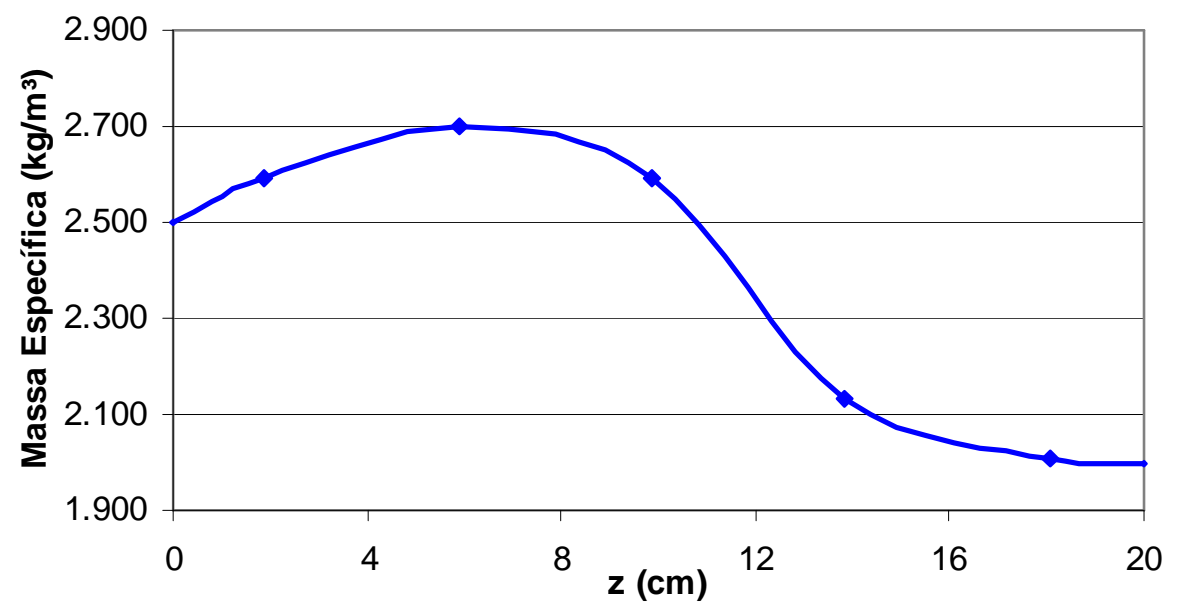

Figura 69 - variação da massa específica ao longo das camadas do CCR - Al em corpos de prova cilíndricos

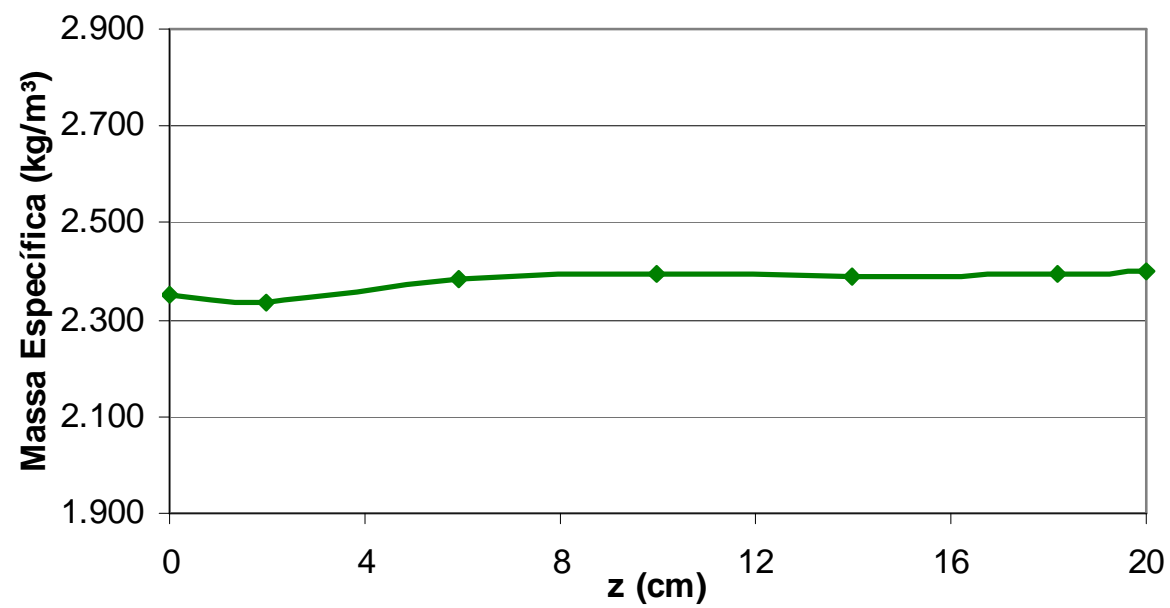

Figura 70 - variação da massa específica ao longo das camadas do CCR - AN em corpos de prova cilíndricos 


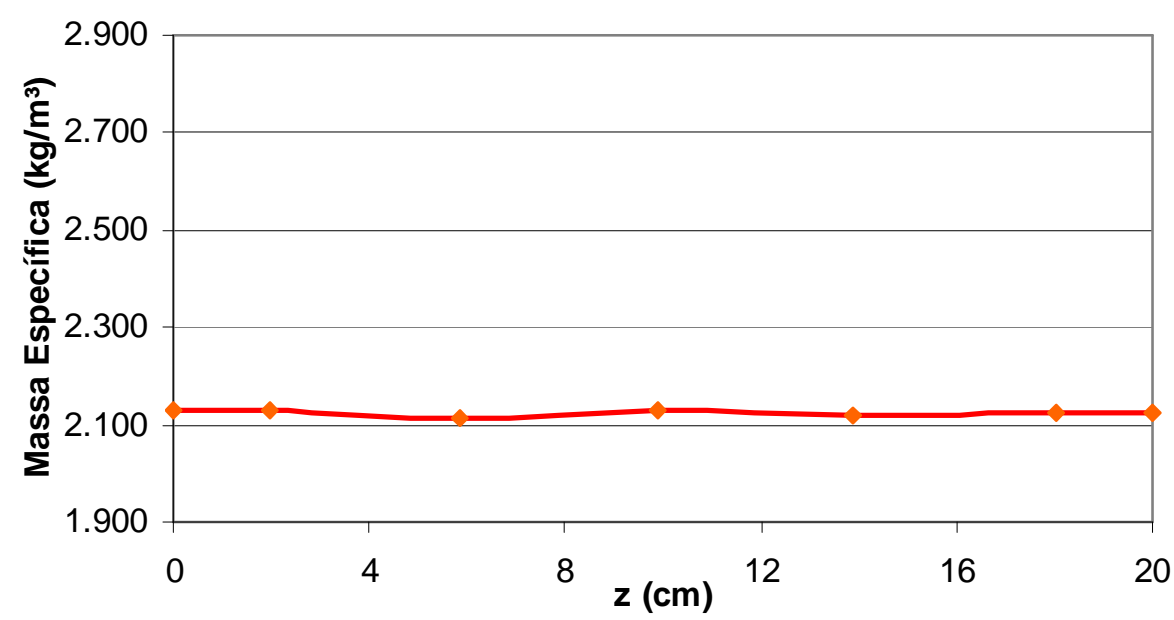

Figura 71 - variação da massa específica ao longo das camadas do CCR - ESC em corpos de prova cilíndricos

\subsubsection{Módulos de elasticidade estáticos aos 35 dias}

Apresentam-se, nas Tabelas 54 a 58, os resultados médios dos módulos de elasticidade obtidos para corpos de prova cilíndricos $-c-e$ prismáticos $-p-$ (com instrumentação por meio de straingages e LVDT) dos CCR estudados (ao nível de $70 \%$ da tensão de ruptura).

Tabela 54 - valores de módulo de elasticidade estático do CCR - Al (35 dias)

\begin{tabular}{ccccccccc}
\hline & & \multicolumn{3}{|c|}{$\mathbf{E}_{\text {straingage }}$} & \multicolumn{3}{c}{$\mathbf{E}_{\text {LVDT }}$} \\
$\mathbf{C P}$ & $\mathbf{n}$ & $\bar{x}$ & $\mathbf{s}$ & $\mathbf{c v}$ & $\bar{x}$ & $\mathbf{s}$ & $\mathbf{c v}$ \\
& & $(\mathrm{GPa})$ & $(\mathrm{GPa})$ & $(\%)$ & $(\mathrm{GPa})$ & $(\mathrm{GPa})$ & $(\%)$ \\
\hline $\mathrm{C}$ & 6 & 32,1 & 3,5 & 10,9 & - & - & - \\
$\mathrm{p}$ & 6 & 28,6 & 4,4 & 15,3 & 24,3 & 3,5 & 14,4 \\
\hline
\end{tabular}

Tabela 55 - valores de módulo de elasticidade estático do CCR - AN (35 dias)

\begin{tabular}{cccccccc}
\hline & & \multicolumn{3}{|c|}{$\mathbf{E}_{\text {straingage }}$} & \multicolumn{3}{c}{$\mathbf{E}_{\text {LVDT }}$} \\
$\mathbf{C P}$ & $\mathbf{n}$ & $\bar{x}$ & $\mathbf{s}$ & $\mathbf{c v}$ & $\bar{x}$ & $\mathbf{s}$ & $\mathbf{c v}$ \\
& & $(\mathrm{GPa})$ & $(\mathrm{GPa})$ & $(\%)$ & $(\mathrm{GPa})$ & $(\mathrm{GPa})$ & $(\%)$ \\
\hline $\mathrm{C}$ & 6 & 31,5 & 4,7 & 14,8 & - & - & - \\
$\mathrm{p}$ & 6 & 31,4 & 4,5 & 14,5 & 27,6 & 6,1 & 22,2 \\
\hline
\end{tabular}


Tabela 56 - valores de módulo de elasticidade estático do CCR - ESC (35 dias)

\begin{tabular}{cccccccc}
\hline & & \multicolumn{3}{|c}{$\mathbf{E}_{\text {straingage }}$} & \multicolumn{3}{c}{$\mathrm{E}_{\text {LVDT }}$} \\
$\mathbf{C P}$ & $\mathbf{n}$ & $\bar{x}$ & $\mathbf{s}$ & $\mathbf{c v}$ & $\bar{x}$ & $\mathbf{s}$ & $\mathbf{c v}$ \\
& & $(\mathrm{GPa})$ & $(\mathrm{GPa})$ & $(\%)$ & $(\mathrm{GPa})$ & $(\mathrm{GPa})$ & $(\%)$ \\
\hline $\mathrm{C}$ & 6 & 21,9 & 0,9 & 4,1 & - & - & - \\
$\mathrm{p}$ & 6 & 19,1 & 0,6 & 2,9 & 14,7 & 0,9 & 6,7 \\
\hline
\end{tabular}

Tabela 57 - valores de módulos de elasticidade estáticos do CCR - Al/ESC (35 dias)

\begin{tabular}{ccccccccc}
\hline & & \multicolumn{3}{|c|}{$\mathbf{E}_{\text {straingage }}$} & \multicolumn{3}{c}{$\mathbf{E}_{\text {LVDT }}$} \\
$\mathbf{C P}$ & $\mathbf{n}$ & $\bar{x}$ & $\mathbf{s}$ & $\mathbf{c v}$ & $\bar{x}$ & $\mathbf{s}$ & $\mathbf{c v}$ \\
& & $(\mathrm{GPa})$ & $(\mathrm{GPa})$ & $(\%)$ & $(\mathrm{GPa})$ & $(\mathrm{GPa})$ & $(\%)$ \\
\hline $\mathrm{C}$ & 6 & 20,2 & 0,6 & 2,7 & - & - & - \\
$\mathrm{p}$ & 6 & 17,5 & 1,2 & 7,2 & 14,1 & 0,5 & 3,6 \\
\hline
\end{tabular}

Tabela 58 - valores de módulos de elasticidade estáticos do CCR - AN/ESC (35 dias)

\begin{tabular}{ccccccccc}
\hline & & \multicolumn{3}{|c|}{$\mathbf{E}_{\text {straingage }}$} & \multicolumn{3}{c}{$\mathbf{E}_{\text {LVDT }}$} \\
$\mathbf{C P}$ & $\mathbf{n}$ & $\bar{x}$ & $\mathbf{s}$ & $\mathbf{c v}$ & $\bar{x}$ & $\mathbf{s}$ & $\mathbf{c v}$ \\
& & $(\mathrm{GPa})$ & $(\mathrm{GPa})$ & $(\%)$ & $(\mathrm{GPa})$ & $(\mathrm{GPa})$ & $(\%)$ \\
\hline $\mathrm{C}$ & 6 & 26,8 & 2,8 & 10,6 & - & - & - \\
$\mathrm{p}$ & 6 & 31,2 & 2,7 & 8,6 & 32,6 & 3,0 & 9,3 \\
\hline
\end{tabular}

Os valores de módulos de elasticidade obtidos por analogia de Möhr e pela curva tensão x deformação diferem-se em cerca de $18 \%$ a $36 \%$, sendo em geral maiores quando obtidos por meio do registro de deformação no straingage de contato, à exceção da mistura com 50 \% de escória granulada de alto forno e 50 \% de areia natural, conforme Figura 72. 


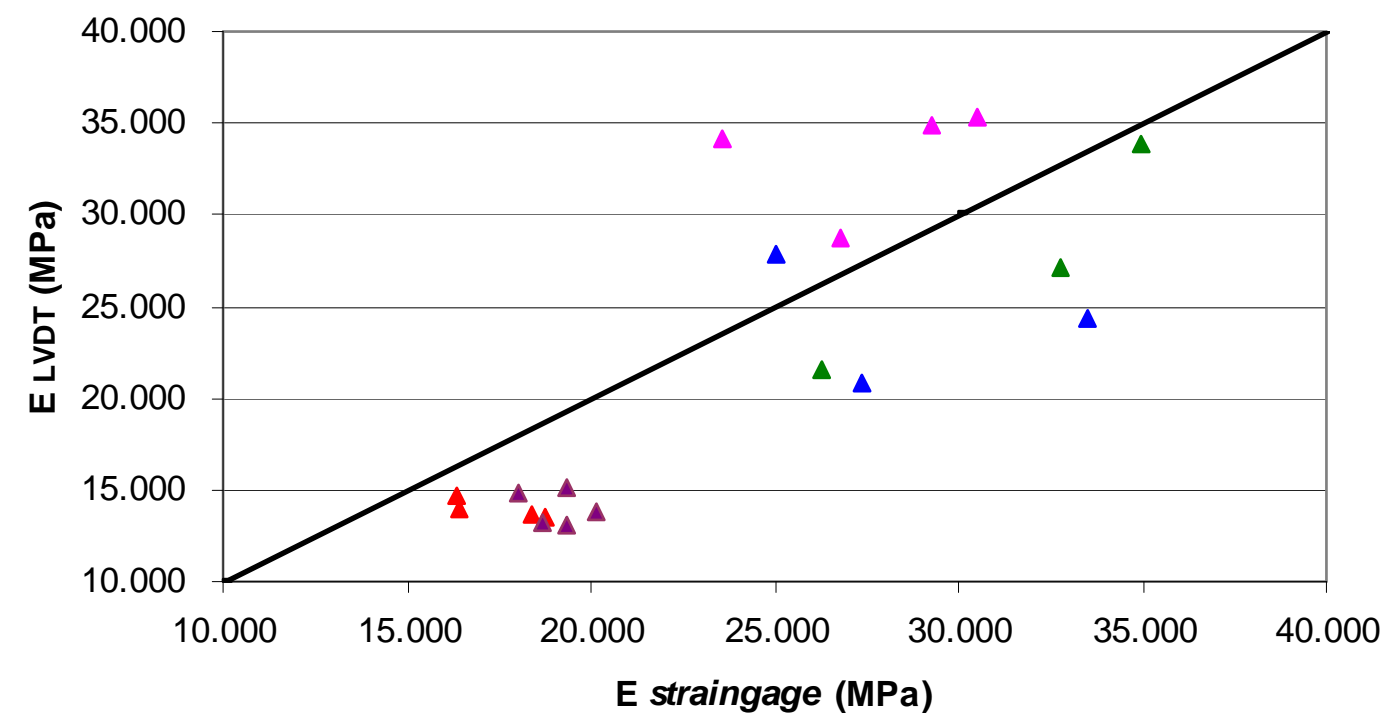

$\triangle \mathrm{CCR}-\mathrm{Al} \triangle \mathrm{CCR}-\mathrm{AN} \triangle \mathrm{CCR}-\mathrm{Al} / \mathrm{ESC} \triangle \mathrm{CCR}-\mathrm{AN} / \mathrm{ESC} \triangle \mathrm{CCR}-\mathrm{ESC}$

Figura 72 - relação entre módulos de elasticidade estáticos medidos em corpos de prova prismáticos

Observa-se, por meio da Tabela 59 e da Figura 73, que a utilização de areia industrial e areia natural resultam em módulos de elasticidade semelhantes; a ação da escória granulada de alto forno em conjunto com a areia industrial apresenta redução expressiva do módulo de elasticidade ao nível da incorporação total do resíduo siderúrgico (30\% a $40 \%$ ) e, tal diminuição, não é percebida quando empregada em conjunto com a areia natural, quando ocorre redução de $16 \%$ no módulo de elasticidade obtido da curva tensão $x$ deformação (em corpos de prova cilíndricos), acréscimo de $9 \%$ em corpos de prova prismáticos (curva tensão $x$ deformação) e aumento de $34 \%$ na obtenção do módulo de elasticidade estático por analogia de Möhr. Ao se considerar a dispersão presente nos resultados de módulo de elasticidade, pode-se afirmar que a presença de grande quantidade de escória contribui para uma redução expressiva de tal parâmetro. 
Tabela 59 - variação porcentual dos resultados de módulos de elasticidade estático em comparação com o CCR padrão

\begin{tabular}{ccc|c}
\hline & \multicolumn{3}{c}{ Variação Porcentual } \\
CCR & \multicolumn{2}{c}{$\mathbf{E}_{\text {straingage }}$} & $\mathbf{E}_{\text {LVDT }}$ \\
& cilindros & prismas & prismas \\
\hline CCR - Al & - & - & - \\
CCR - AN & $-3,4$ & $+9,8$ & $+13,6$ \\
CCR - ESC & $-31,8$ & $-33,2$ & $-39,5$ \\
CCR - Al/ESC & $-37,1$ & $-38,8$ & $-41,9$ \\
CCR - AN/ESC & $-16,5$ & $+9,1$ & $+34,1$ \\
\hline
\end{tabular}

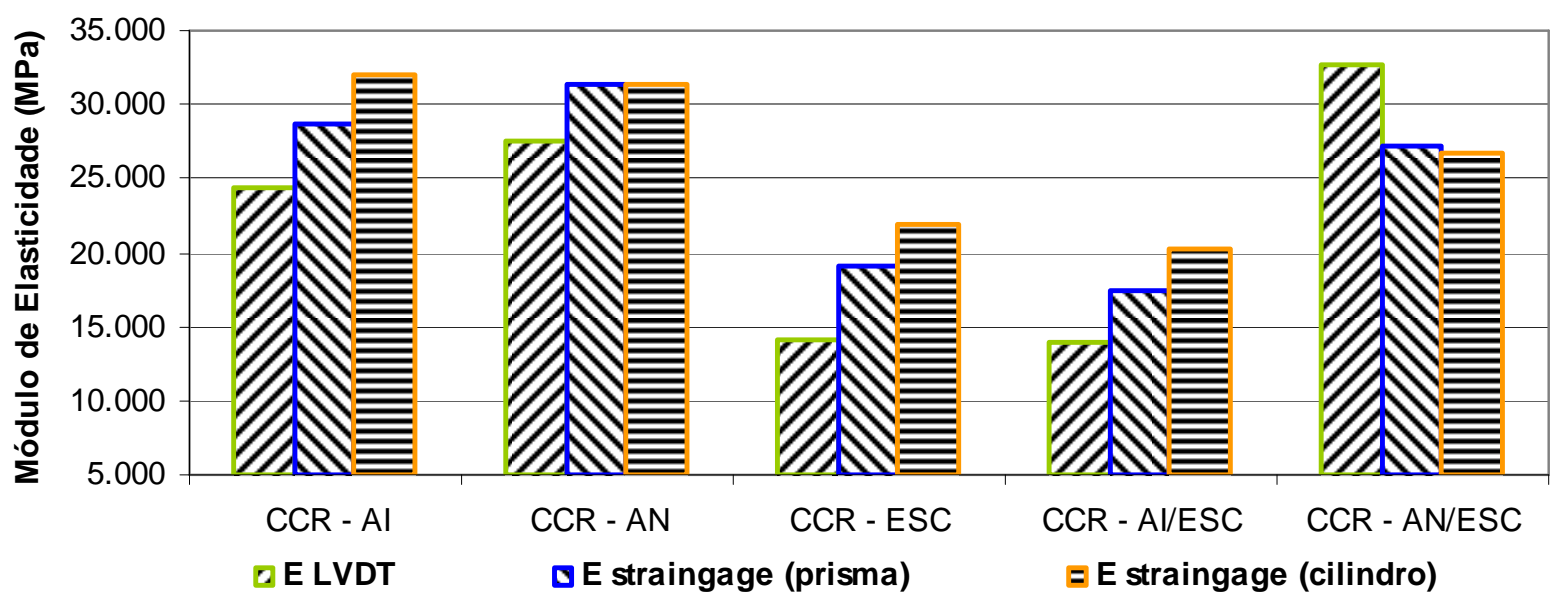

Figura 73 - comparativo entre módulos de elasticidade estáticos dos CCR compostos

\subsubsection{Módulos de elasticidade estáticos aos 180 dias}

Apresentam-se, na Tabela 60, os valores de módulos de elasticidade medidos em corpos de prova cilíndricos aos 180 dias de cura em câmara úmida. Percebe-se que, em comparação com dados obtidos aos 35 dias, os valores de módulo de elasticidade em corpos de prova cilíndricos (empregando straingages) são semelhantes (diferenciando-se no máximo $14 \%$ e empregando-se a substituição total do agregado miúdo por escória granulada de alto forno redundou em diminuição de 44 \% em tal parâmetro, conforme Tabela 61 e Figura 74. 
Tabela 60 - valores de módulo de elasticidade obtidos por straingage aos 180 dias

\begin{tabular}{ccccc}
\hline CCR & $\mathbf{n}$ & $\bar{x}$ & $\mathbf{s}$ & $\mathbf{~ c v}$ \\
& & $(\mathrm{GPa})$ & $(\mathrm{GPa})$ & $(\%)$ \\
$\mathrm{CCR}-\mathrm{Al}$ & 6 & 33,6 & 2,1 & 5,9 \\
$\mathrm{CCR}-\mathrm{AN}$ & 6 & 27,1 & 1,3 & 4,9 \\
$\mathrm{CCR}-\mathrm{ESC}$ & 6 & 18,8 & 2,7 & 14,3 \\
\hline
\end{tabular}

Tabela 61 - variações porcentuais dos módulos de elasticidade aos 180 dias em relação ao CCR padrão e aos dados obtidos aos 35 dias

\begin{tabular}{cccc}
\hline CCR & $\mathbf{n}$ & \multicolumn{2}{c}{$\begin{array}{c}\text { Variação porcentual (\%) } \\
\text { straingage 180 }\end{array}$} \\
& & CCR - Al & 35 dias \\
\hline CCR-Al & 6 & - & $+4,7$ \\
CCR-AN & 6 & $-19,3$ & $-13,9$ \\
CCR-ESC & 6 & $-44,0$ & $-14,1$ \\
\hline
\end{tabular}

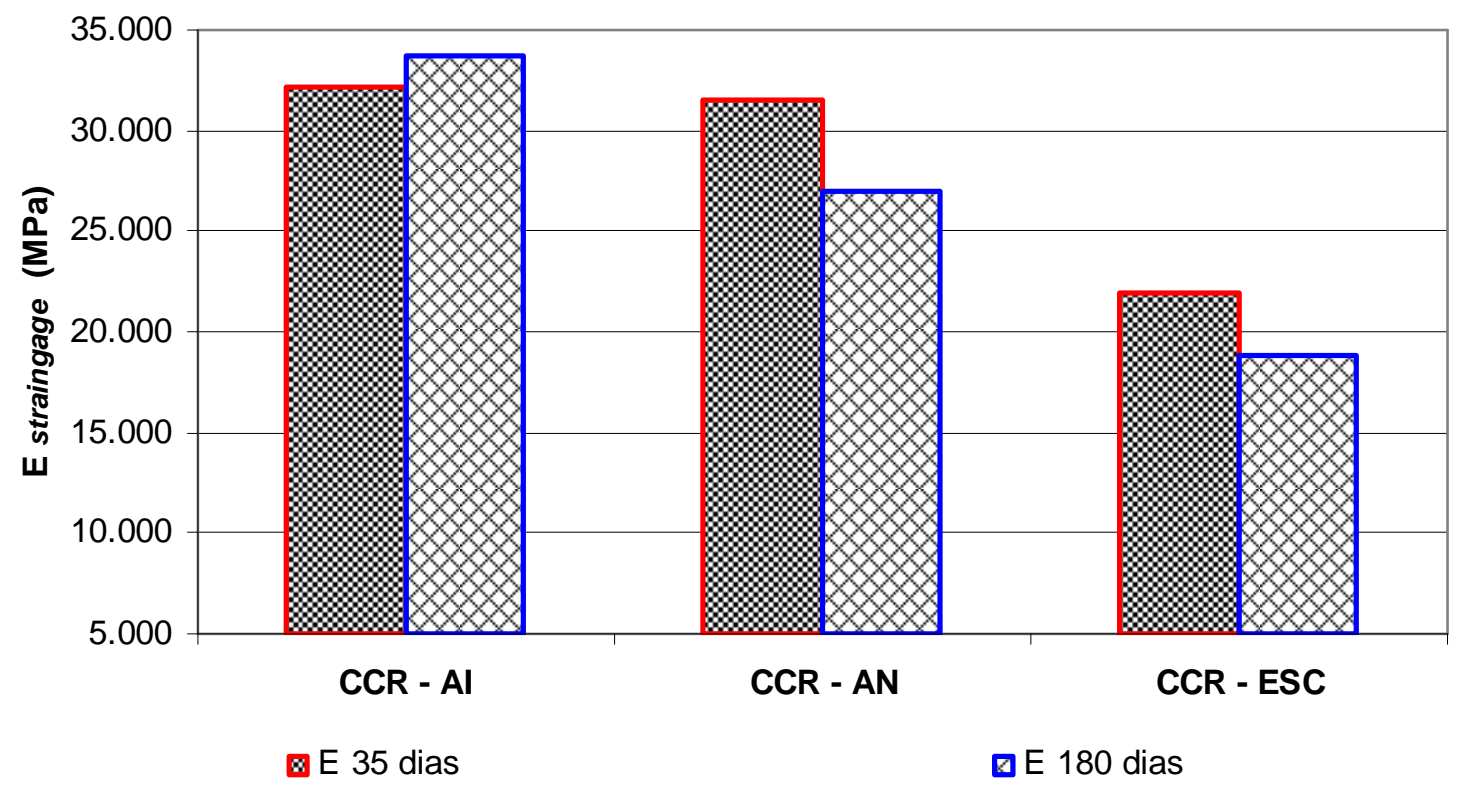

Figura 74 - comparativo entre módulos de elasticidade obtidos em corpos de prova cilíndricos aos 35 e 180 dias 


\subsubsection{Módulos de elasticidade estáticos (ramo seco)}

Mostram-se, nas Tabelas 62 a 64, os valores médios de módulos de elasticidade obtidos por meio de straingages (curva tensão $x$ deformação) e LVDT (analogia de Möhr) em corpos de prova cilíndricos e prismáticos moldados 1,5\% abaixo da umidade de compactação.

Apresenta-se, na Figura 75, o comparativo entre os três tipos de medidas de módulos de elasticidade. Os valores de módulos de elasticidade obtidos por analogia de Möhr e pela curva tensão $x$ deformação diferem-se em cerca de $3 \%$ a $36 \%$, sendo, em geral, maiores quando obtidos por meio do registro da deformação; comportamento este, também verificado para os CCR compactados na umidade ótima.

Tabela 62 - valores médios de módulos de elasticidade estáticos do CCR - Al moldado no ramo seco (35 dias)

\begin{tabular}{ccccccccc}
\hline & & \multicolumn{3}{|c|}{$\mathbf{E}_{\text {straingage }}$} & \multicolumn{3}{c}{$\mathbf{E}_{\text {LVDT }}$} \\
$\mathbf{C P}$ & $\mathbf{n}$ & $\bar{x}$ & $\mathbf{s}$ & $\mathbf{c v}$ & $\bar{x}$ & $\mathbf{s}$ & $\mathbf{c v}$ \\
& & $(\mathrm{GPa})$ & $(\mathrm{GPa})$ & $(\%)$ & $(\mathrm{GPa})$ & $(\mathrm{GPa})$ & $(\%)$ \\
\hline $\mathrm{C}$ & 6 & 28,3 & 2,7 & 9,5 & - & - & - \\
$\mathrm{p}$ & 6 & 26,2 & 2,8 & 10,7 & 26,5 & 2,5 & 9,3 \\
\hline
\end{tabular}

Tabela 63 - valores médios de módulos de elasticidade estáticos do CCR - AN (35 dias)

\begin{tabular}{cccccccc}
\hline & & \multicolumn{3}{|c|}{$\mathbf{E}_{\text {straingage }}$} & \multicolumn{3}{c}{$\mathbf{E}_{\text {LVDT }}$} \\
$\mathbf{C P}$ & $\mathbf{n}$ & $\bar{x}$ & $\mathbf{s}$ & $\mathbf{c v}$ & $\bar{x}$ & $\mathbf{s}$ & $\mathbf{c v}$ \\
& & $(\mathrm{GPa})$ & $(\mathrm{GPa})$ & $(\%)$ & $(\mathrm{GPa})$ & $(\mathrm{GPa})$ & $(\%)$ \\
\hline $\mathrm{C}$ & 6 & 28,2 & 2,6 & 9,1 & - & - & - \\
$\mathrm{p}$ & 6 & 29,3 & 3,4 & 13,1 & 28,4 & 3,2 & 11,5 \\
\hline
\end{tabular}


Tabela 64 - valores médios de módulos de elasticidade estáticos do CCR - ESC (35 dias)

\begin{tabular}{cccccccc}
\hline & & \multicolumn{3}{|c|}{$\mathbf{E}_{\text {straingage }}$} & \multicolumn{3}{c}{$\mathbf{E}_{\text {LVDT }}$} \\
$\mathbf{C P}$ & $\mathbf{n}$ & $\bar{x}$ & $\mathbf{s}$ & $\mathbf{c v}$ & $\bar{x}$ & $\mathbf{s}$ & $\mathbf{c v}$ \\
& & $(\mathrm{GPa})$ & $(\mathrm{GPa})$ & $(\%)$ & $(\mathrm{GPa})$ & $(\mathrm{GPa})$ & $(\%)$ \\
\hline $\mathrm{C}$ & 6 & 24,2 & 4,7 & 19,7 & - & - & - \\
$\mathrm{p}$ & 6 & 22,2 & 0,7 & 3,1 & 16,3 & 3,7 & 22,8 \\
\hline
\end{tabular}

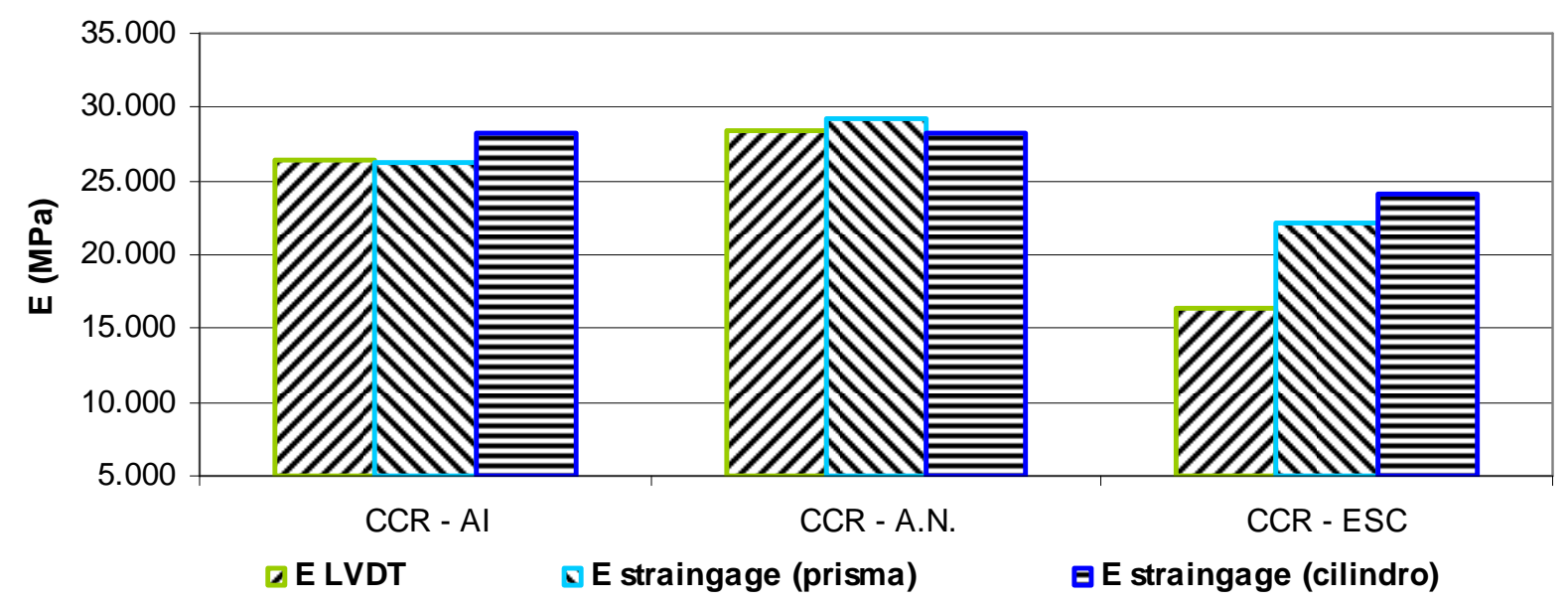

Figura 75 - comparativo entre módulos de elasticidade estáticos dos CCR moldados no ramo seco da curva de compactação

Nota-se, através da Tabela 65, que os valores de módulo de elasticidade dos CCR confeccionados no ramo seco apresentam resultados semelhantes aos CCR moldados na umidade ótima de compactação, diferenciando-se entre si cerca de $10 \%$. Observam-se reduções de aproximadamente $40 \%$ no valor deste parâmetro obtido por analogia de Möhr quando se utiliza escória granulada de alto forno (semelhante à redução ocorrida nos CCR moldados na umidade ótima) e de $15 \%$ nos valores de módulo de elasticidade medidos pelo registro de deformação no straingage de contato fixado. 
Tabela 65 - variações porcentuais dos módulos de elasticidade dos CCR no ramo seco em relação ao CCR padrão e aos dados obtidos para a moldagem realizada na umidade ótima de compactação

\begin{tabular}{|c|c|c|c|c|c|}
\hline \multirow{3}{*}{ CCR } & \multirow{3}{*}{$\mathrm{CP}$} & \multicolumn{4}{|c|}{ Variação Porcentual (\%) } \\
\hline & & \multicolumn{2}{|c|}{ Umidade ótima } & \multicolumn{2}{|c|}{ CCR - Al } \\
\hline & & $\mathbf{E}_{\text {straingage }}$ & $E_{\text {LVDT }}$ & $\mathbf{E}_{\text {straingage }}$ & $E_{\text {LVDT }}$ \\
\hline \multirow{2}{*}{$\mathrm{CCR}-\mathrm{Al}$} & c & $-11,8$ & - & - & - \\
\hline & $p$ & $-8,4$ & $+9,0$ & - & - \\
\hline \multirow{2}{*}{$\mathrm{CCR}-\mathrm{AN}$} & C & $-10,5$ & - & $-0,3$ & - \\
\hline & $p$ & $-6,7$ & $-5,8$ & $+11,8$ & $+7,2$ \\
\hline \multirow{2}{*}{ CCR - ESC } & c & $+10,5$ & - & $-14,5$ & - \\
\hline & $p$ & $+12,9$ & $+10,9$ & $-15,3$ & $-38,5$ \\
\hline
\end{tabular}

\subsubsection{Relação entre módulos de elasticidade e resistências à tração}

Em termos de utilização do CCR em pavimentos, a relação entre o módulo de elasticidade e a resistência estática é um indicador da vida de fadiga de misturas, uma vez que agrega informações de resistência e rigidez. Comparandose dois CCR, o de melhor desempenho seria o de menor razão entre estes parâmetros (baixa rigidez para evitar elevada absorção de tensões que levem ao trincamento prematuro da camada de base e elevada resistência à tração, uma vez que, em geral, uma maior resistência à ruptura é também associada à maior resistência à fadiga).

Apresentam-se na Figura 76 as razões entre módulo de elasticidade e resistências à tração para os CCR confeccionados na umidade ótima de compactação. Observa-se que o concreto com fração areia constituída de 50 \% escória granulada de alto forno e 50 \% areia industrial resultam em menores razões entre módulos de elasticidade e resistências à tração. As misturas compostas integralmente com areia industrial, areia natural ou escória granulada de alto forno apresentam relações semelhantes, com leve vantagem para o CCR Al. A utilização de $50 \%$ de areia natural e $50 \%$ de escória granulada de alto forno resulta na pior relação, sendo a mistura mais susceptível à ação de fadiga oriunda pelas cargas do tráfego. 


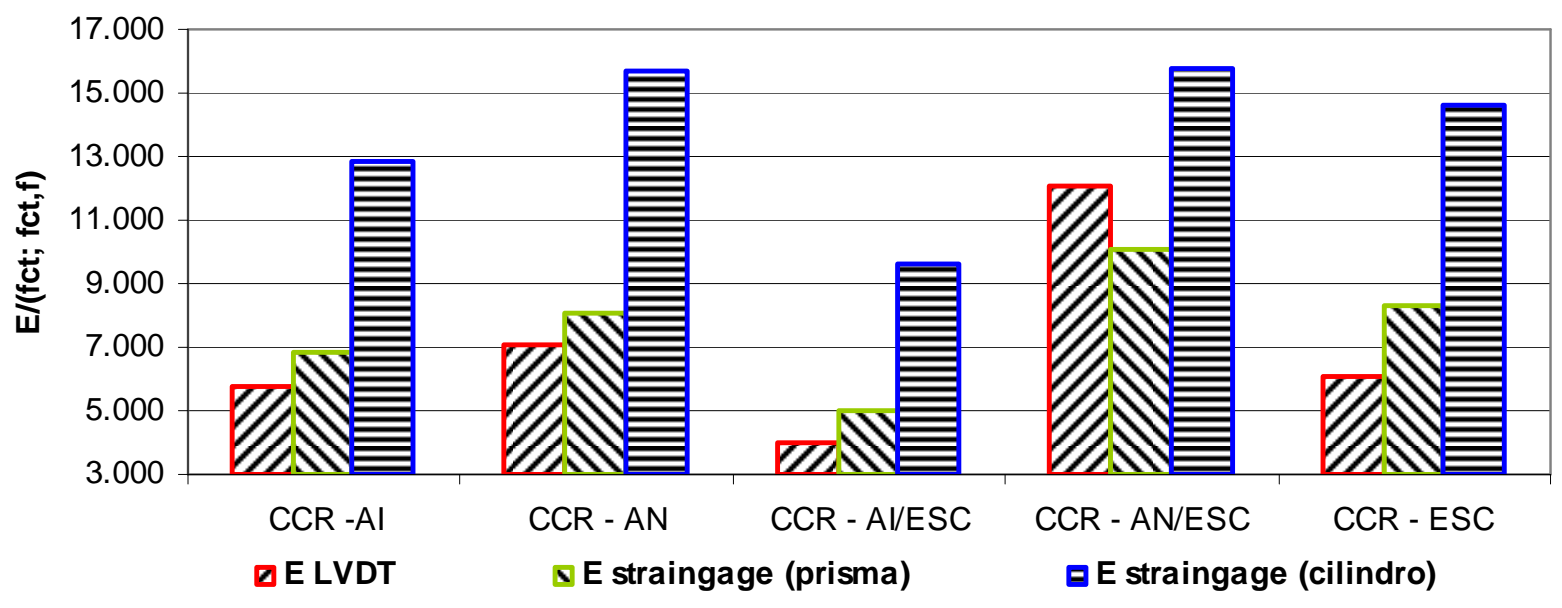

Figura 76 - comparativo da razão entre módulos de elasticidade estáticos e resistências à tração para os CCR moldados na umidade ótima de compactação

Quanto aos CCR moldados $1,5 \%$ abaixo da umidade de compactação (ramo seco) percebe-se pequena vantagem na utilização de areia industrial, seguido pela areia natural e escória granulada de alto forno (Figura 77); entretanto, todas estas misturas apresentam razões superiores àquelas moldadas na umidade ótima de compactação, sendo estas mais expressivas para a utilização de escória como areia, cerca de $28 \%$ a $42 \%$, conforme Tabela 66.

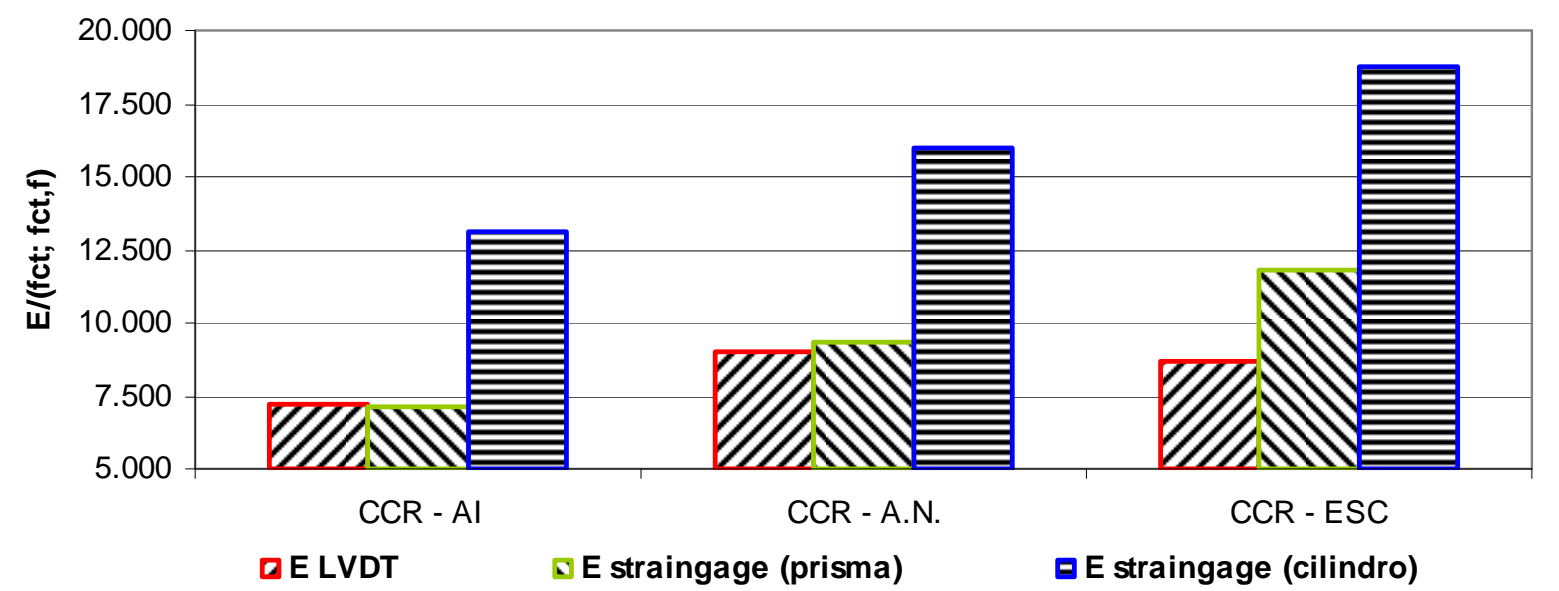

Figura 77 - razão entre módulos de elasticidade estáticos e resistências à tração para os CCR moldados no ramo seco da curva de compactação 
Tabela 66 - variação porcentual das relações de módulo de elasticidade e resistências à tração entre os CCR moldados na umidade ótima e no ramo seco de compactação

\begin{tabular}{c|cc|c}
\hline \multirow{2}{*}{ CCR } & \multicolumn{3}{c}{ Variação porcentual (\%) } \\
& $\mathbf{E}_{\text {straingage }}$ Cilindro & $\mathbf{E}_{\text {straingage }}$ Prisma & $\mathbf{E}_{\text {LVDT }}$ \\
\hline CCR - AI & $+2,4$ & $+4,9$ & $+24,9$ \\
CCR - AN & $+2,1$ & $+16,2$ & $+28,2$ \\
CCR-ESC & $+28,3$ & $+42,4$ & $+42,4$ \\
\hline
\end{tabular}

\subsubsection{Módulos de elasticidade dinâmicos}

Apresentam-se, nas Tabelas 67 a 71, os módulos de elasticidade dinâmicos aferidos pela propagação de onda ultrassônica em corpos de prova prismáticos e cilíndricos nas idades de 7 e 35 dias para todas as misturas e também 180 dias para os CCR - AI, CCR - AN e CCR - ESC.

Tabela 67 - valores de módulos de elasticidade dinâmicos do CCR - AI

\begin{tabular}{|c|c|c|c|c|c|c|c|c|c|c|c|c|}
\hline \multirow[b]{2}{*}{ CP } & \multicolumn{4}{|c|}{$\mathbf{E}_{\text {dinâmico } 7}$} & \multicolumn{4}{|c|}{$\mathbf{E}_{\text {dinâmico } 35}$} & \multicolumn{4}{|c|}{$\mathbf{E}_{\text {dinâmico } 180}$} \\
\hline & $\mathbf{n}$ & $\begin{array}{c}\bar{x} \\
(\mathrm{GPa})\end{array}$ & $\begin{array}{c}\text { s } \\
\text { (GPa) }\end{array}$ & $\begin{array}{l}\text { CV } \\
(\%)\end{array}$ & $\mathbf{n}$ & $\begin{array}{c}\bar{x} \\
(\mathrm{GPa})\end{array}$ & $\begin{array}{c}\text { s } \\
\text { (GPa) }\end{array}$ & $\begin{array}{l}\text { CV } \\
(\%)\end{array}$ & $\mathbf{n}$ & $\begin{array}{c}\bar{x} \\
(\mathrm{GPa})\end{array}$ & $\begin{array}{c}\text { s } \\
\text { (GPa) }\end{array}$ & $\begin{array}{l}\text { CV } \\
(\%)\end{array}$ \\
\hline C & 3 & 33,2 & 1,1 & 3,5 & 6 & 40,6 & 0,5 & 1,3 & 6 & 48,2 & 1,0 & 2,1 \\
\hline$p$ & 3 & 30,7 & 0,6 & 1,9 & 6 & 37,4 & 2,5 & 6,8 & - & - & - & - \\
\hline
\end{tabular}

Tabela 68 - valores de módulos de elasticidade dinâmicos do CCR - AN

\begin{tabular}{|c|c|c|c|c|c|c|c|c|c|c|c|c|}
\hline \multirow[b]{2}{*}{ CP } & \multicolumn{4}{|c|}{$E_{\text {dinâmico } 7}$} & \multicolumn{4}{|c|}{$\mathbf{E}_{\text {dinâmico } 35}$} & \multicolumn{4}{|c|}{$\mathbf{E}_{\text {dinâmico } 180}$} \\
\hline & $n$ & $\begin{array}{c}\bar{x} \\
(\mathrm{GPa})\end{array}$ & $\begin{array}{c}s \\
(\mathrm{GPa})\end{array}$ & $\begin{array}{l}\text { cv } \\
(\%)\end{array}$ & $n$ & $\begin{array}{c}\bar{x} \\
(\mathrm{GPa})\end{array}$ & $\begin{array}{c}\text { s } \\
(\mathrm{GPa})\end{array}$ & $\begin{array}{l}\text { cv } \\
(\%)\end{array}$ & $\mathbf{n}$ & $\begin{array}{c}\bar{x} \\
(\mathrm{GPa})\end{array}$ & $\begin{array}{c}s \\
(\mathrm{GPa})\end{array}$ & $\begin{array}{l}\text { CV } \\
(\%)\end{array}$ \\
\hline C & 3 & 30,7 & 0,7 & 2,3 & 6 & 37,4 & 1,3 & 3,4 & 6 & 42,7 & 0,5 & 1,3 \\
\hline$p$ & 3 & 26,7 & 0,9 & 3,2 & 6 & 37,2 & 1,2 & 3,3 & - & - & - & - \\
\hline
\end{tabular}


Tabela 69 - valores de módulos de elasticidade dinâmicos do CCR - ESC

\begin{tabular}{ccccccccccccc}
\hline & \multicolumn{4}{c}{$\mathbf{E}_{\text {dinâmico 7 }}$} & \multicolumn{4}{c}{$\mathbf{E}_{\text {dinâmico 35 }}$} & \multicolumn{3}{c}{$\mathbf{E}_{\text {dinâmico 180 }}$} \\
$\mathbf{C P}$ & $\mathbf{n}$ & $\bar{x}$ & $\mathbf{s}$ & $\mathbf{c v}$ & & $\bar{x}$ & $\mathbf{s}$ & $\mathbf{c v}$ & $\bar{x}$ & $\mathbf{s}$ & $\mathbf{c v}$ \\
& & $(\mathbf{G P a})$ & $(\mathbf{G P a})$ & $(\%)$ & $\mathbf{n}$ & $(\mathrm{GPa})$ & $(\mathrm{GPa})$ & $(\%)$ & $\mathbf{n}$ & $(\mathrm{GPa})$ & $(\mathrm{GPa})$ & $(\%)$ \\
\hline $\mathrm{C}$ & 3 & 16,9 & 0,2 & 1,1 & 6 & 25,5 & 0,5 & 2,1 & 6 & 28,8 & 0,9 & 3,1 \\
$\mathrm{p}$ & 3 & 16,0 & 1,4 & 8,6 & 6 & 21,8 & 0,5 & 2,3 & - & - & - & - \\
\hline
\end{tabular}

Tabela 70 - valores de módulos de elasticidade dinâmicos do CCR - Al/ESC

\begin{tabular}{ccccccccc}
\hline & \multicolumn{4}{c}{$\mathbf{E}_{\text {dinâmico 7 }}$} & \multicolumn{4}{c}{$\mathbf{E}_{\text {dinâmico } 35}$} \\
$\mathbf{C P}$ & & $\bar{x}$ & $\mathbf{s}$ & $\mathbf{c v}$ & & $\bar{x}$ & $\mathbf{s}$ & $\mathbf{c v}$ \\
& $\mathbf{n}$ & $(\mathrm{GPa})$ & $(\mathrm{GPa})$ & $(\%)$ & $\mathbf{n}$ & $(\mathrm{GPa})$ & $(\mathrm{GPa})$ & $(\%)$ \\
\hline $\mathrm{C}$ & 3 & 28,6 & 0,3 & 1,1 & 6 & 35,5 & 0,5 & 1,5 \\
$\mathrm{p}$ & 3 & 25,2 & 1,2 & 4,7 & 6 & 31,8 & 0,5 & 1,7 \\
\hline
\end{tabular}

Tabela 71 - valores de módulos de elasticidade dinâmicos do CCR - AN/ESC

\begin{tabular}{ccccccccc}
\hline & \multicolumn{4}{c}{$\mathbf{E}_{\text {dinâmico 7 }}$} & \multicolumn{4}{c}{$\mathbf{E}_{\text {dinâmico 35 }}$} \\
$\mathbf{C P}$ & $\mathbf{n}$ & $\bar{x}$ & $\mathbf{s}$ & $\mathbf{c v}$ & $\mathbf{x}$ & $\mathbf{s}$ & $\mathbf{c v}$ \\
& $\mathbf{n}$ & $(\mathrm{GPa})$ & $(\mathrm{GPa})$ & $(\%)$ & & $(\mathrm{GPa})$ & $(\mathrm{GPa})$ & $(\%)$ \\
\hline $\mathrm{C}$ & 3 & 25,3 & 0,2 & 0,8 & 6 & 33,2 & 0,8 & 2,4 \\
$\mathrm{p}$ & 3 & 21,6 & 0,5 & 2,2 & 6 & 31,8 & 1,2 & 3,8 \\
\hline
\end{tabular}

Mostram-se, conforme a Tabela 72, as variações porcentuais entre os módulos de elasticidade dinâmicos obtidos para os CCR usando escória granulada de alto forno e areia natural em relação ao concreto padrão, sendo este com areia industrial. Nota-se que a utilização do agregado siderúrgico como fração areia integral causa diminuição de 37 \% a 50 \% neste parâmetro, independente da idade ao qual é medido; nas substituições parciais (50\%) da areia industrial por este resíduo as quedas observadas são cerca de $13 \%$ a $18 \%$ e em conjunto com a areia natural, $15 \%$ a $30 \%$. 
Tabela 72 - variações porcentuais dos módulos de elasticidade dinâmicos aferidos nos CCR alternativos em comparação com o CCR - $\mathrm{Al}$ aos 7, 35 e 180 dias

\begin{tabular}{|c|c|c|c|c|}
\hline \multirow{2}{*}{ CCR } & \multirow{2}{*}{ CP } & \multicolumn{3}{|c|}{ Variação Porcentual (\%) } \\
\hline & & $E_{\text {dinâmico } 7}$ & $\mathbf{E}_{\text {dinâmico } 35}$ & $\mathbf{E}_{\text {dinâmico } 180}$ \\
\hline \multirow{2}{*}{$\mathrm{CCR}-\mathrm{Al}$} & C & - & - & - \\
\hline & $p$ & - & - & - \\
\hline \multirow{2}{*}{$\mathrm{CCR}-\mathrm{AN}$} & c & $-7,5$ & $-7,9$ & $-11,4$ \\
\hline & $p$ & $-13,0$ & $-0,1$ & - \\
\hline \multirow{2}{*}{ CCR - ESC } & c & $-49,1$ & $-37,2$ & $-40,2$ \\
\hline & $p$ & $-47,9$ & $-41,8$ & - \\
\hline \multirow{2}{*}{$\mathrm{CCR}-\mathrm{Al} / \mathrm{ESC}$} & c & $-13,8$ & $-12,6$ & - \\
\hline & $p$ & $-17,9$ & $-15,1$ & - \\
\hline \multirow{2}{*}{$\mathrm{CCR}-\mathrm{AN} / \mathrm{ESC}$} & c & $-23,8$ & $-18,2$ & - \\
\hline & $p$ & $-29,6$ & $-15,0$ & - \\
\hline
\end{tabular}

O módulo de elasticidade dinâmico é influenciado pela idade de cura dos CCR em câmara úmida, conforme mostrado nas Figuras 78 e 79 e Tabela 73, tendo acréscimos semelhantes para ambas as geometrias de amostras: $20 \%$ a 32 $\%$ para os corpos de prova prismáticos e $18 \%$ a $34 \%$ para os corpos de prova cilíndricos (7 para 35 dias); quando mensura-se aos 180 dias, comparando com 35 dias, este acréscimo é menor, cerca de $11 \%$ a $16 \%$ (para os corpos de prova cilíndricos das misturas CCR - Al, CCR - AN e CCR - ESC).

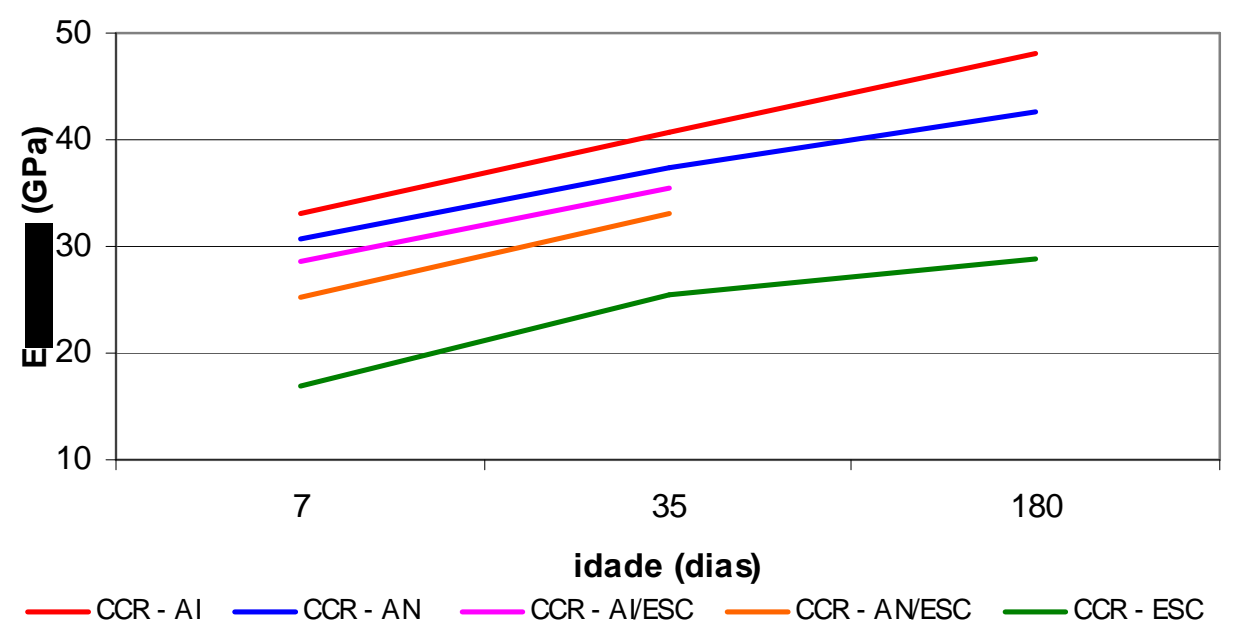

Figura 78 - relação entre módulo de elasticidade dinâmico e idade dos corpos de prova cilíndricos 


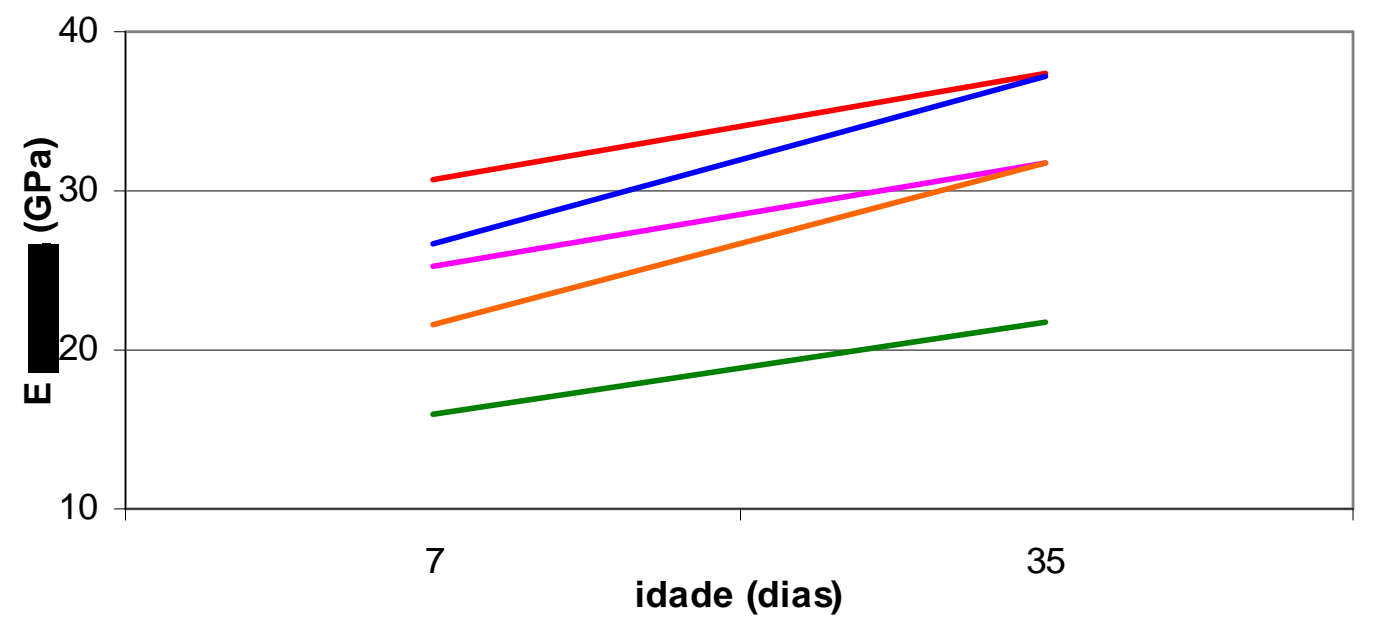

$\longrightarrow$ CCR - AI CCR - AN CCR - AVESC CCR - ANESC —CCR - ESC

Figura 79 - relação entre módulo de elasticidade dinâmico e idade dos corpos de prova prismáticos

Tabela 73 - ganho do módulo de elasticidade dinâmico em relação às idades medidas

\begin{tabular}{|c|c|c|c|}
\hline \multirow[t]{2}{*}{ CCR } & \multirow[t]{2}{*}{ CP } & \multicolumn{2}{|c|}{$\begin{array}{l}\text { Ganho de } E_{\text {dinâmico }} \text { ao } \\
\text { decorrer do tempo (\%) }\end{array}$} \\
\hline & & 7 aos 35 dias & 35 aos 180 dias \\
\hline \multirow{2}{*}{$\mathrm{CCR}-\mathrm{Al}$} & C & 33,7 & 15,8 \\
\hline & $p$ & 26,6 & - \\
\hline \multirow{2}{*}{$\mathrm{CCR}-\mathrm{AN}$} & c & 17,9 & 12,4 \\
\hline & $p$ & 28,2 & - \\
\hline \multirow{2}{*}{ CCR - ESC } & c & 33,7 & 11,4 \\
\hline & $p$ & 26,6 & - \\
\hline \multirow{2}{*}{$\mathrm{CCR}-\mathrm{Al} / \mathrm{ESC}$} & $c$ & 19,4 & - \\
\hline & $p$ & 20,8 & - \\
\hline \multirow{2}{*}{ CCR - AN/ESC } & c & 23,8 & - \\
\hline & $p$ & 32,1 & - \\
\hline
\end{tabular}

A cura realizada em câmara úmida, efetuada em todas as amostras ensaiadas, condiciona a saturação dos poros do CCR e maior velocidade de propagação de onda ultrassônica no meio, resultando em maiores valores de 
módulo de elasticidade dinâmico (quando comparado aos CCR curados ao ar). Apresenta-se, na Figura 80, a relação entre valores de módulo de elasticidade dinâmicos em corpos de prova cilíndricos submetidos à cura por 35 dias em câmara úmida ou ao ar. Nota-se que a utilização de diferentes agregados de fração areia não influencia na relação entre valores, sendo estes, aproximadamente $10 \%$ inferiores para os casos de cura ao ar.

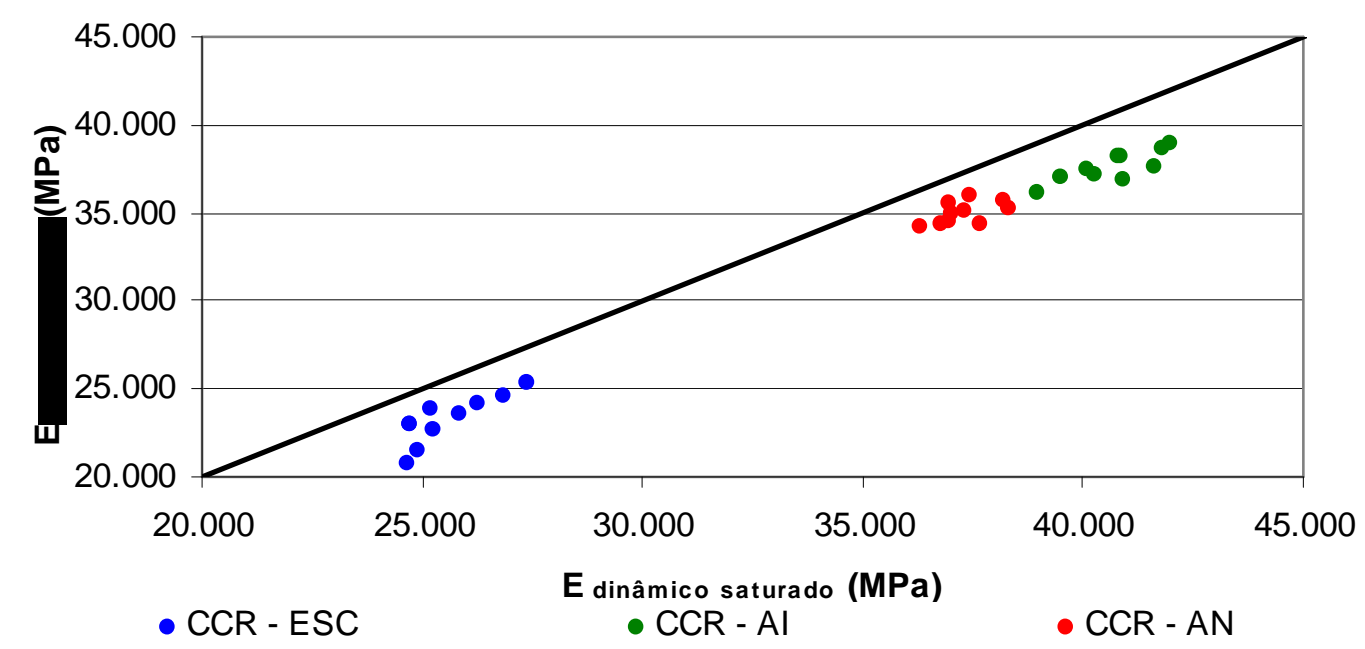

Figura 80 - relação entre módulos de elasticidade dinâmicos aferidos em corpos de prova cilíndricos submetidos à cura úmida e ao ar (35 dias)

Apresentam-se nas Tabelas 74 a 76 os valores de módulos de elasticidade dinâmicos aferidos nos corpos de prova de CCR moldados $1,5 \%$ abaixo da umidade de compactação aos 35 dias.

Tabela 74 - valores de módulos de elasticidade dinâmicos do CCR - Al no ramo seco

\begin{tabular}{cccc}
\hline & \multicolumn{3}{c}{$\mathrm{E}_{\text {dinâmico 35 }}$} \\
$\mathbf{C P}$ & $\bar{x}$ & $\mathbf{s}$ & $\mathbf{c v}$ \\
& $(\mathrm{GPa})$ & $(\mathrm{GPa})$ & $(\%)$ \\
\hline $\mathrm{C}$ & 37,3 & 1,3 & 3,6 \\
$\mathrm{p}$ & 36,8 & 1,0 & 2,8 \\
\hline
\end{tabular}


Tabela 75 - valores de módulos de elasticidade dinâmicos do CCR - AN no ramo seco

\begin{tabular}{cccc}
\hline & \multicolumn{3}{c}{$\mathrm{E}_{\text {dinâmico 35 }}$} \\
$\mathrm{CP}$ & $\bar{x}$ & $\mathbf{s}$ & $\mathbf{c v}$ \\
& $(\mathrm{GPa})$ & $(\mathrm{GPa})$ & $(\%)$ \\
\hline $\mathrm{C}$ & 36,2 & 1,2 & 3,3 \\
$\mathrm{p}$ & 35,2 & 0,9 & 2,6 \\
\hline
\end{tabular}

Tabela 76 - valores de módulos de elasticidade dinâmicos do CCR - ESC no ramo seco

\begin{tabular}{cccc}
\hline & \multicolumn{3}{c}{$\mathbf{E}_{\text {dinâmico 35 }}$} \\
CP & $\bar{x}$ & $\mathbf{s}$ & $\mathbf{c v}$ \\
& $(\mathrm{GPa})$ & $(\mathrm{GPa})$ & $(\%)$ \\
\hline $\mathrm{C}$ & 23,1 & 0,3 & 1,2 \\
$\mathrm{p}$ & 20,5 & 0,7 & 3,5 \\
\hline
\end{tabular}

A confecção do CCR no ramo seco resulta em um concreto com maior tendência a segregação e heterogeneidade, conforme mostrado anteriormente na Figura 64, além de queda nas resistências à tração e massa específica. Assim sendo, em termos de módulo de elasticidade dinâmico, a heterogeneidade e queda na massa específica acarretam em menores velocidades de onda ultrassônica no meio (menores valores de módulo de elasticidade dinâmico), quando comparados com os CCR moldados na umidade ótima de compactação - Figura 81 - sendo pouco mais sensível nos corpos de prova cilíndricos (3\% a $10 \%$ ) do que nos corpos de prova prismáticos (1,5\% a 6,0\%), conforme Tabela 77. 


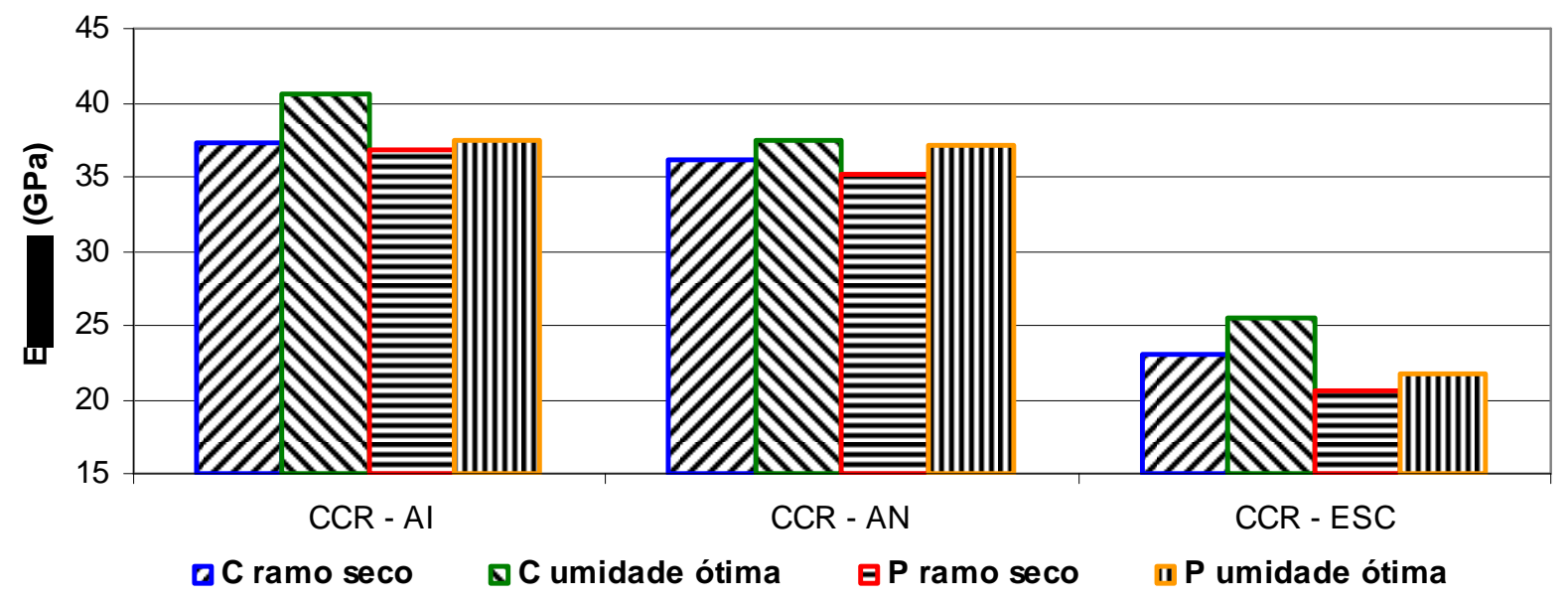

Figura 81 - comparativo entre valores de módulos de elasticidade dinâmicos obtidos em corpos de prova cilíndricos e prismáticos moldados na umidade ótima e no ramo seco de compactação aos 35 dias

Tabela 77 - variação porcentual do módulo de elasticidade dinâmico medido em corpos de prova moldados no ramo seco em relação aos confeccionados na umidade ótima de compactação

\begin{tabular}{ccc}
\hline CCR & CP & $\begin{array}{c}\text { Variação porcentual (\%) } \\
\text { (umidade ótima) }\end{array}$ \\
\hline CCR-Al & $\mathrm{C}$ & $-8,1$ \\
& $\mathrm{p}$ & $-1,6$ \\
$\mathrm{CCR}-\mathrm{AN}$ & $\mathrm{C}$ & $-3,3$ \\
& $\mathrm{p}$ & $-5,4$ \\
$\mathrm{CCR}-\mathrm{ESC}$ & $\mathrm{C}$ & $-9,4$ \\
& $\mathrm{p}$ & $-6,1$ \\
\hline
\end{tabular}

\subsubsection{Relação entre velocidade de onda ultrassônica e módulos de elasticidade}

Assis, Costa e Ferreira (1991b) averiguaram que para concretos plásticos convencionais, após 28 dias de cura úmida, as relações entre os módulos de elasticidade dinâmicos e estáticos eram coerentes em função da velocidade de propagação de onda ultrassônica para concretos especificado pelo fabricante do transdutor. Nesta especificação não há distinção em relação a concretos plásticos, 
concreto de alto desempenho (CAD), CCR ou outros tipos de concretos e nem quanto à geometria dos corpos de prova ensaiados. Entretanto, os mesmos autores, na utilização de agregados graúdos alternativos (laterítico e calcário) demonstram que estas relações não são confiáveis.

Para os CCR confeccionados, as relações entre a velocidade de propagação de onda ultrassônica e os módulos de elasticidade dinâmicos e estáticos não se mostraram adequadas na grande maioria dos casos, tanto em corpos de prova cilíndricos quanto prismáticos (Figuras 82 e 83). Nota-se uma tendência clara de relação entre a velocidade de pulso ultrassônico e o módulo de elasticidade dinâmico, contudo, difere-se daquela prescrita pelo fabricante pelas características peculiares do CCR quanto a sua estrutura frente à outros tipos de concreto.

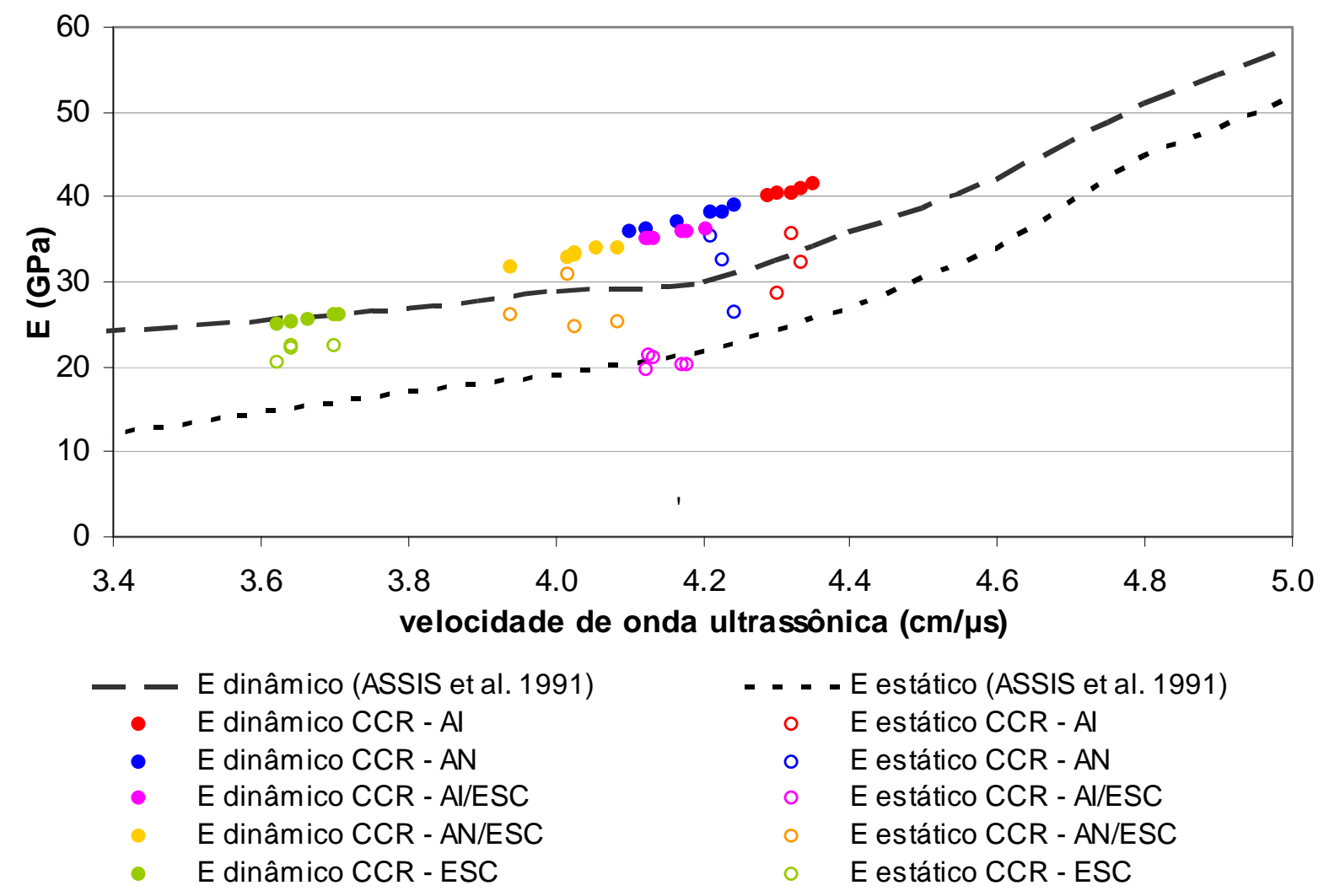

Figura 82 - relação entre velocidade de onda ultrassônica e módulos de elasticidade dinâmicos e estáticos para corpos de prova cilíndricos de CCR 


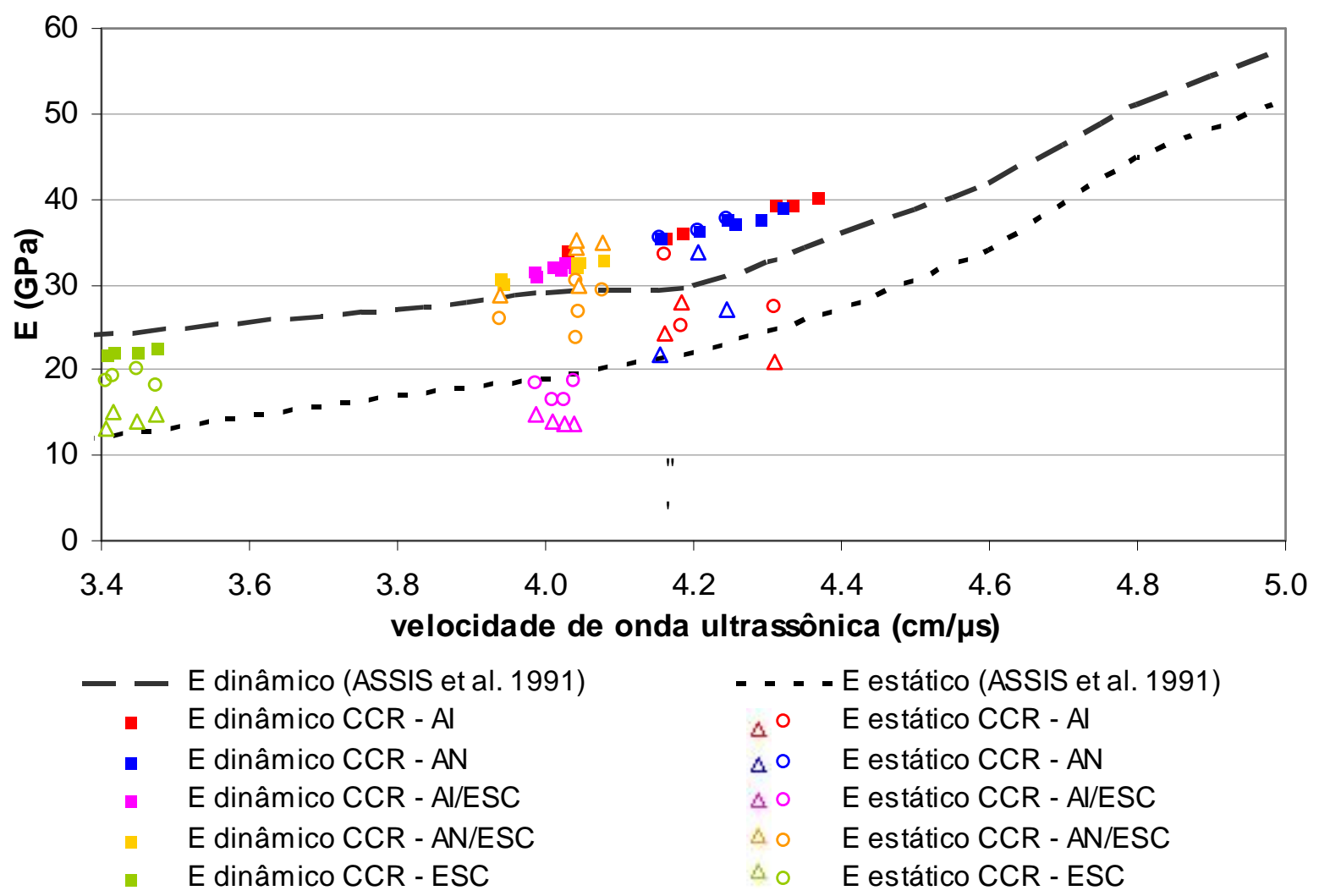

[onde: 0 - módulo de elasticidade estático obtido através da curva tensão x deformação e

$\Delta$ - módulo de elasticidade estático obtido por analogia de Möhr]

Figura 83 - relação entre velocidade de onda ultrassônica e módulos de elasticidade dinâmicos e estáticos para corpos de prova prismáticos de CCR

\subsubsection{Relação entre módulo de elasticidade dinâmico e massa específica dos CCR}

Apresentam-se, nas Figuras 84 e 85, a relação entre o módulo de elasticidade dinâmico e as massas específicas dos corpos de prova cilíndricos e prismáticos de CCR. Percebe-se uma relação direta entre estes parâmetros, dependente da idade e da configuração do corpo de prova. 


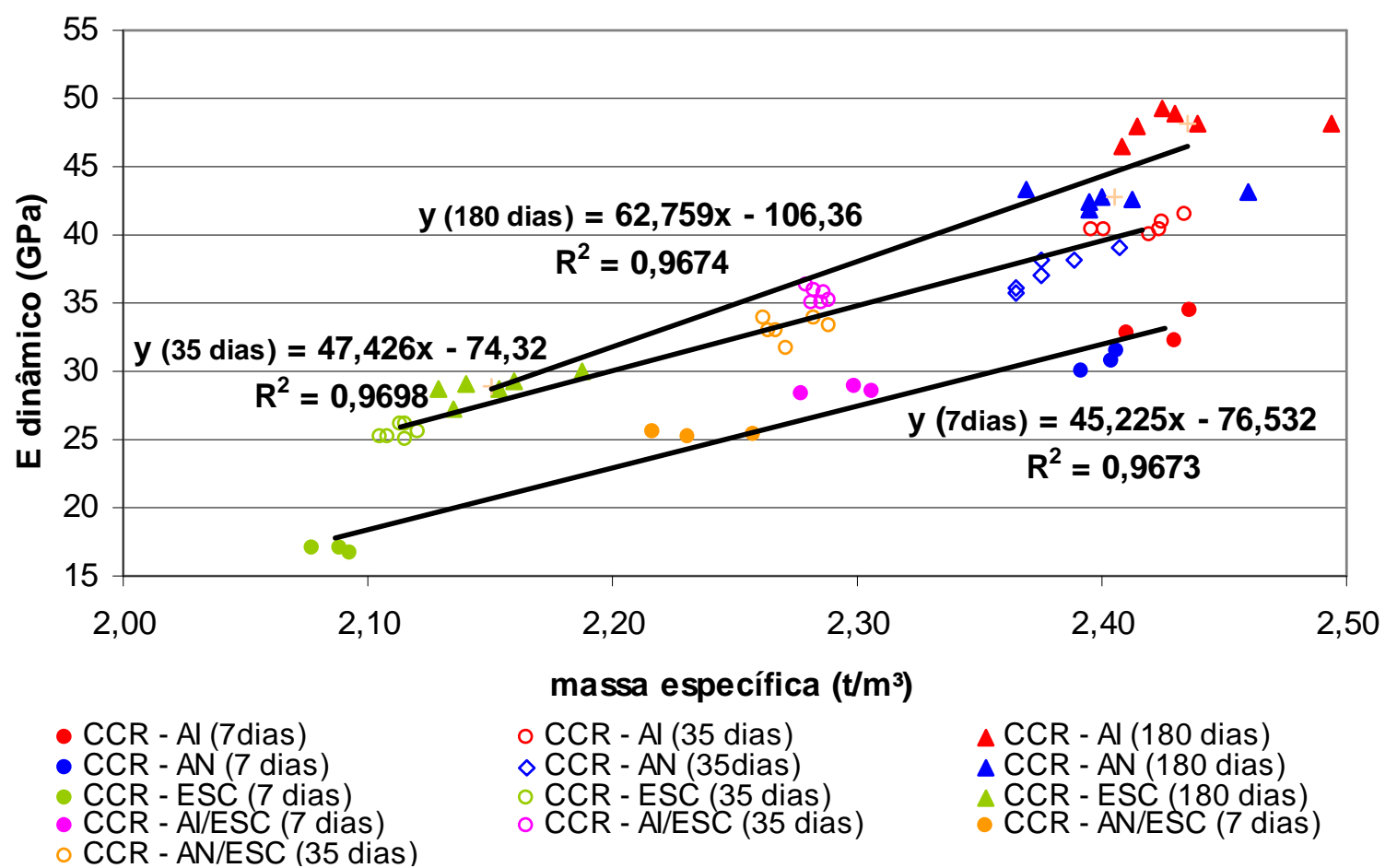

Figura 84 - relação entre módulo de elasticidade dinâmico e massa específica dos corpos de prova cilíndricos de CCR

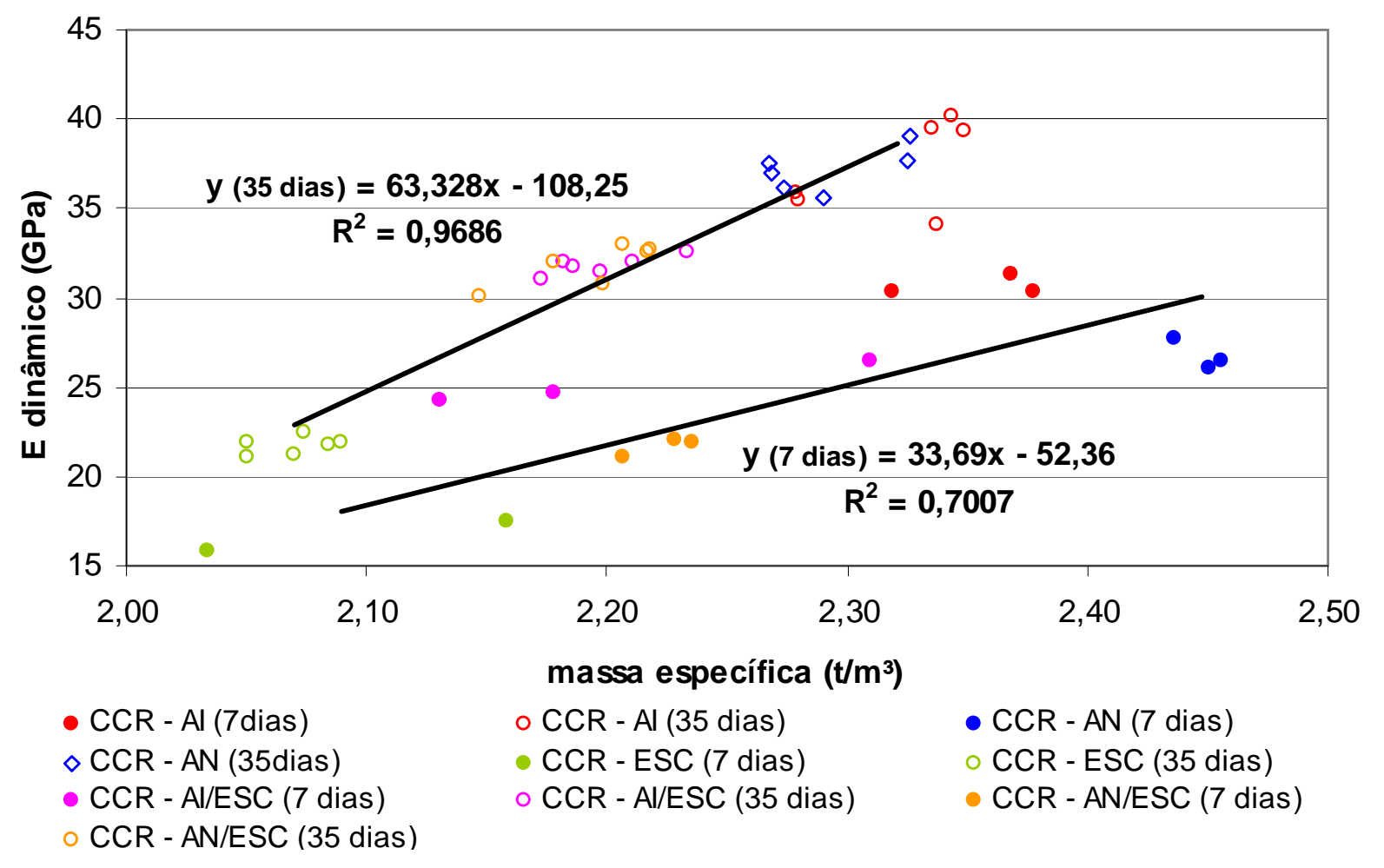

Figura 85 - relação entre módulo de elasticidade dinâmico e massa específica dos corpos de prova prismáticos de CCR 


\subsection{EMPREGO DOS CCR COMO BASE DE PAVIMENTOS}

\subsubsection{Estacionamento para automóveis}

Apresentam-se, na Tabela 78, as tensões de tração na flexão oriundas da carga de veículos leves (automóveis) bem como as tensões de ruptura à tração aferidas pelo ensaio brasileiro (tração indireta por compressão diametral), e suas relações de RT. Nesta análise, foi considerada como camada de rolamento uma mistura asfáltica delgada com fins funcionais, não tendo contribuição estrutural.

Tabela 78 - tensões em pavimento rodoviário sujeito à carga de veículos leves

\begin{tabular}{|c|c|c|c|c|c|}
\hline \multirow{2}{*}{$\begin{array}{c}\text { Análise } \\
\text { (n) }\end{array}$} & \multicolumn{2}{|c|}{ Base em CCR } & \multirow{2}{*}{$\begin{array}{l}\sigma_{\text {ruptura }} \\
(\mathrm{MPa})\end{array}$} & \multirow{2}{*}{$\begin{array}{c}\sigma_{\text {aplicada }} \\
(\mathrm{MPa})\end{array}$} & \multirow{2}{*}{ RT } \\
\hline & Espessura (cm) & Dosagem & & & \\
\hline 1 & & $\mathrm{CCR}-\mathrm{Al}$ & 2,5 & 1,2 & 0,48 \\
\hline 2 & & $\mathrm{CCR}-\mathrm{AN}$ & 2,0 & 1,2 & 0,60 \\
\hline 3 & 5,0 & CCR - ESC & 1,5 & 1,0 & 0,67 \\
\hline 4 & & $\mathrm{CCR}-\mathrm{Al} / \mathrm{ESC}$ & 2,1 & 1,0 & 0,48 \\
\hline 5 & & CCR - AN/ESC & 1,7 & 1,2 & 0,71 \\
\hline 6 & & $\mathrm{CCR}-\mathrm{Al}$ & 2,5 & 1,1 & 0,44 \\
\hline 7 & & $\mathrm{CCR}-\mathrm{AN}$ & 2,0 & 1,1 & 0,55 \\
\hline 8 & 5,5 & CCR - ESC & 1,5 & 0,9 & 0,60 \\
\hline 9 & & $\mathrm{CCR}-\mathrm{Al} / \mathrm{ESC}$ & 2,1 & 0,9 & 0,43 \\
\hline 10 & & CCR - AN/ESC & 1,7 & 1,1 & 0,65 \\
\hline 11 & & $\mathrm{CCR}-\mathrm{Al}$ & 2,5 & 1,0 & 0,40 \\
\hline 12 & & CCR - AN & 2,0 & 1,0 & 0,50 \\
\hline 13 & 6,0 & CCR - ESC & 1,5 & 0,8 & 0,53 \\
\hline 14 & & $\mathrm{CCR}-\mathrm{Al} / \mathrm{ESC}$ & 2,1 & 0,8 & 0,38 \\
\hline 15 & & CCR - AN/ESC & 1,7 & 1,0 & 0,59 \\
\hline 16 & & CCR - Al & 2,5 & 0,9 & 0,36 \\
\hline 17 & & CCR - AN & 2,0 & 0,9 & 0,45 \\
\hline 18 & 6,5 & CCR - ESC & 1,5 & 0,8 & 0,53 \\
\hline 18 & & $\mathrm{CCR}-\mathrm{Al} / \mathrm{ESC}$ & 2,1 & 0,8 & 0,38 \\
\hline 20 & & CCR - AN/ESC & 1,7 & 0,9 & 0,53 \\
\hline
\end{tabular}


Tabela 78 - tensões em pavimento rodoviário sujeito à carga de veículos leves (continuação)

\begin{tabular}{|c|c|c|c|c|c|}
\hline \multirow{2}{*}{$\begin{array}{c}\text { Análise } \\
\text { (ng) }\end{array}$} & \multicolumn{2}{|c|}{ Base em CCR } & \multirow{2}{*}{$\begin{array}{l}\sigma_{\text {ruptura }} \\
(\mathrm{MPa})\end{array}$} & \multirow{2}{*}{$\begin{array}{c}\sigma_{\text {aplicada }} \\
\text { (MPa) }\end{array}$} & \multirow{2}{*}{ RT } \\
\hline & Espessura (cm) & Dosagem & & & \\
\hline 21 & & $\mathrm{CCR}-\mathrm{Al}$ & 2,5 & 0,8 & 0,32 \\
\hline 22 & & CCR - AN & 2,0 & 0,8 & 0,40 \\
\hline 23 & 7,0 & CCR - ESC & 1,5 & 0,7 & 0,47 \\
\hline 24 & & CCR - Al/ESC & 2,1 & 0,7 & 0,33 \\
\hline 25 & & CCR - AN/ESC & 1,7 & 0,8 & 0,47 \\
\hline 26 & & CCR - Al & 2,5 & 0,7 & 0,28 \\
\hline 27 & & $\mathrm{CCR}-\mathrm{AN}$ & 2,0 & 0,7 & 0,35 \\
\hline 28 & 7,5 & CCR - ESC & 1,5 & 0,6 & 0,40 \\
\hline 29 & & $\mathrm{CCR}-\mathrm{Al} / \mathrm{ESC}$ & 2,1 & 0,6 & 0,29 \\
\hline 30 & & CCR - AN/ESC & 1,7 & 0,7 & 0,41 \\
\hline 31 & & $\mathrm{CCR}-\mathrm{Al}$ & 2,5 & 0,6 & 0,24 \\
\hline 32 & & CCR - AN & 2,0 & 0,6 & 0,30 \\
\hline 33 & 8,0 & CCR - ESC & 1,5 & 0,5 & 0,33 \\
\hline 34 & & $\mathrm{CCR}-\mathrm{Al} / \mathrm{ESC}$ & 2,1 & 0,5 & 0,24 \\
\hline 35 & & CCR - AN/ESC & 1,7 & 0,6 & 0,35 \\
\hline
\end{tabular}

As espessuras requeridas para camada de base do pavimento devido à utilização das misturas de CCR compostas, seguindo a relação de projeto entre tensão aplicada e tensão de ruptura $(R T=0,4)$, estão mostradas na Tabela 79.

Tabela 79 - espessuras de base em CCR para pavimento destinado à estacionamento de automóveis

\begin{tabular}{cc}
\hline CCR & $\begin{array}{c}\text { Espessura mínima de base } \\
(\mathbf{c m})\end{array}$ \\
\hline CCR - Al & 6,0 \\
CCR - AN & 7,0 \\
CCR - ESC & 7,5 \\
CCR - Al/ESC & 6,0 \\
CCR - AN/ESC & 7,5 \\
\hline
\end{tabular}


Observa-se, dos resultados obtidos, que a consideração conjunta de parâmetros resistência e módulo de elasticidade, na análise mecanicista acima apresentada, permite concluir que a mistura mais satisfatória no caso de estacionamento para veículos leves foram aquelas utilizando areia industrial ou sua combinação com a escória granulada de alto forno, o que levaria à menor espessura de camada de base para o pavimento.

As soluções mais desfavoráveis dos casos, comparativamente, seriam empregar ou $100 \%$ de escória granulada como fração areia ou misturada com areia natural no CCR. O emprego de areia natural foi também mais desfavorável comparado ao emprego de areia industrial no concreto, requerendo espessura de base de pavimento cerca de $15 \%$ superior.

\subsubsection{Vias urbanas e industriais}

Apresentam-se, na Tabela 80, os níveis de tensões nas camadas de base de pavimentos sujeitos ao tráfego de caminhões e ônibus, a tensão de ruptura dos corpos de prova de CCR e a relação entre ambas; e na Tabela 81, as espessuras mínimas de base requeridas.

\begin{tabular}{|c|c|c|c|c|c|}
\hline \multirow{2}{*}{$\begin{array}{c}\text { Análise } \\
\text { (ng }\end{array}$} & \multicolumn{2}{|c|}{ Base em CCR } & \multirow{2}{*}{$\begin{array}{l}\sigma_{\text {ruptura }} \\
(\mathrm{MPa})\end{array}$} & \multirow{2}{*}{$\begin{array}{c}\sigma_{\text {aplicada }} \\
(\mathrm{MPa})\end{array}$} & \multirow{2}{*}{ RT } \\
\hline & Espessura (cm) & Dosagem & & & \\
\hline 36 & & $\mathrm{CCR}-\mathrm{Al}$ & 2,5 & 1,8 & 0,72 \\
\hline 37 & & $\mathrm{CCR}-\mathrm{AN}$ & 2,0 & 1,8 & 0,90 \\
\hline 38 & 10,0 & CCR - ESC & 1,5 & 1,5 & 1,00 \\
\hline 39 & & $\mathrm{CCR}-\mathrm{Al} / \mathrm{ESC}$ & 2,1 & 1,5 & 0,71 \\
\hline 40 & & $\mathrm{CCR}-\mathrm{AN} / \mathrm{ESC}$ & 1,7 & 1,8 & 1,06 \\
\hline 41 & & $\mathrm{CCR}-\mathrm{Al}$ & 2,5 & 1,2 & 0,48 \\
\hline 42 & & $\mathrm{CCR}-\mathrm{AN}$ & 2,0 & 1,2 & 0,60 \\
\hline 43 & 15,0 & CCR - ESC & 1,5 & 1,0 & 0,67 \\
\hline 44 & & $\mathrm{CCR}-\mathrm{Al} / \mathrm{ESC}$ & 2,1 & 1,0 & 0,48 \\
\hline 45 & & CCR - AN/ESC & 1,7 & 1,2 & 0,71 \\
\hline
\end{tabular}


Tabela 80 - tensões em pavimento rodoviário sujeito à carga de caminhões e ônibus (continuação)

\begin{tabular}{|c|c|c|c|c|c|}
\hline \multirow{2}{*}{$\begin{array}{c}\text { Análise } \\
\text { (n) }\end{array}$} & \multicolumn{2}{|c|}{ Base em CCR } & \multirow{2}{*}{$\begin{array}{l}\sigma_{\text {ruptura }} \\
(\mathrm{MPa})\end{array}$} & \multirow{2}{*}{$\begin{array}{c}\sigma_{\text {aplicada }} \\
(\mathrm{MPa})\end{array}$} & \multirow{2}{*}{ RT } \\
\hline & Espessura (cm) & Dosagem & & & \\
\hline 46 & & $\mathrm{CCR}-\mathrm{Al}$ & 2,5 & 1,1 & 0,44 \\
\hline 47 & & CCR - AN & 2,0 & 1,1 & 0,55 \\
\hline 48 & 16,0 & CCR - ESC & 1,5 & 0,9 & 0,60 \\
\hline 49 & & $\mathrm{CCR}-\mathrm{Al} / \mathrm{ESC}$ & 2,1 & 0,9 & 0,43 \\
\hline 50 & & $\mathrm{CCR}-\mathrm{AN} / \mathrm{ESC}$ & 1,7 & 1,1 & 0,65 \\
\hline 51 & & $\mathrm{CCR}-\mathrm{Al}$ & 2,5 & 0,8 & 0,32 \\
\hline 52 & & CCR - AN & 2,0 & 0,8 & 0,40 \\
\hline 53 & 20,0 & CCR - ESC & 1,5 & 0,7 & 0,47 \\
\hline 54 & & $\mathrm{CCR}-\mathrm{Al} / \mathrm{ESC}$ & 2,1 & 0,7 & 0,33 \\
\hline 55 & & $\mathrm{CCR}-\mathrm{AN} / \mathrm{ESC}$ & 1,7 & 0,8 & 0,47 \\
\hline 56 & & $\mathrm{CCR}-\mathrm{Al}$ & 2,5 & 0,7 & 0,28 \\
\hline 57 & & CCR - AN & 2,0 & 0,7 & 0,35 \\
\hline 58 & 22,0 & CCR - ESC & 1,5 & 0,6 & 0,40 \\
\hline 59 & & $\mathrm{CCR}-\mathrm{Al} / \mathrm{ESC}$ & 2,1 & 0,6 & 0,29 \\
\hline 60 & & CCR - AN/ESC & 1,7 & 0,7 & 0,41 \\
\hline
\end{tabular}

Tabela 81 - espessuras de base em CCR para pavimento rodoviário

\begin{tabular}{cc}
\hline CCR & $\begin{array}{c}\text { Espessura mínima de base } \\
(\mathbf{c m})\end{array}$ \\
\hline CCR - Al & 17,0 \\
CCR - AN & 20,0 \\
CCR - ESC & 22,0 \\
CCR - Al/ESC & 17,0 \\
CCR - AN/ESC & 22,5 \\
\hline
\end{tabular}

Observa-se, novamente, dos resultados obtidos que as mistura mais satisfatória no caso de pavimentos sujeitos ao tráfego de ônibus ou caminhões foi a combinação de areia industrial com escória granulada de alto forno ou somente areia industrial. O CCR - Al/ESC requer espessura mais delgada de base do 
pavimento, aproximadamente $18 \%$ inferior, do que a própria utilização integral da areia natural no concreto.

Ressalta-se, conforme análise $n^{\circ} 38$ da Tabela 80 , que a ação do tráfego de apenas um ônibus ou caminhão é suficiente para a ruptura da camada de base do pavimento constituída por $10 \mathrm{~cm}$ de $\mathrm{CCR}$, devido à esforços de tração na fibra inferior desta camada cimentada $(R T=1)$.

\subsubsection{Pátios de estacionamento de aeronaves executivas e domésticas}

Mostram-se, nas Tabelas 82 e 83 , os níveis de tensões para pavimentos destinados à estacionamento e área de manobras de jatos comerciais tipo Legacy com camada de rolamento constituída por $3 \mathrm{~cm}$ e $6 \mathrm{~cm}$ de CBUQ, respectivamente; e na Tabela 84 a situação onde a aeronave de projeto é um Boeing 747 e são empregadas várias combinações de espessuras para camadas do pavimento.

Tabela 82 - tensões em pavimento aeroportuário destinado à estacionamento de jatos executivos Legacy $(\mathrm{CBUQ}=3 \mathrm{~cm})$

\begin{tabular}{|c|c|c|c|c|c|}
\hline \multirow{2}{*}{$\begin{array}{c}\text { Análise } \\
\text { (n) }\end{array}$} & \multicolumn{2}{|c|}{ Base em CCR } & \multirow{2}{*}{$\begin{array}{l}\sigma_{\text {ruptura }} \\
(\mathrm{MPa})\end{array}$} & \multirow{2}{*}{$\begin{array}{c}\sigma_{\text {aplicada }} \\
(\mathrm{MPa})\end{array}$} & \multirow{2}{*}{ RT } \\
\hline & Espessura (cm) & Dosagem & & & \\
\hline 61 & & $\mathrm{CCR}-\mathrm{Al}$ & 2,5 & 1,6 & 0,64 \\
\hline 62 & & $\mathrm{CCR}-\mathrm{AN}$ & 2,0 & 1,6 & 0,80 \\
\hline 63 & 10,0 & CCR - ESC & 1,5 & 1,3 & 0,87 \\
\hline 64 & & $\mathrm{CCR}-\mathrm{Al} / \mathrm{ESC}$ & 2,1 & 1,3 & 0,62 \\
\hline 65 & & $\mathrm{CCR}-\mathrm{AN} / \mathrm{ESC}$ & 1,7 & 1,6 & 0,94 \\
\hline 66 & & $\mathrm{CCR}-\mathrm{Al}$ & 2,5 & 1,0 & 0,40 \\
\hline 67 & & $\mathrm{CCR}-\mathrm{AN}$ & 2,0 & 1,0 & 0,50 \\
\hline 68 & 15,0 & CCR - ESC & 1,5 & 0,8 & 0,53 \\
\hline 69 & & $\mathrm{CCR}-\mathrm{Al} / \mathrm{ESC}$ & 2,1 & 0,8 & 0,38 \\
\hline 70 & & $\mathrm{CCR}-\mathrm{AN} / \mathrm{ESC}$ & 1,7 & 1,0 & 0,59 \\
\hline 71 & & $\mathrm{CCR}-\mathrm{Al}$ & 2,5 & 0,7 & 0,28 \\
\hline 72 & & $\mathrm{CCR}-\mathrm{AN}$ & 2,0 & 0,7 & 0,35 \\
\hline 73 & 20,0 & CCR - ESC & 1,5 & 0,6 & 0,40 \\
\hline 74 & & $\mathrm{CCR}-\mathrm{Al} / \mathrm{ESC}$ & 2,1 & 0,6 & 0,29 \\
\hline 75 & & CCR - AN/ESC & 1,7 & 0,7 & 0,41 \\
\hline
\end{tabular}


Tabela 83 - tensões em pavimento aeroportuário destinado à estacionamento de jatos executivos Legacy $(\mathrm{CBUQ}=6 \mathrm{~cm})$

\begin{tabular}{|c|c|c|c|c|c|}
\hline \multirow{2}{*}{$\begin{array}{c}\text { Análise } \\
\text { (n) }\end{array}$} & \multicolumn{2}{|c|}{ Base em CCR } & \multirow{2}{*}{$\begin{array}{l}\sigma_{\text {ruptura }} \\
(\mathrm{MPa})\end{array}$} & \multirow{2}{*}{$\begin{array}{c}\sigma_{\text {aplicada }} \\
(\mathrm{MPa})\end{array}$} & \multirow{2}{*}{ RT } \\
\hline & Espessura (cm) & Dosagem & & & \\
\hline 76 & & $\mathrm{CCR}-\mathrm{Al}$ & 2,5 & 1,3 & 0,52 \\
\hline 77 & & $\mathrm{CCR}-\mathrm{AN}$ & 2,0 & 1,3 & 0,65 \\
\hline 78 & 10,0 & CCR - ESC & 1,5 & 1,1 & 0,73 \\
\hline 79 & & $\mathrm{CCR}-\mathrm{Al} / \mathrm{ESC}$ & 2,1 & 1,0 & 0,48 \\
\hline 80 & & CCR - AN/ESC & 1,7 & 1,3 & 0,76 \\
\hline 81 & & $\mathrm{CCR}-\mathrm{Al}$ & 2,5 & 1,1 & 0,44 \\
\hline 82 & & $\mathrm{CCR}-\mathrm{AN}$ & 2,0 & 1,1 & 0,55 \\
\hline 83 & 12,0 & CCR - ESC & 1,5 & 0,9 & 0,60 \\
\hline 84 & & $\mathrm{CCR}-\mathrm{Al} / \mathrm{ESC}$ & 2,1 & 0,9 & 0,43 \\
\hline 85 & & CCR - AN/ESC & 1,7 & 1,1 & 0,65 \\
\hline 86 & & $\mathrm{CCR}-\mathrm{Al}$ & 2,5 & 0,9 & 0,36 \\
\hline 87 & & CCR - AN & 2,0 & 0,9 & 0,45 \\
\hline 88 & 14,0 & CCR - ESC & 1,5 & 0,7 & 0,47 \\
\hline 89 & & $\mathrm{CCR}-\mathrm{Al} / \mathrm{ESC}$ & 2,1 & 0,7 & 0,33 \\
\hline 90 & & CCR - AN/ESC & 1,7 & 0,9 & 0,53 \\
\hline 91 & & $\mathrm{CCR}-\mathrm{Al}$ & 2,5 & 0,7 & 0,28 \\
\hline 92 & & $\mathrm{CCR}-\mathrm{AN}$ & 2,0 & 0,7 & 0,35 \\
\hline 93 & 17,0 & CCR - ESC & 1,5 & 0,6 & 0,40 \\
\hline 94 & & CCR - Al/ESC & 2,1 & 0,7 & 0,33 \\
\hline 95 & & CCR - AN/ESC & 1,7 & 0,6 & 0,35 \\
\hline
\end{tabular}

Tabela 84 - tensões em pavimento aeroportuário destinado à estacionamento e manobra de aeronaves domésticas

\begin{tabular}{|c|c|c|c|c|c|c|}
\hline \multirow{2}{*}{$\begin{array}{c}\text { Análise } \\
\text { (n) }\end{array}$} & \multirow{2}{*}{$\begin{array}{c}\text { CBUQ } \\
\text { Espessura (cm) }\end{array}$} & \multicolumn{2}{|c|}{ Base em CCR } & \multirow{2}{*}{$\begin{array}{l}\sigma_{\text {ruptura }} \\
(\mathrm{MPa})\end{array}$} & \multirow{2}{*}{$\begin{array}{c}\sigma_{\text {aplicada }} \\
(\mathrm{MPa})\end{array}$} & \multirow{2}{*}{ RT } \\
\hline & & Espessura (cm) & Dosagem & & & \\
\hline 96 & & & $\mathrm{CCR}-\mathrm{Al}$ & 2,5 & 1,3 & 0,52 \\
\hline 97 & & & $\mathrm{CCR}-\mathrm{AN}$ & 2,0 & 1,2 & 0,60 \\
\hline 98 & 3,0 & 40,0 & CCR - ESC & 1,5 & 1,2 & 0,80 \\
\hline 99 & & & $\mathrm{CCR}-\mathrm{Al} / \mathrm{ESC}$ & 2,1 & 1,2 & 0,57 \\
\hline 100 & & & CCR - AN/ESC & 1,7 & 1,2 & 0,71 \\
\hline
\end{tabular}


Tabela 84 - tensões em pavimento aeroportuário destinado à estacionamento e manobra de aeronaves domésticas (continuação)

\begin{tabular}{|c|c|c|c|c|c|c|}
\hline Análise & & Base e & I CCR & $\sigma_{\text {ruptura }}$ & $\sigma_{\text {aplicada }}$ & RT \\
\hline (n) & Espessura (cm) & Espessura (cm) & Dosagem & (MPa) & $(\mathrm{MPa})$ & nI \\
\hline 101 & & & $\mathrm{CCR}-\mathrm{Al}$ & 2,5 & 1,2 & 0,48 \\
\hline 102 & & & $\mathrm{CCR}-\mathrm{AN}$ & 2,0 & 1,2 & 0,60 \\
\hline 103 & 6,0 & 40,0 & CCR - ESC & 1,5 & 1,1 & 0,73 \\
\hline 104 & & & $\mathrm{CCR}-\mathrm{Al} / \mathrm{ESC}$ & 2,1 & 1,1 & 0,52 \\
\hline 105 & & & CCR - AN/ESC & 1,7 & 1,2 & 0,71 \\
\hline 106 & & & $\mathrm{CCR}-\mathrm{Al}$ & 2,5 & 1,1 & 0,44 \\
\hline 107 & & & $\mathrm{CCR}-\mathrm{AN}$ & 2,0 & 1,1 & 0,55 \\
\hline 108 & 10,0 & 40,0 & CCR - ESC & 1,5 & 1,0 & 0,67 \\
\hline 109 & & & $\mathrm{CCR}-\mathrm{Al} / \mathrm{ESC}$ & 2,1 & 1,0 & 0,48 \\
\hline 110 & & & CCR - AN/ESC & 1,7 & 1,1 & 0,65 \\
\hline 111 & & & $\mathrm{CCR}-\mathrm{Al}$ & 2,5 & 1,0 & 0,40 \\
\hline 112 & & & CCR - AN & 2,0 & 1,0 & 0,50 \\
\hline 113 & 12,0 & 40,0 & CCR - ESC & 1,5 & 0,9 & 0,60 \\
\hline 114 & & & $\mathrm{CCR}-\mathrm{Al} / \mathrm{ESC}$ & 2,1 & 0,9 & 0,43 \\
\hline 115 & & & CCR - AN/ESC & 1,7 & 1,0 & 0,59 \\
\hline 116 & & & $\mathrm{CCR}-\mathrm{Al}$ & 2,5 & 1,0 & 0,40 \\
\hline 117 & & & $\mathrm{CCR}-\mathrm{AN}$ & 2,0 & 1,0 & 0,50 \\
\hline 118 & 15,0 & 40,0 & CCR - ESC & 1,5 & 0,8 & 0,53 \\
\hline 119 & & & $\mathrm{CCR}-\mathrm{Al} / \mathrm{ESC}$ & 2,1 & 0,8 & 0,38 \\
\hline 120 & & & CCR - AN/ESC & 1,7 & 0,9 & 0,53 \\
\hline 121 & & & $\mathrm{CCR}-\mathrm{Al}$ & 2,5 & 0,8 & 0,32 \\
\hline 122 & & & $\mathrm{CCR}-\mathrm{AN}$ & 2,0 & 0,8 & 0,40 \\
\hline 123 & 20,0 & 40,0 & CCR - ESC & 1,5 & 0,7 & 0,47 \\
\hline 124 & & & $\mathrm{CCR}-\mathrm{Al} / \mathrm{ESC}$ & 2,1 & 0,7 & 0,33 \\
\hline 125 & & & CCR - AN/ESC & 1,7 & 0,8 & 0,47 \\
\hline 126 & & & $\mathrm{CCR}-\mathrm{Al}$ & 2,5 & 0,6 & 0,24 \\
\hline 127 & & & $\mathrm{CCR}-\mathrm{AN}$ & 2,0 & 0,6 & 0,30 \\
\hline 128 & 20,0 & 50,0 & CCR - ESC & 1,5 & 0,5 & 0,33 \\
\hline 129 & & & $\mathrm{CCR}-\mathrm{Al} / \mathrm{ESC}$ & 2,1 & 0,5 & 0,24 \\
\hline 130 & & & CCR - AN/ESC & 1,7 & 0,6 & 0,35 \\
\hline
\end{tabular}


Apresentam-se, por meio da Tabela 85, as espessuras das camadas de revestimento e base dos pavimentos destinados à cargas de jatos executivos comerciais, devido ao emprego dos CCR estudados e, pela Tabela 86, as espessuras da camada de rolamento em concreto asfáltico, sujeito à cargas de aeronaves comerciais, devido à limitação construtiva para execução de camada única da base cimentada em CCR - $40 \mathrm{~cm}$ - efetuada com rolos metálicos lisos vibratórios (categoria V4, apud Balbo, 1993).

Tabela 85 - espessuras de camada de base em CCR para pavimentos aeroportuários sujeitos à estacionamento de jatos executivos

\begin{tabular}{|c|c|c|}
\hline \multirow{2}{*}{ Dosagem } & \multicolumn{2}{|c|}{ Espessura mínima de base em CCR (cm) } \\
\hline & CBUQ $-3 \mathrm{~cm}$ & CBUQ $-6 \mathrm{~cm}$ \\
\hline $\mathrm{CCR}-\mathrm{Al}$ & 15,0 & 13,0 \\
\hline $\mathrm{CCR}-\mathrm{AN}$ & 18,5 & 16,0 \\
\hline CCR - ESC & 20,0 & 17,0 \\
\hline $\mathrm{CCR}-\mathrm{Al} / \mathrm{ESC}$ & 15,0 & 13,0 \\
\hline CCR - AN/ESC & 19,5 & 16,5 \\
\hline
\end{tabular}

Tabela 86 - espessuras de camada de revestimento para pavimentos aeroportuários sujeitos à estacionamento de aeronaves executivas com camada de base em CCR $(40 \mathrm{~cm})$

\begin{tabular}{cc}
\hline CCR & Espessura mínima de concreto asfáltico (cm) \\
\hline CCR - Al & 12,0 \\
CCR - AN & 20,0 \\
CCR - ESC & - \\
CCR - Al/ESC & 14,0 \\
CCR - AN/ESC & - \\
\hline
\end{tabular}

Percebe-se que a utilização integral da escória granulada de alto forno como agregado miúdo acresce aproximadamente $30 \%$ na espessura da camada de base para pavimento destinado a estacionamento de jatos comerciais (em comparação com utilização de areia industrial); a utilização do CCR - Al/ESC apresenta espessuras da camada cimentada similares ao CCR - Al, demonstrando 
vantagem na incorporação do resíduo parcialmente em relação ao emprego total da areia natural (cerca de $23 \%$ de redução na espessura de base para os casos de revestimento asfáltico com $3 \mathrm{~cm}$ e $6 \mathrm{~cm}$ ).

No pavimento sujeito à estacionamento de aeronaves domésticas os CCR utilizando escória granulada de alto forno como fração total areia ou em conjunto com areia natural se mostram inviáveis tecnicamente devido aos níveis de tensões solicitantes e as camadas de pavimento requeridas, tomando como referência a espessura máxima de compactação do $\mathrm{CCR}$ em camada única $(40 \mathrm{~cm})$ pelo equipamento disponível (rolo compactador de categoria V4 apud Balbo, 1993)

\subsubsection{Terminal de contêineres}

A situação averiguada na análise dos CCR empregados como base de pavimento aeroportuário para aeronaves domésticas é confirmada para sua utilização como terminal portuário sujeito à cargas de transtêineres. A utilização de escória granulada de alto forno como agregado miúdo (fração total) do CCR ou sendo empregada parcialmente com areia natural, bem como a utilização integralmente de areia natural, resulta em espessuras de base inviáveis de serem executadas em uma única camada de compactação ou acarretando em espessuras muito espessas de revestimento asfáltico (acima de $20 \mathrm{~cm}$ ). Os níveis de tensões para esta situação estão apresentados na Tabela 87 e as espessuras de CBUQ, levando em consideração as limitações construtivas, mostradas na Tabela 88.

Tabela 87 - tensões em pavimento portuário destinado à terminal de transtêineres

\begin{tabular}{|c|c|c|c|c|c|c|}
\hline \multirow{2}{*}{$\begin{array}{c}\text { Análise } \\
\text { (n) }\end{array}$} & \multirow{2}{*}{$\begin{array}{c}\text { CBUQ } \\
\text { Espessura (cm) }\end{array}$} & \multicolumn{2}{|c|}{ Base em CCR } & \multirow{2}{*}{$\begin{array}{l}\sigma_{\text {ruptura }} \\
(\mathrm{MPa})\end{array}$} & \multirow{2}{*}{$\begin{array}{c}\sigma_{\text {aplicada }} \\
(\mathrm{MPa})\end{array}$} & \multirow{2}{*}{ RT } \\
\hline & & Espessura (cm) & Dosagem & & & \\
\hline 131 & & & $\mathrm{CCR}-\mathrm{Al}$ & 2,5 & 1,3 & 0,52 \\
\hline 132 & & & $\mathrm{CCR}-\mathrm{AN}$ & 2,0 & 1,3 & 0,65 \\
\hline 133 & 3,0 & 40,0 & CCR - ESC & 1,5 & 1,2 & 0,80 \\
\hline 134 & & & $\mathrm{CCR}-\mathrm{Al} / \mathrm{ESC}$ & 2,1 & 1,2 & 0,57 \\
\hline 135 & & & CCR - AN/ESC & 1,7 & 1,3 & 0,76 \\
\hline
\end{tabular}


Tabela 87 - tensões em pavimento portuário destinado à terminal de transtêineres (continuação)

\begin{tabular}{|c|c|c|c|c|c|c|}
\hline \multirow{2}{*}{$\begin{array}{l}\text { Análise } \\
\text { (n) }\end{array}$} & \multirow{2}{*}{$\begin{array}{c}\text { CBUQ } \\
\text { Espessura }(\mathrm{cm})\end{array}$} & \multicolumn{2}{|c|}{ Base em CCR } & \multirow{2}{*}{$\begin{array}{l}\sigma_{\text {ruptura }} \\
(\mathrm{MPa})\end{array}$} & \multirow{2}{*}{$\begin{array}{c}\sigma_{\text {aplicada }} \\
\text { (MPa) }\end{array}$} & \multirow{2}{*}{ RT } \\
\hline & & Espessura (cm) & Dosagem & & & \\
\hline 136 & & & $\mathrm{CCR}-\mathrm{Al}$ & 2,5 & 1,2 & 0,48 \\
\hline 137 & & & $\mathrm{CCR}-\mathrm{AN}$ & 2,0 & 1,2 & 0,60 \\
\hline 138 & 6,0 & 40,0 & CCR - ESC & 1,5 & 1,1 & 0,73 \\
\hline 139 & & & $\mathrm{CCR}-\mathrm{Al} / \mathrm{ESC}$ & 2,1 & 1,1 & 0,52 \\
\hline 140 & & & CCR - AN/ESC & 1,7 & 1,2 & 0,71 \\
\hline 141 & & & $\mathrm{CCR}-\mathrm{Al}$ & 2,5 & 1,1 & 0,44 \\
\hline 142 & & & $\mathrm{CCR}-\mathrm{AN}$ & 2,0 & 1,1 & 0,55 \\
\hline 143 & 10,0 & 40,0 & CCR - ESC & 1,5 & 1,0 & 0,67 \\
\hline 144 & & & $\mathrm{CCR}-\mathrm{Al} / \mathrm{ESC}$ & 2,1 & 1,0 & 0,48 \\
\hline 145 & & & CCR - AN/ESC & 1,7 & 1,1 & 0,65 \\
\hline 146 & & & $\mathrm{CCR}-\mathrm{Al}$ & 2,5 & 1,0 & 0,40 \\
\hline 147 & & & $\mathrm{CCR}-\mathrm{AN}$ & 2,0 & 1,0 & 0,50 \\
\hline 148 & 15,0 & 40,0 & CCR - ESC & 1,5 & 0,9 & 0,60 \\
\hline 149 & & & $\mathrm{CCR}-\mathrm{Al} / \mathrm{ESC}$ & 2,1 & 0,9 & 0,43 \\
\hline 150 & & & CCR - AN/ESC & 1,7 & 1,0 & 0,59 \\
\hline 151 & & & $\mathrm{CCR}-\mathrm{Al}$ & 2,5 & 0,9 & 0,36 \\
\hline 152 & & & $\mathrm{CCR}-\mathrm{AN}$ & 2,0 & 0,9 & 0,45 \\
\hline 153 & 20,0 & 40,0 & CCR - ESC & 1,5 & 0,8 & 0,53 \\
\hline 154 & & & $\mathrm{CCR}-\mathrm{Al} / \mathrm{ESC}$ & 2,1 & 0,8 & 0,38 \\
\hline 155 & & & CCR - AN/ESC & 1,7 & 0,9 & 0,53 \\
\hline 156 & & & $\mathrm{CCR}-\mathrm{Al}$ & 2,5 & 0,7 & 0,28 \\
\hline 157 & & & $\mathrm{CCR}-\mathrm{AN}$ & 2,0 & 0,7 & 0,35 \\
\hline 158 & 20,0 & 50,0 & CCR - ESC & 1,5 & 0,6 & 0,40 \\
\hline 159 & & & $\mathrm{CCR}-\mathrm{Al} / \mathrm{ESC}$ & 2,1 & 0,6 & 0,29 \\
\hline 160 & & & CCR - AN/ESC & 1,7 & 0,7 & 0,41 \\
\hline 161 & & & $\mathrm{CCR}-\mathrm{Al}$ & 2,5 & 0,6 & 0,24 \\
\hline 162 & & & $\mathrm{CCR}-\mathrm{AN}$ & 2,0 & 0,6 & 0,30 \\
\hline 163 & 20,0 & 60,0 & CCR - ESC & 1,5 & 0,5 & 0,33 \\
\hline 164 & & & $\mathrm{CCR}-\mathrm{Al} / \mathrm{ESC}$ & 2,1 & 0,6 & 0,29 \\
\hline 165 & & & CCR - AN/ESC & 1,7 & 0,5 & 0,29 \\
\hline
\end{tabular}


Tabela 88 - espessuras de camada de revestimento para pavimento portuário sujeitos à carga de transtêiner pneumático com camada de base em CCR $(40 \mathrm{~cm})$

\begin{tabular}{cc}
\hline CCR & $\begin{array}{c}\text { Espessura mínima de concreto asfáltico } \\
(\mathbf{c m})\end{array}$ \\
\hline $\mathrm{CCR}-\mathrm{Al}$ & 15,0 \\
$\mathrm{CCR}-\mathrm{AN}$ & - \\
$\mathrm{CCR}-\mathrm{Al} / \mathrm{ESC}$ & 18,0 \\
$\mathrm{CCR}-\mathrm{AN} / \mathrm{ESC}$ & - \\
$\mathrm{CCR}-\mathrm{ESC}$ & - \\
\hline
\end{tabular}

\subsubsection{Pátio de estocagem de pallets}

Apresenta-se, na Tabela 89, os níveis de tensões oriundos de pavimentos portuários sujeitos à cargas estáticas do empilhamento de até cinco pallets. Para este caso, foi considerada como camada de rolamento uma mistura asfáltica delgada sem fins estruturais ou um concreto asfáltico com até $6 \mathrm{~cm}$ de espessura.

Tabela 89 - tensões em pavimento portuário destinado à estocagem de pallets

\begin{tabular}{|c|c|c|c|c|c|c|}
\hline \multirow{2}{*}{$\begin{array}{c}\text { Análise } \\
\text { (ng) }\end{array}$} & \multirow{2}{*}{$\begin{array}{c}\text { CBUQ } \\
\text { Espessura (cm) }\end{array}$} & \multicolumn{2}{|c|}{ Base em CCR } & \multirow{2}{*}{$\begin{array}{l}\sigma_{\text {ruptura }} \\
(\mathrm{MPa})\end{array}$} & \multirow{2}{*}{$\begin{array}{c}\sigma_{\text {aplicada }} \\
\text { (MPa) }\end{array}$} & \multirow{2}{*}{ RT } \\
\hline & & Espessura (cm) & Dosagem & & & \\
\hline 166 & & & $\mathrm{CCR}-\mathrm{Al}$ & 2,5 & 2,7 & 1,08 \\
\hline 167 & & & $\mathrm{CCR}-\mathrm{AN}$ & 2,0 & 2,7 & 1,35 \\
\hline 168 & 0,0 & 20,0 & CCR - ESC & 1,5 & 2,5 & 1,67 \\
\hline 169 & & & $\mathrm{CCR}-\mathrm{Al} / \mathrm{ESC}$ & 2,1 & 2,5 & 1,19 \\
\hline 170 & & & CCR - AN/ESC & 1,7 & 2,7 & 1,59 \\
\hline 171 & & & $\mathrm{CCR}-\mathrm{Al}$ & 2,5 & 1,3 & 0,52 \\
\hline 172 & & & $\mathrm{CCR}-\mathrm{AN}$ & 2,0 & 1,3 & 0,65 \\
\hline 173 & 0,0 & 30,0 & CCR - ESC & 1,5 & 1,2 & 0,80 \\
\hline 174 & & & $\mathrm{CCR}-\mathrm{Al} / \mathrm{ESC}$ & 2,1 & 1,2 & 0,57 \\
\hline 175 & & & CCR - AN/ESC & 1,7 & 1,3 & 0,76 \\
\hline
\end{tabular}


Tabela 89 - tensões em pavimento portuário destinado à estocagem de pallets (continuação)

\begin{tabular}{|c|c|c|c|c|c|c|}
\hline \multirow{2}{*}{$\begin{array}{c}\text { Análise } \\
\text { (ng) }\end{array}$} & \multirow{2}{*}{$\begin{array}{c}\text { CBUQ } \\
\text { Espessura (cm) }\end{array}$} & \multicolumn{2}{|c|}{ Base em CCR } & \multirow{2}{*}{$\begin{array}{l}\sigma_{\text {ruptura }} \\
\text { (MPa) }\end{array}$} & \multirow{2}{*}{$\begin{array}{c}\sigma_{\text {aplicada }} \\
\text { (MPa) }\end{array}$} & \multirow{2}{*}{ RT } \\
\hline & & Espessura (cm) & Dosagem & & & \\
\hline 176 & & & CCR - Al & 2,5 & 0,8 & 0,32 \\
\hline 177 & & & $\mathrm{CCR}-\mathrm{AN}$ & 2,0 & 0,8 & 0,40 \\
\hline 178 & 0,0 & 40,0 & CCR - ESC & 1,5 & 0,7 & 0,47 \\
\hline 179 & & & $\mathrm{CCR}-\mathrm{Al} / \mathrm{ESC}$ & 2,1 & 0,7 & 0,33 \\
\hline 180 & & & CCR - AN/ESC & 1,7 & 0,8 & 0,47 \\
\hline 181 & & & $\mathrm{CCR}-\mathrm{Al}$ & 2,5 & 0,7 & 0,28 \\
\hline 182 & & & CCR - AN & 2,0 & 0,7 & 0,35 \\
\hline 183 & 3,0 & 40,0 & CCR - ESC & 1,5 & 0,7 & 0,47 \\
\hline 184 & & & $\mathrm{CCR}-\mathrm{Al} / \mathrm{ESC}$ & 2,1 & 0,7 & 0,33 \\
\hline 185 & & & CCR - AN/ESC & 1,7 & 0,7 & 0,41 \\
\hline 186 & & & $\mathrm{CCR}-\mathrm{Al}$ & 2,5 & 0,7 & 0,28 \\
\hline 187 & & & $\mathrm{CCR}-\mathrm{AN}$ & 2,0 & 0,7 & 0,35 \\
\hline 188 & 6,0 & 40,0 & CCR - ESC & 1,5 & 0,6 & 0,40 \\
\hline 189 & & & $\mathrm{CCR}-\mathrm{Al} / \mathrm{ESC}$ & 2,1 & 0,6 & 0,28 \\
\hline 190 & & & CCR - AN/ESC & 1,7 & 0,7 & 0,41 \\
\hline
\end{tabular}

Nota-se que as misturas CCR - AN/ESC e CCR - ESC, diferentemente dos demais concretos, necessitam de revestimento asfáltico com fins estruturais para atender a RT de projeto, conforme mostrado na Tabela 90, em função da execução do CCR em única camada de compactação com $40 \mathrm{~cm}$.

Tabela 90 - espessuras de camadas de pavimento portuário sujeitos à estocagem de pallets

\begin{tabular}{ccc}
\hline CCR & $\begin{array}{c}\text { Espessura mínima (cm) } \\
\text { CBUQ }\end{array}$ & CCR \\
\hline CCR - Al & - & 36,0 \\
CCR - AN & - & 40,0 \\
CCR - ESC & 6,0 & 40,0 \\
CCR - Al/ESC & - & 36,5 \\
CCR - AN/ESC & 6,0 & 40,0 \\
\hline
\end{tabular}




\section{CONCLUSÕES}

Os procedimentos de controle na confecção dos CCR resultaram, de um modo geral, em valores médios de massa específica, resistências à tração e módulos de elasticidade com baixos desvios padrão e coeficientes de variação, dentro de padrões de estudos laboratoriais, permitindo comparação confiável entre resultados. Com base nos dados obtidos neste estudo, foi possível encaminhar para as conclusões abaixo enumeradas:

- a massa específica do CCR diminui quando é empregada a escória granulada de alto forno como fração areia, sendo esta diminuição mais sensível na utilização do resíduo como fração areia total;

- as misturas de CCR com areia natural e escória granulada de alto forno requerem maiores quantidades de água de compactação (umidade) do que as misturas com areia industrial; fato relacionado às diferentes naturezas e absorção dos agregados, granulometria e forma dos grãos devido a sua origem (britagem, rio e processo industrial);

- os materiais de fração areia interferem na distribuição da energia de compactação ao longo da profundidade das camadas de CCR em corpos de prova cilíndricos; sendo uniforme na utilização de areia natural ou escória granulada de alto forno e decrescente no emprego de areia industria, quando houve exsudação da mistura durante a confecção dos corpos de prova;

- as resistências à tração em compressão diametral e à tração na flexão acompanharam a tendência verificada para a massa específica; quanto maior a quantidade de escória granulada de alto forno na mistura, maiores são as quedas de resistência. Contudo, este decréscimo não é tão pronunciado na utilização do resíduo em conjunto com a areia industrial (cerca de $16 \%$ );

- mesmo que utilizada como agregado miúdo e sem moagem prévia, a escória granulada de alto forno é ativada por elementos presentes no próprio cimento Portland, conferindo para estes concretos compactados, maiores ganhos de resistências em idades avançadas; 
- modelos empíricos generalistas para estimativa de resistências encontrados na literatura não conseguiram prever as resistências à tração das misturas de CCR compostas em diferentes idades, mostrando que não há equações universais tanto para materiais comumente utilizados, tanto para materiais alternativos;

- em termos de módulo de elasticidade estático, a utilização da escória granulada de alto forno como fração areia ou em combinação com a areia industrial, apresenta redução expressiva neste parâmetro; já na utilização em conjunto a areia natural, esta redução não é percebida, tendo valores semelhantes aos obtidos para agregados naturais (areia industrial ou areia natural);

- a utilização de areia natural ou industrial não interfere significativamente nos parâmetros mecânicos do CCR, sendo obtidos módulos de elasticidade semelhantes e pequena queda nas resistências à tração para as misturas com areia natural;

- a presença de escória granulada de alto forno influencia diretamente o módulo de elasticidade dinâmico do CCR da mesma forma que afeta a massa específica. Ou seja, maiores quantidades de agregado siderúrgico miúdo resultam em menores velocidades de onda ultrassônica no concreto (menores valores de módulo de elasticidade dinâmico). Ainda, mostrou-se que este quesito é dependente da geometria do corpo de prova, saturação dos poros do CCR e idade de ensaio;

- a compactação do CCR no ramo seco (1,5 \% abaixo da umidade de compactação) resulta em concretos com menores resistências à tração e módulo de elasticidade dinâmico, bem como módulos de elasticidade estáticos semelhantes àqueles obtidos para misturas confeccionadas na umidade ótima de compactação, não havendo nenhum tipo de vantagem na redução do teor de água para a compactação deste tipo de concreto; 
O programa experimental de laboratório para estudo de misturas de CCR, realizado isoladamente, não permite comparações entre dados dos concretos concebidos e possíveis benefícios em termos de desempenho destes como camadas de base de pavimentos. Um indicativo para esta avaliação comparativa é a relação entre módulo de elasticidade estático e a resistência à tração; contudo, verificações mecanicistas do nível de tensões no fundo da camada cimentada são de extrema importância para um melhor entendimento do nível de tensão máxima solicitante e de tensão de ruptura do material e parâmetros de dimensionamento. Assim sendo, com base em avaliações de diversas seções de pavimentos asfálticos compostos (com base de concreto), empregando-se como apoio teórico o programa multicamadas MnLayer, pode-se afirmar que:

- a utilização de $50 \%$ de areia industrial e $50 \%$ de escória granulada de alto forno resultam nas menores razões entre módulo de elasticidade e resistência à tração, sendo o CCR com melhor desempenho teórico em relação aos demais pelo fato de apresentar baixo valor de módulo de elasticidade e resistência à tração compatível (menores níveis de tensões na camada cimentada de base);

- a compactação do CCR abaixo da umidade de compactação resulta em maiores relações entre módulo de elasticidade e resistência à tração para todas as misturas; sendo assim, um concreto com pior desempenho do que aqueles moldados na umidade ótima de compactação;

- os CCR utilizando somente areia industrial, ou a mistura entre areia industrial e escória granulada de alto forno apresentam desempenhos similares em campo, requerendo espessuras de base de pavimento semelhantes (as menores espessuras em todos os casos de pavimentos estudados);

- a incorporação de escória em conjunto com a areia natural apresenta desempenho próximo à utilização do resíduo siderúrgico como fração areia total, sendo este, o pior entre os concretos estudados (necessitando maiores espessuras de camada de base de pavimento para um mesmo nível de tensões). Nestes casos, torna-se inviável 
tecnicamente (devido à limitações construtivas) suas utilizações como base de pavimentos destinados à aeronaves domésticas ou área portuária com tráfego de transtêineres pneumáticos (veículos muito pesados).

Devido às limitações quanto ao tempo para realização deste estudo, equipamentos disponíveis, bem como sua abrangência, a pesquisa pode ter continuidade futura, sugerindo-se no mínimo os seguintes estudos:

- adotou-se, presentemente, a faixa granulométrica idealizada por Pittman e Ragan (1998) porque é comumente empregada em meio rodoviário para CCR destinados como base de pavimento, devido a inúmeras vantagens por ela oferecidas quanto ao consumo de cimento e retração do material em pista. Contudo, pode não ser a melhor distribuição granular quando se incorpora a escória granulada de alto forno como agregado miúdo. Em vista disto, sugere-se a utilização de outras faixas granulométricas e verificação de parâmetros mecânicos para comparação com os resultados obtidos nesta pesquisa;

- recomenda-se análise de expansibilidade da escória granulada de alto forno utilizada em misturas de CCR, bem como a medida de resistência à longo prazo;

- possível introdução de pequenas quantidades de cal no CCR, avaliando o impacto deste material nas reações com a escória granulada de alto forno utilizada como agregado miúdo (sem moagem prévia) e nos parâmetros mecânicos das misturas;

- para baixos consumos de cimento, seriam também recomendáveis estudos verificando o impacto da energia de compactação nos mesmos quesitos avaliados neste trabalho, que se prendeu exclusivamente à energia do Proctor Normal;

- ensaios de carregamento cíclicos em misturas de CCR, utilizando escória granulada de alto como agregado, seriam úteis para análises do comportamento à fadiga, parâmetros referentes à previsão de 
desempenho destes concretos e do dimensionamento de pavimentos com estes elementos em camadas de base e de sub-base. 


\section{REFERÊNCIAS BIBLIOGRÁFICAS}

ABREU, J. V. Estudo do concreto de alta resistência compactado com rolo para pavimentação. Dissertação (mestrado). Escola Politécnica da Universidade de São Paulo. São Paulo. 2002. 116 p.

ADAMS, W.; DIRLAM, J. B. Big steel invention and innovation. In: The Quarterly Journal of Economics. 1986.

ALEXANDRE, J.; SEBILEAU, J. L. Le laitier de haut forneau edite por CTPI. Centre Technique et Promotion les Laitiers. Paris. 1988.

AMERICAN CONCRETE INSTITUTE (ACI). ACI 325.10R-95: state-of-the-art report on roller compacted concrete pavements. First Printing. 1995. 31 p.

. Committee 215: considerations for design of concrete structures subjected to fatigue loading. Manual of Concrete Practice. 1991.

. Committee 327: report on roller-compacted concrete pavements. publication 327.XR. 2004. 76 p.

. Compilation N.8: roller compacted pavement. authorized reprint form concrete international: design and construction n2 . 1987. Vol.9. 55 p.

ANDRIOLO, F. R. The use of roller compacted concrete. Editora Oficina de Textos. São Paulo. 1998.

Concreto rolado: mistura quase seca. In: Revista Téchne 125. 2007. p.32-34. 
ARNDT, J. A.; SOUZA, J.; BIANCHINI, M. Influência do índice de forma do agregado graúdo na resistência a compressão do concreto. In: 49ํㅡㄹ Congresso Brasileiro de Concreto. IBRACON. Bento Gonçalves. 2007. p.1 - 9.

ASSOCIAÇÃO BRASILEIRA DE NORMAS TÉCNICAS (ABNT). NBR 5735: Cimento Portland de alto forno. Rio de Janeiro. 1991a.

. NBR 5738. Moldagem e cura de corpos de prova cilíndricos ou prismáticos de concreto. Rio de Janeiro. 1994a. 9p.

. NBR 5743. Cimento Portland: determinação de perda ao fogo. método de ensaio. Rio de Janeiro. 2004a.

. NBR 5744. Cimento Portland: determinação de resíduo insolúvel. método de ensaio. Rio de Janeiro. 2004b

NBR 7182. Solo: ensaio de compactação. Rio de Janeiro. 1986a.

. NBR 7211. Agregados para concreto. Rio de Janeiro. 2005.

- NBR 7215. Cimento Portland: determinação da resistência à compressão. Rio de Janeiro. 1997. 8p.

NBR 7217. Agregados: determinação da composição granulométrica. método de ensaio. Rio de Janeiro. 1986b.

NBR 7218. Agregados: determinação do teor de argila em torrões e materiais friáveis. Rio de Janeiro. 1987a. 2p.

NBR 7219. Agregados: determinação do teor de materiais pulverulentos. Rio de Janeiro. 1983. 
. NBR 7220. Agregados: determinação de impurezas orgânicas em agregado miúdo e graúdo. Rio de Janeiro. 1987b.

NBR 7222. Argamassa e concreto: determinação da resistência à tração por compressão diametral de corpos de prova. Rio de Janeiro. 1994b. 3p.

. NBR 7224. Cimento Portland e outros materiais em pó: determinação da área específica. Rio de Janeiro. 1984.

. NBR 9776. Agregados: determinação da massa específica de agregados miúdos por meio do frasco Chapman. Rio de Janeiro. 1987c.

NBR 11578. Cimento Portland composto. Rio de Janeiro. 1991b.

- NBR 11580. Cimento Portland: determinação da água da pasta de consistência normal. Rio de Janeiro. 1991c.

NBR 11581. Cimento Portland: determinação dos tempos de pega. Rio de Janeiro. 1991d.

. NBR 12042. Materiais inorgânicos: determinação do desgaste por abrasão. Rio de janeiro. 1992. 3p.

NBR 12142. Concreto: determinação da resistência à tração na flexão em corpos de prova prismáticos. Rio de Janeiro. 1991e. 4p.

. Projeto CB 18:400.04-008. Argamassa para assentamento e revestimento de paredes e tetos: determinação do modulo de elasticidade dinâmico através da propagação de onda ultrassônica. 2008. 6p.

Projeto PO-GT 5004. Avaliação do grau de vitrificação de escórias de alto forno por microscopia de luz transmitida polarizada. revisão 4. 2002a. 10p. 
Projeto PO-GT 5016. Determinação do índice de refração de sólidos ao microscópio óptico de luz transmitida. revisão 1. 2002b. 7p.

ASSIS, V. J. D.; COSTA, C. R. V.; FERREIRA, H. C. Aplicação de ensaios não destrutivos para caracterização de concretos confeccionados a base de agregados convencionais e alternativos. In: 25 Pavimentação. São Paulo. 1991a. p.663 - 689.

Avaliação dos módulos de deformação de concretos confeccionados com agregados convencionais e alternativos através de métodos destrutivos e não destrutivos. In: 25ª Reunião Anual de Pavimentação. São Paulo. 1991b. p.691 - 712.

BAER, W. The development of brazilian steel industry. University of Vanderbilt. Ed. U.V. 1970. vol.1.

BALADO, J. G. Criterios actuales para el proyecto estructural de los pavimentos de hormigón. Instituto del Cemento Portland Argentino (ICPA). 1978. vol.10. 138p.

BALBO, J. T. Estudo das propriedades mecânicas das misturas de brita e cimento e sua aplicação aos pavimentos semi-rígidos. Tese (doutorado). Universidade de São Paulo. Escola Politécnica. São Paulo. 1993. 149 p.

Alguns conceitos diferenciadores dos materiais estabilizados com cimento. In: 7ª Reunião de Pavimentação Urbana. São José dos Campos. 1996. p. $275-294$.

Pavimentos asfálticos híbridos-rígidos: perspectivas para baixos e elevados volumes de tráfego. In: 36 ${ }^{\mathrm{a}}$ Reunião Anual de Pavimentação. Curitiba. 2005. 
Britas graduadas tratadas com cimento: uma avaliação de sua durabilidade sob o enfoque de porosidade, tenacidade e fratura. Revista Transportes, Volume XIV, número 1. 2006. p.45-63.

Pavimentação asfáltica: materiais, projeto e restauração. Oficina de Textos. São Paulo. 2007. 558p.

.; KHAZANOVICH, L. Desenvolvimento de rotina e interface do programa MnLayer para camadas elásticas. Fundação de Amparo à Pesquisa do Estado de São Paulo (FAPESP). Relatório Final. Processo 2006/01907-6. São Paulo. 2007

BATISTA, E. L.; GRAÇA, N. G.; BITTENCOURT, R. M. Estudo da eficiência do concreto compactado com rolo para barragens quando dosado com escória de alto forno em substituição ao cimento. In: 47ํㅡㄹ Congresso Brasileiro do Concreto. IBRACON. Vol.II: barragens de concreto. 2005. p.109- 117.

BATTAGIN, A. F. Contribuição ao conhecimento das propriedades do cimento Portland de alto forno. Associação Brasileira de Cimento Portland (ABCP). São Paulo. 1988.

BORGES, V. E. S.; CASCUDO, O.; GRAÇA, N. G. CCR com maiores consumos de materiais cimentícios. In: $48^{\circ}$ Congresso Brasileiro do Concreto. IBRACON. Rio de Janeiro. 2006. p.1 - 15.

BRAGA, J. A.; ROSÁRIO, L. C.; DUARTE, J. D. C.; LACERDA, S. S. Utilização de finos: sub-produto de britagem nos concretos rolado e convencional. In: XVIII Seminário Nacional de Grandes Barragens. Comitê Brasileiro de Grandes Barragens (CBGB). Foz do Iguaçu. 1989. p.385 - 404. 
BRODERSEN, H. A. Zür abhängigkeit der transportvorgänge verschiedener ionen im beton von struktur und zusammensetzung des zementsteins. In: Beton Informationen. 1983. p.36 - 38. vol. 23.

CANADIAN PORTLAND CEMENT ASSOCIATION (CPCA). Thickness design for concrete highway and street pavements. Canadian Edition. 1984.

CARDOSO, S. H.; PITTA, M. R.; TRICHÊS, G. Concreto rolado para pavimentação: estudo do comportamento à fadiga. In: 25a Reunião Anual de Pavimentação. São Paulo. 1991. p.255 - 282.

CARMINE, O. C. Las escorias siderurgicas, su geración, composición y propiedades en niveles de producción. Curso de Pósgrado en Siderurgia. Instituto Argentino de Siderurgia. 1985.

CARMO, A. D.; CARVALHO, C. R. V.; CASTRO, L. F. A. Otimização do roteiro tecnológico aplicado no refino do ferro gusa. In: XV Simpósio Anual da Associação Brasileira de Metalurgia e Materiais (ABM), Belo Horizonte, 2005.

CARVALHO, M. D. O concreto rolado como camada final de base e revestimento de pavimentos urbanos. In: $1^{\circ}$ Simpósio de Obras de Concreto Compactado com Rolo. 1995. p.563 - 580.

.; GODINHO, D. P.; FERREIRA Jr., S. Características e aplicações do concreto rolado em pavimentação. In: $22^{a}$ Reunião Anual de Pavimentação. Maceió. 1987. p.275 - 316.

CASTRO, L. F. A.; TAVARES, R. P.; KLEIN, C. A.; FUJIHARA, F. K. Escória de alto forno: formação e efeitos sobre o processo. In: $55^{\circ}$ Congresso da Associação Brasileira de Metalurgia (ABM), Rio de Janeiro. 2000. p.687 - 697 . 
CEMBUREAU. Sol-ciment: une etude de la littérature. Technical Translation. The Cement Statistical and Technical Association. Malmö. 1960.

CERVO, T. C. Estudo da resistência à fadiga de concreto de cimento Portland para pavimentação. Tese (doutorado). Universidade de São Paulo. Escola Politécnica. São Paulo. 2004. 220p.

CHEHEBE, J. R; Geração e destinação de escória pela indústria siderúrgica brasileira. In: Seminário sobre Resíduos Siderúrgicos. Rio de Janeiro. 1987. vol. B, p. $1-37$.

$\mathrm{CHO}, \mathrm{Y}$; YEO, S. H. Application of recycled waste aggregate to lean concrete sub base in highway pavement. In: Canadian Journal of Civil Engineering $n^{\circ} 6$. vol.31. Ottawa. 2004.p.1101 - 1108.

CINCOTTO, M. A.; MELO, A. A; REPETTE, W. L. Effect of different activators type and dosages and relation to autogenous shrinkage of activated blast furnace slag cement. In: Proceedings of the 11th International Congress on the Chemistry of Cement. África do Sul. 2003. p.1878 - 1887.

CONSELHO NACIONAL DE TRÂNSITO (CONTRAN). Resolução n²10. Publicação no Diário Oficial da União em 13 de novembro de 2006. Brasília. 2006. $4 p$.

CONSULTORA DE INGENIERÍA S.A. (CONINSA). Aeródromo de Venato Tuerto: pista, rodaje, plataforma, calles de servicio y camino de acceso. Memoria de Ingeniería. Dirección Provincial de Vialidad. Santa Fe. 1978.

DEPARTAMENTO NACIONAL DE ESTRADAS E RODAGEM (DNER). Manual de pavimentos de concreto rolado: histórico, características tecnológicas, estado da arte, materiais, dosagem e normas pertinentes. Rio de Janeiro. 1992. vol.1, 169 p. 
. ME 035: agregados: determinação da abrasão "Los Angeles". 1998a. 6p.

ME 089: sanidade com o emprego de soluções de sulfato de sódio ou de magnésio. 1994a. $4 p$.

. PRO 262/94: escórias de aciaria para pavimentos rodoviários. especificação de material. 1994b. 4 p.

PRO 263/94: emprego de escórias de aciaria em pavimentos asfálticos. - procedimento. 1994c. 3 p.

. Manual de reabilitação de pavimentos asfálticos. Rio de Janeiro. 1998b.

DEPARTAMENTO NACIONAL DE PRODUÇÃO MINERAL (DNPM). Sumário mineral. estatísticas/2008. disponível em <http://www.dnpm.gov.br/ conteudo.asp?IDSecao=156> acesso em: 2 de agosto de 2009 .

DIAS, E. G.; GUERRA, E. A.; OLIVEIRA, J. C. F.; GOZ, R. S.; BITENCOURT, R. M.; ANDRADE, W. P. Estudo de dosagens para concreto compactado a rolo: obras de desvio da usina Serra da Mesa. In: XVIII Seminário Nacional de Grandes Barragens. CBGB. Foz do Iguaçu. 1989. p.493- 528.

DZIERVA, F. Obtenção do aço: histórico e conceitos relativos ao processo siderúrgico. documento série 2530-07. Departamento de Engenharia Elétrica da Universidade Federal do Paraná, Curitiba. 2007. 3 p.

ESPER, M. W.; BATTAGIN, A. F. Propriedades do cimento Portland de alto forno como aglomerante para aplicação em barragens. In: XVIII Seminário Nacional de Grandes Barragens. CBGB. Foz do Iguaçu. 1989. p.703 - 725. 
FEILO, A. L.; ROYSTER, P. H. Slag viscosity tables for blast furnace work. In: $3^{\text {rd }}$ Bureau of Miner Tech. 1988. p.143 - 152.

FLOOD, H.; BRUEGGEMANN, E. O. Archive eisennhuetten. E.A.U. Duseldorf. 1956. $42 p$.

FREASON, J. P. H. Sulfate resistance of combination of Portland cement and ground granulated blast furnace slag. Proceedings of the Second International Conference on Fly Ash, Sílica Fume, Slag and Natural Pozzolans in Concrete. Malhorta Ed. Michigan. 1986. p.1495 - 1524.

GEISELER, H.; KOLLO, H.; LANG, E. Influence of blast furnace cements on durability of concrete structures. In: ACI Materials Journal. mai./jun. 1995.

GODINHO, D. P.; JUNIOR, C. G. S. Dosagem do concreto rolado e do concreto simples do pavimento rígido do corredor de ônibus uranos da estrada de Itapecerica. In: 6ª Reunião de Pavimentação Urbana. Santos. 1995. p.352 - 365.

;; DAMO, B. N.; ZANETTE, W.; ROSA, L. C. O pavimento de concreto na serra do Rio do Rastro. In: 21ำ Reunião de Pavimentação Urbana. Salvador. 1986. p.589 - 609 .

GONÇALVES, F. F.; FERREIRA, M. C. N. F.; COSTA, G. O. Emprego de escória de alto forno nos estudos de concreto compactado a rolo, rico em pasta, para a barragem da UHE de Bocaina. In: XVIII Seminário Nacional de Grandes Barragens. CBGB. Foz do Iguaçu. 1989. p.679 - 701.

GRAÇA, N. G.; MENDES, H. S.; BATISTA, E. L.; BORGES, V. E. S.; CARASEK, H.; CASCUDO, O. A influência do grau de compactação nas propriedades do concreto compactado com rolo. In: 46ํㅡㄹ Congresso Brasileiro do Concreto. Vol.II: construção em concreto. IBRACON. Florianópolis. 2004. p.33 - 47. 
GROSSI, L. C.; BALTHAZAR, M. A. B.; REGO, J. J. V. Concepção, objetivos e programação da utilização da pista experimental circular do IPR/DNER no estudo dos pavimentos de concreto rolado. In: 25 aeunião Anual de Pavimentação. São Paulo. 1991. p.2395 - 2411.

GUERRA, E. A.; OLIVEIRA, J. C. F.; FONTOURA, J. T. F.; SANTOS, M. C.; BITTENCOURT, R. M.; ANDRADE, W. P. Influência da finura da escória de alto forno moída nas propriedades do concreto compactado a rolo. In: XVIII Seminário Nacional de Grandes Barragens. CBGB. Foz do Iguaçu. 1989. p. $473-$ 492.

HAMASSAKI, L. T. Aspectos da aplicabilidade do ensaio de ultrassom em concretos. Boletim 17. EPUSP. 1987.

HERASYMENKO, P. Zeit electrochent und angewandte. In: Physical Chemistry. 1941. vol.8. .; SPEIGHT, G. E. Iron steel industry. Wisconsin, 1956.

HOGAN, F. J.; MEUSEL, J. W. Evaluation for durability and strength development of a ground granulated blast furnace slag. In: Cement Concrete and Aggregates, n91. 1981. p.40-52. vol 3.

HOPKINS, R. W. Physical chemistry and metal extraction. Garnett. Londres. 1954.

HÜBER, J. Roads in Germany. Technical Bulletin. Federal Ministry of Transport. Frankfurt.1992.

INSTITUTO BRASILEIRO DO CONCRETO (IBRACON). Pavimentos: as boas práticas da engenharia nacional e internacional. Revista Concreto n\%4. ano XXXIV. jan./fev./mar. 2007. p.89. 
INSTITUTO BRASILEIRO DE SIDERURGIA (IBS); Anuário estatístico: produção siderúrgica brasileira. 2009.

; Índices de produção da siderurgia brasileira. Instituto Brasileiro de Siderurgia: estatísticas e desenvolvimento, disponível em: <http://www.ibs.org.br/estatisticas/estatisticas.htm> acesso em 2 de abril de 2008. 2005.

INSTITUTO DEL CEMENTO PORTLAND ARGENTINO (ICPA). EI uso de escorias de altos hornos como agregado para el hormigón. Boletín no 11. 1981. 47p.

INSTITUTO GEOLÓGICO Y MINERO DE ESPAÑA (IGME). Índices y bases de datos de recursos minerales. documentos IGME. disponível em <http://www.igme.es/internet/default.asp >. acesso em 17 de agosto de 2009.

JOFRÉ, C.; CHONGGANG, S.; BERGA, L.; BUIL, J. M. Roller compacted concrete pavements for motorways and main highways: the Spanish practice. In: VI Simposio Internacional sobre Carreteras de Hormigón. Proceedings: Tema S. Madrid. 1990. p.155 - 165.

JOHN, V. M. Cimentos de escória ativada com silicatos de sódio. Tese (doutorado). Escola Politécnica da Universidade de São Paulo, São Paulo. 1995. 189p.

JOHNSON, L. A. Estimation on phase composition in system $3 \mathrm{CaO}-\mathrm{SiO}_{2}$; $2 \mathrm{CaO}-\mathrm{SiO} 2 ; 2 \mathrm{CaO}-\mathrm{Al}_{2} \mathrm{O}_{3}$ and $4 \mathrm{CaO}-\mathrm{Al}_{2} \mathrm{O}_{3}-\mathrm{Fe}_{2} \mathrm{O}_{3}$ at clinkering temperature. In: $2^{\text {nd }}$ Chemical Research of Industry. Londres. 1986. 
JORGE, M.; MAMEDE, F.; CARASEK, H.; CASCUDO, O. Ataque do concreto compactado com rolo por águas puras. In: $43^{\circ}$ Congresso Brasileiro do Concreto. IBRACON. 2001. p.1 - 15.

KEIL, F. Blast furnace and steel slag. Staleisen. Düsseldorf, 1963. 104 p.

KIM, Y. S. Roller-compacted concrete shoulder construction on interstate highway in Georgia. In: Journal of the Transportation Research Board. 2007. p.71 -79 .

KOMLOS, K.; POPOVICS, S.; NÜRNBERGEROVA, T.; BABAL, B.; POPOVICS, J. $S$. Ultrasonic pulse velocity test of concrete properties as specified in various standards. In: 18 Cement and Concrete Composities. Grã-Bretanha. 1996. p.357 364.

KOUDA, M. Experimental pavement using household waste slag. In: Waste Management n¹6. Grã Bretanha. 1996. p.461 - 474.

LEE, A. R. Blast furnace slag in iron steel industry. Ed. Arnold. 1를 Edção. 1974. $79 \mathrm{p}$.

LIDUÁRIO, A. S.; FARIAS, L. A.; DE ALBUQUERQUE, A. C.; ANDRADE, M. A. S. Utilização da escória de alto forno moída no concreto convencional e compactado com rolo. In: Tecnologia em Metalurgia e Materiais n91. vol.2. São Paulo. jul./set. 2005. p.35 - 39.

; FARIAS, L. A.; MUNIZ, F. C.; HASPARYK, N. P.; SILVA. W. A.; ANDRADE, M A. S. Estudo do comportamento do agregado pulverizado nas propriedades do concreto convencional e do concreto compactado com rolo. In: 46 Congresso Brasileiro do Concreto. Vol II: Construção em Concreto. IBRACON. Florianópolis. 2004. p. 920 - 932. 
LIM, S. N.; WEE, T. H. Autogenous shrinkage of ground granulated blast furnace slag concrete. In: ACI Materials Journal. set./out. 2000. vol.97, n5.

LITTLE, A. D. Ações institucionais da siderurgia brasileira para disseminação do uso das escórias. Workshop: gerenciamento de residuos sólidos no setor minero-metalúrgico. IBS. Rio de Janeiro. 2009. 33 p.

LONGO, A. Investigaciones de industrias minerales del sistema de centros del INTI. Documento del Departamento de Química de la Facultad Regional Haedo, Universidad Tecnológica Nacional, Argentina, 1982.

; CARRIZO, H.; POZZI, A. M. Estudio de prefactibilidad para la elaboración de cemento mezcla. SOMISA. boletín técnico, convenio A y E. 1989. $103 \mathrm{p}$.

LONGUET, P.; BURGLEN, L.; ZELWER, A. La phase liquide du ciment hydrate. In: $1^{a}$ Revue des Materiaux. 1973. p.33-41.

MARQUES, J. C. Escória de alto forno: estudo visando seu emprego no preparo de argamassas e concretos. Dissertação (mestrado). Escola Politécnica da Universidade de São Paulo. São Paulo. 1994. 175 p.

MASSUCATO, C. J. Utilização de escória granulada de alto forno à carvão vegetal como adição no concreto. Dissertação (mestrado). Universidade Estadual de Campinas. Faculdade de Engenharia Civil, Arquitetura e Urbanismo. 2005. 105p.

MATHUR, S.; SONI, S. K.; MURTY, A. Utilization of industrial wastes in lowvolume roads. In: Transportation Research Record 1652. 2001 p. $246-256$.

Mc CAFFERY, R. S.; OESTERLE, J. F. Desulfuring power of iron blast furnace slags. Toronto. 1993. $34 \mathrm{p}$. 
MEALLA, R.; CASTAÑEDA E.; RETAMOZO, Z. Geración y posibilidades de utilizaciones de escorias de altor hornos zapla. 1989. 21p.

MEHTA, P. K. Durability of concrete in marine environment: a review. performance of concrete in marine environment, SP-65. American Concrete Institute, Michigan. 1980. p.1- 15.

Advancements in concrete technology: reflections about technology choices. In: Concrete International, Farmington Hills. 1999. p.69 - 76.

; MONTEIRO, P. J. Concreto: microestrutura, propriedades e materiais. São Paulo: Editora Ibracon, 2004. $3^{\mathrm{a}}$ ed. 674 p.

MELO, D. G. V. M.; ZANETTI, J. J.; ANDREUCCI, C. J. Execução do pavimento rígido da Rodovia dos Imigrantes - pista descendente. In: $45^{\circ}$ Revista Concreto. IBRACON. jan - fev - mar 2007. p.37- 47.

MUAN, A.; OSBORN, E. I. Phase equilibrant among oxides in steelmaking. Wesley Publishing Company, 1975. 236 p.

MUÑOZ, M. C.; VERA, C. C. Hormigón compactado seco para pavimentos: correlación entre resistencias a hendimiento a distintas edades. In: 25 Reunião de Pavimentação. São Paulo. 1991. p.433 - 453.

NAGATO, Y. Estudo de dispositivo para determinação experimental do módulo de deformação longitudinal do concreto em compressão. Boletim Técnico, Universidade Federal do Rio de Janeiro. 1983.

NANNI, A. Abrasion resistance of roller compacted concrete. In: ACI Materials Journal n6. Vol.86. 1989. 
OZYILDIRIM, C. Evaluation of high-performance concrete pavement in Newport News, Virginia. In: Transportation Research Record 1775. 2001. p.118 124.

PÁRAMO, J. A. Estabilización granular. In: 1ํ Simposio sobre Investigaciones Camineras, Experiencia e Investigación en la Argentina y Sudamérica. Instituto de Pesquisas Rodoviárias, Rio de Janeiro, 1965.

PASKO, T. J. Pavements: past, present and future. In: Concrete International n5. 1998. Vol.20. p. $47-52$.

PATRICIO, M.; BOTTER, R. C. Evolução e uso de tecnologia da informação aplicada a terminais de contêineres no Brasil. Universidade de São Paulo. Departamento de Engenharia Naval e Oceânica. São Paulo. 2004. 16p.

PITMAN, D. W.; RAGAN, S. A. Drying shrinkage of roller-compacted concrete for pavement applications. In: ACI Materials Journal n9. vol.95. jan./fev. 1998.

PITTA. M. R.; DÍAZ, P. H. Estado del arte de pavimentos de concreto compactado con rodillo. In: 25aㅗ Reunião Anual de Pavimentação. São Paulo. 1991. p.605- 634 .

RAGAN, S. A.; PITTMAN, D. W.; GROGAN, W. P. An investigation of the frost resistance of air-entrained and nonair-entrained roller-compacted concrete mixtures for pavement applications. Technical Report GL-90-18, U.S. Army Enginner Waterways Experiment Station, Vicksburg, 1990.

REGO, J. J. V.; GROSSI, L. C. Relatório preliminar de progresso da pesquisa sobre pavimentos de concreto rolado. In: 25a Reunião Anual de Pavimentação. São Paulo. 1991. p.2349 - 2394. 
RESCHKE, J. S.; CECCATO, D. M; MASUERO.; A. B; MORAES, C. A. M.; VILELA, A. C. F.; Avaliação da utilização de escória granulada de fundição como substituição de parte do cimento em concreto. In: Revista de Ciência e Tecnologia de Materiais de Construção Civil n91. vo I.2. 2005. p.78 - 91.

RIBEIRO, A. B.; CASTO, A. T.; SANTANA, M. T. Avaliação da eficiencia do ensaio de ultra-sons para controlo da ligação entre camadas em barragens de CCR. In: 47ํㅡㄹ Congresso Brasileiro do Concreto. Vol.Il: barragens de concreto. IBRACON. Recife. 2005. p.17 - 26.

RIBEIRO, A. C.; BITTENCOURT, S.; ALMEIDA, I. R. Study on high performance roller compacted concrete. Materials and Structure. RILEM. 2000. vol.33. p.398 402.

RIBEIRO, C. C.; PINTO, J. D. S.; STARLING, T. Avaliação da resistência e da durabilidade do concreto composto com escória de alto forno, brita zero e aditivos plastificantes. In: 58 Reunião Anual da SBPC. Florianópolis. 2006.

RICCI, G. Estudo de características mecânicas do concreto compactado com rolo com agregados reciclados de construção e de demolição para pavimentação. Dissertação (mestrado). Universidade de São Paulo. Escola Politécnica. São Paulo. 2007. 196 p.

ROY, D. M.; IDORN, G. M. Hydration, structure and properties of blast furnace slag cements, mortars and concrete. In: ACI Materials Journal. nov./dez. 1982. p. $444-457$.

SANTOS, F. O. Hormigón compactado con rodillo. In: Revista de Obras Públicas. 1988. p.959- 975.

SANTOS, S. B. Método da ascultação sísmica de refração: uma alternativa para o controle do grau de compactação das camadas de concreto 
compactado com rolo. In: 30ª Reunião Anual de Pavimentação. Salvador. 1996. p. $1575-1602$.

; HOLANDA, F. G.; Determinação das propriedades mecânicas de concreto de cimento Portland, quando da utilização de seixo rolado da região da grande João Pessoa. In: 23ạ Reunião Anual de Pavimentação. Florianópolis. 1988. p.1051 - 1081 .

SCANDIUZZI, L.; BATTAGIN, A. F. O uso da escória granulada de alto forno como agregado miúdo no concreto de cimento Portland. In: $25^{\circ}$ Reunião Anual de Pavimentação. São Paulo. 1991. p.1 - 26.

SCHIEL $\beta$, P.; RAUPACH, M. Einflu $\beta$ der betonzusammensetzung und der umgebungsbedingungen auf die chloridinduzierte korrosion von stahl im beton. In: Beton Informationen n`30. 1990. p.43 - 54.

SHENCK, H. Physical chemistry of steelmaking. Bisra. 1945. 34 p.

SHORT, N. R.; PAGE, C. L. The diffusion of chloride íons through Portland and bçended cement pastes In: $2^{\text {nd }}$ Conference on Slag and Blended Cements. Bélgica. 1981. 8 p.

SMOLCZYK, H. G. Slag structure and identification of slags. In: Proceedings of Seventh International Congress Chemistry Cement. 1980. p.1 - 16.

SOCIEDAD MIXTA SIDERURGICA ARGENTINA (SOMISA). Diseño de un sínter de basicidad dos y mayor que dos empleando escorias de alto horno en la mezcla a sinterizar. ensayos preliminares, $1985.6 \mathrm{p}$.

TASHIRO, K. Compotment de la zone cohésive na haut fourneau. In: Revue de Metallurgie, 1980. p.1027 - 1035. vol. 3. 
TAYABJI, S. D.; OKAMOTO, P. A. Engineering properties of roller-compacted concrete. In: Transportation Research Record 1136. 1987. p.33 - 45.

TEMKIN, M.; SAMARIN, A.; SCHVARTSMAN, L. A. Acta physico-chimica, URSS. 1945. 82p.

THE AMERICAN CONCRETE PAVEMENT ASSOCIATION (ACPA). 100 years of innovation. disponível em: <http://pavement.com/PavTech/AbtConc/History/Introduction.html> acesso em: 13 de dezembro de 2009. 2001.

TIGERSCHIOLD, M. Stahl und eisen. Hamburgo. 1950. 38 p.

TORRENT, R.; ELOLA, A.; SZTEINBERG, S. Propiedades de los hormigones con adición de escoria granulada de alto horno y aplicaciones especiales. Escorias Siderurgicas: Geración, Propiedades y Utilizaciones, Instituto Latinoamericano del Fiero y el Acero. 1990.

TOSTICARELLI, J. Memoria de ingeniería de la ruta provincial no 13: tramo: ruta nacional no 34 , sección $50+000-83+200$. Reconstrucción y Repavimentación., Dirección Provincial de Viabilidad Santa Fé. 1978.

; ANGELONE, S.; ANDREONI, R. Escoria de acearia: estadio actual de estudios sobre su utilización. In: Escorias Siderurgicas: Geración, Propiedades e Utilizaciones vol.1. Instituto Latinoamericano del Fiero e el Acero (ILAFA). Santiago do Chile. 1987.

TUDESHKI, H.; HERTEL, H. El valor económico-nacional de la industria de la piedra y la arena representado en el ejemplo la República Federal de Alemania. In: Aggregates International n\%4. edición español . 2008. 
VAN DAM, T. J.; PETERSON, K. R.; SUTTER, L. L.; HOUSEWRIGHT, M. E. Deterioration in concrete pavements constructed with slag coarse aggregate. In: Transportation Research Record 1834. 2003. p.8 - 15.

VIRGALLETE, S. J.; BELL, L. W.; CALL, B. M.; EHMKE, B. A. Ground granulated blast furnace slag as cementicious constituent in concrete and mortar. In: $\mathrm{ACl}$ Materials Journal, title n92-M36, mai./jun. 1995.

WAELKENS, G. S. Geración y propiedades de las escorias siderúrgicas. Sociedad Mixta Siderúrgica Argentina. Relatorio de Trabajo. Argentina. 1971.

WOLLE, C. M.; COSTA, R. L. R.; BAUER, L. A. F. Avaliação de características do concreto por ensaios de ultra-som. In: Revista Politécnica. Universidade de São Paulo. São Paulo. 1973.

YÜKSEL, I.; GENÇ, A. Properties of concrete containing nonground ash and slag as fine aggregate. In: ACI Materials Journal 104. title n9104-M44. jul./ago. 2007. 